\title{
DESIGN FIRES FOR MOTELS AND HOTELS
}

BY

\section{ZHENGRONG CHEN}

\author{
A Thesis Submitted to \\ the Ottawa-Carleton Institute for Civil Engineering (OCICE), \\ Department of Civil and Environmental Engineering at Carleton University \\ in Partial Fulfilment of the Requirements for the Degree of \\ Master of Applied Science in Civil Engineering
}

Carleton University

Ottawa, Ontario, Canada

December 2008

(C) Copyright 2008, Zhengrong Chen 
Library and

Archives Canada

Published Heritage

Branch

395 Wellington Street

Ottawa ON K1A 0N4

Canada
Bibliothèque et

Archives Canada

Direction du

Patrimoine de l'édition

395 , rue Wellington

Ottawa ON K1A 0N4

Canada

Your file Votre référence

ISBN: 978-0-494-52042-0

Ourfile Notre référence

ISBN: 978-0-494-52042-0

NOTICE:

The author has granted a nonexclusive license allowing Library and Archives Canada to reproduce, publish, archive, preserve, conserve, communicate to the public by telecommunication or on the Internet, loan, distribute and sell theses worldwide, for commercial or noncommercial purposes, in microform, paper, electronic and/or any other formats.

The author retains copyright ownership and moral rights in this thesis. Neither the thesis nor substantial extracts from it may be printed or otherwise reproduced without the author's permission.
AVIS:

L'auteur a accordé une licence non exclusive permettant à la Bibliothèque et Archives Canada de reproduire, publier, archiver, sauvegarder, conserver, transmettre au public par télécommunication ou par l'Internet, prêter, distribuer et vendre des thèses partout dans le monde, à des fins commerciales ou autres, sur support microforme, papier, électronique et/ou autres formats.

L'auteur conserve la propriété du droit d'auteur et des droits moraux qui protège cette thèse. $\mathrm{Ni}$ la thèse ni des extraits substantiels de celle-ci ne doivent être imprimés ou autrement reproduits sans son autorisation.
In compliance with the Canadian

Privacy A'ct some supporting forms may have been removed from this thesis.

While these forms may be included in the document page count, their removal does not represent any loss of content from the thesis.
Conformément à la loi canadienne sur la protection de la vie privée, quelques formulaires secondaires ont été enlevés de cette thèse.

Bien que ces formulaires aient inclus dans la pagination, il n'y aura aucun contenu manquant.

\section{Canadä}




\section{Abstract}

With performance-based building codes, fire protection engineers can apply engineering approaches for fire safety design, rather than merely rely on prescriptive requirements. The development of design fires for different building categories is essential to performance-based approaches. In this project, design fires for one building category, motels and hotels, was studied.

In order to quantify the fire loads and their composition in motels and hotels, a fire load survey was conducted in 10 motels and 12 hotels in Canada's National Capital Region, Ottawa and Gatineau area, in 2007. Based on the field survey, two full-scale fire tests, one representing a bedroom with one bed and the other representing a bedroom with two beds, were designed and conducted at NRCC/Carleton (National Research Council of Canada/Carleton University) Fire Research Lab in 2008. For the two tests, the parameters, such as heat release rate, temperature, heat flux, and gas concentration were measured and/or calculated. Recommended design fire curves are presented.

A field model, Fire Dynamics Simulator (FDS), was used to simulate the full-scale fire tests. Two virtual fuels were developed and used in three different fuel layouts. The results of the model compared well with the experimental data. 
To those surveyed motels and hotels 


\section{Acknowledgements}

First and foremost, I would like to thank my supervisor, Dr. George Hadjisophocleous, for his valuable guidance and help with my thesis. He taught me to think critically in the graduate course, Fire Modelling, and he also taught me to think outside of the box in the thesis project. His knowledge and hard work have greatly impressed me.

I would like to thank Dr. Jim Mehaffey, for teaching me two graduate courses, Fire Dynamics I and II, and for his encouragement and advice on this project.

I am indebted to Dr. Noureddine Benichou, who was once my co-supervisor, for giving me many valuable reference papers. It was in the graduate course that he taught, Structural Design for Fire Resistance, where I had my first encounter with Fire Safety Engineering.

I would like to thank Dr. Guylene Proulx, Dr. Burkan Isgor and Dr. Guy Felio for their teaching in the graduate courses, People in Fire, Finite Elements in Field Problems, and Infrastructure Assets Management, respectively.

I would like to thank co-supervisor, Dr. Ehab Zalok for his great help in the fire load surveys, and to thank Dr. Alex Bwalya for giving me valuable advice and information on the fire tests.

A special thanks goes to our technician, Mr. Ba Lam-Thien, who spent lots of time and effort in setting up the fire tests. Special thanks also go to the staff at National 
Research Council Canada (NRCC) Fire Research Lab: Mr. Bruce Taber, Sasa Muradori, Eric Gibbs, George Crampton and Josip Cingel. Without their help, I would not have conducted the tests smoothly and successfully.

I am grateful to all of the surveyed motels and hotels, the names of which could not be mentioned here as we agreed. I extend my gratitude to the Salvation Army, who donated most of the furniture for the tests. My gratitude also goes to NSERC and the FPInnovations Forintek division for funding the Fire Safety Engineering program at Carleton University.

I want to say 'Thank You' to my classmates---Yoon J. Ko, Richard Michels, Xin Mu, Hao Cheng, Osama Salem, Lei Peng, Qingfei Jia, and Ling Lu---for giving me help during the tests and/or for their animated discussions with me as I worked on this project.

I am also greatly indebted to Professor Logie, who taught me the skills necessary to write a thesis, and gave me a chance to do a dry run presentation in her writing class.

I want to thank my parents and brother, for their love, financial support, and technical debates as professional engineers.

Last, but not least, I want to thank Ming, who always believes that I could reach my goals.

vi 


\section{Table of Contents}

Abstract $\quad$ iii

Acknowledgements $\quad$ v

Table of Contents vii

List of Tables $\quad$ xi

List of Figures $\quad$ xiii

$\begin{array}{ll}\text { Nomenclature } & \text { xviii }\end{array}$

$\begin{array}{ll}\text { Chapter 1: Introduction } & 1\end{array}$

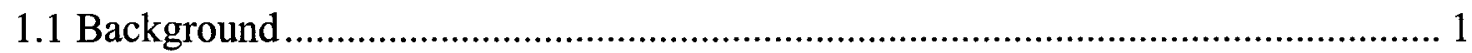

1.1.1 Prescriptive-based Building Code …............................................................ 2

1.1.2 Performance-based Building Code ............................................................... 4

1.1.3 Fire Protection Design for Buildings .................................................... 8

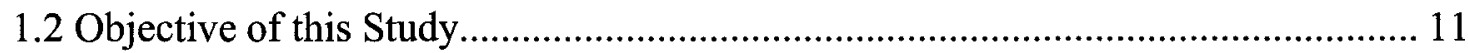

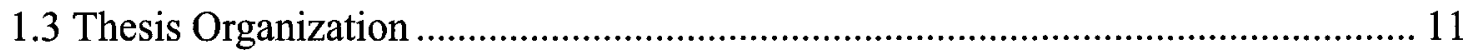

$\begin{array}{ll}\text { Chapter 2: Literature Review } & 13\end{array}$

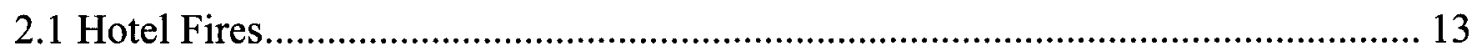

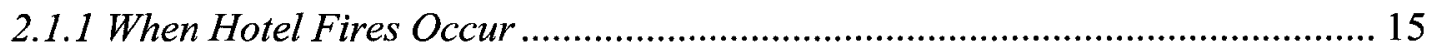

2.1.2 Ignition Source and First Ignited Items ................................................ 15

2.2 Design Fires and Design Fire Scenarios ........................................................ 17

2.2.1 Pre-flashover Stage and T-squared Fires ................................................. 20

vii 
2.2.2 Post-flashover Stage and Flashover 22

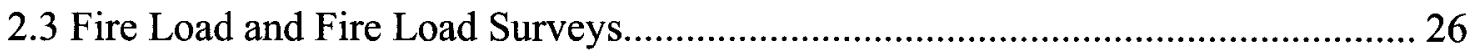

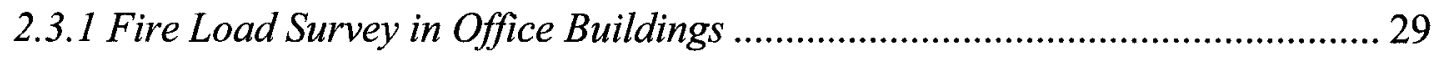

2.3.2 Fire Load Survey in Residential Buildings ................................................ 33

2.3.3 Fire Load Survey in Motels and Hotels .......................................................... 34

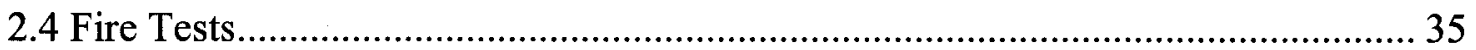

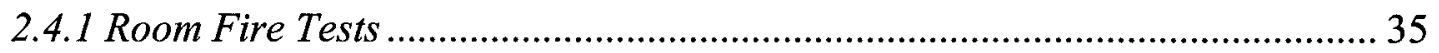

2.4.2 Heat Release Rate Measurements .............................................................. 44

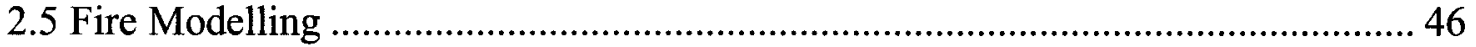

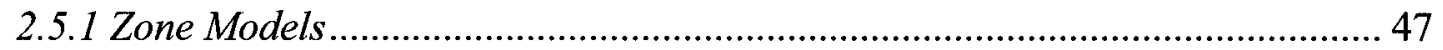

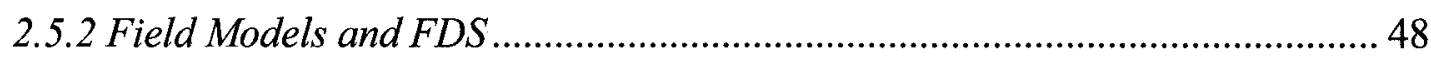

2.5.3 Model Application in Room Fire ........................................................... 50

Chapter 3: Fire Load Survey $\quad 54$

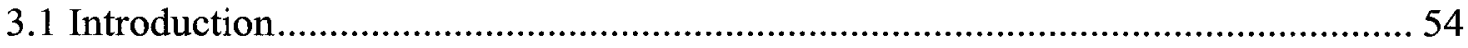

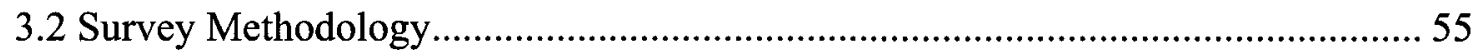

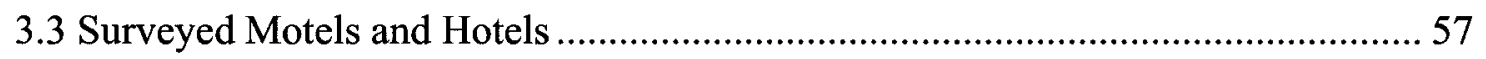

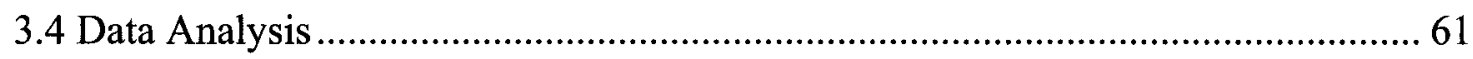

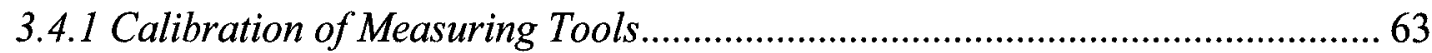

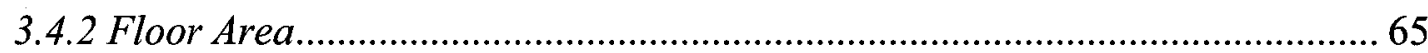

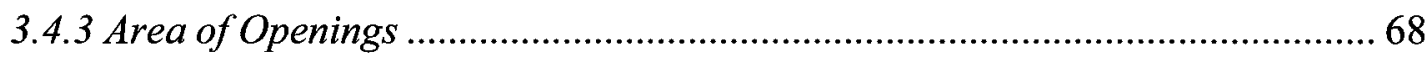

3.4.4 Percentage of Floor Area Covered by Furnishings..................................... 71

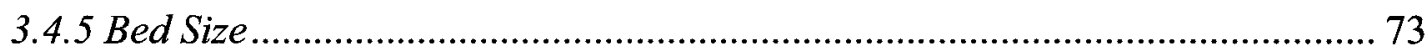

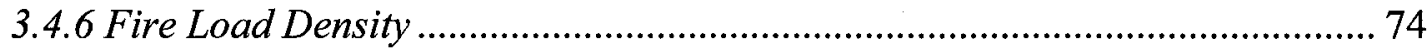

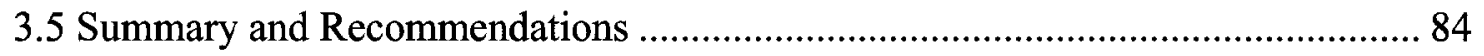

$\begin{array}{ll}\text { Chapter 4: Full-Scale Fire Tests } & 87\end{array}$

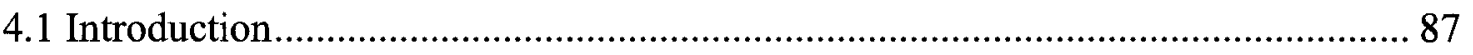

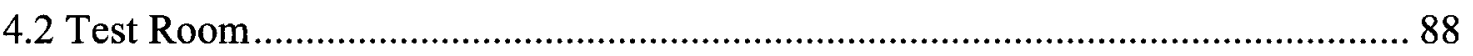

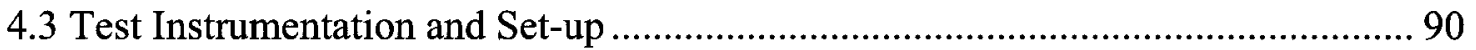

viii 
4.3.1 Heat Release Rate (HRR) Measurement .................................................... 90

4.3.2 Instrumentation in the Test Room .............................................................. 93

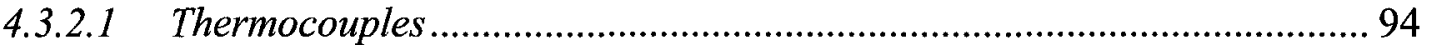

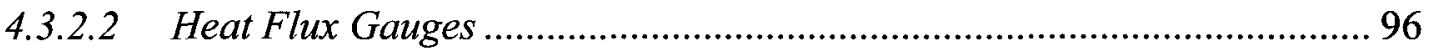

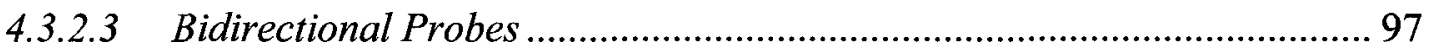

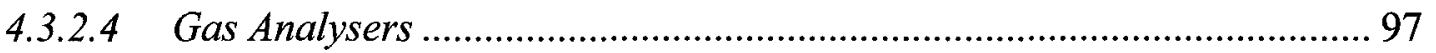

4.3.3 Instrumentation facing the Window Opening .............................................. 98

4.3.3.1 Heat Flux Gauges and Thermocouples................................................. 98

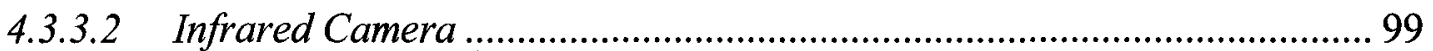

4.3.3.3 Digital Video Camera and Still Camera............................................... 99

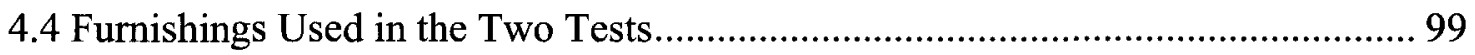

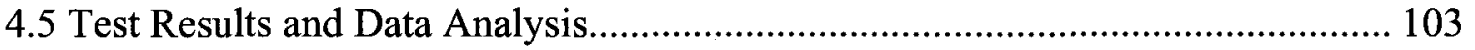

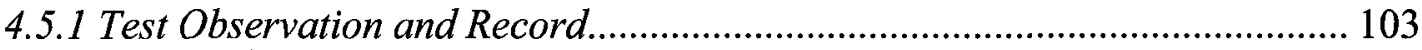

4.5.2 Heat Release Rate ..................................................................................... 105

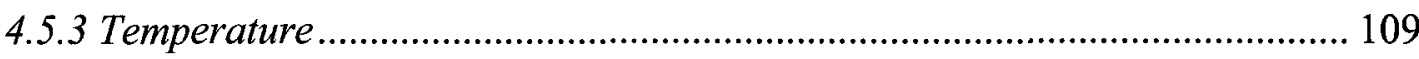

4.5.3.1 The First Test ...................................................................................... 111

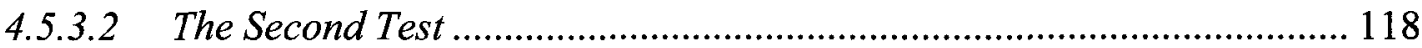

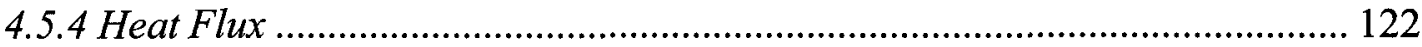

4.5.5 Pressure Difference at the Window Opening.............................................. 127

4.5.6 Gas Concentration in the Test Room ........................................................ 128

4.6 Data Derived for Design Fires ................................................................... 131

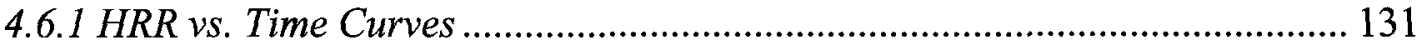

4.6.2 Temperature beneath the Ceiling............................................................ 134

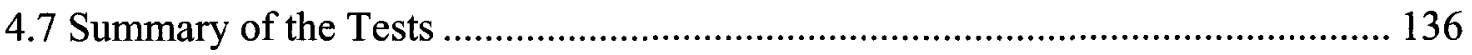

$\begin{array}{ll}\text { Chapter 5: FDS Modelling } & 138\end{array}$

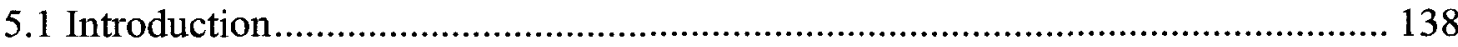

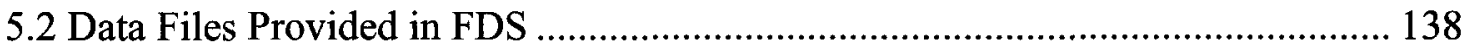

5.3 Virtual Fuels Developed for FDS Modelling .................................................... 139

5.4 FDS Simulation for the Fire Test 1 .............................................................. 141 ix 
5.4.1 Heat Release Rate Prediction.

5.4.2 Temperature Prediction ......................................................................... 146

5.4.3 Gas Concentration Prediction ................................................................. 150

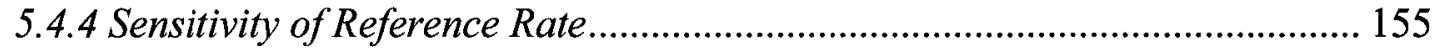

5.5 FDS Simulation for the Fire Test 2 .......................................................... 156

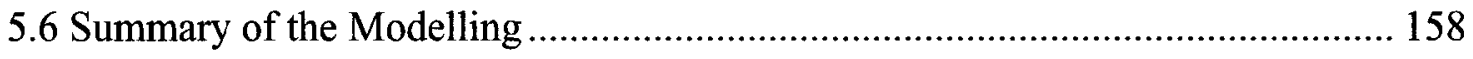

Chapter 6: Conclusions and Recommendations 160

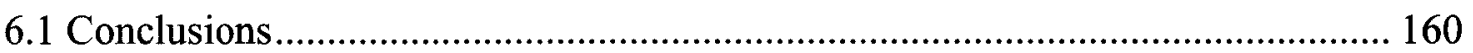

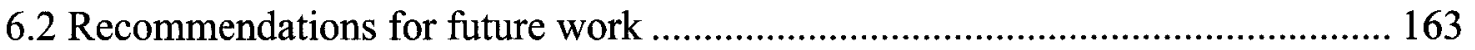

$\begin{array}{ll}\text { References: } & 165\end{array}$

$\begin{array}{ll}\text { Appendices: } & 170\end{array}$ 


\section{List of Tables}

Table 1 Structures of performance-based codes in 3 countries ......................................... 4

Table 2 Prescription vers Performance [9] …………................................................ 8

Table 32001 Canadian fire losses in selected property classifications of non-residential, commercial and residential structures $[11,13]$.

Table 4 Average annual* fire losses in selected classifications of non-residential, commercial and residential structures in the United States from 1980 to 1998 [11, 13].. 14

Table 5 Causes of civilian deaths and injuries of hotel and motel fires, 1982-1986:

annual average unknown-cause fires allocated proportionally [12] ................................. 16

Table 6 Type of materials first ignited for fire events in hotels/motels [11] .................. 17

Table 7 Terminology related to design fires [17] ....................................................... 18

Table 8 Categories of t-squared fires [21] ................................................................. 21

Table 9 Summary of methods for predicting minimum heat release rate for flashover ... 23

Table 10 Summary of equations used in the EUROCODE method ................................. 25

Table 11 Fire severity for Various Fuel Loads (modified from [16]).............................. 28

Table 12 Summary of the mean value of the total fire load comparisons [39]................. 35

Table 13 Summary of model information and prediction (modified from 2 tables of [57])

52

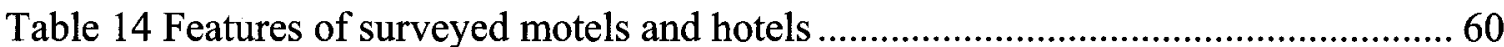

Table 15 Specifications of the ultrasonic measuring device (modified from [62]) .......... 64

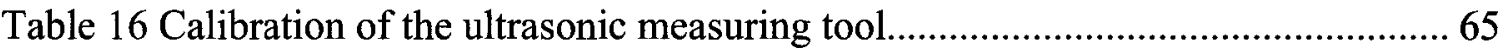

Table 17 Bed or mattress size on the market ................................................................ 73

Table 18 Distribution of bed size in the surveyed motels and hotels .............................. 74

Table 19 Fire load density for guest rooms in motels and hotels .................................... 75

Table 20 Total fire load density in different motel and hotel categories .......................... 77 
Table 21 Moveable fire load density in different motel and hotel categories 78

Table 22 Summaries of Fire load survey data for motels and hotels........................... 85

Table 23 Framing and lining materials used in the CFMRD project [63] ...................... 89

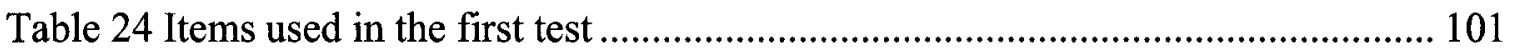

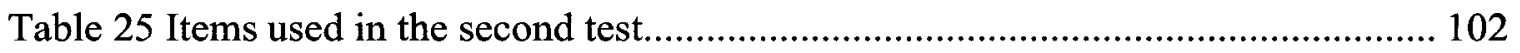

Table 26 Fire load density for the two tests ............................................................ 103

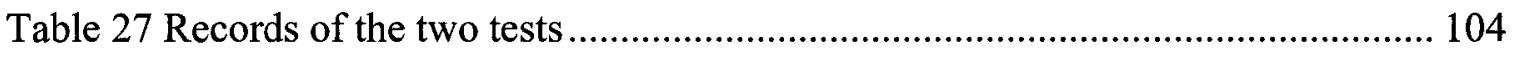

Table 28 Characteristic values of heat release rate in the two tests............................ 109

Table 29 Thermocouple number and height for five thermocouple trees in the room ... 110 Table 30 Thermocouple number and height for three thermocouple trees at the window

Table 31 The time of "over range" appeared to HF gauges in the 1st test 122

Table 32 Virtual fuel packages for different commercial stores (summarized from [60]) 140

Table 33 Material and thermal properties for two virtual fuels 141 


\section{List of Figures}

Figure 1 The idealized structure of the performance-based regulatory system [8] ........... 6

Figure 2 Basic building design and construction process [3] .................................. 9

Figure 3 Steps of performance-based design (modified from [3], [10]) ........................ 10

Figure 4 Stages of fire development in a room (modified from [18]) .......................... 19

Figure 5 A simple design fire curve [19] .............................................................. 19

Figure 6 Heat release rate for different growth rates [19] ..................................... 21

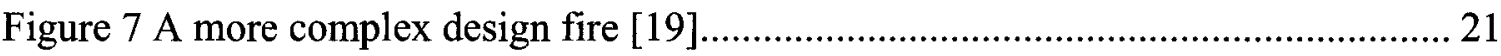

Figure 8 Time-temperature curves for different ventilation factors and fire loads [29]... 26

Figure 9 The dimensions of the room and hood for the original (1982) ASTM proposed

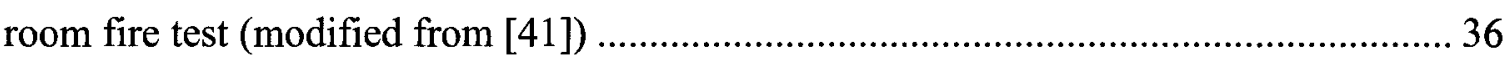

Figure 10 Plan view of experimental room for single room tests with furniture [41] ..... 37

Figure 11 Elevation view of experimental room for single room tests with furniture [41]

Figure 12 Heat release rate during single room tests with furniture [41] ....................... 38

Figure 13 Gas concentrations measured during single room tests with furniture [41] ..... 38

Figure 14 Diagram of furnishings and instrumentation for Test 1 [42] ......................... 39

Figure 15 Diagram of furnishings and instrumentation for Test 2 [42] ........................ 40

Figure 16 Temperature in the middle of room vs time for Test 1 [42] ......................... 41

Figure 17 Temperature in the middle of room vs time for Test 2 [42] ......................... 41

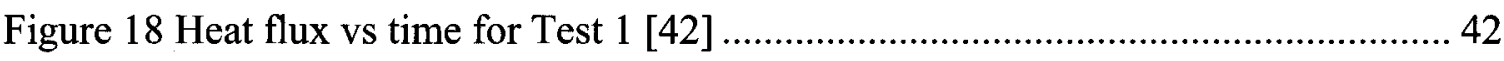

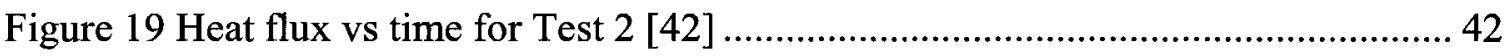

Figure 20 Oxygen concentration vs time for Test 1 [42] ......................................... 43

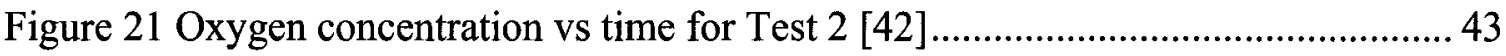

Figure 22 Schematic of a full-scale fire test combustion system [47] .......................... 45 xiii 


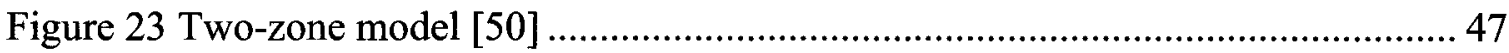

Figure 24 Field model for enclosure fire [49] ................................................... 50

Figure 25 Layout of the main compartment in Dalmarnock Test One [57] .................... 51

Figure 26 Predicted heat release rate in the whole compartment [57] ........................... 53

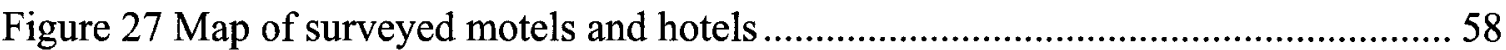

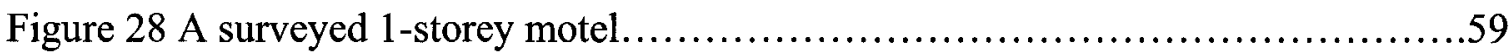

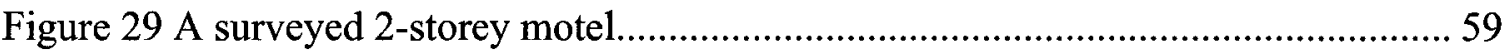

Figure 30 A surveyed hotel having building age of $100+$ years .................................. 59

Figure 31 A surveyed hotel having building age of 6 years ...................................... 59

Figure 32 Floor plan of a typical hotel guest room with one bed .................................. 62

Figure 33 Floor plan of a hotel suite room with one bed [61] .................................. 62

Figure 34 Difference of the two measuring tools before and after calibration ................ 64

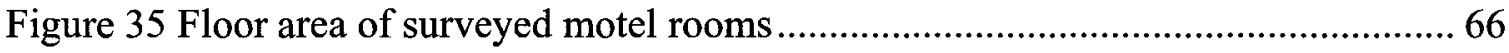

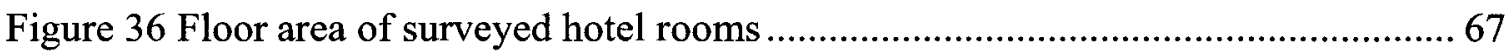

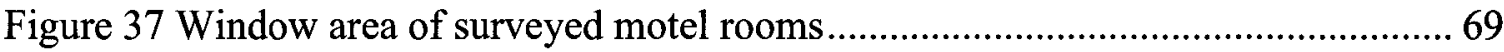

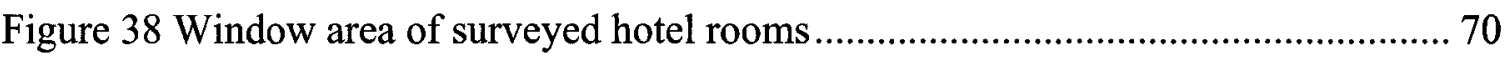

Figure 39 Percentage of floor coverage in surveyed motel rooms ............................... 71

Figure 40 Percentage of floor coverage in surveyed hotel rooms ................................. 72

Figure 41 Total fire load density in different motel and hotel categories...................... 75

Figure 42 Fire load density of different combustibles in motel bedrooms with one bed .79

Figure 43 Fire load density of different combustibles in motel bedrooms with two beds 79

Figure 44 Fire load density of different combustibles in standard hotel bedrooms with one bed

Figure 45 Fire load density of different combustibles in standard hotel bedrooms with two beds 80

Figure 46 Fire load density of different combustibles in luxury hotel bedrooms with one bed

Figure 47 Fire load density of different combustibles in luxury hotel bedrooms with two beds 
Figure 48 Fire load density of different combustibles in hotel suite bedrooms with one bed

Figure 49 Fire load density of different combustibles in hotel suite bedrooms with two beds 82

Figure 50 Fire load density of different combustibles in hotel living rooms. 83

Figure 51 Fire load density of different combustibles in hotel bedrooms plus living

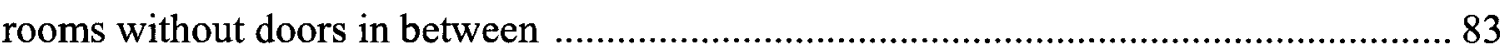

Figure 52 Construction details of the roof in the CFMRD project [63] ........................ 89

Figure 53 Hood and exhaust duct for heat release rate measurement........................... 92

Figure 54 Measurement locations for heat release rate ............................................ 92

Figure 55 Layout of instrumentation in the test room ............................................ 93

Figure 56 Section view of instrumentation at window opening .................................. 94

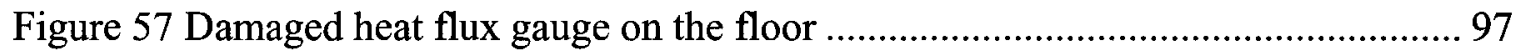

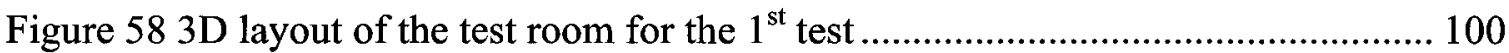

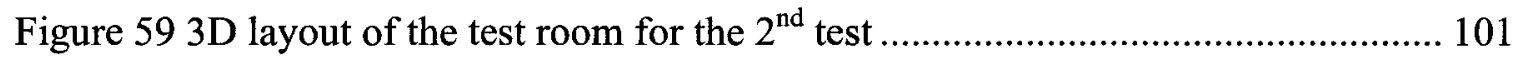

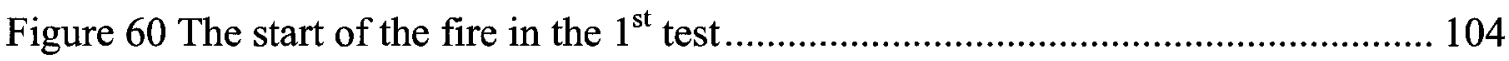

Figure 61 Temperature and $\mathrm{O}_{2}$ concentration before using the delay time for $1^{\text {st }}$ test $\ldots 106$

Figure 62 Temperature and $\mathrm{O}_{2}$ concentration after using the delay time for $1^{\text {st }}$ test ..... 106

Figure 63 Temperature and $\mathrm{O}_{2}$ concentration before using the delay time for $2^{\text {nd }}$ test. .107

Figure 64 Temperature and $\mathrm{O}_{2}$ concentration after using the delay time for $2^{\text {nd }}$ test $\ldots . .107$

Figure 65 Heat release rates for the two full-scale tests .......................................... 108

Figure 66 Temperatures of TC tree at northwest in the $1^{\text {st }}$ test.................................... 112

Figure 67 Temperatures of TC tree at southwest in the $1^{\text {st }}$ test ................................. 112

Figure 68 Temperatures of TC tree at northeast in the $1^{\text {st }}$ test................................. 113

Figure 69 Temperatures of TC tree at southeast in the $1^{\text {st }}$ test.................................... 113

Figure 70 Temperatures of TC tree at northwest corner in the $1^{\text {st }}$ test ......................... 114

Figure 71 Test picture at 300 seconds in the $1^{\text {st }}$ test .............................................. 115

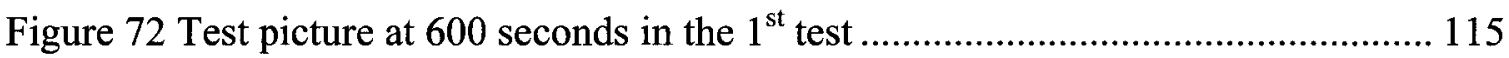

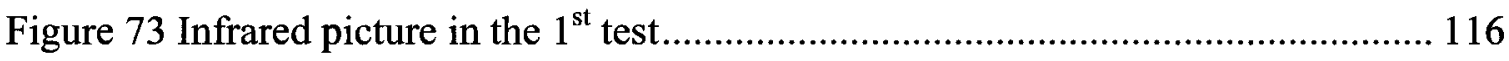




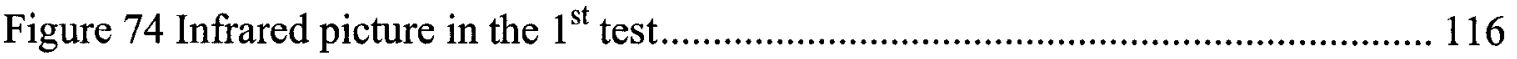

Figure 75 Temperatures of TC trees at the window opening in the $1^{\text {st }}$ test .................... 117

Figure 76 Temperature of TC tree at northwest in the $2^{\text {nd }}$ test .................................... 119

Figure 77 Temperature of TC tree at southwest in the $2^{\text {nd }}$ test ....................................... 119

Figure 78 Temperature of TC tree at northeast in the $2^{\text {nd }}$ test ....................................... 120

Figure 79 Temperature of TC tree at southeast in the $2^{\text {nd }}$ test ..................................... 120

Figure 80 Temperatures of TC tree at northwest corner in the $2^{\text {nd }}$ test........................... 121

Figure 81 Temperatures of TC trees at the window opening in the $2^{\text {nd }}$ test ................... 121

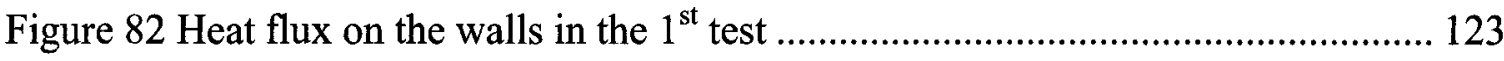

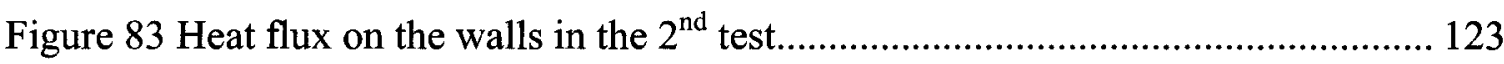

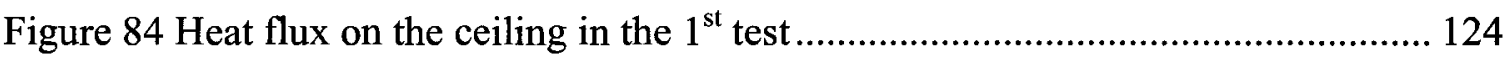

Figure 85 Heat flux on the ceiling in the $2^{\text {nd }}$ test .................................................. 124

Figure 86 Heat flux measured $3 \mathrm{~m}$ outside the window opening in the $1^{\text {st }}$ test .............. 126

Figure 87 Heat flux measured $3 \mathrm{~m}$ outside the window opening in the $2^{\text {nd }}$ test ............. 126

Figure 88 Pressure difference at the window opening in the $1^{\text {st }}$ test .............................. 127

Figure 89 Concentration of $\mathrm{O}_{2}$ in the test room in the $1^{\text {st }}$ test ........................................ 129

Figure 90 Concentration of $\mathrm{CO}$ and $\mathrm{CO}_{2}$ in the test room in the $1^{\text {st }}$ test........................ 129

Figure 91 Concentration of $\mathrm{O}_{2}$ in the test room in the $2^{\text {nd }}$ test..................................... 130

Figure 92 Concentration of $\mathrm{CO}$ and $\mathrm{CO}_{2}$ in the test room in the $2^{\text {nd }}$ test...................... 130

Figure 93 Heat release rate design curves for the $1^{\text {st }}$ test.............................................. 133

Figure 94 Heat release rate design curves for the 2 nd test .......................................... 134

Figure 95 Average ceiling temperature for the two tests............................................. 135

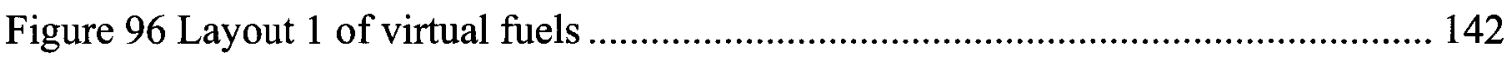

Figure 97 Layout 2 of virtual fuels ......................................................................... 143

Figure 98 Heat release rate prediction by using PROPANE with two virtual fuel

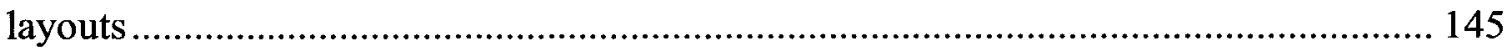

Figure 99 Heat release rate prediction by using PU with two virtual fuel layouts ......... 145

Figure $100 \mathrm{TC}$ tree temperature prediction by using PROPANE and virtual fuel layout 1 
Figure 101 TC tree temperature prediction by using PROPANE and virtual fuel

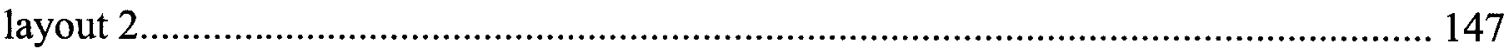

Figure 102 TC tree temperature prediction by using PU and virtual fuel layout $1 \ldots \ldots . .148$

Figure 103 TC tree temperature prediction by using PU and virtual fuel layout $2 \ldots \ldots . .148$

Figure 104 Ceiling center temperature prediction by using PA with two virtual fuel

layouts

Figure 105 Ceiling center temperature prediction by using PU with two virtual fuel

layouts 149

Figure $106 \mathrm{CO}$ and $\mathrm{CO}_{2}$ prediction by using PROPANE and virtual fuel layout $1 \ldots \ldots .151$

Figure $107 \mathrm{CO}$ and $\mathrm{CO}_{2}$ prediction by using PROPANE and virtual fuel layout $2 \ldots \ldots .151$

Figure $108 \mathrm{CO}$ and $\mathrm{CO}_{2}$ prediction by using $\mathrm{PU}$ and virtual fuel layout 1 .................. 152

Figure $109 \mathrm{CO}$ and $\mathrm{CO}_{2}$ prediction by using $\mathrm{PU}$ and virtual fuel layout 2 .................. 152

Figure $110 \mathrm{O}_{2}$ prediction by using PROPANE and virtual fuel layout 1 ..................... 153

Figure $111 \mathrm{O}_{2}$ prediction by using PROPANE and virtual fuel layout 2 .................... 153

Figure $112 \mathrm{O}_{2}$ prediction by using PU and virtual fuel layout 1 ................................. 154

Figure $113 \mathrm{O}_{2}$ prediction by using PU and virtual fuel layout 2 .............................. 154

Figure 114 Sensitivity of the Reference Rate ......................................................... 155

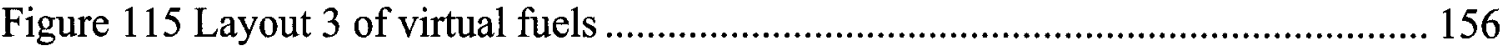

Figure 116 Heat release rate prediction by using two gaseous fuels in layout 3 ........... 157

xvii 


\section{Nomenclature}

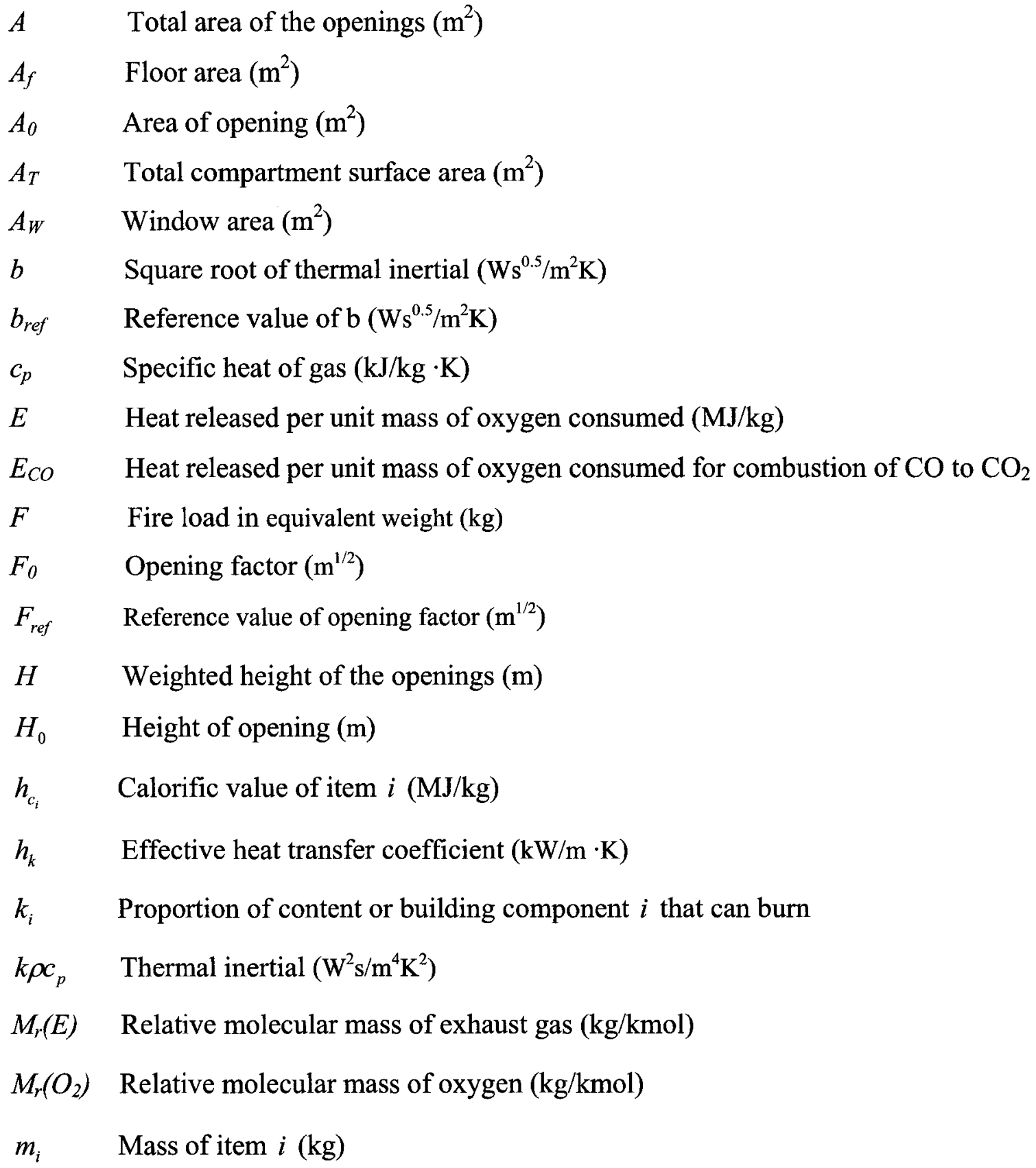


$\dot{m}_{g} \quad$ Gas flow rate out the opening $(\mathrm{kg} / \mathrm{s})$

$P_{a m b} \quad$ Pressure of ambient air $(\mathrm{Pa})$

psf Pounds per square foot $\left(\mathrm{lb} / \mathrm{ft}^{2}\right)$

$Q \quad$ Total fire load in a compartment (MJ)

$\dot{Q} \quad$ Rate of heat release $(\mathrm{kW})$, heat release rate of the fire $(\mathrm{kW})$

$\dot{Q}_{o} \quad$ Reference heat release rate $(\mathrm{kW})$

$Q_{t}^{\prime \prime} \quad$ Fire load density $\left(\mathrm{MJ} / \mathrm{m}^{2}\right)$

$\dot{q} \quad$ Heat release rate of the fire $(\mathrm{kW})$

$\dot{q}_{\text {loss }} \quad$ Net radiative and convective heat transfer from the upper gas layer $(\mathrm{kW})$

$R H_{a m b} \quad$ Relative humidity of ambient air (\%)

$T_{g} \quad$ Temperature of the upper gas layer $(\mathrm{K})$

$T_{g, \max } \quad$ Maximum temperature (K)

$T_{a m b} \quad$ Temperature of ambient air (K)

$T_{\infty} \quad$ Ambient temperature $(\mathrm{K})$

$T^{*} \quad$ Empirical constant (K)

$t \quad$ Time after effective ignition (s)

$t_{o} \quad$ Time to reach the reference heat release rate (s)

$X_{\mathrm{H}_{2} \mathrm{O}}^{0} \quad$ Mole fraction of $\mathrm{H}_{2} \mathrm{O}$ in the incoming air

$X_{O_{2}}^{0} \quad$ Measured mole fraction of $\mathrm{O}_{2}$ in the incoming air

$X_{\mathrm{CO}_{2}}^{0} \quad$ Measured mole fraction of $\mathrm{CO}_{2}$ in the incoming air

$X_{C O}^{0} \quad$ Measured mole fraction of $\mathrm{CO}$ in the incoming air

$X_{O_{2}} \quad$ Measured mole fraction of $\mathrm{O}_{2}$ in the exhaust gases

$X_{\mathrm{CO}_{2}} \quad$ Measured mole fraction of $\mathrm{CO}_{2}$ in the exhaust gases

$X_{C O} \quad$ Measured mole fraction of $\mathrm{CO}$ in the exhaust gases

xix 


$\begin{array}{ll}\alpha & \text { Growth rate }\left(\mathrm{kW} / \mathrm{s}^{2}\right), \text { combustion expansion factor } \\ \rho_{\infty} & \text { Density of air }\left(\mathrm{kg} / \mathrm{m}^{3}\right) \\ \varepsilon & \text { Emissivity of hot gas } \\ \sigma & \text { Stefan-Boltzmann constant }\left(\mathrm{kW} / \mathrm{m}^{2} \cdot \mathrm{K}^{4}\right) \\ \theta_{1} & \text { Burning rate stoichiometry } \\ \theta_{2} & \text { Wall steady-state losses } \\ \theta_{3} & \text { Wall transient losses } \\ \theta_{4} & \text { Opening height effect } \\ \theta_{5} & \text { Combustion efficiency } \\ \phi & \text { Oxygen depletion factor }\end{array}$




\section{Chapter 1: Introduction}

\subsection{Background}

Fire safety is one of the major concerns in building design, and building codes provide a set of safety requirements for designers, engineers, code officials, and other building practitioners to fulfill. The Code of Hammurabi was regarded as the first building code in history, which can be traced back to about 4000 years ago, when King Hammurabi of Babylonia reigned from $1955 \mathrm{BC}$ to $1913 \mathrm{BC}$ [1]. In the United States, the early building and fire regulations adopted in some territories, such as New Amsterdam (1645), Virginia (1662), Boston (1683), and Philadelphia (1696), are prior to the formation of the United States (1776) [2]. The first modern building code of the United States was published in $1905[2]$.

There are two main types of building codes: prescriptive-based and performancebased building codes. The prescriptive-based building codes have been used in engineering design for about 100 years around the world, and, for example, the first modern building code of the United States (1905) was a prescriptive-based code. The prescriptive building code is defined by SFPE (Society of Fire Protection Engineers) Engineering Guide [3] as "a code or standard that prescribes fire safety for a generic use 
or application. Fire safety is achieved by specifying certain construction characteristics, limiting dimensions, or protection systems without referring to how these requirements achieve a desired fire safety goal".

During the last twenty or thirty years, the performance-based building codes have aroused worldwide interests, and some countries have changed their building codes from prescriptive-based to performance-based. In fact, the first building code in history, the Code of Hammurabi, was a performance-based code, but the objective was simply the penalty for failure [1].

For the prescriptive-based building code, the goal of a fire safety design is to satisfy specific requirements or code provisions, but for the performance-based design, the goal is to meet code mandated objectives by using accepted means of verification, and designers are allowed to use 'any' solutions that meet the objectives [2].

\subsubsection{Prescriptive-based Building Code}

The first modern building code of the United States, published in 1905, was triggered by the widespread loss of life and property by fire in the late $19^{\text {th }}$ century. With time, the prescriptive-based codes became thicker by the addition of new prescriptive requirements following large building fires to address the specific concerns raised by those fires. For example, before the first performance-based code for England and Wales was adopted in 1985 , the document of their prescriptive-based code was 307 pages, while their new performance-based code was only 23 pages [2]. 
Prescriptive-based building codes have a number of advantages. For prescriptive design, engineers or designers only need to follow the requirements specified in the prescriptive-based building codes, and little analysis, knowledge or even time is needed. It is also easier and more comfortable for AHJs (Authority Having Jurisdiction) to check and accept fire safety designs [4].

Another advantage is that the prescriptive design can cover a broad range of conditions and the diversity of facilities being protected. Even though the inherent safety factors can be so high to cause redundancies, which cost money, it can provide sufficient flexibility for future changes [4], and disaster could be avoided by redundancy. Babrauskas [5] pointed out that most of the major fire disasters occurred because of a series of failures or a string of failures occurred in a row, rather than the failure of any one safety system.

A disadvantage of the prescriptive design is that the design can be unreasonably expensive due to higher inherent safety factors and redundant considerations. Furthermore, the unreasonable expensive design may not protect a particular facility in the most effective way [4].

Another disadvantage is that the prescriptive approach can hinder innovation by not allowing designers to utilize new materials or new technologies that are not accepted in the existing prescriptive-based codes. New versions of national prescriptive-based building codes are expected to be updated and released in 5 years, 10 years, or even 
longer periods so they cannot keep up with changes in technologies and construction methods.

\subsubsection{Performance-based Building Code}

The first adopted performance-based building code in the world was the one for England and Wales in 1985. Later on, countries such as New Zealand (1992), Australia (1996), Japan (2000), and Canada (2005) have adopted performance-based building codes [2, 6]. The National Building Code of China is still prescriptive-based, but performance-based concepts have been accepted in the construction of the 2008 Beijing Olympic venues [6]. The first draft of the IBC (International Building Code) performance-track code was issued in 1998 [5].

All performance-based building codes state a set of objectives which have to be met by the designs; however, different structures are used in different countries. Table 1 presents a summary of the structure system of performance-based codes in New Zealand, Australia, and Canada.

Table 1 Structures of performance-based codes in 3 countries

\begin{tabular}{|c|c|c|c|c|}
\hline New Zealand 1992 [2] & \multicolumn{2}{|r|}{ Australia 1995 [2] } & \multicolumn{2}{|r|}{ Canada $2005[6,7]$} \\
\hline L1 Objectives & L1 & Objectives & \multirow{2}{*}{\multicolumn{2}{|c|}{$\begin{array}{ll}\text { D-A } & \text { Objectives: } \\
& (\mathrm{OS}, \mathrm{OH}, \mathrm{OA}, \mathrm{OP})\end{array}$}} \\
\hline L2 Functional Requirements & $\mathrm{L} 2$ & Functional Statements & & \\
\hline \multirow[t]{3}{*}{ L3 Performance Criteria } & L3 & Performance Requirements & D-A & Functional Statements \\
\hline & L4-A & Deem to Satisfy & D-B & Acceptable Solution \\
\hline & L4-B & Verification Methods & & \\
\hline
\end{tabular}

Note: L-Level; D-Division; OS-Safety; OH-Health; OA-Accessibility; OP-Fire and Structural Protection of Buildings 
The performance-based New Zealand building code has three levels: objectives, functional requirements, and performance criteria. The performance building code of Australia consists of four levels. The first three levels are similar to the code of New Zealand, and level 4 includes two parts: deem to satisfy solutions and verification methods [2]. The National Building Code of Canada 2005 is an objective-based model code that has three divisions. Division A includes four main objectives, which are Safety (OS), Health (OH), Accessibility (OA), and Fire and Structure Protection of buildings (OP), as well as functional statements that are interconnected with the objectives. Division B provides acceptable solutions, and division $\mathrm{C}$ includes administrative provisions $[6,7]$.

The common points of the three national building codes are the objectives, functional statements and performance requirements, which can be traced back to the early idealized structure of the performance-based regulatory system proposed by the Nordic Committee on Building Regulations (NKB) in 1978 [8], Figure 1. 


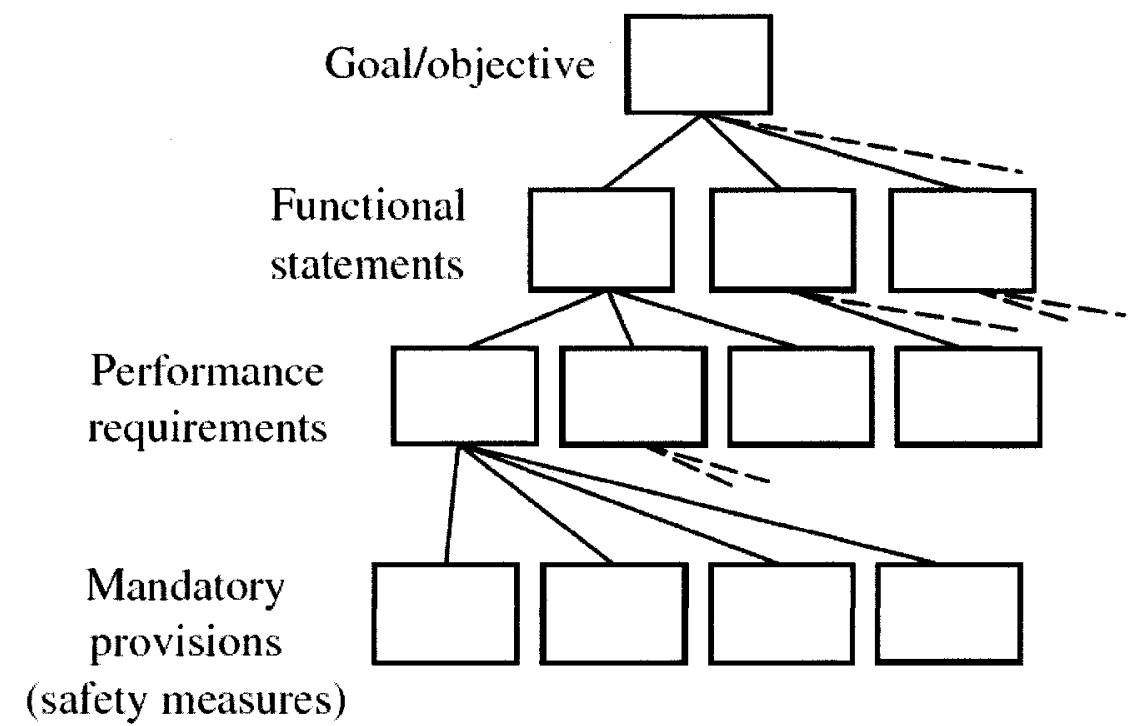

Figure 1 The idealized structure of the performance-based regulatory system [8]

The structure of the performance-based building codes illustrates the difference with the prescriptive-based codes, where only the prescriptive solutions are provided. In the performance-based building code, engineers or designers can use 'any' solutions that meet the objectives, rather than only a single set or limited solutions allowed in the prescriptive-based codes [2]. Therefore, the performance-based building codes allow designers to use new materials and new technologies by verifying that the new materials or new technologies can meet the mandated objectives.

Another significant advantage of performance-based building codes is that rational designs can be made, especially in unconventional projects that may not be amenable to analysis under prescriptive codes. Performance-based approaches can also provide a rational tool for designers to meet owner's desire to increase the level of safety over the legal minimum requirements [5]. 
The disadvantages of performance-based design are the need for time-consuming analysis and the need for more knowledge for both designers and AHJ. These are part of the reasons that the performance-based building codes have only been adopted by few countries in the world.

One of the main concerns for adopting performance-based codes is that they may lead to designs that provide much less fire safety than those under prescriptive codes. While the performance-based building codes are initially applied in the large, high-dollar projects, it could mean that the buildings with larger numbers of people may have relatively lower safety standards than those with small number of people [5].

From an historical overview of the development of building regulations, Hadjisophocleous et al. [9] summarized the advantages and disadvantages of prescriptive-based and performance-based regulations as shown in Table 2. The performance-based codes have superiority over prescriptive codes in economic, flexibility and globalization aspects. The difficulty to prove compliance with the set of objectives in the performance-based approach could be resolved with the development of computer models and engineering tools [9]. 
Table 2 Prescription vers Performance [9]

\begin{tabular}{|c|c|c|}
\hline Code Type & Advantages & Disadvantages \\
\hline $\begin{array}{l}\text { Prescriptive } \\
\text { codes }\end{array}$ & $\begin{array}{l}\text { - Straightforward evaluation of } \\
\text { compliance with established } \\
\text { requirements } \\
\text { - No requirements for high level of } \\
\text { engineering expertise }\end{array}$ & $\begin{array}{l}\text { - Requirements specified without } \\
\text { statement of objectives } \\
\text { - Complexity of the structure of codes } \\
\text { - No promotion of cost-effective designs } \\
\text { - Very little flexibility for innovation } \\
\text { - Presumption that there is only one } \\
\text { way of providing the level of safety }\end{array}$ \\
\hline $\begin{array}{l}\text { Performance } \\
\text { codes }\end{array}$ & $\begin{array}{l}\text { - Establishment of clear safety goals } \\
\text { and leaving the means of achieving } \\
\text { those goals to the designer } \\
\text { - Permit innovative design solutions } \\
\text { that meet the performance } \\
\text { requirements } \\
\text { - Eliminate technical barriers to trade } \\
\text { for a smooth flow of products } \\
\text { - Facilitate harmonization of } \\
\text { international regulation systems } \\
\text { - Facilitate use of new knowledge when } \\
\text { available } \\
\text { - Allow for cost-effectiveness and } \\
\text { flexibility in design } \\
\text { - Non complex documents } \\
\text { - Permit the prompt introduction of new } \\
\text { technologies to the market place }\end{array}$ & $\begin{array}{l}\text { - Difficult to define quantitative levels of } \\
\text { safety (performance criteria) } \\
\text { - Need for education because of lack of } \\
\text { understanding especially during first } \\
\text { stages of application } \\
\text { - Difficult to evaluate compliance with } \\
\text { established requirements } \\
\text { - Need of computer models for } \\
\text { evaluating performance }\end{array}$ \\
\hline
\end{tabular}

\subsubsection{Fire Protection Design for Buildings}

Figure 2 [3] presents a typical basic building design and construction process, which can be used in either prescriptive-based design or performance-based design, or both. In comparison with the prescriptive-based design, the early involvement of performancebased approaches in the designs, such as in the feasibility or conceptual design phase, can provide benefits of flexible design, innovative utilization of new materials and/or new technologies, better fire safety approaches, and maximal benefit/cost ratio. 
Recommended steps in the performance-based design process are given in Figure 3, which is reproduced from the SFPE Engineering Guide [3, 10].

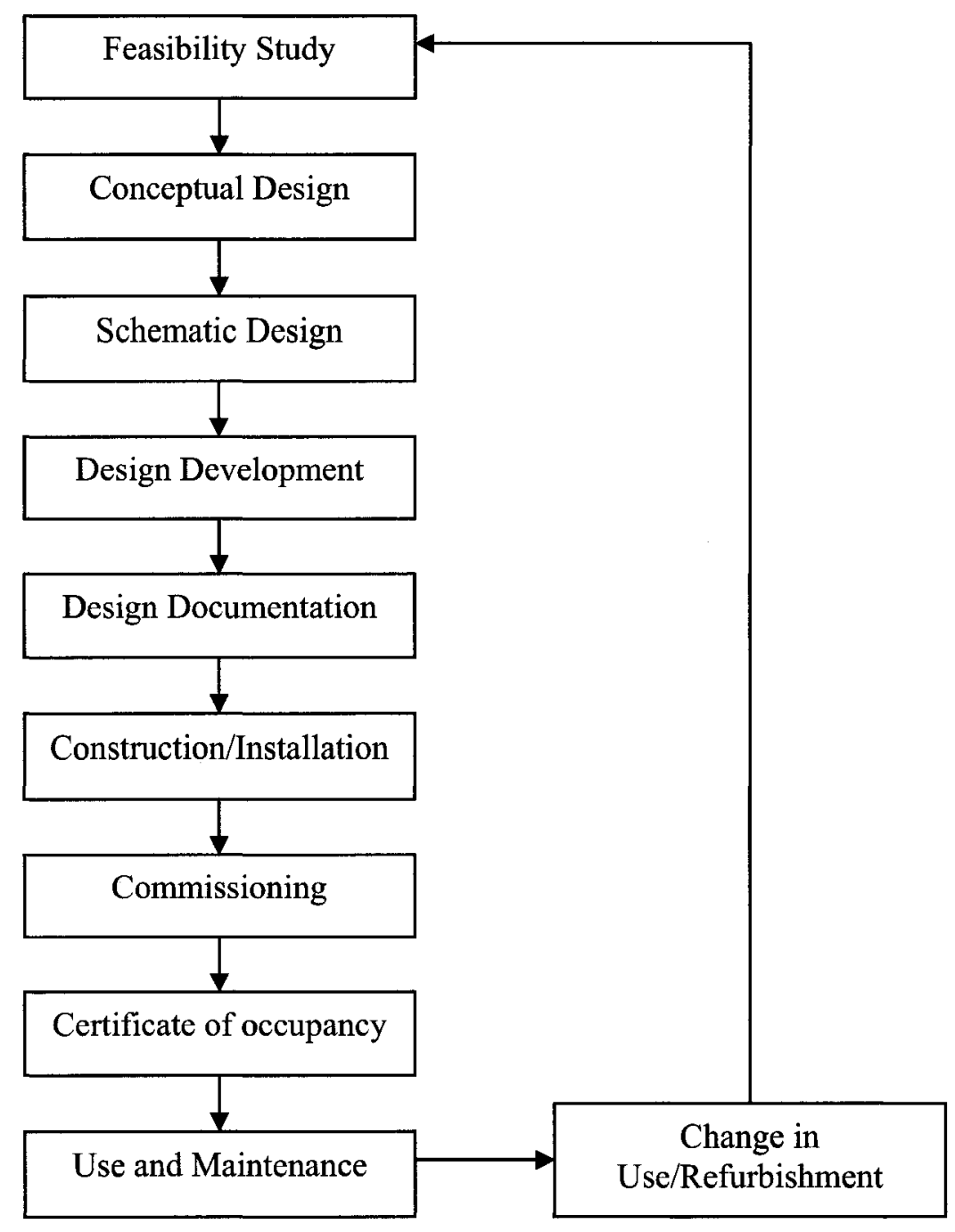

Figure 2 Basic building design and construction process [3] 


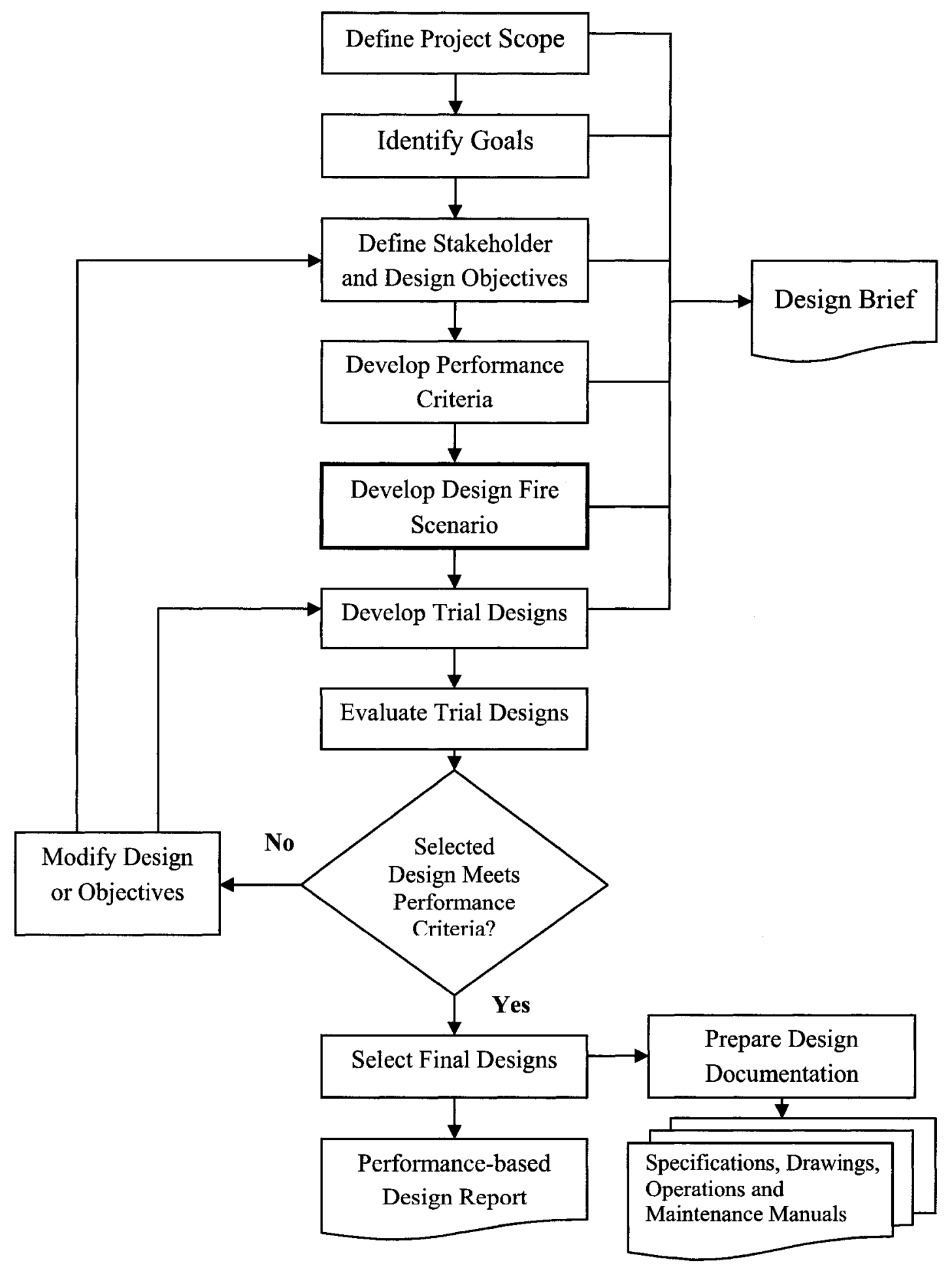

Figure 3 Steps of performance-based design (modified from [3], [10])

10 


\subsection{Objective of this Study}

Some countries in the world have changed their building codes from prescriptive to performance-based, and other countries around the world are interested to adopt the performance-based approach. One of the most challenging tasks for applying performance-based designs is to develop design fires for different building categories. For this, the fire loads in different building categories need to be well understood, and the engineering tools, such as computer models, need to be reliable and available for use by engineers and designers.

Motels and hotels belong to the residential occupancy group, and are considered as a "sleeping risk" with more fire safety concerns to public. However, very few studies have been conducted in this building category.

The objective of this research is to determine the fire loads for motels and hotels, and also to obtain experimental data through full-scale fire tests, which can be used to compare the results of computer modelling.

\subsection{Thesis Organization}

This research project deals with design fires for motels and hotels. The scope of this report covers four major aspects: literature review, fire load surveys, experimental tests, and fire modelling. The main contents of each chapter are listed below: 
Chapter 1: discusses the advantages and disadvantages of prescriptive-based and performance-based codes, and also introduces the fire protection design using the performance-based approach. The objective of this research is also presented.

Chapter 2: provides a literature review on statistical data of hotel fires; possible design fire scenarios; fire load surveys conducted in office buildings, residential buildings, and hotels; fire tests from heat release rate measurements and room fire tests; an introduction of zone models and field models used in the fire community, and a modelling exercise of room fires.

Chapter 3: presents the fire load survey of 10 motels and 12 hotels conducted in Canada's National Capital Region, Ottawa and Gatineau area, from March 2007 to August 2007.

Chapter 4: discusses the test setup, instrumentation, results and analyses of two fullscale room fire tests, conducted in the NRC/Carleton Fire Research Lab in 2008.

Chapter 5: presents a computer simulation of the hotel room fire tests using the Fire Dynamic Simulator (FDS) model, and a simplified approach used to develop input data files for FDS modelling.

Chapter 6: presents a summary of this research and recommendations for future research work. 


\section{Chapter 2: Literature Review}

\subsection{Hotel Fires}

The National Building Code of Canada (NBCC) [7] provides major occupancy classifications so every building can be classified into one of the six groups (Group A, B, C, D, E, and F), or one of the divisions under the specific group. Hotels and motels are categorised into Group C---residential occupancies. Some examples of other classifications are: Educational properties (non-residential schools and colleges) belong to Division 2 of Group A; nursing homes and facilities that care for the aged belong to Division 2 of Group B; business and office properties belong to Group D; stores and other mercantile establishments belong to Group E; low-hazard general item warehouses belong to Division 3 of Group F [11]. Most countries in the world also adopt the classification of hotels as a type of residential premises [12].

Statistical data of fire losses in selected classifications of non-residential, commercial and residential structures in Canada in 2001 are presented in Table 3 [11]. As the table shows, 218 hotel/motel fires were reported in Canada in 2001. The average annual fire losses in similar building categories in the United States from 1980 to 1998 are given in 
Table 4 [11], which shows that there was an average of 7400 hotel/motel fires annually during the period of 1980 to 1998 in the United States.

Table 32001 Canadian fire losses in selected property classifications of non-residential, commercial and residential structures $[11,13]$

\begin{tabular}{lcccc}
\hline \multicolumn{1}{c}{ Property classification } & \multicolumn{3}{c}{ Property loss } & \\
& Fires & per fire (CD) & Injuries & Deaths \\
\hline Office & 233 & 47800 & 5 & 0 \\
Hotel, inn, motel, etc. & 218 & 73600 & 25 & 1 \\
Home for Aged & 93 & 4200 & 7 & 2 \\
Textile and clothing store & 44 & 32000 & 2 & 0 \\
Furniture, appliance and electronics store & 38 & 98500 & 1 & 0 \\
Department and variety store & 105 & 72300 & 1 & 0 \\
Food and beverage store & 202 & 60400 & 9 & 0 \\
Restaurant or bar & 349 & 51300 & 19 & 0 \\
Church, funeral parlor, etc. & 66 & 57100 & 1 & 0 \\
School, college, university & 420 & 28400 & 19 & 0 \\
Theatre, auditorium, studio, recreation or social club, & 231 & 34700 & 6 & 0 \\
library, museum, art gallery, amusement or & & & & \\
recreational place, etc. & & & & \\
Warehouse/storage & 291 & 154300 & 6 & 0 \\
\hline
\end{tabular}

Table 4 Average annual* fire losses in selected classifications of non-residential, commercial and residential structures in the United States from 1980 to $1998[11,13]$

\begin{tabular}{lcccc}
\hline \multirow{2}{*}{ Property classification } & \multicolumn{4}{c}{ Average annual fire losses 1980-1998 } \\
\cline { 2 - 5 } & Fires & $\begin{array}{c}\text { Property loss } \\
\text { per fire (USD) }\end{array}$ & Injuries & Deaths \\
\hline Hotels/motels & 7400 & 9000 & 408 & 46 \\
Care homes for aged & 3600 & 1600 & 228 & 15 \\
Eating and drinking & 14800 & 11700 & 245 & 11 \\
Stores and mercantile & 25150 & 19500 & 486 & 22 \\
Business and office & 7950 & 20400 & 113 & 4 \\
General item warehouse & 2280 & 35400 & 28 & 1 \\
Religious and funeral & 2490 & 24800 & 29 & 3 \\
Educational & 9200 & 10200 & 194 & 2 \\
Other public assembly & 5640 & 16500 & 85 & 7 \\
\hline
\end{tabular}

* The numbers throughout the remainder of this report are the average each year, over the nineteenperiod from 1980 through 1998 
The major hotel fires around the world from 1909 to 2006 are listed in Appendix A. One of the biggest hotel fires in the United States history is the MGM Grand Hotel fire, in Las Vegas, Nevada, on the early morning of November 21, 1980. The MGM Grand Hotel was a 23-story high-rise building. 85 guests and hotel employees were killed, and about 600 were injured in this fire [14].

\subsubsection{When Hotel Fires Occur}

From the reported data on fire events and their outcomes in hotels/motels in Canada from 1980 to 1998 , Richardson [11] noticed that the greatest percentage of fire injuries was from fires that occurred between midnight and 6:00 am and the greatest percentage of property loss was between 9:00 pm and 6:00 am. The percentage of fires starts to decrease between the 3:00-6:00 am time period. He also noted that Saturdays and Sundays were the peak days in terms of number of fires, and fire injuries.

Hansell and Morgen [15] analysed the U.K. fire statistical data-base for 1978 and 1979. They found that an average of 0.375 casualties per hour from $8: 00$ am to $23: 59 \mathrm{pm}$, and 9.75 causalities from 0:00 am to 7:59 am. It shows that 26 times more causalities occur during nighttime than during daytime. This illustrates that hotels represent a 'sleeping risk' as they are more heavily populated at night.

\subsubsection{Ignition Source and First Ignited Items}

According to the U.K. fire statistical data-base for 1978 and 1979, smoker's materials were the major ignition source, and caused about $40 \%$ of all fires. The fire incidents 
caused by smoker's materials during the night were about twice as many as that during the day $(55 \%$ to $29 \%)$ [15].

In the United States, the NFPA Survey from 1982 to 1986 indicates that smoking materials were also the major ignition source in terms of civilian deaths and injuries from fires in hotels and motels [12]. Table 5 shows the causes of civilian deaths and injuries of hotel and motel fires.

Table 5 Causes of civilian deaths and injuries of hotel and motel fires, 1982-1986: annual average unknown-cause fires allocated proportionally [12]

\begin{tabular}{lcc}
\hline Cause & $\begin{array}{c}\text { Civilian } \\
\text { deaths }\end{array}$ & $\begin{array}{c}\text { Civilian } \\
\text { injuries }\end{array}$ \\
\hline Smoking materials & 21 & 143 \\
Incendiary or suspicious causes & 18 & 138 \\
Cooking equipment & 4 & 43 \\
Heating equipment & 4 & 29 \\
Open flame, embers or torches & 3 & 14 \\
Electrical distribution & 2 & 39 \\
Child playing & 2 & 8 \\
Other equipment & 1 & 18 \\
Other heat & 1 & 7 \\
Natural causes & 1 & 4 \\
Appliances, tools or air conditioning & 1 & 32 \\
Exposure (to other hotel fire) & 1 & 2 \\
Total & 59 & 475 \\
Source: NFIRS (1982-1986) & & \\
\hline
\end{tabular}

Richardson [11] analysed the Canadian fire statistics from 1980 to 1998 , and found that the category of 'mattress, pillow or bedding, linen other than bedding, wearing apparel not on a person, unclassified or unknown soft goods or wearing apparel' was the leading type of materials first ignited in terms of number of fires (28.1\%) with 75.5 injuries per 1000 fires. The largest number of injuries per 1000 fires was 110.7 with 
relatively a small number of fires $(3.8 \%)$, which was caused by 'upholstered furniture, cabinetry, unclassified or unknown furniture'. Table 6 shows the type of materials first ignited for fire events in hotels/motels.

Table 6 Type of materials first ignited for fire events in hotels/motels [11]

\begin{tabular}{lccc}
\hline Type of material first ignited--hotel/motel properties & $\begin{array}{c}\text { Fires } \\
\text { (per cent) }\end{array}$ & $\begin{array}{c}\text { Injuries } \\
\text { (per 1000 fires) }\end{array}$ & $\begin{array}{c}\text { Property loss } \\
\text { per fire (USD) }\end{array}$ \\
\hline $\begin{array}{l}\text { Mattress, pillow or bedding, linen other than bedding, } \\
\text { wearing apparel not on a person, unclassified or }\end{array}$ & 28.1 & 75.5 & 5900 \\
unknown soft goods or wearing apparel & & & \\
Rubbish, trash or waste, dust, fibre or lint & 13.9 & 25.2 & 3400 \\
Cooking material & 8.9 & 28.8 & 2300 \\
$\begin{array}{l}\text { Electrical wire or cable insulation } \\
\text { Interior wall covering, floor covering or surface, } \\
\text { ceiling covering or surface }\end{array}$ & 7.6 & 46.4 & 7500 \\
$\begin{array}{l}\text { Structural member or framing, unclassified or un- } \\
\text { known type structural member or framing }\end{array}$ & 4.1 & 60.5 & 14000 \\
$\begin{array}{l}\text { Upholstered furniture, cabinetry, unclassified or } \\
\text { unknown furniture }\end{array}$ & 3.8 & 110.7 & 8600 \\
$\begin{array}{l}\text { Exterior sidewall covering or finish, exterior roof } \\
\text { covering or finish, exterior trim }\end{array}$ & 3.6 & 14.8 & 14400 \\
\begin{tabular}{l} 
Percentage of all losses depicted by data \\
\hline
\end{tabular} & $76 \%$ & $74 \%$ & $72 \%$ \\
\hline
\end{tabular}

\subsection{Design Fires and Design Fire Scenarios}

In fire safety design, the design fire(s) needs to be appropriately selected, due to its impact on "all aspects of fire safety performance, including the fire resistance for structures, compartmentation against fire spread, egress systems, manual or automatic detection systems, suppression systems, and smoke control" [16]. As the performance criteria have been established in the performance-based design, the first part of the 
engineer's work is to identify the possible fire scenarios and design fire scenarios [3].

The definitions of fire scenario, design fire scenario, design fire, and design fire curve

from two source references were summarized by Bwalya in Table 7 [17].

Table 7 Terminology related to design fires [17]

\begin{tabular}{|c|c|c|}
\hline \multirow[b]{2}{*}{ Term } & \multicolumn{2}{|c|}{ Definition by source reference } \\
\hline & ISO/TR-13387-2 [58] & SFPE engineering guide [3] \\
\hline Fire scenario & $\begin{array}{l}\text { A qualitative description of the course of a } \\
\text { specific fire with time, identifying key events } \\
\text { that characterize the fire and differentiate it } \\
\text { from other possible fires }\end{array}$ & $\begin{array}{l}\text { A set of conditions that defines the } \\
\text { development of fire and the spread } \\
\text { of combustion products throughout } \\
\text { a building or part of a building }\end{array}$ \\
\hline $\begin{array}{l}\text { Design fire } \\
\text { Scenario }\end{array}$ & $\begin{array}{l}\text { A specific fire scenario on which an analysis } \\
\text { will be conducted. It includes a description } \\
\text { of the impact on the fire of building } \\
\text { features, occupants, fire safety systems and } \\
\text { would typically define the ignition source } \\
\text { and process, the growth of the fire on the } \\
\text { first item ignited, the spread of the fire, the } \\
\text { interaction of the fire with the building } \\
\text { occupants and the interaction with the } \\
\text { features and fire safety systems within } \\
\text { the building }\end{array}$ & $\begin{array}{l}\text { A set of conditions that defines or } \\
\text { describes the critical factors } \\
\text { determining the outcomes of trial } \\
\text { Designs }\end{array}$ \\
\hline $\begin{array}{l}\text { Design fire } \\
\text { Design } \\
\text { fire curve }\end{array}$ & $\begin{array}{l}\text { Design fire: A quantitative temporal descrip- } \\
\text { tion of assumed fire characteristics based on } \\
\text { appropriate fire scenarios. Variables used in } \\
\text { the description include: HRR, fire size } \\
\text { (including flame length), quantity of fire } \\
\text { effluent, temperatures of hot gases, and time } \\
\text { to key events such as flashover }\end{array}$ & $\begin{array}{l}\text { Design fire curve: An engineering } \\
\text { description of a fire in terms of } \\
\text { HRR versus time (or in other } \\
\text { terms elaborated in the stated } \\
\text { reference) for use in a design fire } \\
\text { Scenario }\end{array}$ \\
\hline
\end{tabular}

In terms of the temperature or heat release rate development in the compartment, enclosure fires are normally divided into different stages, including ignition, growth, flashover, fully developed and decay. Figure 4 presents the stages of fire development in a room in the absence of an active suppression system [18]. 


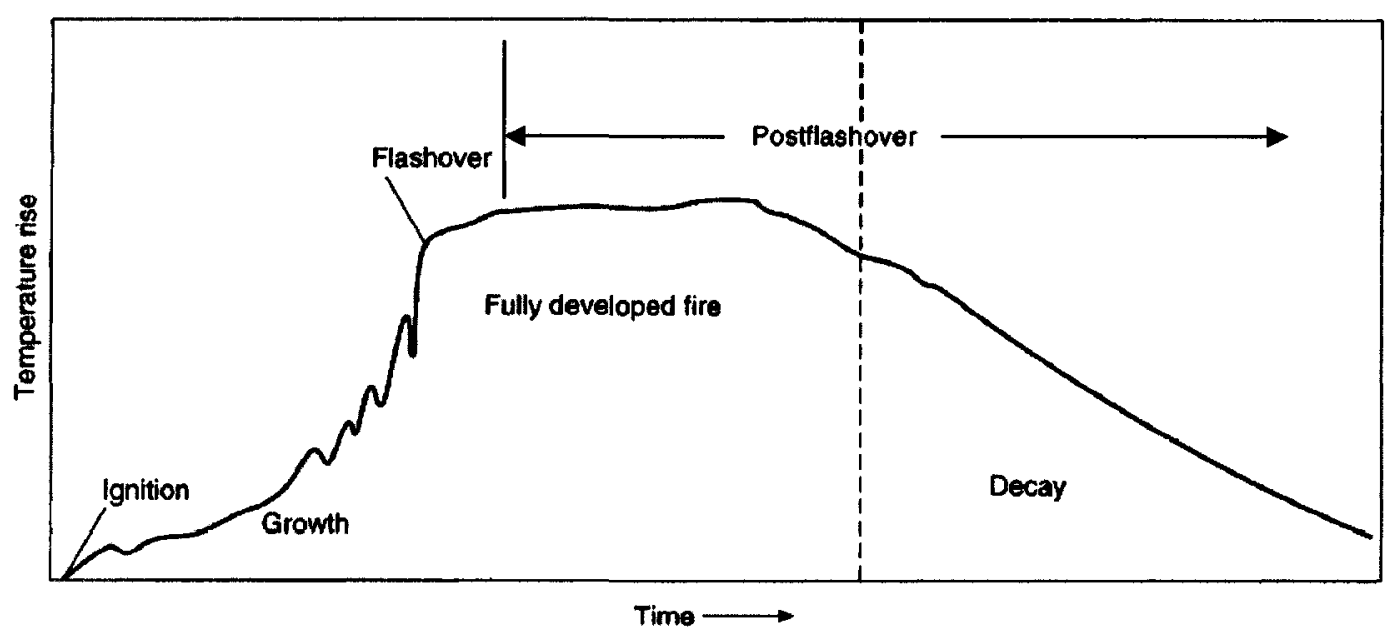

Figure 4 Stages of fire development in a room (modified from [18])

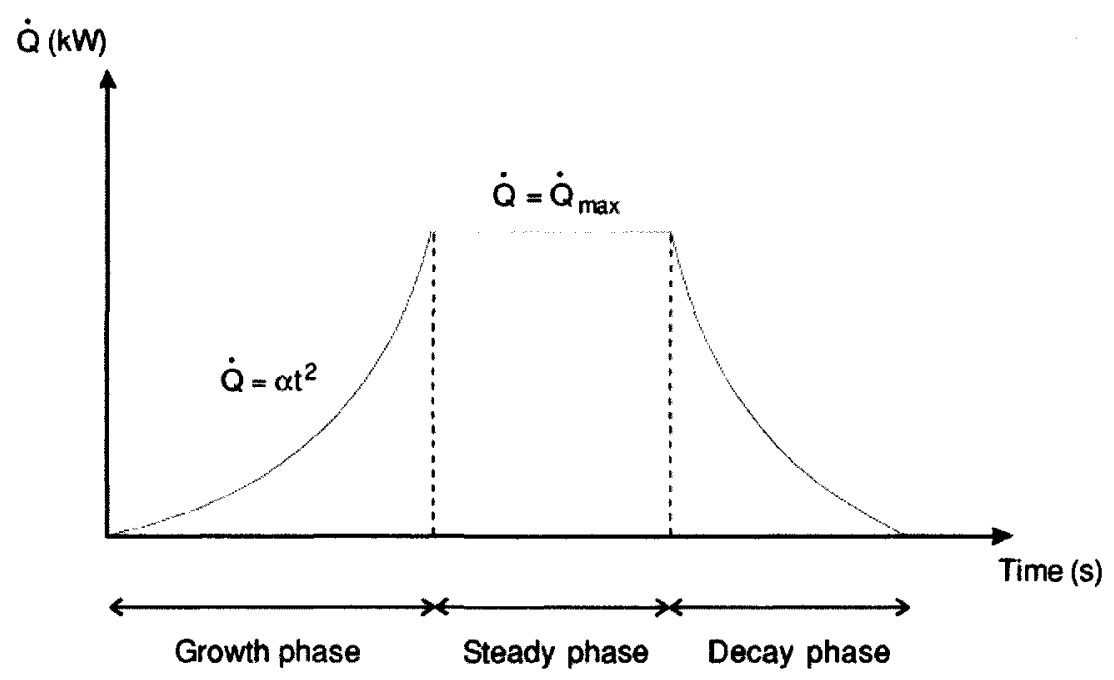

Figure 5 A simple design fire curve [19]

In fire safety engineering design, the fire development can be simplified into two stages: pre-flashover fire and post-flashover fire. The concern in the pre-flashover fire is the safety of humans, while the design objective in the post-flashover fire is to ensure structural stability and safety of firefighters [19]. Figure 5 presents an example of a simple design fire curve [19], which is similar to Figure 4 [18]. 


\subsubsection{Pre-flashover Stage and T-squared Fires}

In the pre-flashover stage of a real fire, the heat release rate is practically always increasing, and the growth is commonly quantified as a function of time squared. Equation 2.1 is one of the most widely used equations of the t-squared design fire given by NFPA [20]. Equation 2.2 [19] is similar to Equation 2.1, where the growth factor $\alpha$, can be derived by substituting the values of reference heat release rate $\dot{Q}_{o}$, and time to reach the reference heat release rate $t_{o}$ in Equation 2.1 .

$$
\begin{aligned}
& \dot{Q}=\dot{Q}_{o}\left(\frac{t}{t_{o}}\right)^{2} \\
& \dot{Q}=\alpha \cdot t^{2}
\end{aligned}
$$

Where, $\dot{Q}=$ rate of heat release $(\mathrm{kW})$

$$
\begin{aligned}
& \dot{Q}_{o}=\text { reference heat release rate }(\mathrm{kW}) \text {, usually taken as } 1000 \mathrm{~kW} \\
& t_{o}=\text { time to reach the reference heat release rate }(\mathrm{s}) \\
& t=\text { time after effective ignition (s) } \\
& \alpha=\text { growth rate coefficient }\left(\mathrm{kW} / \mathrm{s}^{2}\right)
\end{aligned}
$$

Four different growth rates: ultra fast, fast, medium, and slow are presented in Figure 6 , and the corresponding values of $\alpha$ and the characteristic time in different design fire scenarios are given in Table 8 [21]. The t-squared fire is typically for a single burning item [21], and a more complex design fire is provided in Figure 7 [19]. 


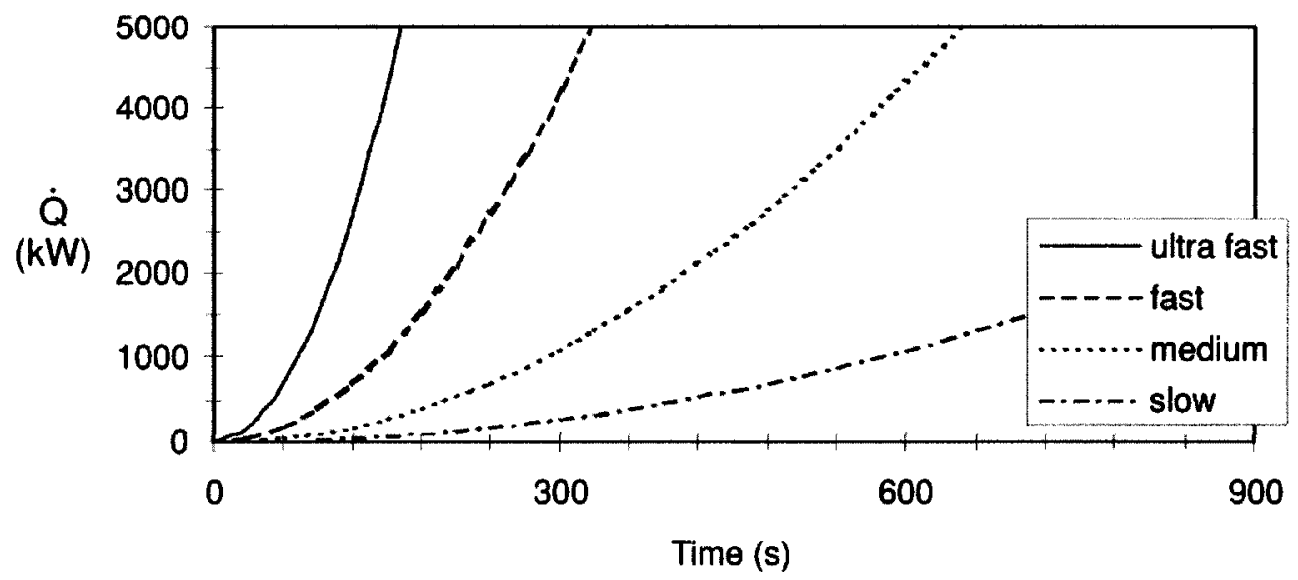

Figure 6 Heat release rate for different growth rates [19]

Table 8 Categories of t-squared fires [21]

\begin{tabular}{|l|l|l|l|}
\hline $\begin{array}{c}\text { Growth } \\
\text { Rate }\end{array}$ & \multicolumn{1}{|c|}{ Design Fire Scenarlo } & \multicolumn{1}{|c|}{ Value of $\alpha$} & $\begin{array}{l}\text { Characteristic } \\
\text { time, } t_{0}(\mathbf{s})\end{array}$ \\
\hline Slow & \multicolumn{1}{|c|}{ Floor coverings } & 0.00293 & 600 \\
\hline Medium & Shop counters, office furniture & 0.0117 & 300 \\
\hline Fast & $\begin{array}{l}\text { Bedding, displays and padded work-station } \\
\text { partitioning }\end{array}$ & 0.0466 & 150 \\
\hline Ultra-fast & $\begin{array}{l}\text { Upholstered furniture and stacked furniture near } \\
\text { combustible linings, lightweight furnishings, } \\
\text { packing material in rubbish pile, non-fire-retarded } \\
\text { plastic foam storage, cardboard of plastic boxes } \\
\text { in vertical storage arrangement. }\end{array}$ & 0.1874 & 75 \\
\hline
\end{tabular}

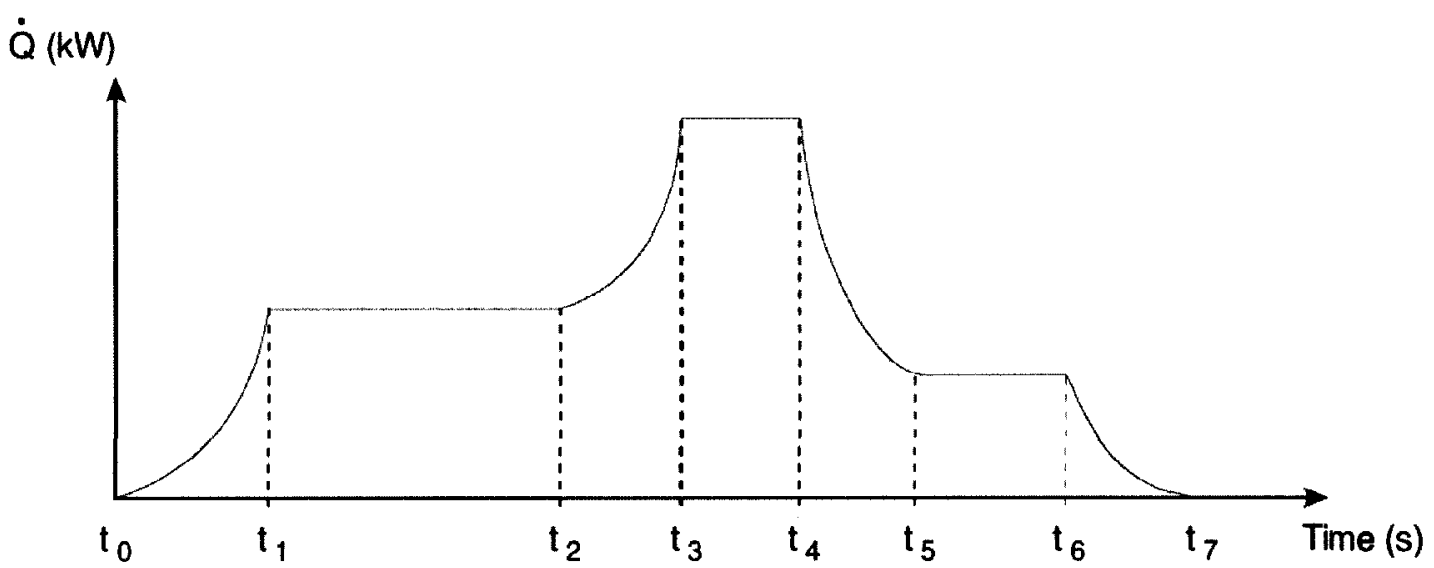

Figure 7 A more complex design fire [19] 


\subsubsection{Post-flashover Stage and Flashover}

Flashover is normally regarded as the transition from a growth fire to a fully developed fire [18], and also the transition of burning from one or two items to all the combustibles in the compartment. The widely used criteria for flashover are based on the radiation from the hot gas in the compartment [18]. One of the criteria is the temperature of the hot gas between 500 and $600^{\circ} \mathrm{C}$, and another important criterion is the heat flux at floor level of the compartment reaching $15-20 \mathrm{~kW} / \mathrm{m}^{2}$.

A minimum heat release rate required for flashover can be predicted by different methods, such as method of MQH (McCaffrey, Quintiere, and Harkleroad) [22], method of Babrauskas [23], and method of Thomas [24]. All of these methods are based on the conservation of energy in the upper hot layer of a compartment, derived by McCaffrey, Quintiere, and Harkleroad. Equation 2.3 gives the conservation of energy expression to the upper layer.

$$
\dot{Q}=\dot{m}_{g} c_{p}\left(T_{g}-T_{\infty}\right)+\dot{q}_{\text {loss }}
$$

Where, $\dot{Q}=$ heat release rate of the fire $(\mathrm{kW})$

$$
\begin{aligned}
& \dot{m}_{g}=\text { gas flow rate out the opening }(\mathrm{kg} / \mathrm{s}) \\
& c_{p}=\text { specific heat of gas }(\mathrm{kJ} / \mathrm{kg} \cdot \mathrm{K}) \\
& T_{g}=\text { temperature of the upper gas layer }(\mathrm{K}) \\
& T_{\infty}=\text { ambient temperature }(\mathrm{K}) \\
& \dot{q}_{\text {loss }}=\text { net radiative and convective heat transfer from the upper gas layer }(\mathrm{kW})
\end{aligned}
$$


Table 9 summarises the three methods for predicting the minimum heat release rate for flashover with the respectively derived equations (Equation 2.4, 2.5, and 2.6), and the corresponding equations, values and assumptions that were substituted in the same conservation of energy expression, Equation 2.3.

Table 9 Summary of methods for predicting minimum heat release rate for flashover

\begin{tabular}{|c|c|c|}
\hline Methods & Equations, values and assumptions & Minimum $\dot{Q}$ for flashover \\
\hline $\mathrm{MQH}[22]$ & $\begin{array}{l}\qquad \dot{m}_{g} \approx \sqrt{g} \rho_{\infty} A_{0} \sqrt{H_{0}} \\
\qquad \dot{q}_{\text {loss }}=h_{k} A_{T}\left(T_{g}-T_{\infty}\right) \\
\text { Where } \\
\Delta T_{g}=T_{g}-T_{\infty}=500 \quad c_{p}=1.0 \mathrm{~kJ} / \mathrm{kg} \cdot \mathrm{K} \\
\rho_{\infty}=1.18 \mathrm{~kg} / \mathrm{m}^{3}(\text { density of air }) \\
A_{0}=\text { area of opening }\left(\mathrm{m}^{2}\right) \\
H_{0}=\text { height of opening }(\mathrm{m}) \\
h_{k}=\text { effective heat transfer coefficient }(\mathrm{kW} / \mathrm{mK}) \\
A_{T}=\text { total compartment surface area }\left(\mathrm{m}^{2}\right)\end{array}$ & $\begin{array}{r}\dot{Q}=610\left(h_{k} A_{T} A_{0} \sqrt{H_{0}}\right)^{1 / 2} \\
\ldots \ldots(2.4)\end{array}$ \\
\hline $\begin{array}{c}\text { Babrauskas } \\
{[23]}\end{array}$ & $\begin{array}{l}\qquad \dot{m}_{g} \approx 0.5 A_{0} \sqrt{H_{0}} \\
\qquad \dot{q}_{l o s s}=\varepsilon \sigma\left(T_{g}^{4}-T_{\infty}^{4}\right)\left(0.40 A_{T}\right) \\
\text { Where } \\
T_{g}=873 K T_{\infty}=298 K \\
\varepsilon=0.5 \text { (emissivity of hot gas) } \\
\sigma=5.67 \times 10^{-11} \mathrm{~kW} / \mathrm{m}^{2} \cdot \mathrm{K}^{4} \text { (Stefan-Boltzmann } \\
\text { constant) } \\
\frac{A_{T}}{A_{0} \sqrt{H_{0}}} \approx 50\end{array}$ & $\begin{array}{l}\text { Calculated: } \\
\dot{Q}=600 A_{0} \sqrt{H_{0}} \\
\text { Revised by tests: } \\
\dot{Q}=750 A_{0} \sqrt{H_{0}} \ldots \ldots(2.5)\end{array}$ \\
\hline $\begin{array}{c}\text { Thomas } \\
\text { [24] }\end{array}$ & $\begin{array}{l}\quad \dot{m}_{g} \approx 0.5 A_{0} \sqrt{H_{0}} \\
\begin{array}{l}\dot{q}_{\text {loss }} \\
=h_{c}\left(T_{g}-T_{w}\right) \frac{A_{T}}{2}+\varepsilon \sigma\left(2 T_{g}^{4}-T_{w}^{4}-T_{f l r}^{4}\right)\left(\frac{A_{T}}{6}\right) \\
\quad \approx 7.8 A_{T}\end{array} \\
\text { Where } \\
T_{g}=577^{\circ} \mathrm{C} \text { or: } \Delta T_{g}=600^{\circ} \mathrm{C} \\
c_{p}=1.26 \mathrm{~kJ} / \mathrm{kg} \cdot \mathrm{K}\end{array}$ & $\begin{array}{r}\dot{Q}=7.8 A_{T}+378 A_{0} \sqrt{H_{0}} \\
\ldots \ldots(2.6)\end{array}$ \\
\hline
\end{tabular}


After flashover, the major concern shifts from safety of humans to structural stability and safety of firefighters $[19,21]$, since the prevailing conditions may have exceeded the tenability limits [21]. Correspondingly, the importance of predicting heat release rate at the pre-flashover stage is changed to that of predicting temperature at the post-flashover stage [21].

Babrauskas $[25,26]$ developed a method to predict the upper gas temperature in a post-flashover compartment by adding a series of factors in one equation, Equation 2.7. Each factor represents a different physical phenomenon [18], and these factors can be derived from equations or tables presented in the literature [25, 26, and 18].

$$
T_{g}=T_{\infty}+\left(T^{*}-T_{\infty}\right) \cdot \theta_{1} \cdot \theta_{2} \cdot \theta_{3} \cdot \theta_{4} \cdot \theta_{5}
$$

Where, $T_{g}=$ temperature of the upper gas layer $(\mathrm{K})$

$$
\begin{aligned}
& T_{\infty}=\text { ambient temperature }(\mathrm{K}) \\
& T^{*}=\text { empirical constant }, 1725 \mathrm{~K} \\
& \theta_{1}=\text { burning rate stoichiometry } \\
& \theta_{2}=\text { wall steady-state losses } \\
& \theta_{3}=\text { wall transient losses } \\
& \theta_{4}=\text { opening height effect } \\
& \theta_{5}=\text { combustion efficiency }
\end{aligned}
$$

The EUROCODE method [27], which is regarded as the most widely-used method for predicting post-flashover temperature [21], combined the factors that affect the fire 
growth and intensity such as fire load density, compartment size, ventilation area, and construction materials [28]. Noticed that the factors used in the EUROCODE method [27] and the method of Babrauskas [25, 26] are different. The EUROCODE method treats the fire development as two phases, the heating phase and the decay phase, and a parametric fire temperature is defined in the heating phase. Table 10 summarizes the equations for the two phases, Equation 2.8 and 2.9, used in the EUROCODE method.

Table 10 Summary of equations used in the EUROCODE method

\begin{tabular}{|c|c|}
\hline Phases & Equations for predicting temperatures [27] \\
\hline Heating & $\begin{array}{l}T=1325\left(1-0.324 e^{-0.2 t^{*}}-0.204 e^{-1.7 t^{*}}-0.472 e^{-19 t^{*}}\right) \ldots . .(2.8) \\
\text { Where } \\
t^{*}=t\left(\frac{\left(F_{0} / F_{\text {ref }}\right)}{\left(b / b_{\text {ref }}\right)}\right)^{2}=t\left(\frac{F_{0}}{\sqrt{k \rho c_{p}}}\right)^{2}\left(\frac{1160}{0.04}\right)^{2} \\
k \rho c_{p}=\text { thermal inertial } \\
b=\sqrt{k \rho c_{p}} ; \quad b_{r e f}=1160 \mathrm{Ws}^{0.5} / \mathrm{m}^{2} \mathrm{~K} \\
F_{0}=\frac{A_{0} \sqrt{H_{0}}}{A_{t}} \quad \text { (opening factor); } F_{r e f}=0.04 \mathrm{~m}^{1 / 2}\end{array}$ \\
\hline $\begin{array}{l}\text { Decay or } \\
\text { Cooling }\end{array}$ & $\begin{array}{ll}T_{g}=T_{g, \max }-625\left(t^{*}-t_{d}^{*}\right) & \text { for } t_{d}^{*} \leq 0.5 \\
T_{g}=T_{g, \max }-250\left(3-t_{d}^{*}\right)\left(t^{*}-t_{d}^{*}\right) & \text { for } 0.5 \leq t_{d}^{*} \leq 2.0 \ldots \ldots(2.9) \\
T_{g}=T_{g, \max }-250\left(t^{*}-t_{d}^{*}\right) & \text { for } t_{d}^{*} \geq 2.0 \\
\text { Where } & \\
t_{d}^{*}=t_{d}\left(\frac{F_{0}}{\sqrt{k \rho c_{p}}}\right)^{2}\left(\frac{1160}{0.04}\right)^{2} ; t_{d}=\frac{0.13 \times 10^{-3} Q_{t}^{\prime \prime}}{F_{0}} \\
T_{g, \text { max }}=\text { maximum temperature at } t_{d}^{*}=t_{d} \\
Q_{t}^{\prime \prime}=\text { fire load density }\left(\mathrm{MJ} / \mathrm{m}^{2}\right)\end{array}$ \\
\hline
\end{tabular}


The equations used in the EUROCODE method were derived from the timetemperature curves provided by Magnusson and Thelandersson [29] in Figure 8. The time-temperature curves can be referenced in structural design for fire resistance by knowing the fire load and the ventilation factors.
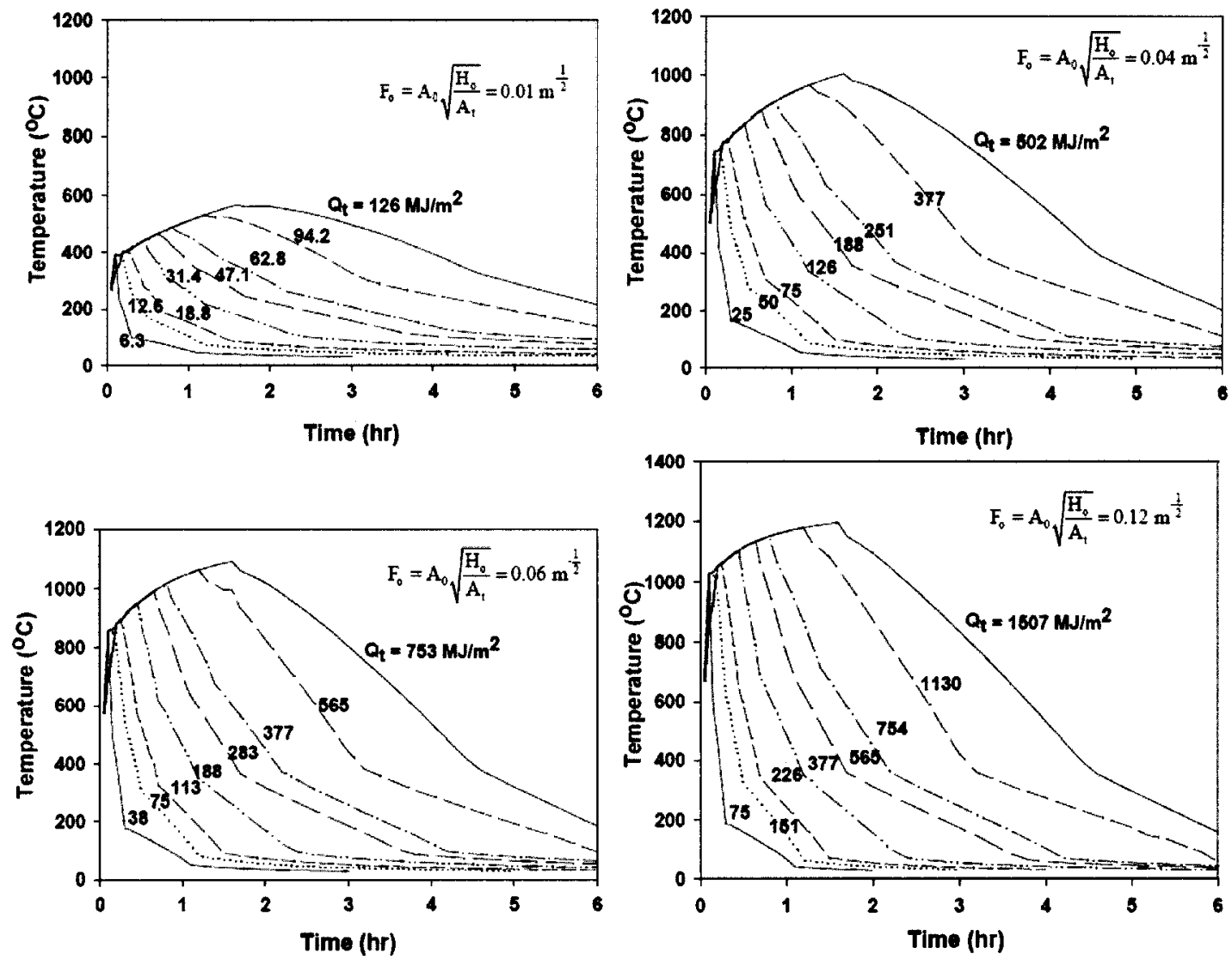

Figure 8 Time-temperature curves for different ventilation factors and fire loads [29]

\subsection{Fire Load and Fire Load Surveys}

In performance-based design, one of the important steps is design fires, which needs knowledge of fire loads and their composition in a variety of buildings. In fact, in applying performance-based design in engineering disciplines, there are two important 
elements that need to be well understood, developed, and known; one is the underlying science, and another is the design loads [4]. In comparison with structural engineering that is based on the Newtonian equations for balancing forces [4] and has been applied in structural design for about 200 years, the underlying science of fire protection engineering, or fire science, which is a relatively young engineering disciple, has been highly developed since twenty or thirty years ago [5]. It is also in this twenty or thirty year period that most countries around the world have aroused interests to change their codes from prescriptive to performance-based and some countries have already adopted performance-based building codes.

The design loads in structural engineering are mainly differentiated as 'dead loads' and 'live loads' [30]. Similarly, in fire safety engineering, the fire loads in a compartment are divided into "fixed fire loads' and "moveable fire loads". All combustible materials in or on the walls, floor and ceiling are considered as fixed fire loads; and all other combustible items that are brought into the compartment are considered as moveable fire loads.

However, fire loads are different from the loads in structural engineering in that fire is not a real load, since the impact of the fire is not only limited to one compartment, as fire can spread to other rooms and areas in the building or adjacent buildings. In addition, the building itself has a large impact on fire development, especially the openings [16].

In fire safety design, it is a challenge to determine realistic fire loads, because of the numerous possible arrangements of fire loads in most buildings. The worse case fire 
loads, or bounding loads, are normally used by fire safety engineers. In some cases, most likely fire loads for many different scenarios are also used [4].

Fire load data are historically established by surveys [16]. Fire load surveys in different building categories can be conducted by either physically entering buildings, or using questionnaires through the internet [31]. For the on-site fire load survey, two methods, the weighing technique and the inventory technique, or a combination of the two, can be used. Culver [32] evaluated the inventory technique, and the results obtained from the inventory technique are reasonable.

The first fire load survey was conducted by Ingberg [16] in the late 1920's. He published his first detailed data in 1942, and a second set of data in 1957. Ingberg [16] also established the relationship between fuel load and fire severity in Table 11.

Table 11 Fire severity for Various Fuel Loads (modified from [16])

\begin{tabular}{|c|c|}
\hline $\begin{array}{c}\text { Fuel Load } \\
\left(\mathrm{lb} / \mathrm{ft}^{2}\right)\end{array}$ & $\begin{array}{c}\text { Fire Severity } \\
\text { (hours) }\end{array}$ \\
\hline 5 & 0.5 \\
\hline 10 & 1 \\
\hline 15 & 1.5 \\
\hline 20 & 2 \\
\hline 30 & 3 \\
\hline 40 & 4.5 \\
\hline 50 & 7 \\
\hline 60 & 8 \\
\hline 70 & 9 \\
\hline
\end{tabular}




\subsubsection{Fire Load Survey in Office Buildings}

Fire load surveys of office buildings have been conducted by Bryson and Gross in the USA in 1967 [33]; Baldwin et al. in the UK in 1970 [34]; Culver in the USA in 1976 [32]; Kumar and Rao in India in 1997 [35], respectively.

In 1967, Bryson and Gross [33] conducted a survey of live floor loads and fire loads at the same time in two office buildings in the United States. The survey of live floor loads was to provide comprehensive data of the actual loads that are applied to structures for structural design. The survey of fire loads was to update and extend the survey of the combustible contents conducted by Ingberg about 30 years before.

The first surveyed office building was an 11-story reinforced concrete building, and was surveyed from February to May 1967 with the surveyed area of $70,820 \mathrm{ft}^{2}\left(6,579 \mathrm{~m}^{2}\right)$ in 335 rooms. The second surveyed building was a 7-story reinforced concrete building, and was surveyed in July 1967 with the total surveyed area of $125,950 \mathrm{ft}^{2}\left(11,701 \mathrm{~m}^{2}\right)$ in 556 rooms, including a sampling of $55,130 \mathrm{ft}^{2}\left(5,122 \mathrm{~m}^{2}\right)$ of space considered to be representative of $573,000 \mathrm{ft}^{2}\left(53,233 \mathrm{~m}^{2}\right)$. The average survey rates in the first and second office building are $590 \mathrm{ft}^{2} / \mathrm{hr}\left(54.8 \mathrm{~m}^{2} / \mathrm{hr}\right)$, and $430 \mathrm{ft}^{2} / \mathrm{hr}\left(39.9 \mathrm{~m}^{2} / \mathrm{hr}\right)$, respectively.

Bryson and Gross [33] divided fire loads into two categories---'moveable contents' and 'interior finish', which corresponds to two categories of 'moveable fire loads' and 'fixed fire loads' that are normally used in recent years. The major data they recorded in the survey were room use and dimensions, number of assigned personnel and sex, item weight, location, and description. The direct weighting method was mainly used to 
determine the weights of items, and where the items could not be weighed, the weights were obtained by estimating the thickness and area.

By converting all weights to equivalent weights of combustibles having a calorific value of $8000 \mathrm{Btu} / \mathrm{lb}(18608 \mathrm{~kJ} / \mathrm{kg})$, Bryson and Gross [33] presented the surveyed fire loads in pounds per square foot (psf), with the mean value of the total fire load of 6.0 and $4.8 \mathrm{psf}$ in the first and the second surveyed office building, respectively. The corresponding fire loads in mega joule (MJ) per square metre are 545 and $435 \mathrm{MJ} / \mathrm{m}^{2}$.

Also at the end of the 1960s, Baldwin and his colleagues [34] conducted a survey of fire loads in two office buildings in the United Kingdom, and published a paper in March 1970. Unlike Bryson et al., they randomly chose two office buildings from a total of about 100 . One building was 5 storeys with a plan area of $245 \mathrm{~m}^{2}$, and the other building was 6 storeys with a plan area of $490 \mathrm{~m}^{2}$.

Baldwin and his colleagues [34] analysed the data of fire loads in terms of fire-load per unit window area $\left(F / A_{w}\right)$ and fire load per unit floor area $\left(F / A_{f}\right)$. The fire-load per unit window area $\left(\mathrm{F} / \mathrm{A}_{\mathrm{w}}\right)$ can be used as a criterion to distinguish the fire by ventilation controlled or fire-load controlled. In a fairly shallow compartment, with a depth to height ratio of 1.22 , the fire can be treated as ventilation controlled when the fire-load per unit window area $\left(F / \mathrm{A}_{\mathrm{w}}\right)$ is greater than $150 \mathrm{~kg} / \mathrm{m}^{2}\left(30 \mathrm{lb} / \mathrm{ft}^{2}\right)$, and otherwise the fire in fireload controlled. The fire-load per unit floor area $\left(F / A_{f}\right)$ is widely used as the fire load density. 
From the analysis of the 93 surveyed rooms in the two buildings, Baldwin and his colleagues [34] derived the mean values of the fire-load per unit window area and the fire-load per unit floor area, which are $55 \mathrm{~kg} / \mathrm{m}^{2}\left(11.3 \mathrm{lb} / \mathrm{ft}^{2}\right)$ and $20 \mathrm{~kg} / \mathrm{m}^{2}\left(4.13 \mathrm{lb} / \mathrm{ft}^{2}\right)$, respectively. The percentage of floor area covered by furnishings, as the distribution of the fuel, is 27 percent on average. They also noticed that there is no correlation between the fire-load density and the size of the room.

In 1973, a comprehensive survey of fire loads and live loads in office buildings was initiated in the United States by the General Services Administration (GSA), the National Academy of Sciences (NAS), and the National Bureau of Standards (NBS). A total of 2433 rooms were surveyed in the twenty-three office buildings from August 1974 to August 1975 [32].

The survey samples of the buildings were randomly selected from the available lists throughout the country by considering three building characteristics: geographic location, height and building age. Only twelve of the twenty originally selected private buildings were given survey permission due to apprehension concerns on the disruption of the normal business activities in the offices and the potential use of the survey results. Also because of the difficulties in obtaining survey permission, only 4 additional private buildings were surveyed by working through city building officials. The total of sixteen private buildings, plus six randomly selected government buildings and one NBS Administration Building composes the survey samples of a total of twenty-three office buildings located in various regions throughout the United States [32]. 
The inventory method, rather than the direct weighting, which was normally used before, was used in this survey [32]. The measurement error by using the inventory technique is about 10 percent, but it represents only a relatively small fraction of the variability of live loads. The magnitude of the loads in the surveyed rooms was not affected by the three building characteristics: geographic location, height, and building age, but the use of the room had a significant influence on both fire loads and live loads. File rooms, libraries, and storage rooms had larger values.

The mean value of the percentage of the room floor area occupied by the furniture shows a slight decrease with room area. For rooms less than $100 \mathrm{ft}^{2}\left(9.29 \mathrm{~m}^{2}\right)$, the mean value is about 40 percent of the floor area occupied, and for the majority of the surveyed rooms larger than $100 \mathrm{ft}^{2}\left(9.29 \mathrm{~m}^{2}\right)$, the mean percentage of floor area occupied by furniture is between 20 to 30 percent. The interior finish fire load (or fixed fire load) ranges from $1.0 \mathrm{psf}\left(4.88 \mathrm{~kg} / \mathrm{m}^{2}\right)$ to $1.9 \mathrm{psf}\left(9.28 \mathrm{~kg} / \mathrm{m}^{2}\right)$, and has a contribution to the total fire load in the range from less than five percent to about fifty percent [32].

From July 1992 to July 1993, Kumar and Rao [35] conducted a fire load survey in 388 rooms of eight government office buildings with height up to four stories in India. The total surveyed floor area was about $11,720 \mathrm{~m}^{2}$. The fire load was divided into two categories, 'non-moveable contents' and moveable contents'. For all surveyed rooms, the average fire load and the standard deviation were $348 \mathrm{MJ} / \mathrm{m}^{2}$ and $262 \mathrm{MJ} / \mathrm{m}^{2}$ respectively. The storage and file rooms had the maximum fire load of $1860 \mathrm{MJ} / \mathrm{m}^{2}$, and the corridors had the minimum fire load of $153 \mathrm{MJ} / \mathrm{m}^{2}$. The percentage of non-moveable fire loads and 
moveable fire loads were $11.7 \%$ and $88.3 \%$, respectively. The composition of furniture was $68.1 \%$ of steel, $31.6 \%$ of wood and $0.3 \%$ of plastic by their weights. There was no definite relationship between fire load and floor level of buildings.

\subsubsection{Fire Load Survey in Residential Buildings}

In comparison with the numbers of fire load surveys conducted in office buildings, surveys conducted in residential buildings are fewer, due to the difficulty to obtain permission in private dwellings because of privacy and other considerations [36].

Kumar and Rao [36] conducted a fire load survey in 35 residential buildings in India from September 1991 to May 1992. The 35 residential buildings were randomly selected, and all of them were located in the city area of an Indian city, Kanpur. The total surveyed floor area was $4256.6 \mathrm{~m}^{2}$ in a total of 413 rooms, and the mean floor area was $10.3 \mathrm{~m}^{2}$. The inventory technique was used in the survey, because of the difficulty to get permission from residents to directly weigh items in their homes. The inventory technique was proven to be a convenient and time-saving method.

For all surveyed rooms, the mean value and standard deviation of fire load was 116.5 Mcal $/ \mathrm{m}^{2}\left(487.0 \mathrm{MJ} / \mathrm{m}^{2}\right)$ and $61.0 \mathrm{Mcal} / \mathrm{m}^{2}\left(255.0 \mathrm{MJ} / \mathrm{m}^{2}\right)$, respectively. The highest mean value of fire load was $203.9 \mathrm{Mcal} / \mathrm{m}^{2}\left(852.3 \mathrm{MJ} / \mathrm{m}^{2}\right)$ for the store rooms, and the lowest mean value of fire load was $66.7 \mathrm{Mcal} / \mathrm{m}^{2}\left(278.8 \mathrm{MJ} / \mathrm{m}^{2}\right)$ for the verandah. The fixed fire loads and moveable fire loads were $52.66 \%$ and $47.34 \%$, respectively [36]. 
One specific feature of the fire loads in residential buildings, which was observed to be different from that in office buildings, was that the mean value of fire loads decreases as the number of rooms occupied by one family increases. In the survey results of residential buildings [36] and office buildings [32, 35], there was no definite relationship between the load magnitude and building height. The room use has a significant effect on the composition and magnitude of the fire load in residential buildings.

A recent survey of fire loads in Canadian homes was conducted by the National Research Council of Canada (NRCC) [31]. The survey method was done by distributing questionnaires through the internet. A questionnaire consisted of 64 questions. The survey results show that a mean value of fire load density for main floor living rooms is $600 \mathrm{MJ} / \mathrm{m}^{2}$, and that for basement living rooms is $500 \mathrm{MJ} / \mathrm{m}^{2}$.

\subsubsection{Fire Load Survey in Motels and Hotels}

Motels and hotels, as a type of residential premises, have the features of regular residential buildings, and also some features of office buildings. The difficulty to obtain permission to conduct fire load surveys in motels and hotels could be similar to or even harder than that for residential buildings. Very few papers on fire load surveys in motels and hotels could be found.

In a 1983 report prepared for the Fire Commission of the Conseil International du Batiment (CIB W14), the $80^{\text {th }}$ percentile of the moveable fire load density for hotel bedrooms was given as $420 \mathrm{MJ} / \mathrm{m}^{2}$ [37]. In New Zealand, Yii [38] conducted a recent 
survey in some offices, residential buildings and motels, and he provided a summary of the mean values of the total fire loads for the three categories shown in Table 12 . The mean value of total fire load density for motels is $552 \mathrm{MJ} / \mathrm{m}^{2}$, and those for offices and bedrooms are $950 \mathrm{MJ} / \mathrm{m}^{2}$ and $724 \mathrm{MJ} / \mathrm{m}^{2}$, respectively.

Table 12 Summary of the mean value of the total fire load comparisons [39]

\begin{tabular}{|c|c|c|c|c|c|c|c|c|}
\hline \multirow[t]{2}{*}{ Building Occupancy } & \multicolumn{2}{|c|}{ Surveyed } & \multicolumn{2}{|c|}{$\begin{array}{c}\text { Robertson \& Gross, } \\
1970\end{array}$} & \multicolumn{2}{|c|}{ Barnett, 1984} & \multicolumn{2}{|c|}{ Narayanan, 1994} \\
\hline & $\left(\mathrm{kg} / \mathrm{m}^{2}\right)$ & $\left(\mathrm{MJ} / \mathrm{m}^{2}\right)$ & $\left(\mathrm{kg} / \mathrm{m}^{2}\right)$ & $\left(\mathrm{MJ} / \mathrm{m}^{2}\right)$ & $\left(\mathrm{kg} / \mathrm{m}^{2}\right)$ & $\left(\mathrm{MJ} / \mathrm{m}^{2}\right)$ & $\left(\mathrm{kg} / \mathrm{m}^{2}\right)$ & $\left(\mathrm{MJ} / \mathrm{m}^{2}\right)$ \\
\hline Offices & 57 & 950 & $35-212$ & $585-3540$ & 22 & 436 & 37.8 & 681 \\
\hline Residence (bedroom) & 43 & 724 & $40-69$ & $668-1152$ & 1 & 1 & / & I \\
\hline Motel & 33 & 552 & 1 & 1 & 1 & 1 & 1 & 1 \\
\hline
\end{tabular}

\subsection{Fire Tests}

In history, the first controlled fire tests, testing of walls, were conducted in 1891 in Germany, and the fire test facility used for the tests was established in 1884. Britain was the second country in the world to conduct fire tests of walls in 1899 . In the United States, the earliest fire tests of nonload-bearing walls were conducted in 1901, and the first formal test station was established in 1902 by Columbia University [39], both of which were earlier than the first modern building code in North American that was released in 1905 .

\subsubsection{Room Fire Tests}

Prior to the $1970 \mathrm{~s}$, most of the fire tests were conducted on the fire endurance of individual elements of the room, such as walls, doors, floors and columns, and there was little need to perform experimental studies of room fires [40]. This situation changed in 
the 1970 s with the development of mathematical theories of room fires. The first room calorimeter, the Monsanto Room Calorimeter, for measuring heat release rate in full scale was developed in 1978 by Warren Fitzgerald in the United States. The dimension of the small test room was $2.7 \times 2.7 \times 2.7 \mathrm{~m}$, and the test samples were relatively small, free standing combustible items. Later, a standard room fire test was developed by ASTM in 1982, with a room size of $2.45 \times 3.67 \times 2.45 \mathrm{~m}$, and a single doorway opening size of $0.76 \times 2.03$ m, shown in Figure 9 [41]. In 1986, the Nordic countries in Europe published the NORDTEST method for room fire tests, which was later adopted by ISO (the International Organization for Standardization). The ISO test room has a room dimension of $2.4 \times 3.6 \times 2.4 \mathrm{~m}$ high and an opening size of $0.8 \times 2.0 \mathrm{~m}$. The flow rate capacity of the exhaust system is from $0.5 \mathrm{~kg} / \mathrm{s}$ to $4.0 \mathrm{~kg} / \mathrm{s}$ [40].

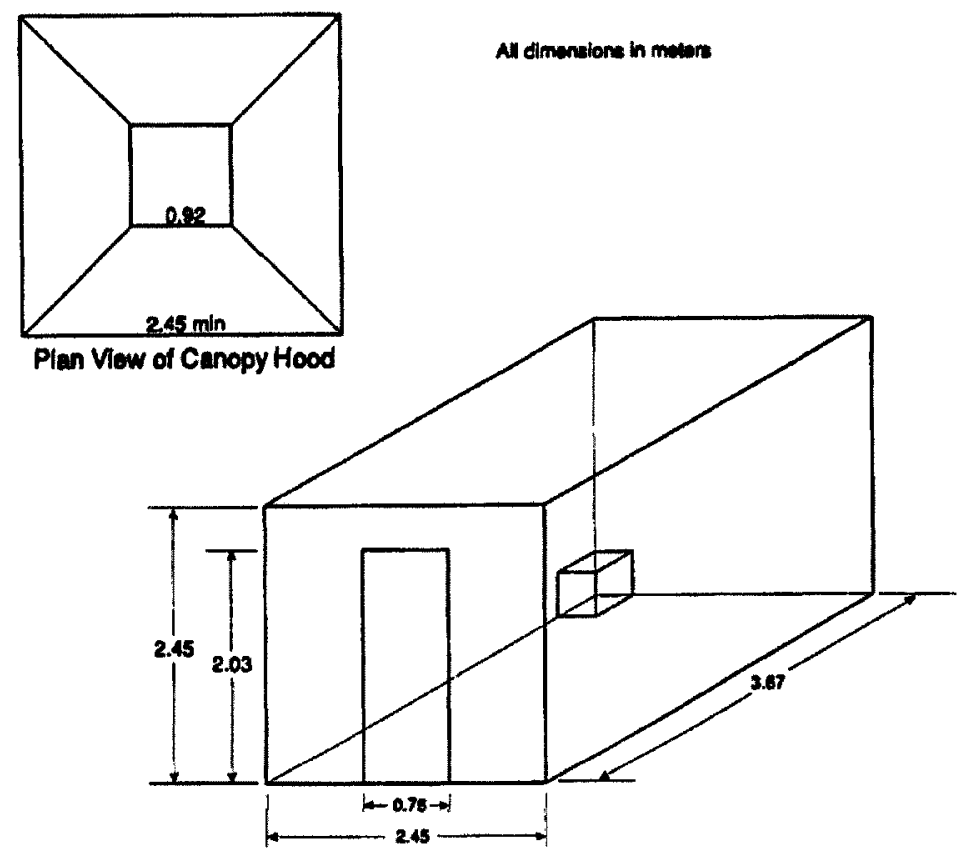

Figure 9 The dimensions of the room and hood for the original (1982) ASTM proposed room fire test (modified from [41]) 
Except for the standard test rooms discussed above, other dimensions of test rooms were also used to conduct room fire tests. In the United States, a test room with dimensions of $2.26 \times 3.94 \times 2.31 \mathrm{~m}$ was built in the large-scale fire test facility at the National Institute of Standards and Technology (NIST) at Gaithersburg, MD, where four tests with furniture were conducted [41]. The plan view and the elevation view of the test room are presented in Figure 10.
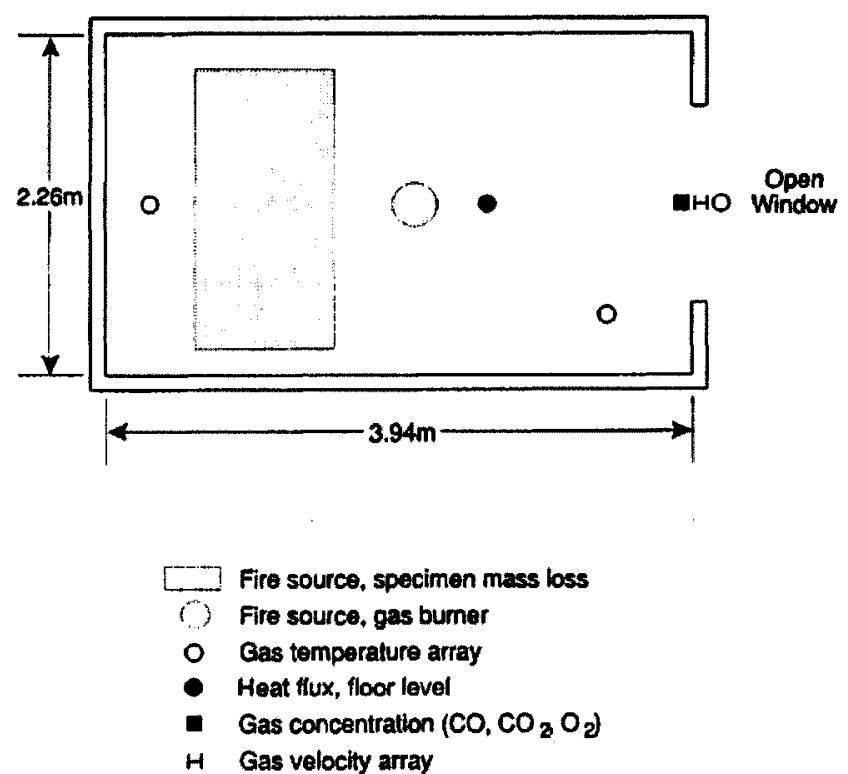

Figure 10 Plan view of experimental room for single room tests with furniture [41]

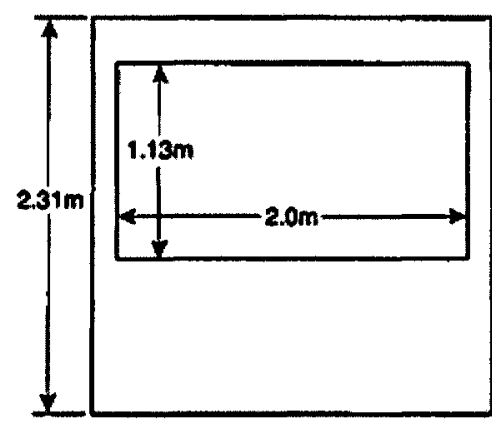

Test 1

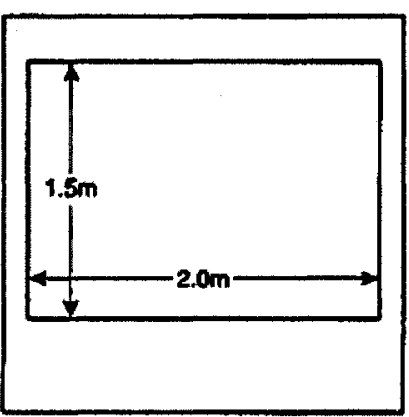

Test 2

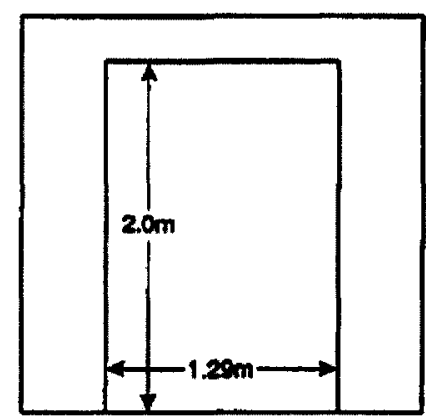

Test 5,6

Figure 11 Elevation view of experimental room for single room tests with furniture [41] 37 
A love seat or armchair was used in each of the four tests. Figure 12 presents the heat release rates in the four tests. Three of them have very close peak values at $2.5 \mathrm{MW}$, and another one has a slightly lower peak value with a little earlier development. Gas concentrations of $\mathrm{O}_{2}, \mathrm{CO}_{2}$, and $\mathrm{CO}$ were also measured and provided in Figure 13.

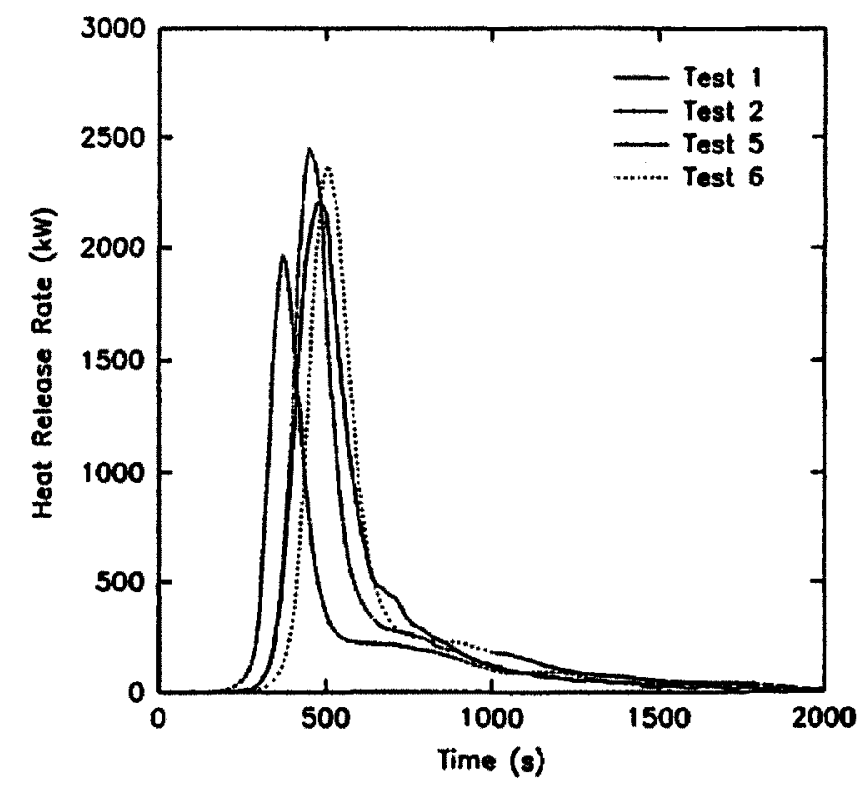

Figure 12 Heat release rate during single room tests with furniture [41]
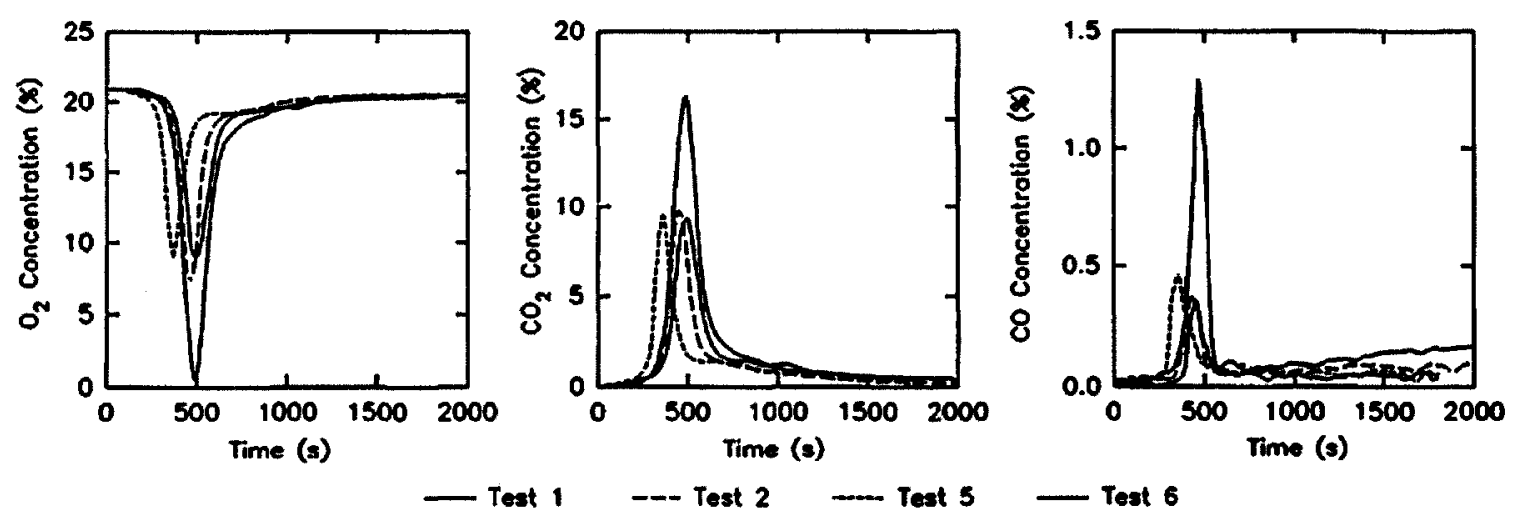

Figure 13 Gas concentrations measured during single room tests with furniture [41] 
In 1996, two full-scale room fire experiments were conducted at the University of Maryland (UM) [42]. The test room had dimensions of $3.66 \times 3.66 \times 2.44 \mathrm{~m}$, and was located on the first floor of the burn tower. The two tests used the same size of door, $0.91 \times 2.09 \mathrm{~m}$, and the same size of window frame of $1.07 \times 0.93 \mathrm{~m}$ with 2 panes of glass for each window. The major difference of the two tests was a $90^{\circ}$ counter clock wise rotation of the room in Test 2 due to the characteristics of the burn tower enclosure [42]. This change made Test 2 have more fresh air availability at the window, and less air at the door than Test 1. Figure 14 and Figure 15 provides the diagrams of the floor plans, furnishings and instrumentation for Test 1 and Test 2, respectively.
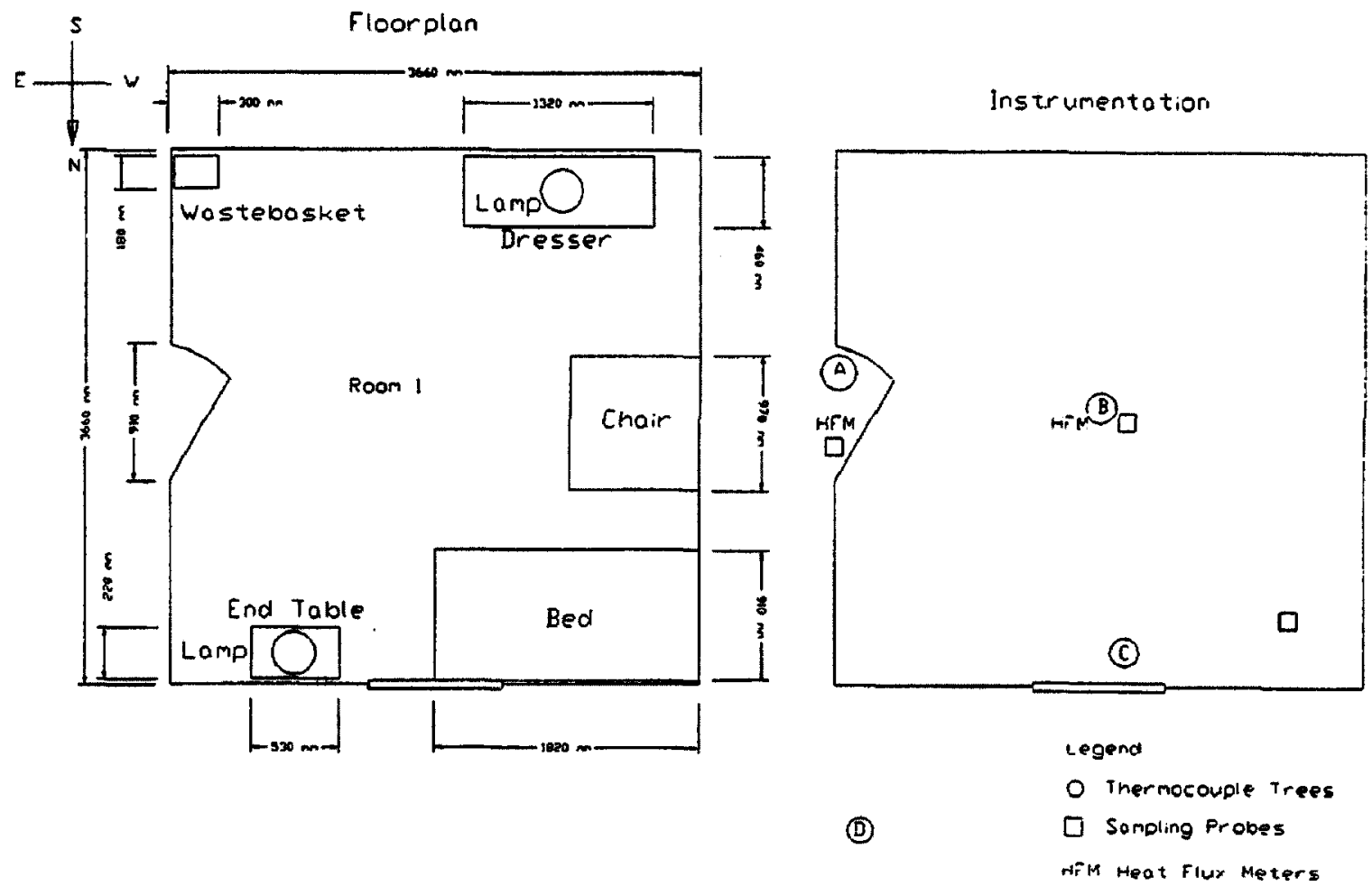

Figure 14 Diagram of furnishings and instrumentation for Test 1 [42] 

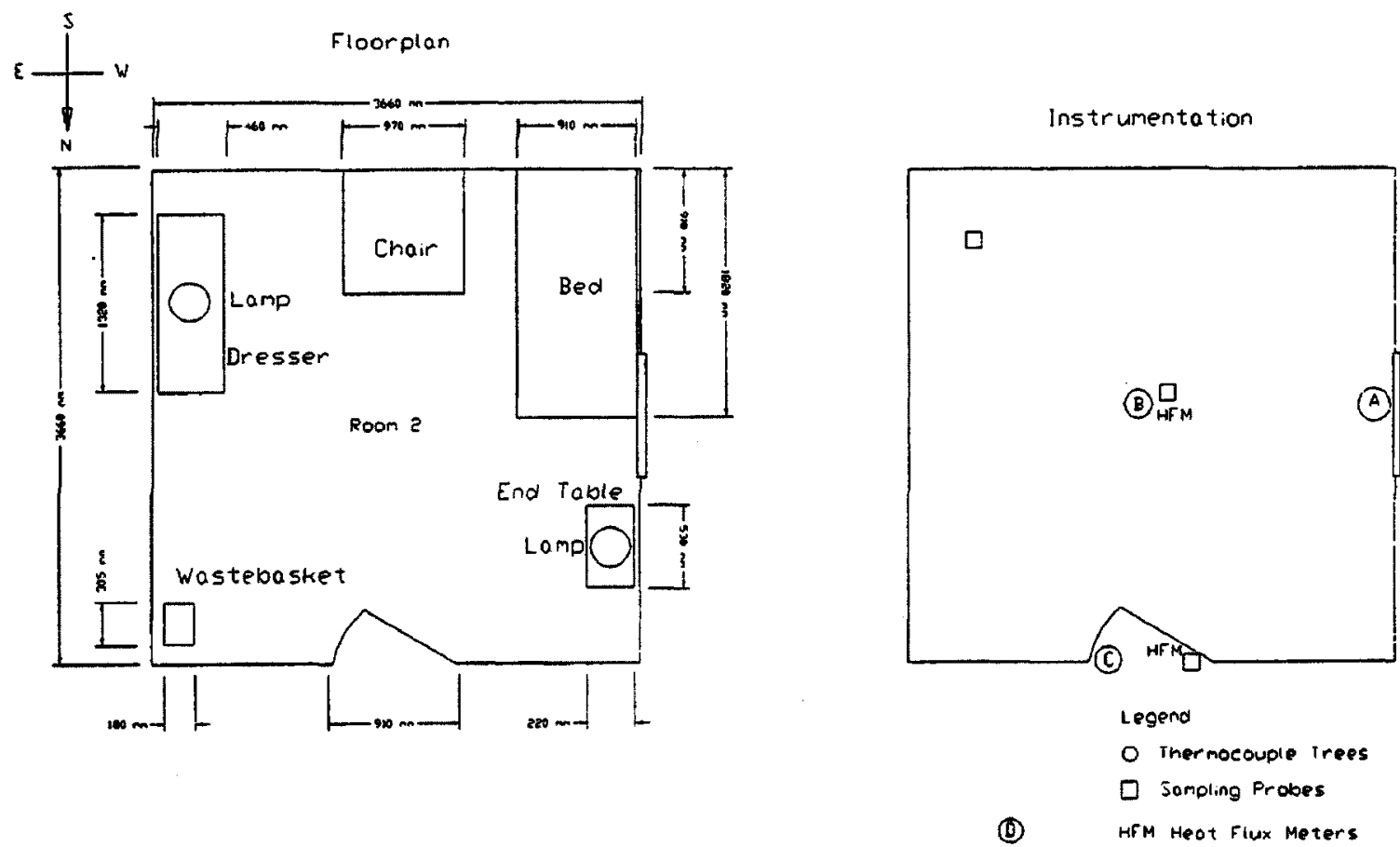

Figure 15 Diagram of furnishings and instrumentation for Test 2 [42]

For each of the two full-scale room fire experiments, four thermocouple trees, three gas sampling probes and two heat flux meters were used to measure temperature, gas concentration and heat flux, but there was no heat release rate measurement. Figure 16 and Figure 17 provide the temperatures measured in the middle of the room for the two tests. In both tests, the temperatures reached a first peak value of $900^{\circ} \mathrm{C}$ at about 350 seconds. Figure 18 and Figure 19 present the heat flux measured at the doorway and in the middle of the room. Both measuring locations were placed $0.15 \mathrm{~m}$ from the floor. Figure 20 and Figure 21 provide the oxygen concentration measured by two systems, UM and NIST. $\mathrm{CO}$ and $\mathrm{CO}_{2}$ were only measured at the SW corner above the dresser by NIST, but data was not provided in the report. 


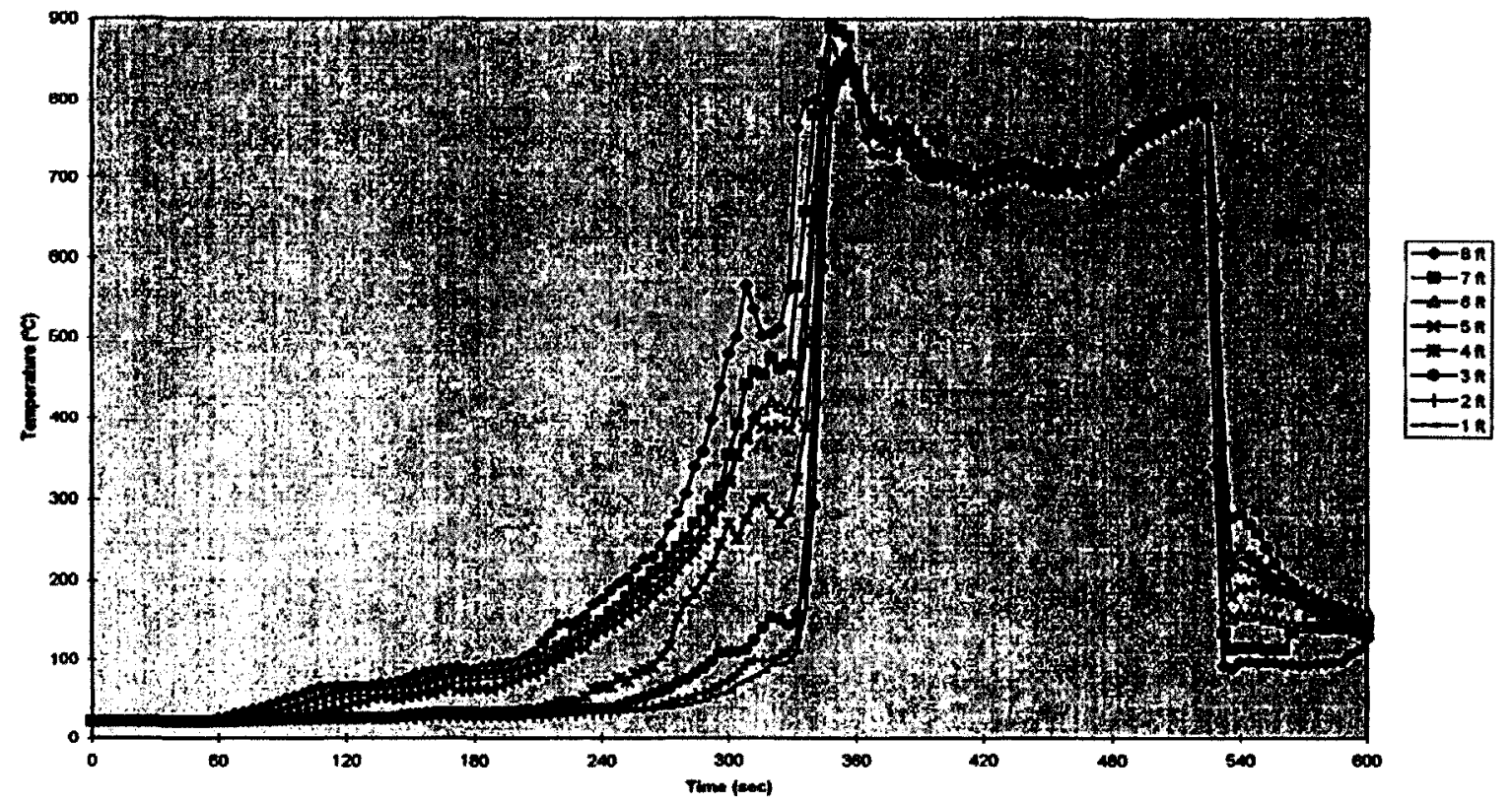

Figure 16 Temperature in the middle of room vs time for Test 1 [42]

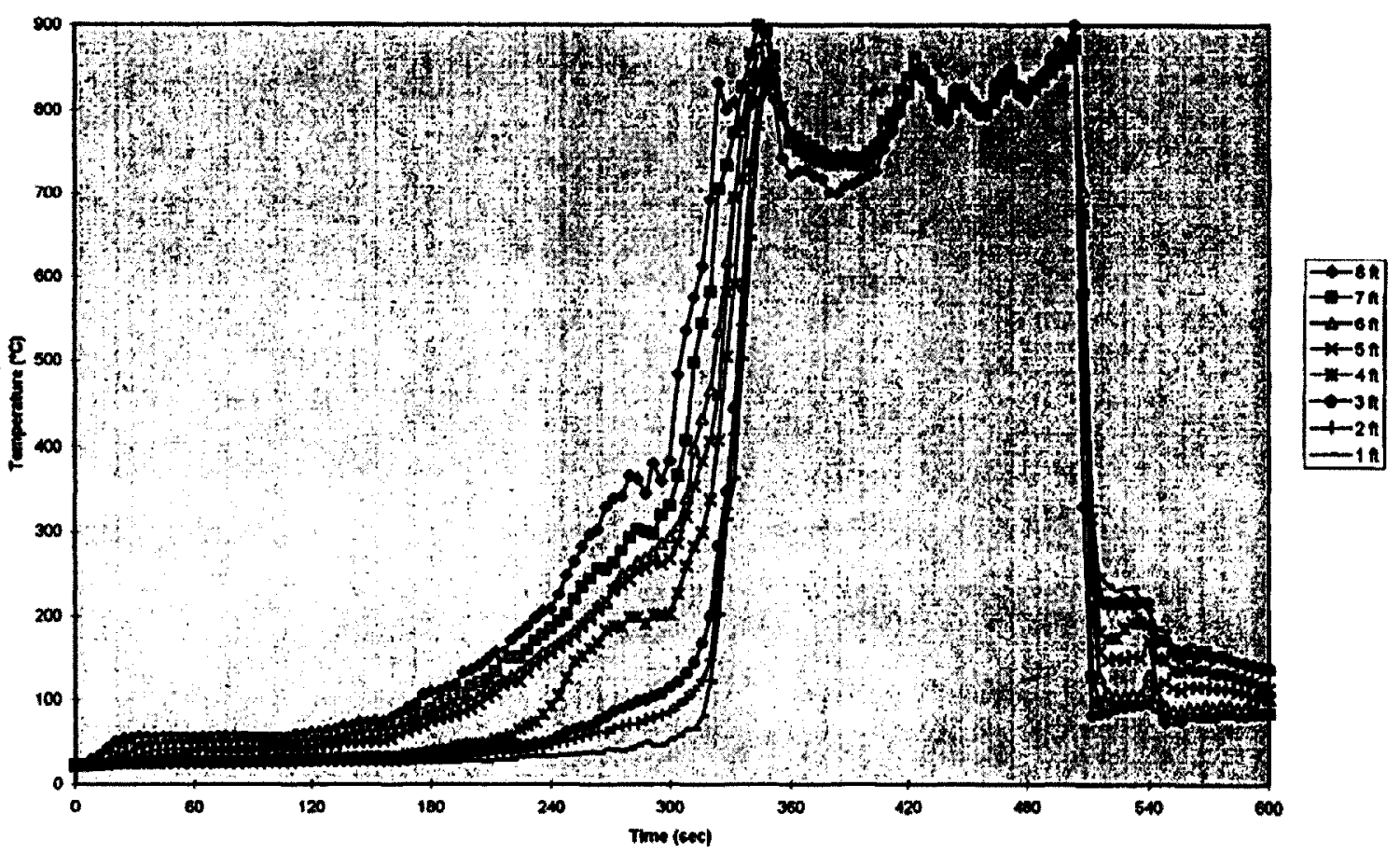

Figure 17 Temperature in the middle of room vs time for Test 2 [42] 


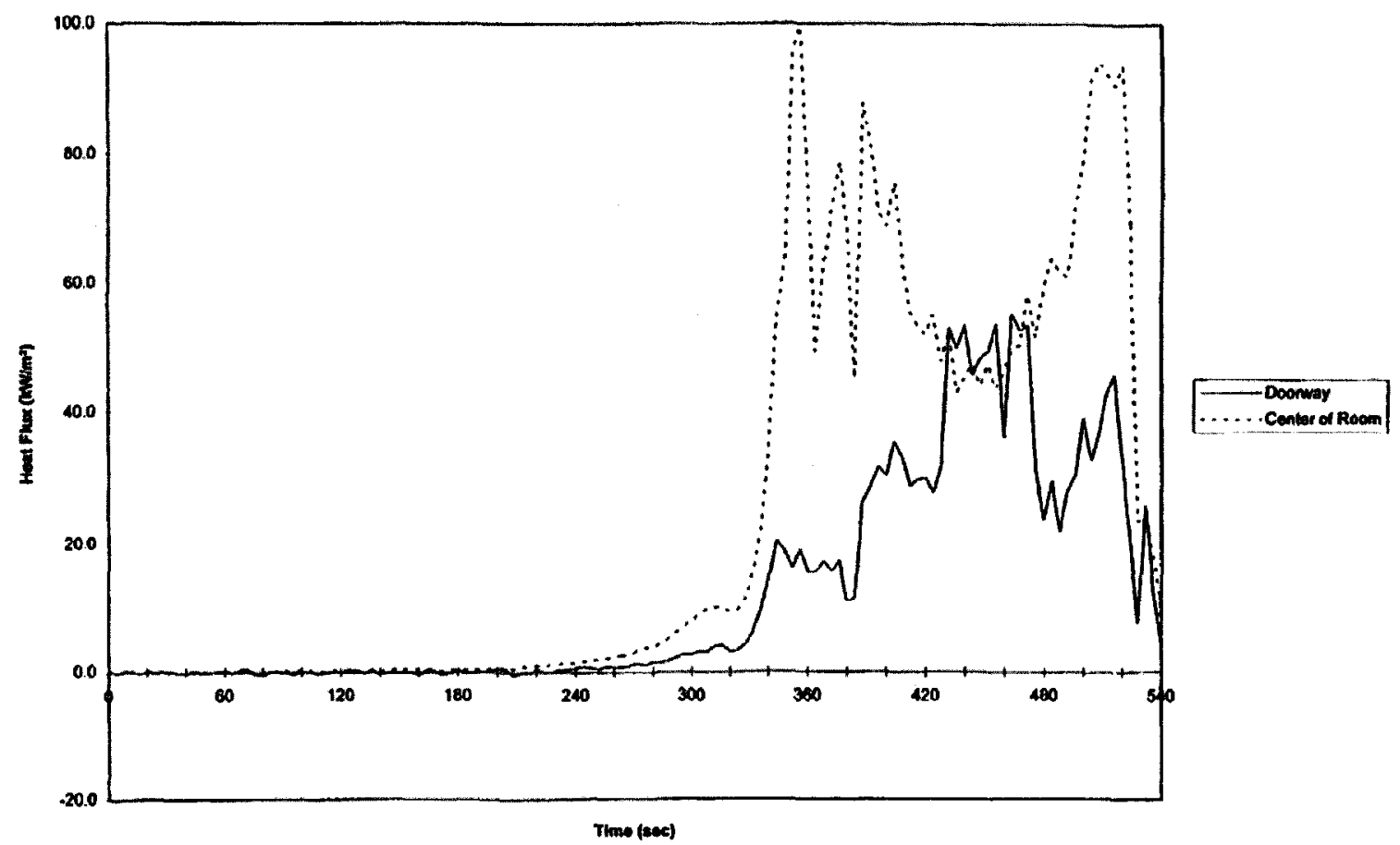

Figure 18 Heat flux vs time for Test 1 [42]

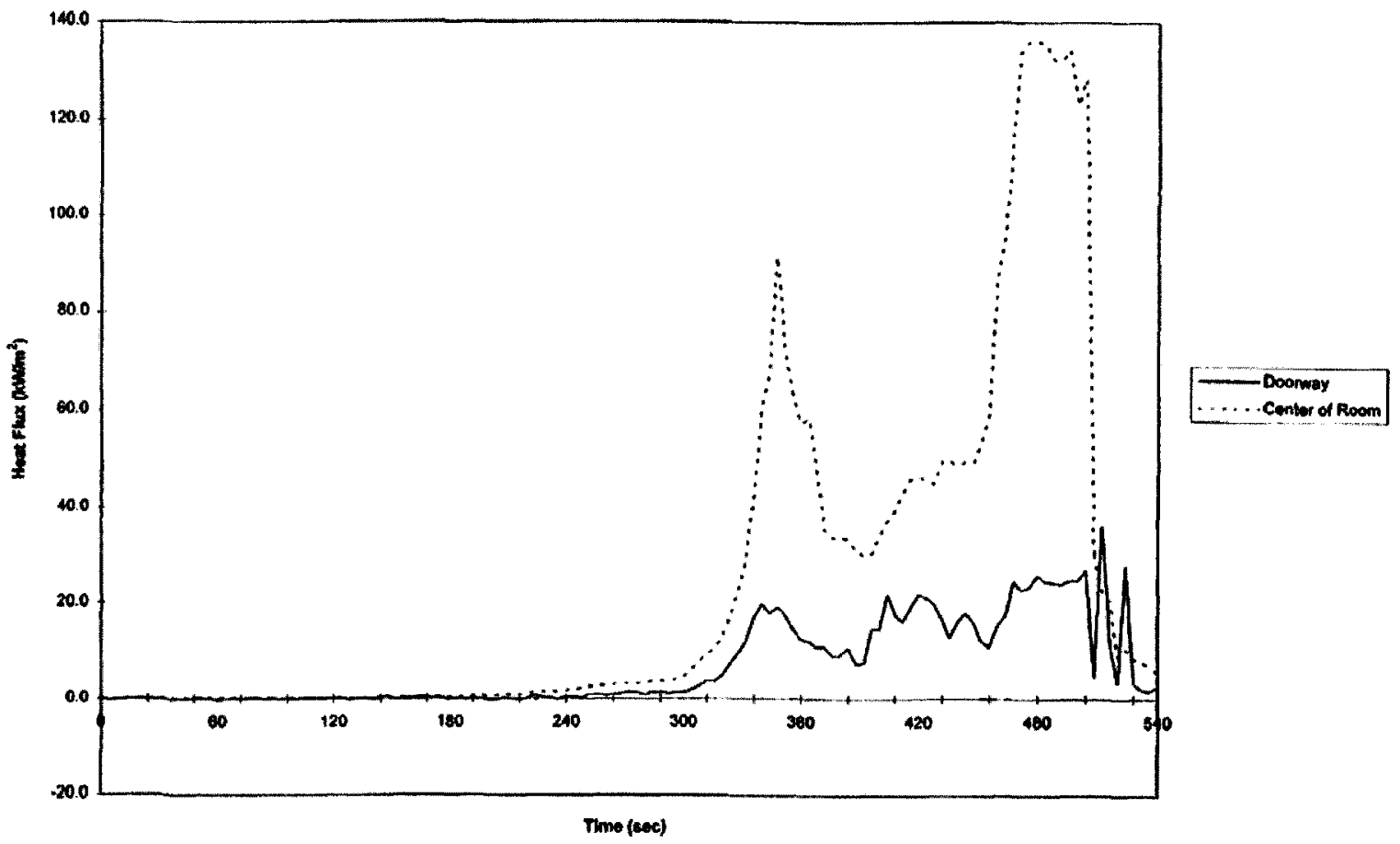

Figure 19 Heat flux vs time for Test 2 [42]

42 


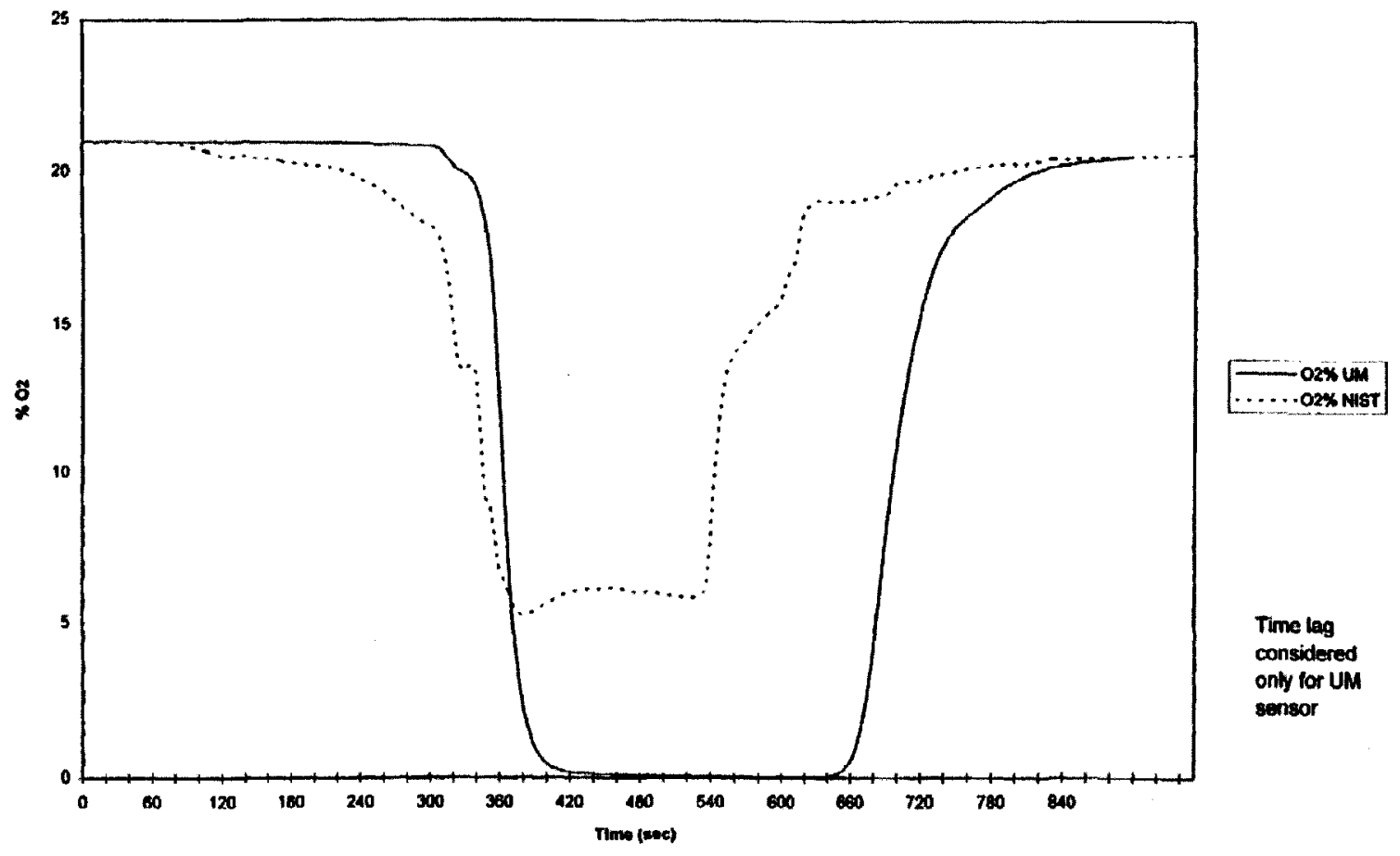

Figure 20 Oxygen concentration vs time for Test 1 [42]

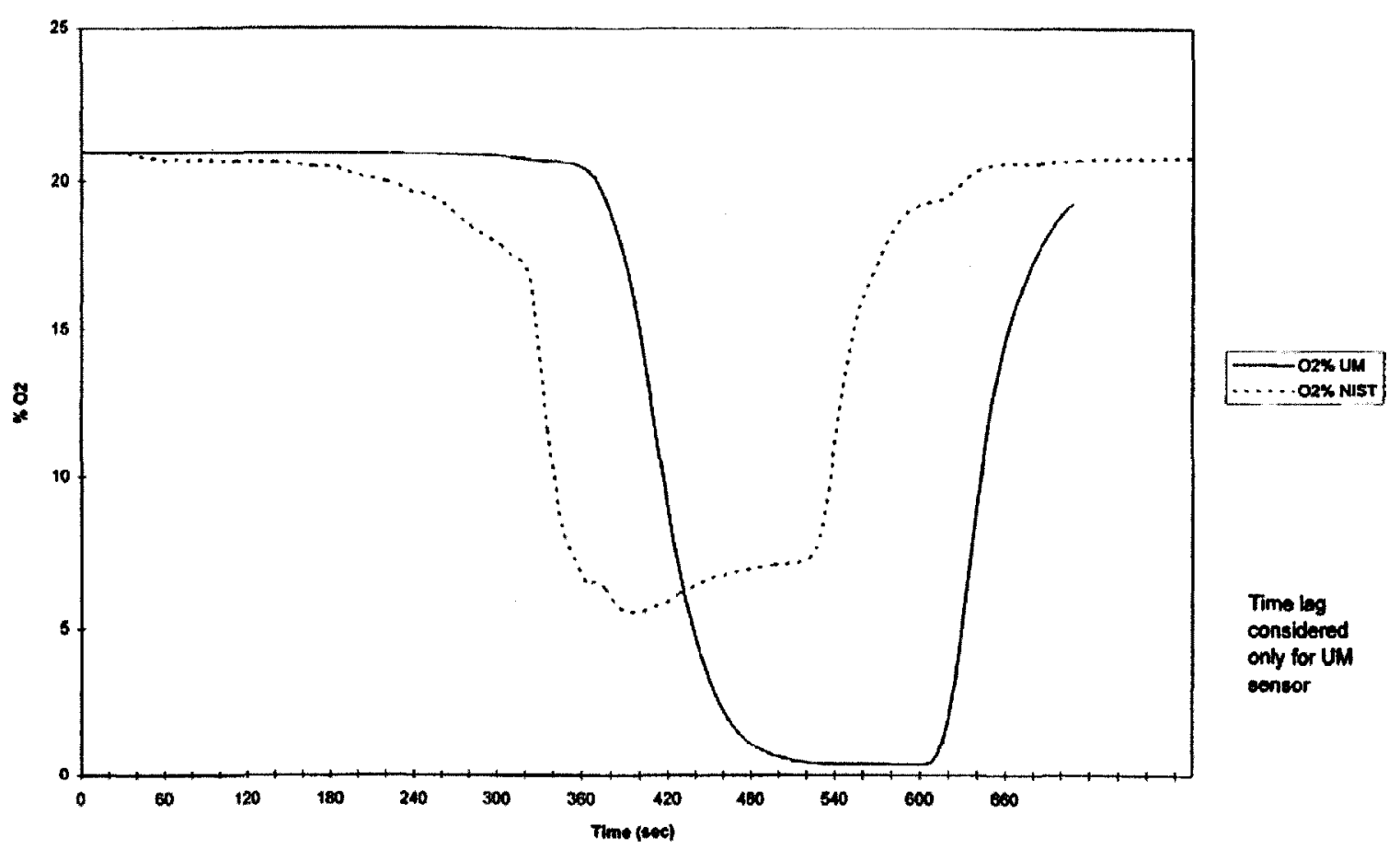

Figure 21 Oxygen concentration vs time for Test 2 [42] 


\subsubsection{Heat Release Rate Measurements}

The heat release rate is one of the most important fire parameters, which is widely used to define how fast fires develop and how big they are. However, a direct measurement of the heat release rate of a fire is very difficult because of the dynamic and vigorous characteristic of the fires, and the influence of the compartment and its opening.

In order to measure heat release rate in full scale fire tests, the first room calorimeter, was developed in 1978 by Warren Fitzgerald in the United States [40]. The theory of this application was initially from a discovery by Thornton in 1917, who found that almost the same amount of heat is produced per unit mass of oxygen consumed in fires for a large number of organic materials [43]. Thornton's rule, named as the oxygen consumption principle, was later developed and quantified by many researchers, such as Hinkley et al. in 1968, [44], Parker in 1977 [45], and Huggett in 1980 [46].

In 1991, Janssen [47] proposed a set of equations for calculating heat release rate that were developed especially for full-scale fire test applications. One of the main simplifying assumptions in his analysis is that the amount of energy released by complete combustion per unit mass of oxygen consumed is taken as a constant, and the value is an average of $\mathrm{E}=13.1 \mathrm{MJ} / \mathrm{kg}$ of $\mathrm{O}_{2}$ proposed by Huggett. Figure 22 presents the schematic of a full-scale fire test calorimeter. The minimum requirement for heat release rate calculation is to measure the $\mathrm{O}_{2}$ concentration and mass flow rate. The accuracy of the calculation can be improved by additional measurements of the concentration of $\mathrm{CO}_{2}$, $\mathrm{CO}$, and $\mathrm{H}_{2} \mathrm{O}$. He provided the calculation procedures and equations for four different 
cases: only $\mathrm{O}_{2}$ measured; both $\mathrm{O}_{2}$ and $\mathrm{CO}_{2}$ measured; $\mathrm{O}_{2}, \mathrm{CO}_{2}$, and $\mathrm{CO}$ measured; and $\mathrm{O}_{2}$, $\mathrm{CO}_{2}, \mathrm{CO}$, and $\mathrm{H}_{2} \mathrm{O}$ measured.

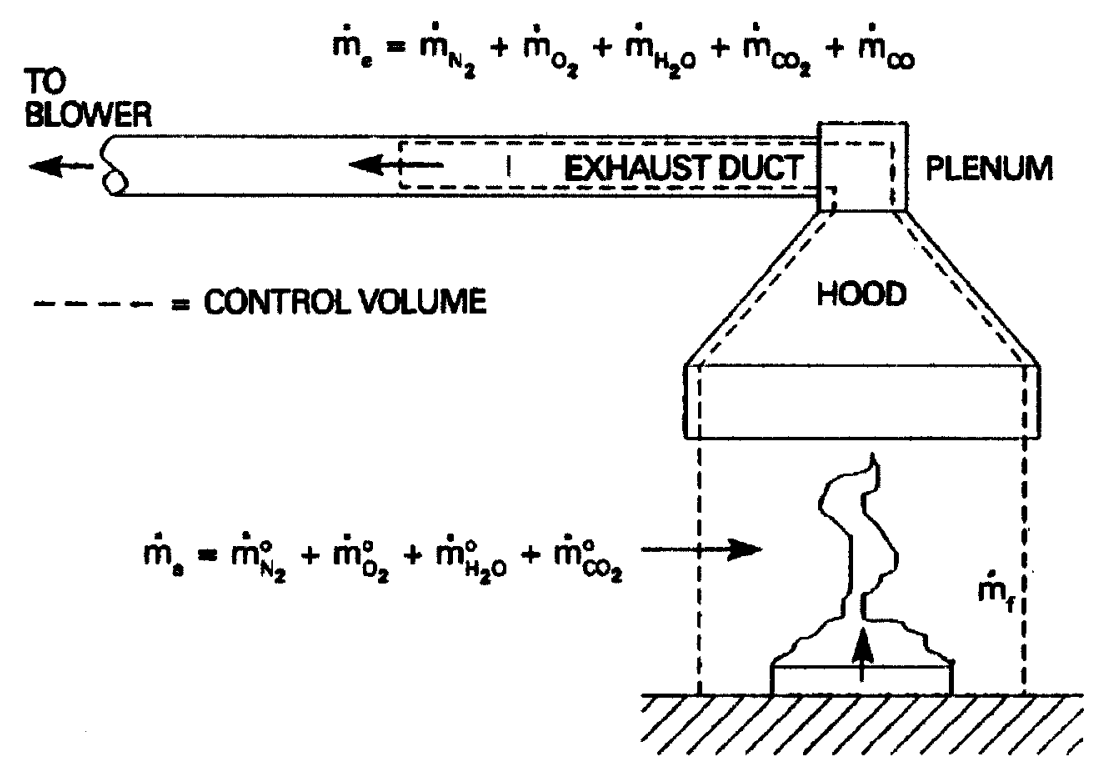

Figure 22 Schematic of a full-scale fire test combustion system [47]

Janssen's equations were also used in the Large Fire Research Facility at the National Institute of Standards and Technology (NIST) for heat release rate calculations [48]. The equations shown below that are the equations for the third case in Janssen's paper where $\mathrm{O}_{2}, \mathrm{CO}_{2}$, and $\mathrm{CO}$ are measured. The set of equations for heat release rate calculation [48]:

$$
\begin{gathered}
\dot{q}=\left(E \phi-\left(E_{C O}-E\right) \frac{1-\phi}{2} \frac{X_{C O}}{X_{O_{2}}}\right) \frac{\dot{m}_{e}}{1+\phi(\alpha-1)} \frac{M_{r}\left(O_{2}\right)}{M_{r}(E)}\left(1-X_{H_{2} O}^{0}\right) X_{O_{2}}^{0} \\
\phi=\frac{X_{O_{2}}^{0}\left(1-X_{C_{2}}-X_{C O}\right)-X_{O_{2}}\left(1-X_{C_{2}}^{0}\right)}{X_{O_{2}}^{0}\left(1-X_{O_{2}}-X_{C_{2}}-X_{C O}\right)}
\end{gathered}
$$


$X_{H_{2} O}^{0}=\frac{R H_{a m b}}{100} \frac{\left(0.6107+0.06052 T_{a m b}-0.0002088 T_{a m b}^{2}+0.00007376 T_{a m b}^{4}\right)}{P_{a m b}}$

where

$\dot{q}=$ heat release rate of the fire $(\mathrm{kW})$

$\phi=$ oxygen depletion factor

$T_{\text {amb }}=\quad$ temperature of ambient air $(293.13 \mathrm{~K})$

$P_{a m b}=\quad$ pressure of ambient air $(101.3 \mathrm{kPa})$

$R H_{a m b}=$ relative humidity of ambient air $(50 \%)$

$\alpha=$ combustion expansion factor (1.105)

$E=$ heat released per unit mass of oxygen consumed $\left(13.1 \mathrm{MJ} / \mathrm{kg}\right.$ of $\mathrm{O}_{2}$ )

$E_{C O}=$ heat released per unit mass of oxygen consumed for combustion of $\mathrm{CO}$ to $\mathrm{CO}_{2}$ $\left(\approx 17.6 \mathrm{MJ} / \mathrm{kg}\right.$ of $\left.\mathrm{O}_{2}\right)$

$M_{r}(E)=$ relative molecular mass of exhaust gas $(\approx 28.97 \mathrm{~kg} / \mathrm{kmol})$

$M_{r}\left(O_{2}\right)=$ relative molecular mass of oxygen $(\approx 32 \mathrm{~kg} / \mathrm{kmol})$

$X_{\mathrm{H}_{2} \mathrm{O}}^{0}=$ mole fraction of $\mathrm{H}_{2} \mathrm{O}$ in the incoming air

$X_{O_{2}}^{0}=$ measured mole fraction of $\mathrm{O}_{2}$ in the incoming air*

$X_{\mathrm{CO}_{2}}^{0}=$ measured mole fraction of $\mathrm{CO}_{2}$ in the incoming air*

$X_{C O}^{0}=$ measured mole fraction of $\mathrm{CO}$ in the incoming air*

$X_{O_{2}}=$ measured mole fraction of $\mathrm{O}_{2}$ in the exhaust gases*

$X_{\mathrm{CO}_{2}}=$ measured mole fraction of $\mathrm{CO}_{2}$ in the exhaust gases*

$X_{C O}=$ measured mole fraction of $\mathrm{CO}$ in the exhaust gases*

* as measured in the gas analyzer located downstream of the cold traps and desicant

\subsection{Fire Modelling}

With the emergence of performance-based building codes and the development of computer technologies, computer models for fire simulation have been increasingly used in fire research and fire safety design. Fire models can be divided into two main categories: probabilistic and deterministic models. The probabilistic models can predict 
statistical probabilities about the transition from one stage of fire growth to another, but can not directly use the physical and chemical principles involved in fires. However, the pure probabilistic models can be combined with deterministic models to form hybrid models. Deterministic models can predict the movement of smoke and heat in enclosures, and they can be subdivided into two types: zone models, and field models or computational fluid dynamics (CFD) models [49].

\subsubsection{Zone Models}

In fire protection engineering, zone models were developed to simulate enclosure fires. Some of the zone models can be only used for the fire room, while other models can be used for several rooms [49]. Zone models, also called two-zone models, normally treat the room as two gaseous layers, upper hot layer and lower cold layer. The conservation of mass, species, and energy are applied to the control volumes of the two gaseous layers. Figure 23 shows the two gaseous layers used in two-zone models [50].

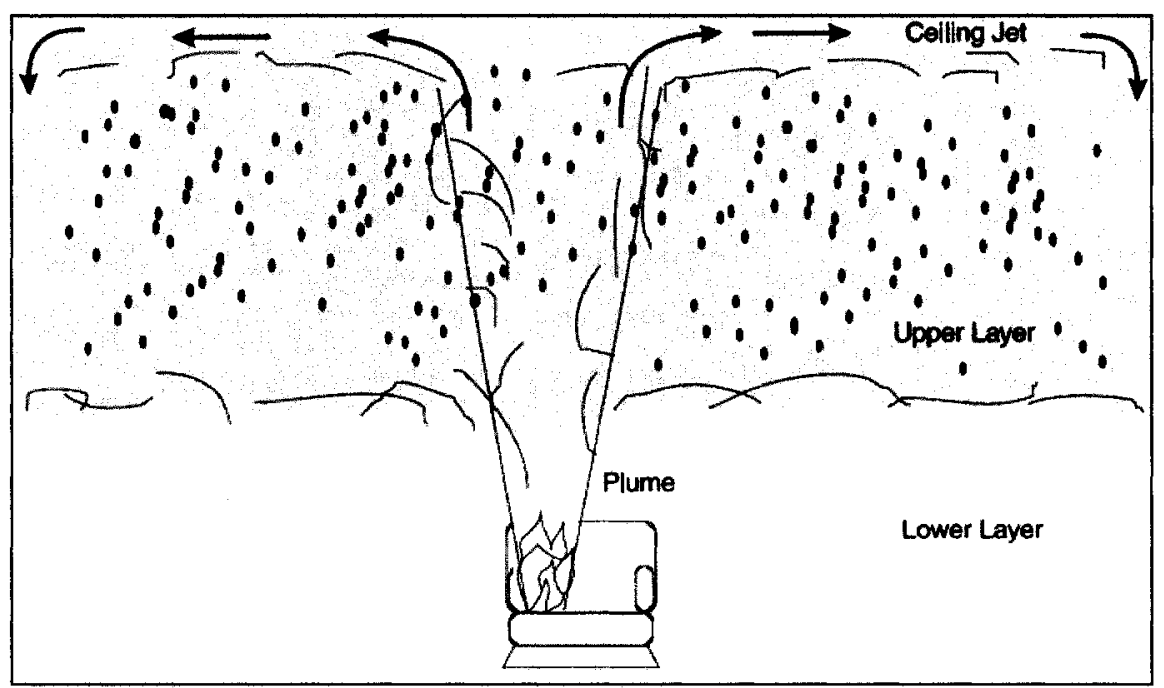

Figure 23 Two-zone model [50]

47 
CFAST (Consolidated Model of Fire and Smoke Transport) is a two-zone fire model that can be used to predict the evolving distribution of smoke, fire gases and temperature throughout compartments during a fire [50]. The fire itself needs to be prescribed by the user. In CFAST, each compartment is treated as two gas layers. CFAST can be applied to the compartments with space from $1 \mathrm{~m}^{3}$ to $1000 \mathrm{~m}^{3}$, and the size of the compartment governs the appropriate size of the fire that can be modelled [50]. The computational time of zone models is of the order of seconds for a modern personal computer.

\subsubsection{Field Models and FDS}

In contrast to zone models, which were developed and applied within the fire community, field models or computational fluid dynamics (CFD) models were developed as a tool for solving general fluid flow problems. The development of CFD technology can be traced back to the early 1920 s, when the feasibility of using numerical methods to solve the governing equations of fluid flow was first demonstrated by Lewis Richardson, whose purpose was weather prediction [51].

The Fire Dynamics Simulator (FDS) is a CFD model developed for fire and smoke modelling. FDS solves numerically a form of the Navier-Stokes equations, which is appropriate for low-speed, thermally-driven flow that focuses on smoke and heat transport from fires. The Smagorinsky form of Large Eddy Simulation (LES) is the default mode to treat turbulence, and if the underlying numerical mesh is fine enough, a Direct Numerical Simulation (DNS) can be performed [52 and 53]. In comparison with 
other CFD models, FDS has fast computational speed and relatively modest requirements in terms of computational hardware [54].

The first version of FDS was released by the National Institute of Standards and Technology (NIST) in February 2000. Gradual improvements of FDS have been made in version 2 (2001), version 3 (2002), and version 4 (2004) [54]. The latest version 5 was first released in October 2007, and from version 5, a formal revision management system has been implemented [53]. Until now, the newest version number, FDS 5.2.4, indicates the FDS revision management system of the fifth major release, second significant upgrade, and fourth minor upgrade.

One of the important changes in FDS version 5 is that multiple layers of materials can be modelled by specifying them in a new namelist group called $M A T L$, while a single homogeneous layer was assumed in the previous versions. This change can provide a better prediction of a room fire with ordinary furniture, but the FDS user's guide also addressed the difficulty of simulating a room fire with ordinary furniture as one of the most challenge applications of FDS, due to the sensitivity of the model to the thermal and material properties of real materials [52].

A fire can be designated in two ways in FDS. The first is to specify a heat release rate per unit area. The second way is to specify a HEAT_OF_REACTION, and other thermal parameters, in which case the burning rate of the fuel depends on the net feedback to the surface. The mixture fraction combustion model is automatically invoked and used in both cases. For the solid fuels, the parameter of heat release rate per unit area, ignition 
temperature, heat of vaporization, and heat of combustion can be used to control the burning rate by the modeller [52].

The grid size is the most important numerical parameter in CFD models. McGranttan [55] pointed out that using grid cells of the order of $10 \mathrm{~cm}$ could be good enough to simulate a house fire, but the resolution of about $1 \mathrm{~mm}$ might be required for simulating the details of the flame, such as its temperature. Figure 24 shows a large number of rectilinear volumes, called meshes, used in FDS modelling [49].

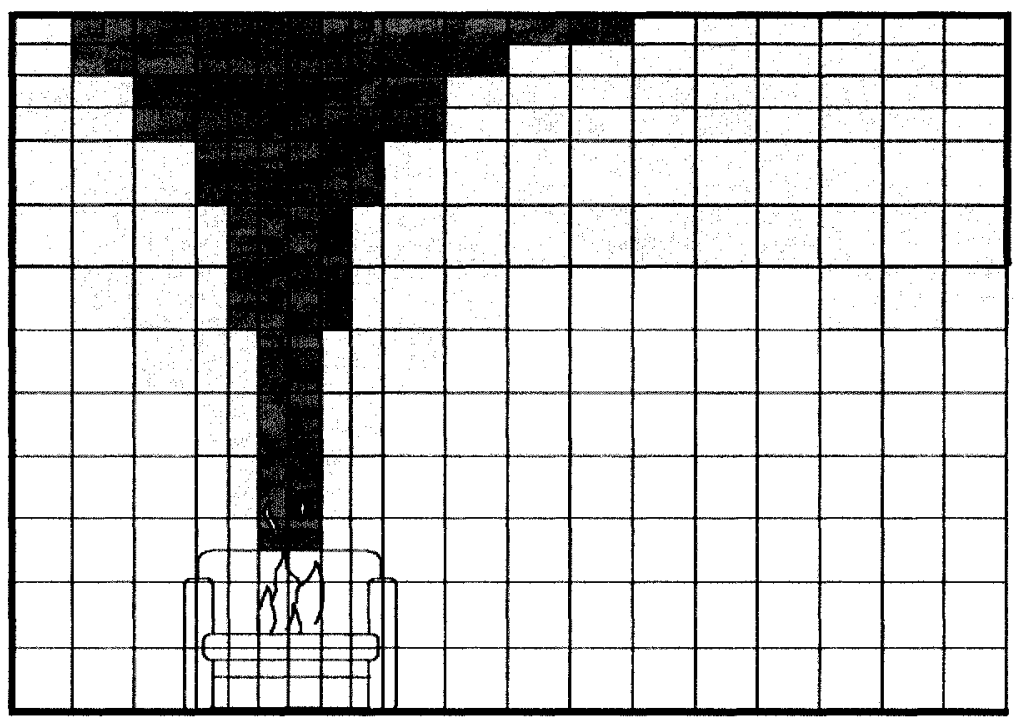

Figure 24 Field model for enclosure fire [49]

\subsubsection{Model Application in Room Fire}

An extensive round-robin exercise to model a large scale compartment fire test has been conducted in England, recently. The fire test used for modelling is the Dalmarnock Test One, a post-flashover compartment fire experiment held on July $25^{\text {th }}, 2006$, in a two- 
bedroom single-family flat, which was located on the $4^{\text {th }}$ floor of a 23 -storey reinforced concrete building in Dalmarnock, Glasgow [56]. Six international independent teams participated, and all of them worked in fire and used fire modelling as part of their professional practice. A total of ten simulations were submitted, including eight models using FDS, and two models using CFAST. The same information about the test setup, such as the compartment layout shown in Figure 25, was given to all of the teams [57]. Table 13 summarizes the information and some predictions of their modelling.

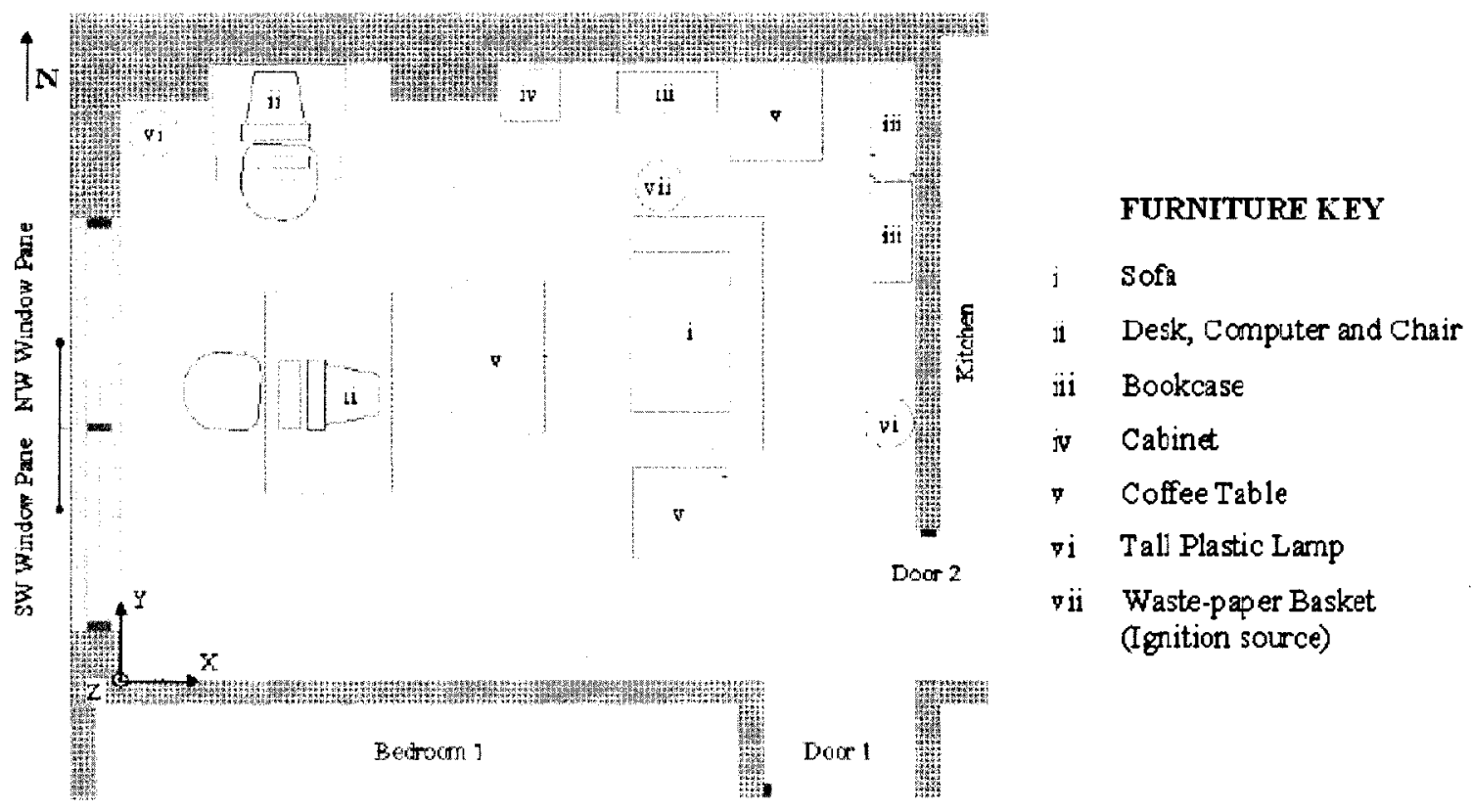

Figure 25 Layout of the main compartment in Dalmarnock Test One [57] 
Table 13 Summary of model information and prediction (modified from 2 tables of [57])

\begin{tabular}{|cccc|cc|}
\hline \multicolumn{3}{|c|}{ Model Information } & \multicolumn{2}{c|}{ Model Prediction } \\
\hline$\#$ & $\begin{array}{c}\text { Fire } \\
\text { Model }\end{array}$ & $\begin{array}{c}\text { ERT* } \\
(\mathrm{h})\end{array}$ & $\begin{array}{c}\text { Grid } \\
(\mathrm{mm})\end{array}$ & $\begin{array}{c}\text { Time to } \\
\text { Flashover (s) }\end{array}$ & $\begin{array}{c}\text { Maximum Smoke } \\
\text { Layer Temp. }\left({ }^{\circ} \mathrm{C}\right)\end{array}$ \\
\hline A1 & CFAST & 0.01 & -- & 850 & 792 \\
A2 & FDS4 & 153 & 50 & 780 & 1026 \\
B & FDS4 & 23 & $5-500$ & 841 & 1070 \\
C & CFAST & 0.01 & -- & no flashover & 211 \\
D1 & FDS4 & 19 & 100 & 200 & 720 \\
D2 & FDS4 & 128 & $50-100$ & 77 & 1153 \\
E1 & FDS4 & 55 & 100 & 180 & 900 \\
E2 & FDS4 & 33 & 100 & 180 & 1170 \\
F1 & FDS4 & 170 & 90 & 720 & 590 \\
F2 & FDS4 & 170 & 90 & 850 & 650 \\
Ave: & & & & 591 & 828 \\
\hline Exp*: & & & 300 & 750 \\
\hline
\end{tabular}

* ERT_Estimated Running Time in the computer; Exp_Experimental data

From two simulations using CFAST, one did not predict flashover, and the predicted maximum smoke layer temperature was very low at $211^{\circ} \mathrm{C}$; the other had a good prediction of the maximum smoke layer temperature at $792^{\circ} \mathrm{C}$, but the predicted time to flashover was quite long at 850 seconds. For the eight simulations using FDS, different grid sizes were used. Three of them used $100 \mathrm{~mm}$, two used $90 \mathrm{~mm}$, one used $50 \mathrm{~mm}$, and another used multiple meshes. Simulation number D1 had relatively a good prediction with 200 seconds to flashover and $720^{\circ} \mathrm{C}$ of the maximum smoke layer temperature. Simulation A2 had the lower mesh size, but did not show good prediction results. The average time to flashover of the ten simulations was about double of the experimental data, and the reason could be the involvement of window breakage, which made the 
simulation even harder. The average value of the predicted maximum smoke layer temperature is relatively good with only about $10 \%$ higher than the experimental data.

Figure 26 depicts the predicted heat release rate of the ten simulations, and also the experimental data. Both of the two models that use CFAST had lower prediction of the heat release rate. For the eight models using FDS, the simulation number E1 had a good prediction, but others did not have good results. One overpredicted the fire by about $100 \%$ and the other six predictions were lower [57].

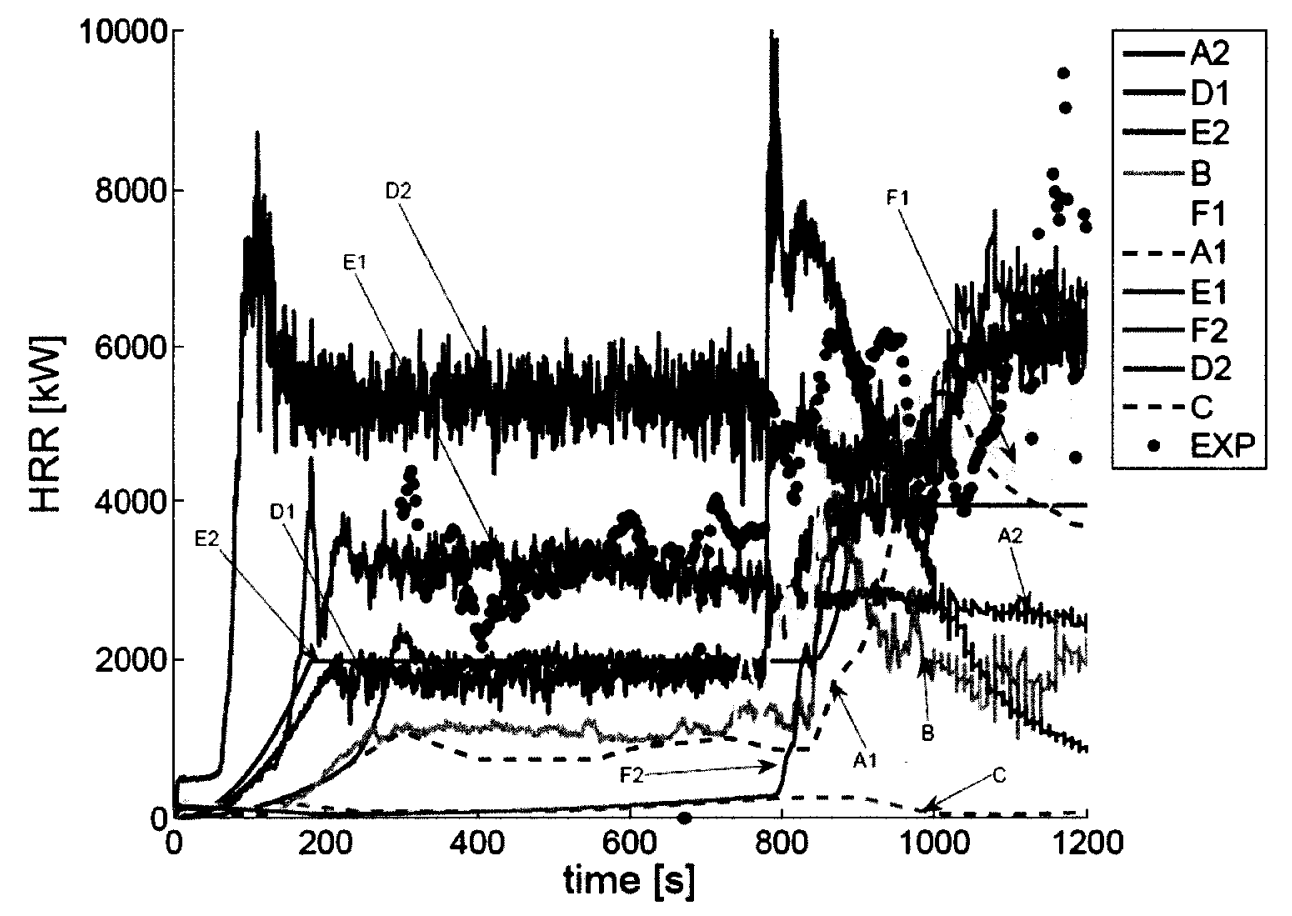

Figure 26 Predicted heat release rate in the whole compartment [57] 


\section{Chapter 3: Fire Load Survey}

\subsection{Introduction}

In prescriptive-based building codes, the goal of a fire safety design is to satisfy code provisions [5]; hence there is no need for designers to consider fire loads in building design. By contrast, in structural engineering, it is impossible and unimaginable to design buildings without considering dead loads and live loads. As countries around the world change their codes from prescriptive to performance-based, fire safety engineers started to apply the engineering approach for fire safety design, rather than merely rely on empirical technology. One of the important steps in performance-based approaches is design fires, which are defined as "an idealization of real fires that may occur in the building", in ISO/TR 13387-2 [58]. The cornerstone of design fires is the determination of fire loads and their composition in a variety of buildings.

In this research, fire load surveys for motels and hotels have been conducted in Canada's National Capital Region---Ottawa and Gatineau area, from March 2007 to August 2007. "The National Capital Region has a total population of 1,130,761 (2006), and consists of an area of 5,318.36 square kilometers that straddles the boundary between the provinces of Ontario and Quebec" [59]. 
The survey was conducted in 10 motels and 12 hotels. The surveyed motels were either one-storey or two-storey buildings, except for one three-storey building. Most of: the surveyed hotels were high-rise buildings, covering hotel ratings from 2-star to 5-star, building age from 6 years to over 100 years, and storeys from 3 to 24 .

Data related to fire load were collected in the field survey. The dimensions of the surveyed guest rooms were measured and recorded for calculating fire load densities and determining fuel arrangements. The dimensions of openings were also measured due to their important role in enclosure fire development.

\subsection{Survey Methodology}

As loads in structural engineering are usually differentiated as 'dead loads' and 'live loads' $[30]$, the fire load in a compartment can be divided into a fixed fire load and a moveable fire load. The fixed fire load consists of all combustible materials in or on the walls, floor and ceiling; and the moveable fire load consists of all other combustible items that are brought into the compartment.

The total fire load in a compartment can be calculated by using the following equation $[35,60]$ :

$$
Q=\sum k_{i} m_{i} h_{c_{i}}
$$

Where, $Q=$ total fire load in a compartment (MJ),

$$
k_{i}=\text { proportion of content or building component } i \text { that can burn, }
$$


$m_{i}=$ mass of item $i(\mathrm{~kg})$, and

$h_{c_{i}}=$ calorific value of item $i(\mathrm{MJ} / \mathrm{kg})$.

The goal of a fire load survey is to determine the mass of each item $m_{i}$, and their calorific values $h_{c_{i}}$. For determining the mass of each item, either the weighing technique or inventory technique, or a combination of the two can be used during the survey. As the types of combustibles are identified through the survey, their calorific values can be derived from the literature $[35,60]$.

To facilitate the survey process, a specific survey form for motels and hotels was developed, and provided in Appendix B. The survey form was divided into the following 6 sections: (1) brief information of surveyed motels and hotels that includes hotel name, address, building age, number of rooms and stories, and survey date; (2) draft floor plan; (3) room dimensions; (4) opening dimensions; (5) fixed fire loads; (6) moveable fire loads: this section was further divided into 4 categories: furniture, bedding, electronics, and others including paper, curtain, rubbish bins and Christmas trees.

A similar survey procedure was applied to all of the surveyed motels and hotels. Building information was collected, and data related to fire load in the surveyed room were measured and/or recorded following the sequence of the specific hotel survey form. Digital photos were taken in the surveyed rooms for assisting data analysis and reproducing furniture arrangements for the tests. 
In the survey process, the inventory technique was the main method used, and weighing items in the surveyed guest rooms was seldom used because of the fact that most of the surveyed rooms were already cleaned and ready for renting. Some common items, such as telephone books and rubbish bins, were pre-weighed. In some hotels, the bedding items were weighed in their storage rooms or in other guest rooms while housekeepers were doing the cleaning. The inventory technique was applied to most of the furniture by measuring their dimensions and taking pictures. For some standard common furniture, their masses were determined by matching target furniture to the data sheets obtained from manufacturers or from information found on the internet. The mass of other furniture was derived by calculating the volume of wood, and multiplying it by the corresponding densities. When the wood species was unknown, a density of $550 \mathrm{~kg} / \mathrm{m}^{3}$ was assumed. Assumptions have been made on the mass of some items, such as plastics contained in TVs, microwaves, coffee makers, and fridges, shown in Appendix C. The calorific values of different combustible materials or assumptions used in calculating the fire loads are also provided in Appendix C.

\subsection{Surveyed Motels and Hotels}

The fire load survey was conducted in 10 motels and 12 hotels in Canada's National Capital Region---Ottawa and Gatineau area, from March 2007 to August 2007. Two of the ten surveyed motels were located in Gatineau, which is situated on the northern bank of the Ottawa River. The other eight motels were located in Ottawa----6 motels were located at the east, west, south and downtown of Ottawa city area, separately; 2 motels 
located at a rural area, 60 kilometres west from downtown Ottawa. Except for one threestorey building, the surveyed motels were either one-storey or two-storey buildings.

Most hotels in the city are high-rise buildings, and they are either located in the downtown area for convenience or close to tourist sites. The surveyed hotels were selected from different hotel rating groups. They included three 2-star, five 3-star (including two "pure" suite hotels), two 4-star, and two 5-star hotels. Two surveyed hotels were located in Gatineau, and the other ten hotels are located in downtown Ottawa. The surveyed hotel buildings cover ages from 6 years to $100+$ years, and storeys from 3 to 24. The geographic locations of the surveyed motels and hotels are shown in Figure 27. Typical pictures of the surveyed motels and hotels are presented in Figures 28 to 31 .

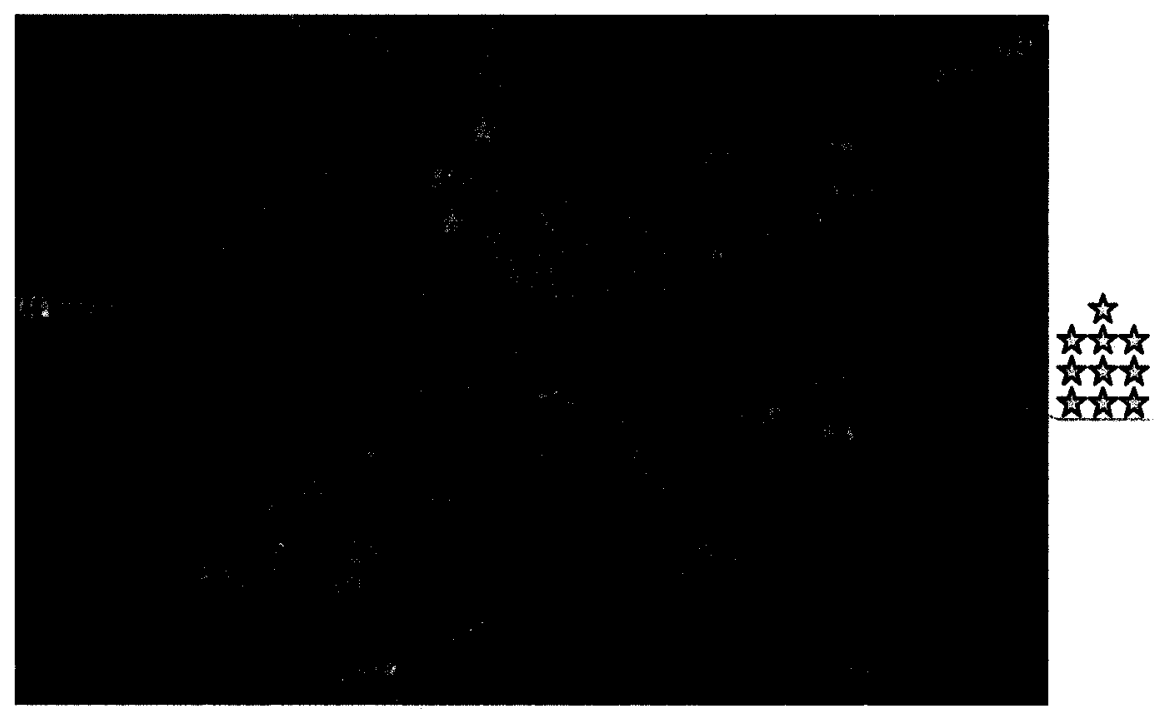

Figure 27 Map of surveyed motels and hotels

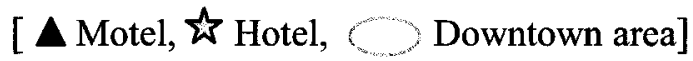

[*2 motels, about $60 \mathrm{~km}$ west of downtown Ottawa are not shown on this map] 


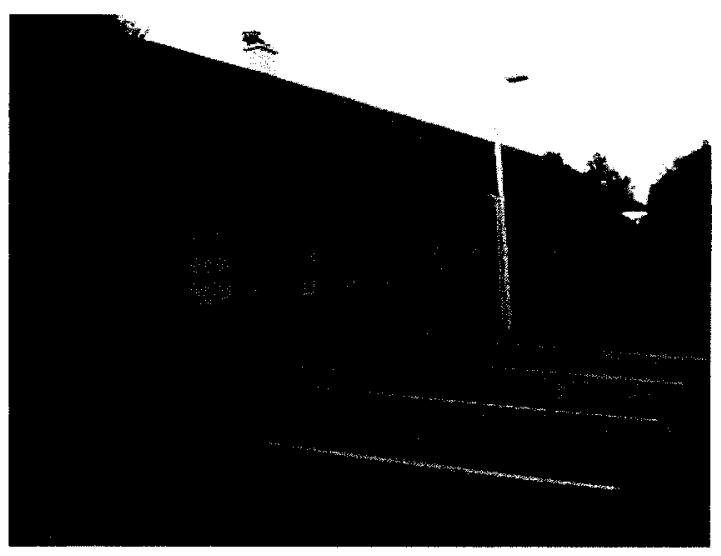

Figure 28 A surveyed 1-storey motel

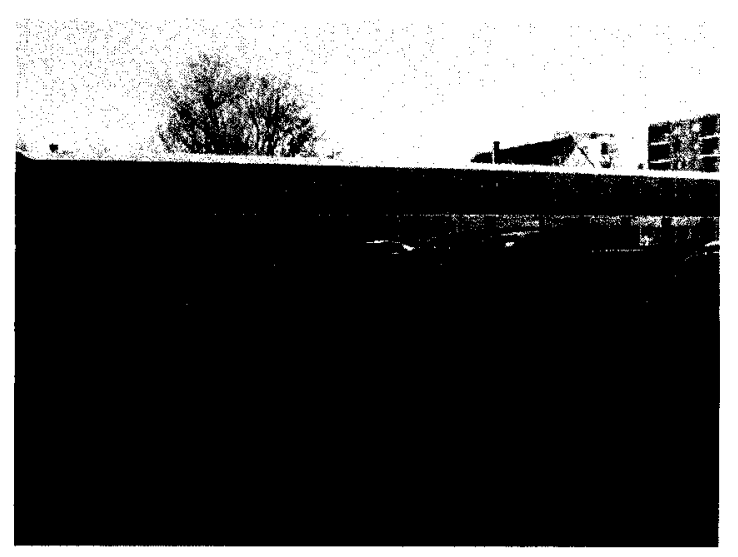

Figure 29 A surveyed 2-storey motel

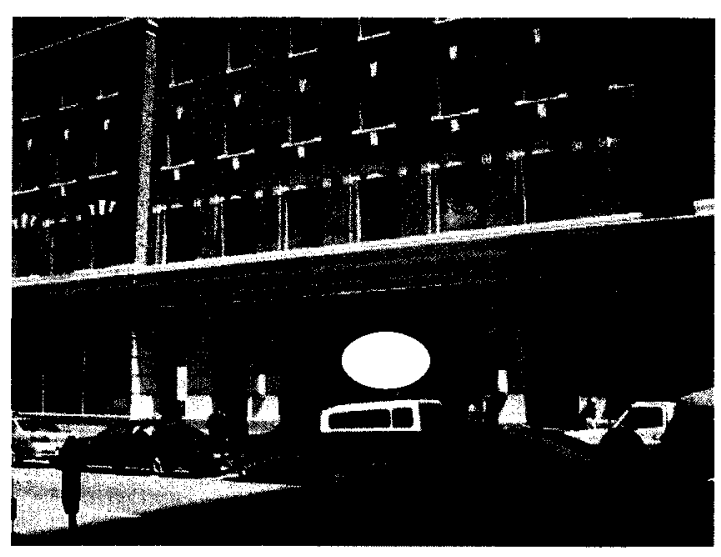

Figure 30 A surveyed hotel having building age of $100+$ years

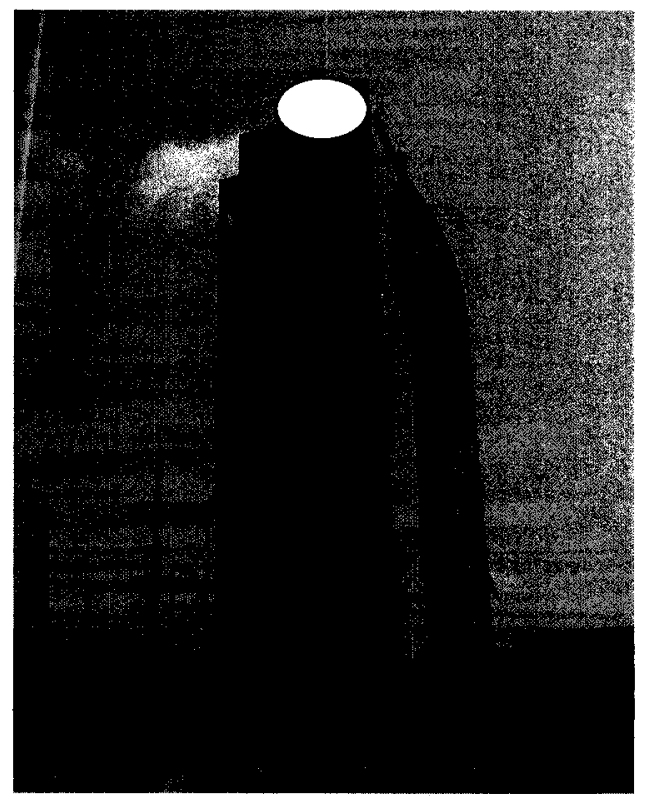

Figure 31 A surveyed hotel having building age of 6 years 59 
One specific feature of motel and hotel buildings is that one type of guest room in a building represents many rooms with the same layout, interior finish and inside items, which are named "representing rooms" and recorded in this research. This feature of motel and hotel buildings makes them different than any other building, like offices, dwellings, schools and hospitals. The hotel rating, building age, storeys, number of surveyed rooms, and representing rooms are given in Table 14.

Table 14 Features of surveyed motels and hotels

\begin{tabular}{|c|c|c|c|c|c|c|}
\hline & No. & $\begin{array}{l}\text { Rating } \\
\text { (Star) }\end{array}$ & $\begin{array}{l}\text { Building } \\
\text { Age (yr) }\end{array}$ & $\begin{array}{c}\text { Building } \\
\text { Stories } \\
\end{array}$ & $\begin{array}{c}\text { Surveyed } \\
\text { Rooms }\end{array}$ & $\begin{array}{c}\text { Representing } \\
\text { Rooms } \\
\end{array}$ \\
\hline \multirow{11}{*}{ Motel } & 1 & & $\sim 50$ & 2 & 3 & 20 \\
\hline & 2 & & unknown & 2 & 2 & 38 \\
\hline & 3 & & $\sim 32$ & 2 & 1 & 19 \\
\hline & 4 & & $\sim 43$ & 2 & 3 & 26 \\
\hline & 5 & & $\sim 40$ & $1 ; 2$ & 4 & 45 \\
\hline & 6 & & $\sim 45$ & 1 & 2 & 19 \\
\hline & 7 & & $\sim 40$ & 2 & 3 & 27 \\
\hline & 8 & & $\sim 28$ & $2 ; 3$ & 3 & 78 \\
\hline & 9 & & $\sim 50$ & 1 & 2 & 25 \\
\hline & 10 & & $\sim 42$ & 2 & 2 & 18 \\
\hline & Sum & & & & 25 & 315 \\
\hline \multirow{13}{*}{ Hotel } & 1 & 2 & $100+$ & 6 & 4 & 20 \\
\hline & 2 & 2 & 44 & 3 & 1 & 3 \\
\hline & 3 & 2 & 18 & 19 & 2 & 212 \\
\hline & 4 & 3 & $\sim 15$ & 22 & 6 & 120 \\
\hline & 5 & 3 & $20 \sim 30$ & 12 & 1 & 98 \\
\hline & 6 & 3 & $34 ; 15$ & $8 ; 12$ & 4 & 131 \\
\hline & 7 & 3 & 29 & 13 & 4 & 241 \\
\hline & 8 & 3 & 20 & 21 & 2 & 281 \\
\hline & 9 & 4 & 30 & $10 ; 18$ & 4 & 280 \\
\hline & 10 & 4 & 35 & 18 & 3 & 236 \\
\hline & 11 & 5 & 22 & 24 & 2 & 176 \\
\hline & 12 & 5 & 6 & 20 & 3 & 243 \\
\hline & Sum & & & & 36 & 2041 \\
\hline
\end{tabular}

60 
In the 10 surveyed motels, 25 guest rooms with a total floor area of $567 \mathrm{~m}^{2}$ were surveyed, which may represent 315 motel guest rooms with a total representing floor area of $7,108 \mathrm{~m}^{2}$. In the 12 surveyed hotels, a total of 36 hotel guest rooms, including 10 suites were surveyed, which may represent 2,041 hotel guest rooms with a total surveyed floor area of $1,094 \mathrm{~m}^{2}$ and a total representing floor area of $58,395 \mathrm{~m}^{2}$.

\subsection{Data Analysis}

The fire load survey was conducted only in the guest rooms or suites of motels and hotels. Other areas such as atria, corridors, stairwells, storage rooms, offices, and banquet and/or meeting rooms were not included in the survey.

In the field survey, some doors of bathrooms, kitchens, and bedrooms in suites were noticed to be closed, and some were open, which could be the same in the real scenario that some guests may likely keep the inside doors closed, and some guests may likely leave the doors open. In the following data analysis of this research, the assumption was made that all the doors inside the guest rooms are closed, including the doors of bedrooms, living rooms, bathrooms, and kitchens. A suite room was divided into 2 rooms, bedroom and living room, if there was a door in between. Therefore, the bathrooms, and kitchens with doors, were excluded from the following calculations and analysis. Typical floor plans for a regular hotel guest room with one bed and a hotel suit room with one bed are given in Figure 32 and Figure 33. 


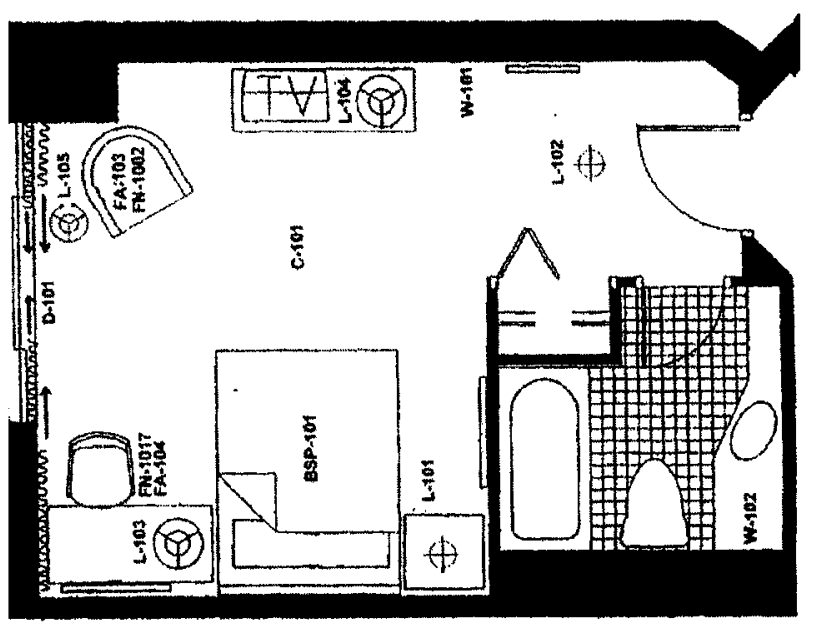

Figure 32 Floor plan of a typical hotel guest room with one bed

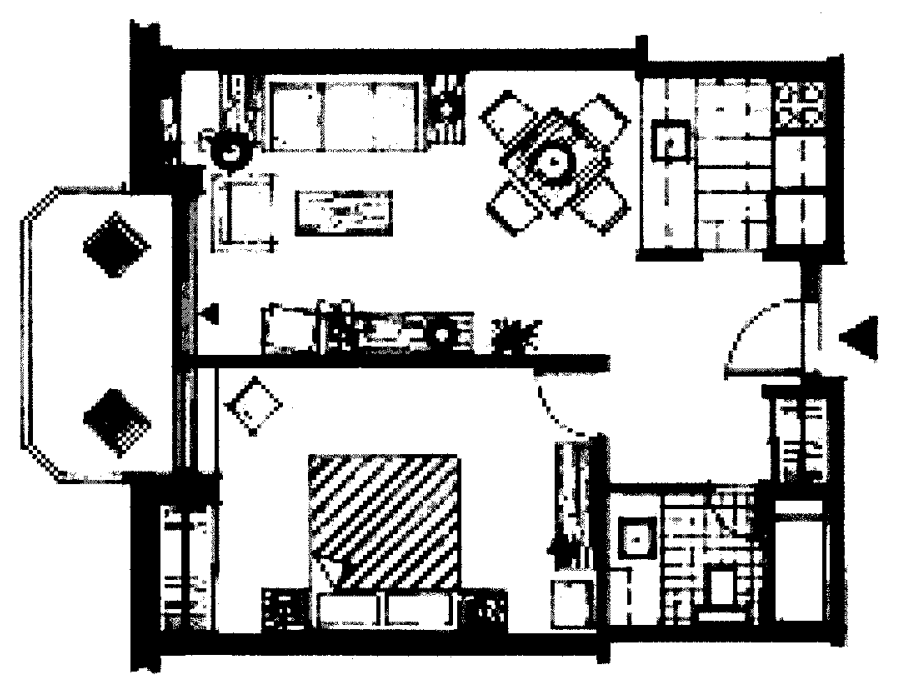

Figure 33 Floor plan of a hotel suite room with one bed [61]

The surveyed hotels were selected by hotel ratings. From observation in the field survey and description of hotel ratings, the hotels with rating of 2-star and 3-star have a slight difference, and the hotels with rating over 3-star are relatively luxurious. In this research, surveyed hotels were categorized into 3 groups---two in terms of hotel ratings: "standard hotels" with hotel rating below 3-star and "luxury hotels" with rating over 3.5star; and another one group is "hotel suites" for those suites that consist of one or two 62 
bedrooms and one living room. A bedroom in a hotel guest room has either one bed or two beds. A hotel suite has one bedroom (or two bedrooms) and a living room with or without a door in between, and may or may not have a kitchen.

Recorded survey data and the number of surveyed rooms were used to calculate fire load density in each bedroom and living room, and to determine the contribution of different combustible materials to the fire load. In addition, data was collected to calculate typical floor area, area of openings and percentage of floor area covered by furnishings for bedrooms with one bed and two beds, and living rooms of suites in different hotel categories.

\subsubsection{Calibration of Measuring Tools}

For length measurements, two measuring tools were used in the survey. One is a regular tape rule, and another is an ultrasonic measuring device. The tape rule is convenient and accurate to measure the dimensions of openings, furniture, and other items; and the ultrasonic measuring device is ideal and fast for measuring interior room dimensions. The specifications of the ultrasonic measuring device are provided in Table 15.

In the field survey, the ultrasonic measuring device was only used for measuring room dimensions, and the tape rule was used for all of other dimension measurements. The accuracy of the ultrasonic measuring device was tested by measuring the distance to three walls with the ultrasonic measuring device and the tape rule. Test data are given in Appendix D. Calibration of the ultrasonic measuring device was made according to the 
measuring difference of the ultrasonic measuring tool, which is given in Table 16. Figure 34 shows the calibration results of the two measuring tools.

Table 15 Specifications of the ultrasonic measuring device (modified from [62])

\begin{tabular}{ll}
\hline Dimensions: & 1.2 in. $\mathrm{H} \times 2.8$ in. W x 4.4 in. $\mathrm{L}(3.1 \mathrm{~cm} \mathrm{x} 7.2 \mathrm{~cm} \times 11 \mathrm{~cm})$ \\
Weight: & $3.5 \mathrm{oz} .(100 \mathrm{~g})$ without battery \\
Battery Type: & 9 -Volt alkaline \\
Battery Life: & Up to 100,000 continuous accurate readings \\
Accuracy: & Within $\pm 0.5 \% \pm 1$ digit (in still air) \\
Measurement Range: & $1 \mathrm{ft} .10$ in. to $41 \mathrm{ft} .(55 \mathrm{~cm}$ to $12.5 \mathrm{~m})$ \\
Aperture Angle: & Approximately \pm 5 degrees \\
Display: & 5 digit liquid crystal display \\
\hline
\end{tabular}

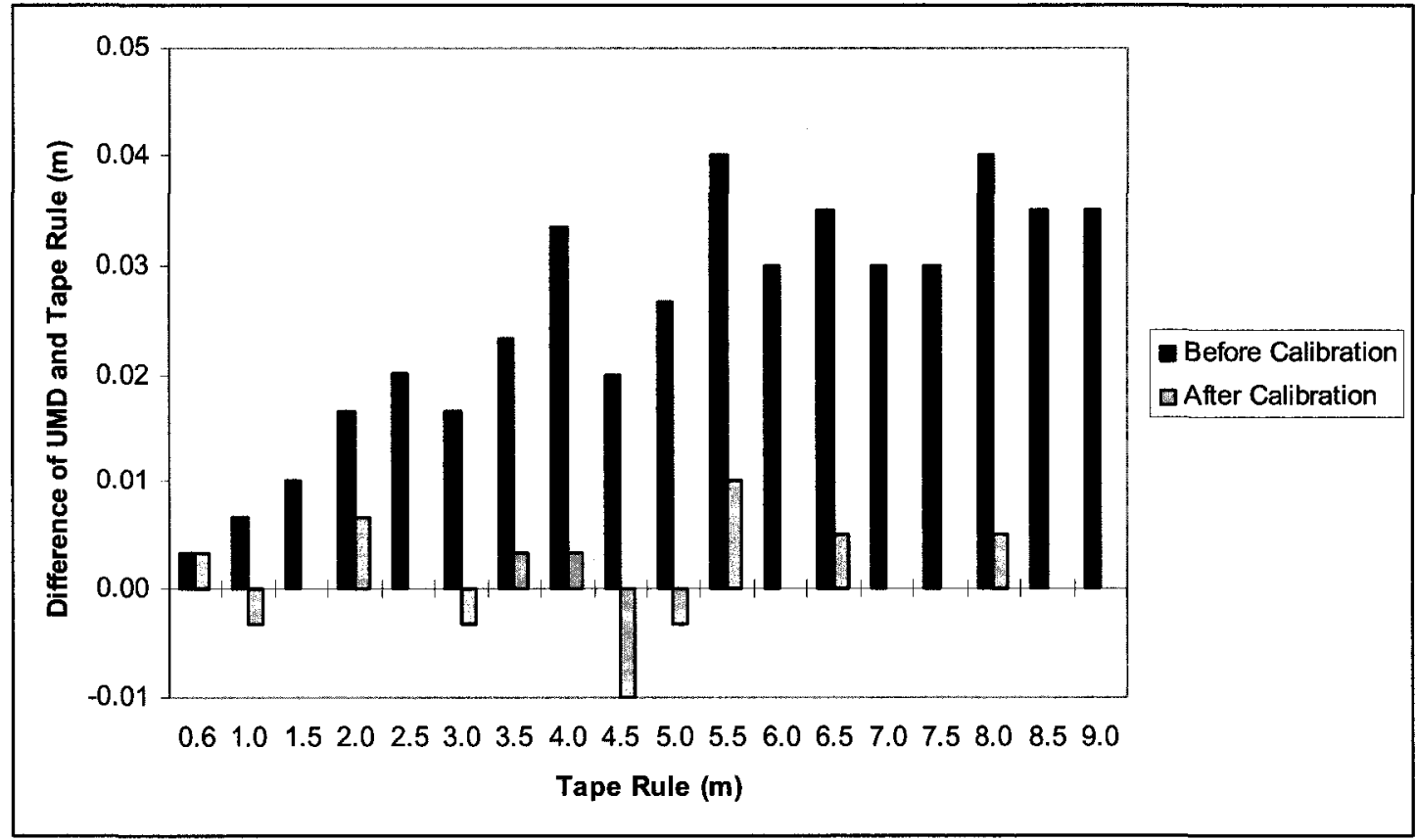

Figure 34 Difference of the two measuring tools before and after calibration 
Table 16 Calibration of the ultrasonic measuring tool

\begin{tabular}{cc}
\hline Measurement $(\mathrm{m})$ & Calibration $(\mathrm{m})$ \\
\hline $1.0-2.0$ & -0.010 \\
$2.0-4.0$ & -0.020 \\
$4.0-8.0$ & -0.030 \\
$8.0-9.0$ & -0.035 \\
\hline
\end{tabular}

\subsubsection{Floor Area}

In the 10 selected motels, the survey was conducted in 25 typical guest rooms, including 13 bedrooms with one bed; 10 bedrooms with two beds; 1 bedroom with two double beds and one single bed; and 1 suite room having a bedroom with two beds and a kitchen within the living room. The 25 surveyed guest rooms had a total floor area of $567 \mathrm{~m}^{2}$ and may represent 315 guest rooms with a total represented floor area of $7,108 \mathrm{~m}^{2}$.

Figure 35 shows the floor area of the surveyed motel rooms. The floor area of bedrooms with one bed has a minimum, maximum, mean, and $95^{\text {th }}$ percentile values of $15.5 ; 33.2 ; 20.4$; and $29.4 \mathrm{~m}^{2}$ respectively, and a standard deviation of $5.67 \mathrm{~m}^{2}$. The floor area of motel bedrooms with two beds has a minimum, maximum, mean and $95^{\text {th }}$ percentile values of $15.7 ; 33.2 .0 ; 22.9$; and $29.8 \mathrm{~m}^{2}$ respectively, and a standard deviation of 4.75 . The mean and $95^{\text {th }}$ percentile floor areas of the surveyed motel rooms with two beds are slightly higher than that of the guest rooms with one bed. The maximum floor areas of rooms with one bed and two beds are the same because the rooms had the same floor plan regardless of bed types. In a suite having a living room with a kitchen inside, 
the floor area of the bedroom with two beds is $17.8 \mathrm{~m}^{2}$ which is $5.1 \mathrm{~m}^{2}$ lower than the mean value of the regular guest bedrooms with two beds.

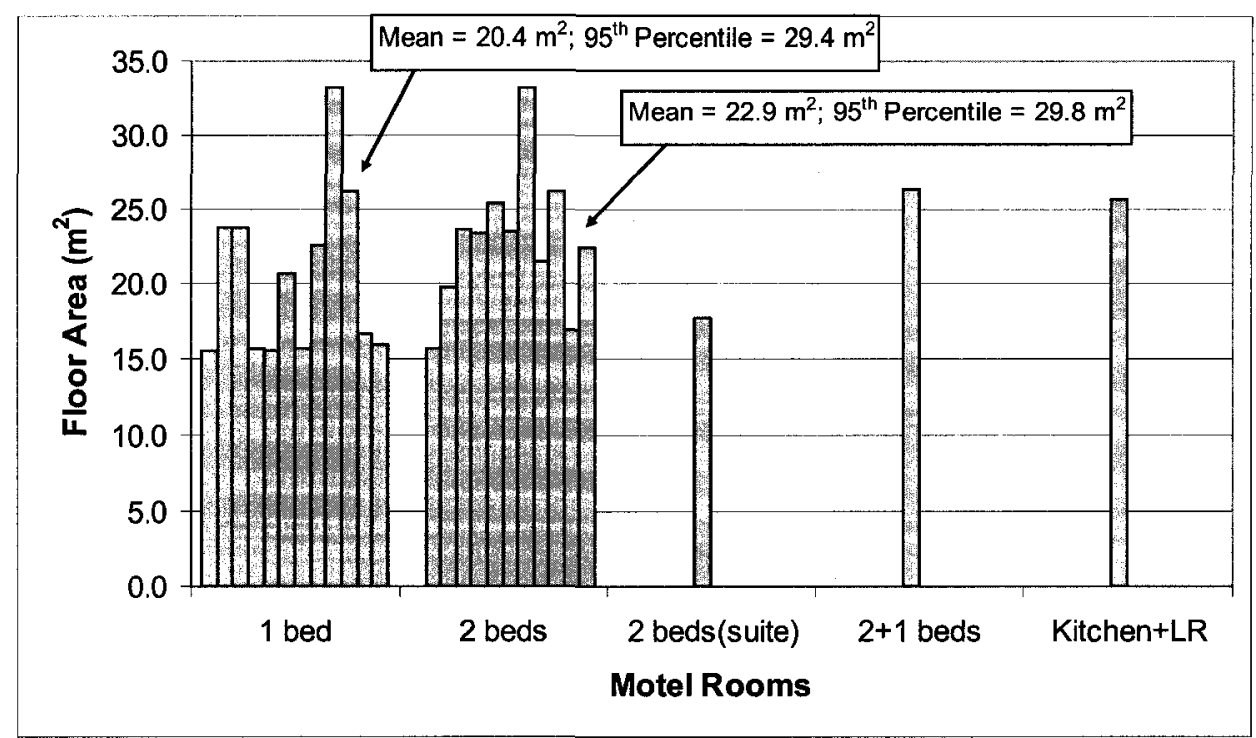

Figure 35 Floor area of surveyed motel rooms

[ $* 2$ beds (suite): a motel bedroom with 2 beds in a suite; $2+1$ beds: a motel bedroom with 2 double beds and 1 single bed; Kitchen+LR: a motel living room with kitchen inside]

The 12 surveyed hotels consist of three 2-star, five 3-star (including two suite hotels), two 4-star, and two 5-star hotels. The survey was conducted in 36 hotel guest rooms including 10 suites, with a total floor area of $1,094 \mathrm{~m}^{2}$, which may represent about 2,041 hotel guest rooms with a total represented floor area of $58,395 \mathrm{~m}^{2}$.

Figure 36 shows the floor areas of the surveyed hotel rooms. The floor areas of bedrooms with one bed for standard hotels, luxury hotels, and hotel suites have a minimum value of $17.0,20.1$, and $11.2 \mathrm{~m}^{2}$; a maximum value of $29.4,32.8$, and $15.0 \mathrm{~m}^{2}$; a mean value of $22.8,26.2$, and $13.2 \mathrm{~m}^{2}$; a $95^{\text {th }}$ percentile of $28.3,32.1$, and $15.0 \mathrm{~m}^{2}$; and 
a standard deviation of $4.41,4.83$, and 1.96 , respectively. The floor areas of bedrooms with two beds for standard hotels, luxury hotels, and hotel suites have a minimum value of $20.3,26.0$, and $11.2 \mathrm{~m}^{2}$; a maximum value of $32.9,32.8$, and $17.2 \mathrm{~m}^{2}$; a mean value of $26.0,28.4$, and $14.6 \mathrm{~m}^{2}$; a $95^{\text {th }}$ percentile value of $31.9,32.2$, and $17.0 \mathrm{~m}^{2}$, and a standard deviation of $5.32,2.92$, and 3.07 , respectively.

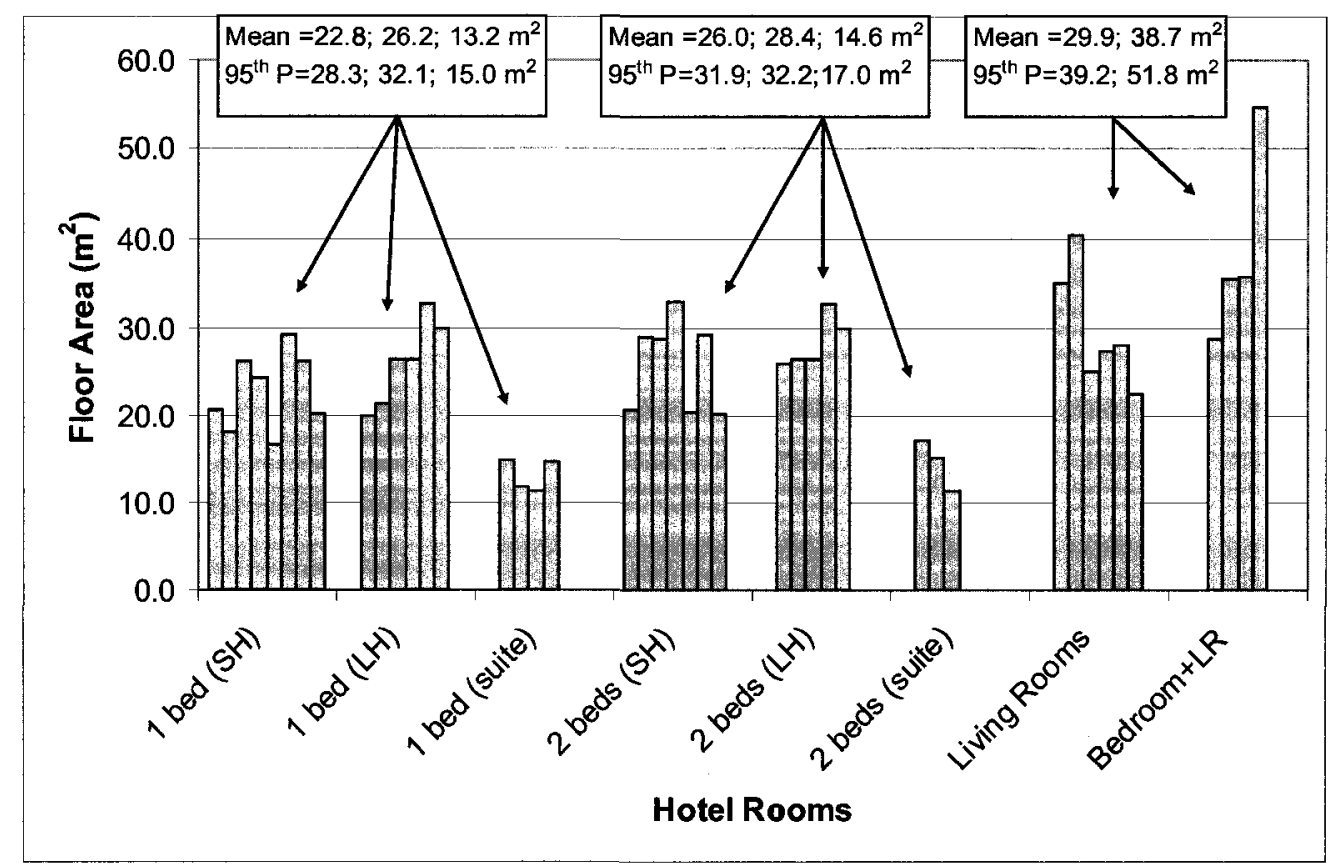

Figure 36 Floor area of surveyed hotel rooms

[ $\left.{ }^{*} \mathrm{SH}\right)$ : standard hotels including 2, 3 star; $(\mathrm{LH})$ : luxury hotels above 3 star; (suite): hotel suite bedrooms having doors to living rooms; Bedroom+LR: suite bedrooms plus living rooms without doors in between]

The floor areas of luxury hotel bedrooms with one bed have minimum, maximum, mean and $95^{\text {th }}$ percentile values higher than those of standard hotel rooms. The floor area of luxury hotel bedrooms with two beds also have minimum and mean values higher than those of standard hotel rooms, but have similar maximum and $95^{\text {th }}$ percentile values as 
those of standard hotel rooms. All the values of the floor areas of hotel suites are significantly lower than those of standard hotels and luxury hotels, because of the extra area of the living room beside the bedroom in a suite.

The floor areas of living rooms with doors to the bedrooms have a minimum, maximum, mean and $95^{\text {th }}$ percentile values of $22.6 ; 40.5 ; 29.9$; and $39.2 \mathrm{~m}^{2}$ respectively, and a standard deviation of 6.69. The floor areas of bedrooms plus living rooms without doors in between have a minimum, maximum, mean and $95^{\text {th }}$ percentile values of 28.9 ; $54.6 ; 38.7$; and $51.8 \mathrm{~m}^{2}$ respectively, and a standard deviation of 11.07 .

\subsubsection{Area of Openings}

As the assumption was made before that all the doors in the guest rooms are closed, the areas of doors were not considered as openings in this research, except some doors to balconies having small windows, which were counted to the areas of windows in the guest rooms. The window area of the surveyed motel and hotel rooms are discussed below.

Figure 37 shows the window area of the surveyed motel rooms. The window area of motel bedrooms with one bed has a minimum, maximum, mean and $95^{\text {th }}$ percentile values of $1.65 ; 3.79 ; 2.54$; and $3.34 \mathrm{~m}^{2}$ respectively, and a standard deviation of 0.60 . The window area of bedrooms with two beds has a minimum, maximum, mean and $95^{\text {th }}$ percentile values of $1.62 ; 3.79 ; 2.51 ;$ and $3.41 \mathrm{~m}^{2}$ respectively, and a standard deviation of 0.60 . The window area of motel bedrooms with one bed and two beds did not show 
much difference. The maximum window area is significantly higher than all of other windows because of the large window and glass door to the back balcony.

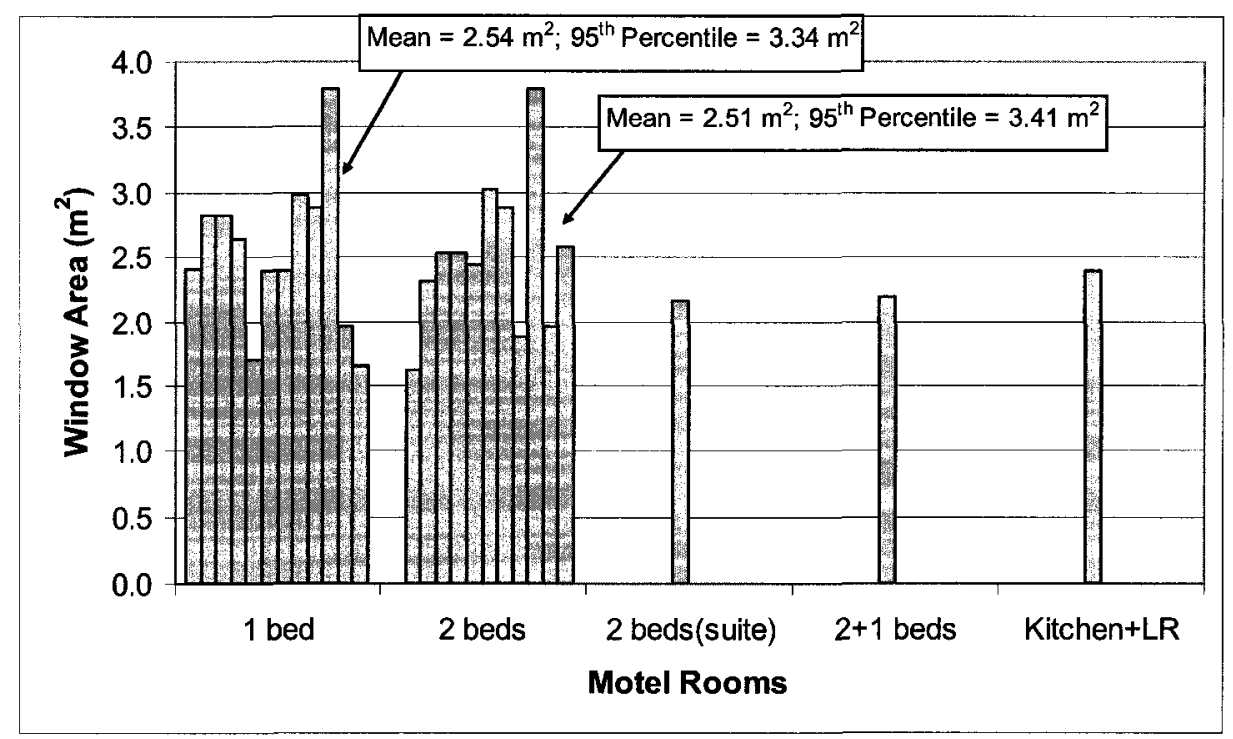

Figure 37 Window area of surveyed motel rooms

[ $* 2$ beds (suite): a motel bedroom with 2 beds in a suite; $2+1$ beds: a motel bedroom with 2 double beds and 1 single bed; Kitchen+LR: a motel living room with kitchen inside]

The window area of the surveyed hotel rooms is shown in Figure 38. The window areas of bedrooms with one bed for standard hotels, luxury hotels, and suite hotels have a minimum value of $2.03,3.13$, and $1.32 \mathrm{~m}^{2}$; a maximum value of $6.60,10.00$, and $3.00 \mathrm{~m}^{2}$; a mean value of $3.98,5.92$, and $1.87 \mathrm{~m}^{2}$; a $95^{\text {th }}$ percentile value of $6.39,9.18$, and $2.80 \mathrm{~m}^{2}$; and a standard deviation of $1.56,2.55$, and 0.76 respectively. The window areas of bedrooms with two beds for standard hotels, luxury hotels, and suite hotels have a minimum value of $2.03,3.13$, and $1.59 \mathrm{~m}^{2}$; a maximum value of $6.00,10.00$, and $2.67 \mathrm{~m}^{2}$; a mean value of $2.95,5.26$, and $1.98 \mathrm{~m}^{2}$; a $95^{\text {th }}$ percentile value of $5.20,9.34$, and $2.57 \mathrm{~m}^{2}$; and a standard deviation of $1.42,3.06$, and 0.60 respectively. The window 
areas of bedrooms with one bed and with two beds in luxury hotels have minimum, maximum, mean and $95^{\text {th }}$ percentile values higher than those of two type bedrooms at standard hotel rooms.

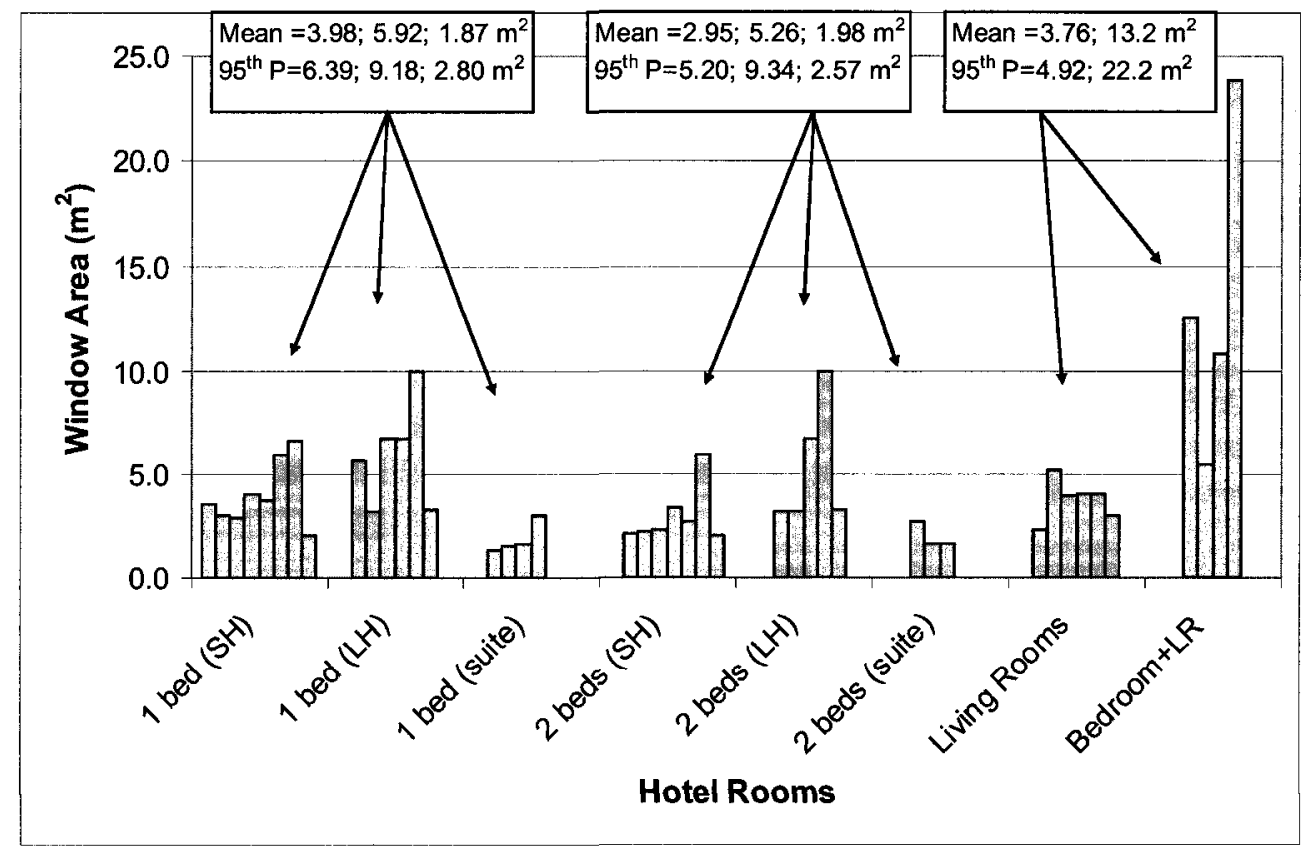

Figure 38 Window area of surveyed hotel rooms

[*(SH): standard hotels including 2, 3 star; (LH): luxury hotels above 3 star; (suite): hotel suite bedrooms having doors to living rooms; Bedroom+LR: suite bedrooms plus living rooms without doors in between]

The window areas of living rooms with doors to bedrooms have minimum, maximum, mean and $95^{\text {th }}$ percentile values of $2.30 ; 5.22 ; 3.76$; and $4.92 \mathrm{~m}^{2}$ respectively, and a standard deviation of 1.00 . The window areas of bedrooms plus living rooms without doors in between have minimum, maximum, mean and $95^{\text {th }}$ percentile values of $5.50 ; 23.84 ; 13.22$; and $22.16 \mathrm{~m}^{2}$, respectively, and a standard deviation of 7.70 . All the values of window areas in bedrooms plus living rooms without doors in between are much higher than those of other hotel room categories. 


\subsubsection{Percentage of Floor Area Covered by Furnishings}

For both motels and hotels, the percentage of floor area covered by furniture, electronics, and other movable objects, was calculated and given in Figure 39 and Figure 40. In the surveyed motels, the amount of floor space occupied by furniture and equipment in bedrooms with one bed has a mean value of $33.0 \%$ and a $95^{\text {th }}$ percentile value of $40.2 \%$; and in bedrooms with two beds, a mean value of $40.3 \%$ and a $95^{\text {th }}$ percentile value of 48.2\%. The standard deviations are 5.12 and 5.69 respectively. This shows that the percentage of floor coverage for motel bedrooms with two beds is higher than that for motel bedrooms with one bed. The percentage of floor coverage in a living room with kitchen inside is $36 \%$, which is higher than the mean value for the motel bedrooms with one bed, and lower than the mean value for the motel bedrooms with two beds.

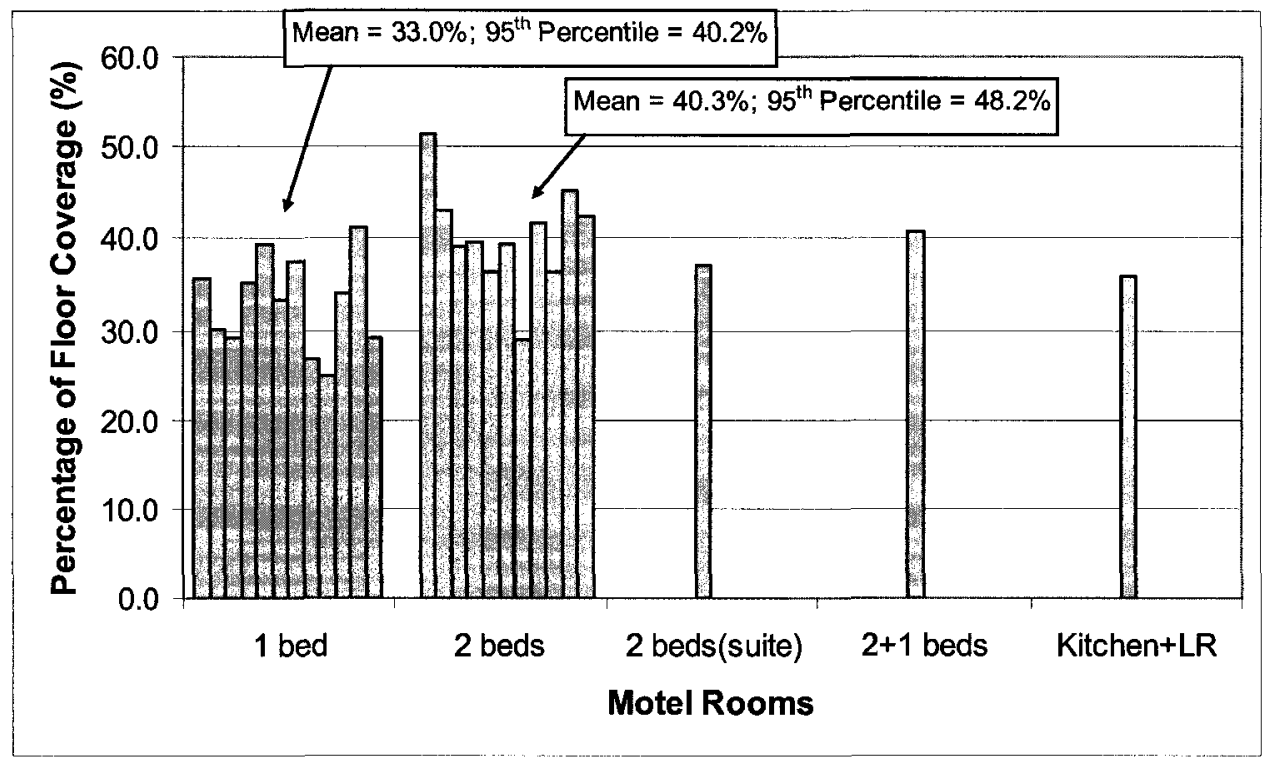

Figure 39 Percentage of floor coverage in surveyed motel rooms

[ $* 2$ beds (suite): a motel bedroom with 2 beds in a suite; $2+1$ beds: a motel bedroom with 2 double beds and 1 single bed; Kitchen+LR: a motel living room with kitchen inside] 


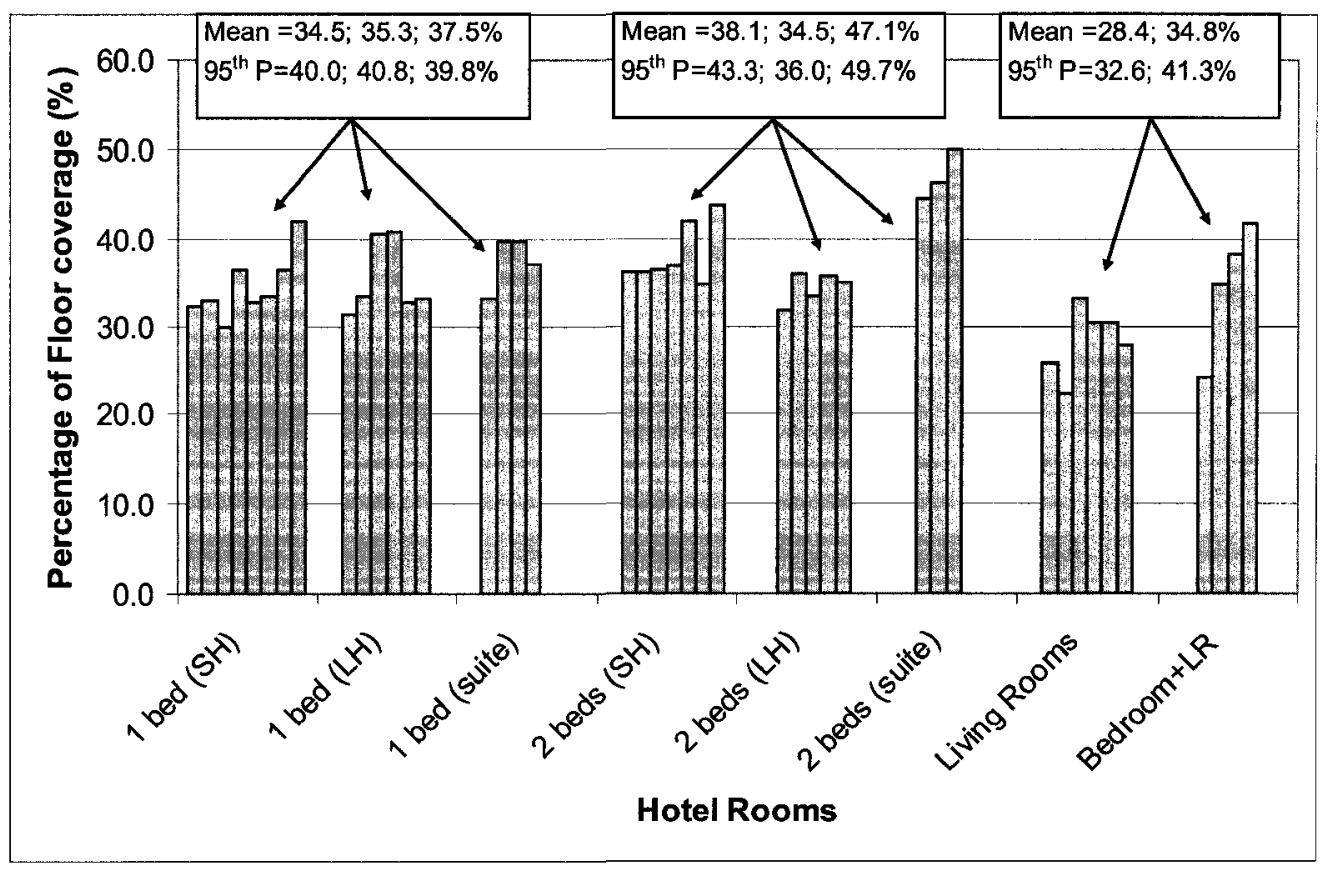

Figure 40 Percentage of floor coverage in surveyed hotel rooms

[*(SH): standard hotels including 2, 3 star; (LH): luxury hotels above 3 star; (suite): hotel suite bedrooms having doors to living rooms; Bedroom+LR: suite bedrooms plus living rooms without doors in between]

In the surveyed hotels, the mean value of the percentage of floor area covered by furniture and other contents in bedrooms with one bed in standard hotels, luxury hotels, hotel suites is $34.5 \%, 35.3 \%$, and $37.5 \%$ respectively, and in bedrooms with two beds is $38.1 \%, 34.5 \%$, and $47.1 \%$ respectively. The mean value of the percentage of floor area covered by furniture and contents in living rooms is $28.4 \%$; and the mean value in bedrooms plus living rooms without doors in between is $34.8 \%$. The percentage of floor coverage in the living rooms is lower than the values in the bedrooms and bedrooms plus living rooms. 
The percentage of floor coverage in bedrooms of motels and hotels is higher than that in office buildings, where the amount of floor space occupied by furniture and equipment is $25-30 \%$ [34].

\subsubsection{Bed Size}

Table 17 shows the regular bed or mattress size on the market. In the whole surveyed motels and hotels, no California king bed was found in any of the bedrooms of motels and hotels; only one twin bed was found with 2 double beds in a motel bedroom; and only two twin $\mathrm{x}$-long beds were found in a bedroom of a suite, which had a second bedroom with one queen bed. The number of surveyed rooms and the representing rooms having the same bed size in different categories of motels and hotels is given in Table 18.

Table 17 Bed or mattress size on the market

\begin{tabular}{llccc}
\hline \multirow{2}{*}{ Bed Size } & \multicolumn{2}{c}{ Also Known as: } & \multicolumn{2}{c}{ Bed or Mattress Dimension } \\
& & (in) & Area $\left(\mathrm{m}^{2}\right)$ \\
\hline Twin & Single & $39^{\prime \prime} \times 75^{\prime \prime}$ & $0.99 \times 1.91$ & 1.89 \\
Twin X-Long & Extra Long Single & $39^{\prime \prime} \times 80^{\prime \prime}$ & $0.99 \times 2.03$ & 2.01 \\
Double & Full & $54^{\prime \prime} \times 75^{\prime \prime}$ & $1.37 \times 1.91$ & 2.61 \\
Queen & Queen & $60^{\prime \prime} \times 80^{\prime \prime}$ & $1.52 \times 2.03$ & 3.10 \\
King & Eastern or Standard King & $78^{\prime \prime} \times 80^{\prime \prime}$ & $1.98 \times 2.06$ & 4.03 \\
California King & Western King & $72^{\prime \prime} \times 84^{\prime \prime}$ & $1.83 \times 2.13$ & 3.90 \\
\hline
\end{tabular}


Table 18 Distribution of bed size in the surveyed motels and hotels

\begin{tabular}{|c|c|c|c|c|c|c|c|}
\hline \multirow{2}{*}{\multicolumn{2}{|c|}{ Categories }} & \multirow{2}{*}{$\begin{array}{l}\text { Total } \\
\text { Rooms }\end{array}$} & \multicolumn{5}{|c|}{ Number of Rooms with following Bed Size } \\
\hline & & & Twin & \multirow{2}{*}{$\begin{array}{c}\text { Twin } \\
\text { X-Long } \\
-\end{array}$} & \multirow{2}{*}{$\frac{\text { Double }}{6(75)}$} & \multirow{2}{*}{$\begin{array}{l}\text { Queen } \\
5(49)\end{array}$} & King \\
\hline \multirow{4}{*}{$\begin{array}{c}\text { Bedrooms } \\
\text { With } \\
1 \text { bed }\end{array}$} & Motels & $12(125)^{\mathrm{a}}$ & - & & & & $1(1)$ \\
\hline & Standard hotels & $9(433)$ & - & - & - & $4(140)$ & $5(293)$ \\
\hline & Luxury hotels & $6(505)$ & - & - & - & $2(140)$ & $4(365)$ \\
\hline & Hotel Suites & $7(225)$ & & - & $1(9)$ & $4(208)$ & $2(8)$ \\
\hline \multirow{4}{*}{$\begin{array}{c}\text { Bedrooms } \\
\text { With } \\
2 \text { beds }\end{array}$} & Motels & $13(190)$ & $1(1)^{b}$ & - & $9(141)$ & $4(49)$ & - \\
\hline & Standard hotels & $7(416)$ & - & - & $2(256)$ & $5(160)$ & - \\
\hline & Luxury hotels & $5(410)$ & - & - & $5(410)$ & - & - \\
\hline & Hotel Suites & $2(52)$ & - & $1(29)^{\mathrm{c}}$ & $1(32)$ & $1(20)$ & - \\
\hline
\end{tabular}

a number in parentheses is the amount of representing rooms.

b 1(1) not counted in the total number of rooms, because the twin bed was in a motel bedroom with another 2 double beds, and the number of room was counted in the motel bedrooms with 2 double beds.

${ }^{c} 1(29)$ not counted in the total number of rooms, because the suite had 2 bedrooms--one having 2 twin $x-$ long beds and one having one queen bed, and was counted in the hotel suite with one queen bed.

\subsubsection{Fire Load Density}

Moveable fire load density and total fire load density for motels, hotels and all surveyed guest rooms are summarized in Table 19. The three mean values of moveable fire load density are close to $387 \mathrm{MJ} / \mathrm{m}^{2}$. The $80^{\text {th }}$ percentile of moveable fire load density for motels and hotels, range from 436 to $453 \mathrm{MJ} / \mathrm{m}^{2}$, which is close to the reported value of $420 \mathrm{MJ} / \mathrm{m}^{2}$ [37]. The mean value of the total fire load density is $535 \mathrm{MJ} / \mathrm{m}^{2}$ for motels, which is also close to the data provided by Yii [38]. The mean value of the total fire load density for hotels is $560 \mathrm{MJ} / \mathrm{m}^{2}$, and that for all of the surveyed guest rooms is $550 \mathrm{MJ} / \mathrm{m}^{2}$. Figure 41 provides $95^{\text {th }}$ percentile and mean values of the total fire load density in different motel and hotel categories. 
Table 19 Fire load density for guest rooms in motels and hotels

\begin{tabular}{ccccccccc}
\hline & \multicolumn{3}{c}{ Moveable Fire Load Density } & & \multicolumn{3}{c}{ Total Fire Load Density } \\
\cline { 2 - 3 } & $\begin{array}{c}\text { Motels } \\
\left(\mathrm{MJ} / \mathrm{m}^{2}\right)\end{array}$ & $\begin{array}{c}\text { Hotels } \\
\left(\mathrm{MJ} / \mathrm{m}^{2}\right)\end{array}$ & $\begin{array}{c}\text { All Rooms } \\
\left(\mathrm{MJ} / \mathrm{m}^{2}\right)\end{array}$ & & $\begin{array}{c}\text { Motels } \\
\left(\mathrm{MJ} / \mathrm{m}^{2}\right)\end{array}$ & $\begin{array}{c}\text { Hotels } \\
\left(\mathrm{MJ} / \mathrm{m}^{2}\right)\end{array}$ & $\begin{array}{c}\text { All Rooms } \\
\left(\mathrm{MJ} / \mathrm{m}^{2}\right)\end{array}$ \\
\hline Minimum & 202 & 145 & 145 & & 371 & 279 & 279 \\
Maximum & 569 & 571 & 571 & & 736 & 848 & 848 \\
Mean & 383 & 391 & 388 & & 535 & 560 & 550 \\
$80 \%$ & 436 & 453 & 453 & & 605 & 638 & 632 \\
$95 \%$ & 501 & 544 & 539 & & 712 & 776 & 753 \\
Standard deviation & 89 & 105 & 98 & & 100 & 123 & 115 \\
\hline
\end{tabular}

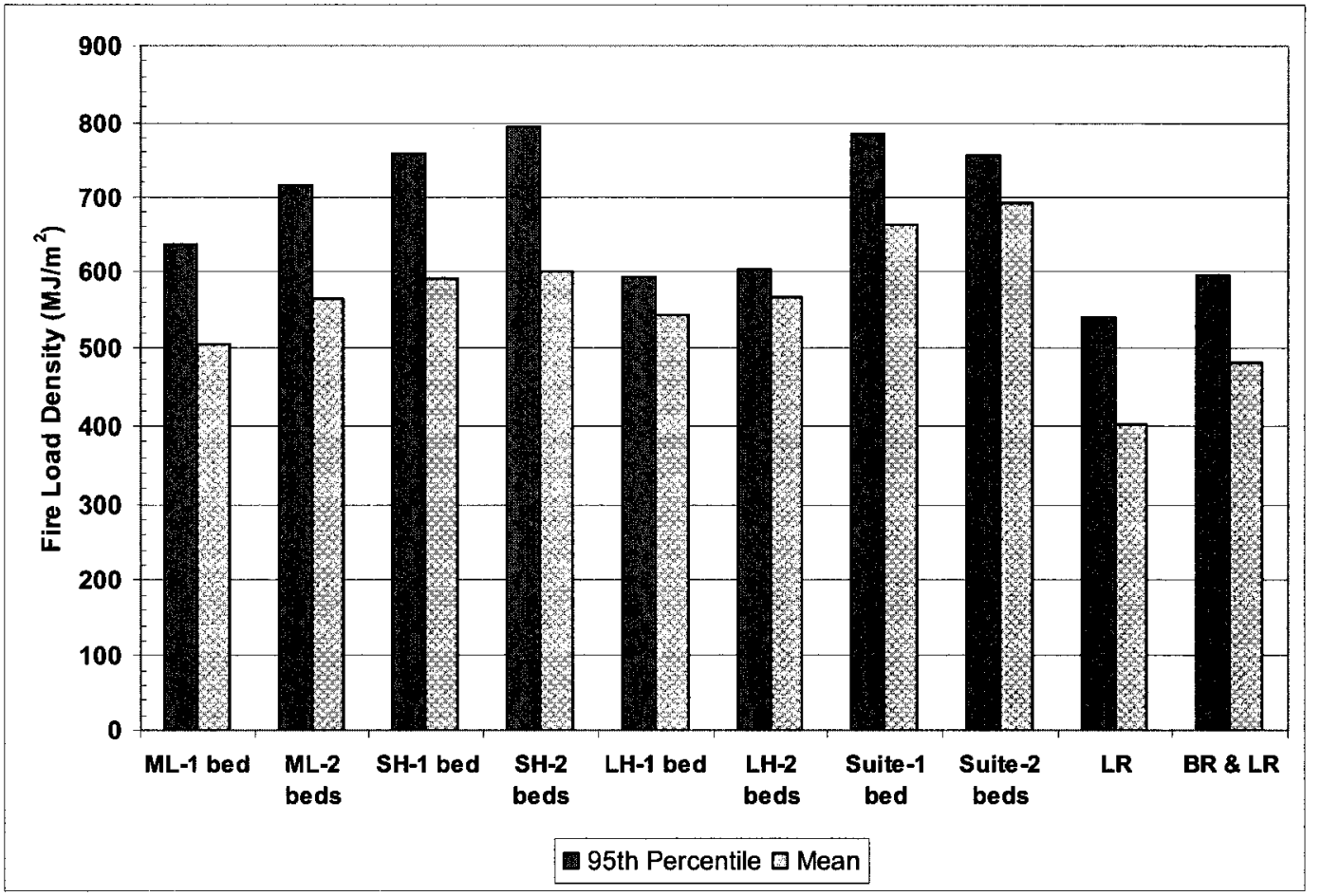

Figure 41 Total fire load density in different motel and hotel categories

[ML: motels; SH: standard hotels; LH: luxury hotels; Suite: hotel suites; LR: living rooms; BR \&LR: hotel bedrooms plus living rooms without doors in between] 
Figure 41 shows that the two types of bedrooms in standard hotels and hotel suites have the highest $95^{\text {th }}$ percentile values of fire load density ranging from 757 to $795 \mathrm{MJ} / \mathrm{m}^{2}$. The mean values of two types of bedrooms in hotel suites ranging from 664 to $691 \mathrm{MJ} / \mathrm{m}^{2}$ are higher than all other mean values which range from 401 to $601 \mathrm{MJ} / \mathrm{m}^{2}$. In motels, standard hotels and luxury hotels, the $95^{\text {th }}$ percentile value and mean value for bedrooms with two beds are higher than the values for bedrooms with one bed. In hotel suites, the $95^{\text {th }}$ percentile value for bedrooms with two beds is slightly lower than the value for bedrooms with one bed, but the mean value for bedrooms with two beds is also higher than the mean value for bedrooms with one bed. The mean values of fire load density in all the bedrooms of standard hotels and luxury hotels are close and range from 543 to $601 \mathrm{MJ} / \mathrm{m}^{2}$. The living rooms have the lowest mean and $95^{\text {th }}$ percentile fire load density values, and also the lowest values of the percentage of floor area covered by furnishings.

Table 20 and Table 21 provide the total fire load density and moveable fire load density of different combustible materials in different room types and hotel categories. Figure 42 to Figure 51 present the distribution of the total fire load density for different combustible materials in different room types and hotel categories. 
Table 20 Total fire load density in different motel and hotel categories

\begin{tabular}{|c|c|c|c|c|c|c|c|c|}
\hline Categ & ries & Wood & Plastic & Textile & Paper & Mattress & & Total \\
\hline & Mean & 306.7 & 23.4 & 26.5 & 6.8 & 12 & 151 & \\
\hline ML-1 bed & $95 \%$ & 444.9 & 33.4 & 52.9 & 21.5 & 163.0 & 60.6 & 636.8 \\
\hline & $\%$ Contri. $^{a}$ & 60.6 & 4.6 & 5.2 & 1.3 & 25.2 & 3.0 & 100.0 \\
\hline & Mean & 274.9 & 20.4 & 27.8 & 7.5 & 220.0 & 14.8 & 565.5 \\
\hline ML-2 beds & $95 \%$ & 377.9 & 29.8 & 39.2 & 18.6 & 274.7 & 48.2 & 714.9 \\
\hline & $\%$ Contri. & 48.6 & 3.6 & 4.9 & 1.3 & 38.9 & 2.6 & 100.0 \\
\hline & Mean & 341.5 & 17.3 & 39.2 & 15.7 & 137.2 & 39.5 & 590.3 \\
\hline SH-1 bed & $95 \%$ & 538.1 & 25.6 & 53.3 & 22.4 & 161.1 & 66.0 & 758.2 \\
\hline & $\%$ Contri. & 57.8 & 2.9 & 6.6 & 2.7 & 23.2 & 6.7 & 100.0 \\
\hline & Mean & 300.1 & 16.0 & 45.2 & 16.7 & 199.7 & 23.0 & 600.5 \\
\hline SH- 2 beds & $95 \%$ & 476.0 & 24.9 & 54.6 & 21.1 & 246.8 & 38.8 & 795.4 \\
\hline & $\%$ Contri. & 50.0 & 2.7 & 7.5 & 2.8 & 33.2 & 3.8 & 100.0 \\
\hline & Mean & 315.1 & 13.0 & 43.5 & 17.4 & 120.1 & 33.5 & 542.6 \\
\hline LH-1 bed & $95 \%$ & 347.8 & 16.2 & 56.1 & 19.4 & 130.0 & 41.9 & 593.8 \\
\hline & $\%$ Contri. & 58.1 & 2.4 & 8.0 & 3.2 & 22.1 & 6.2 & 100.0 \\
\hline & Mean & 296.4 & 13.1 & 46.5 & 17.2 & 159.0 & 34.7 & 567.0 \\
\hline LH-2 beds & $95 \%$ & 319.1 & 16.1 & 61.6 & 19.1 & 171.4 & 44.1 & 604.1 \\
\hline & $\%$ Contri. & 52.3 & 2.3 & 8.2 & 3.0 & 28.0 & 6.1 & 100.0 \\
\hline & Mean & 383.6 & 11.3 & 33.3 & 20.5 & 214.8 & 0.0 & 663.6 \\
\hline Suite-1 bed & $95 \%$ & 516.9 & 18.6 & 37.7 & 28.4 & 233.5 & 0.0 & 786.1 \\
\hline & $\%$ Contri. & 57.8 & 1.7 & 5.0 & 3.1 & 32.4 & 0.0 & 100.0 \\
\hline & Mean & 308.8 & 19.8 & 44.0 & 23.2 & 295.1 & 0.0 & 690.9 \\
\hline Suite- 2 beds & $95 \%$ & 372.2 & 24.9 & 47.0 & 25.5 & 304.6 & 0.0 & 756.8 \\
\hline & $\%$ Contri. & 44.7 & 2.9 & 6.4 & 3.4 & 42.7 & 0.0 & 100.0 \\
\hline & Mean & 296.0 & 24.1 & 26.0 & 14.3 & 0.0 & 40.6 & 401.0 \\
\hline LR & $95 \%$ & 431.4 & 29.9 & 58.2 & 18.8 & 0.0 & 69.4 & 541.5 \\
\hline & $\%$ Contri. & 73.8 & 6.0 & 6.5 & 3.6 & 0.0 & 10.1 & 100.0 \\
\hline & Mean & 316.4 & 14.0 & 31.6 & 12.6 & 71.6 & 35.5 & 481.7 \\
\hline BR \& LR & $95 \%$ & 419.2 & 21.9 & 41.8 & 16.1 & 77.0 & 39.8 & 596.0 \\
\hline & $\%$ Contri. & 65.7 & 2.9 & 6.6 & 2.6 & 14.9 & 7.4 & 100.0 \\
\hline
\end{tabular}

${ }^{a} \%$ contribution in the table: percentage of contribution to mean value of each category. 
Table 21 Moveable fire load density in different motel and hotel categories

\begin{tabular}{|c|c|c|c|c|c|c|c|c|}
\hline Categ & bries & Wood & Plastic & Textile & Paper & Mattress & Sofa & Total \\
\hline & Mean & 81.1 & 11.5 & 7.4 & 1.0 & 63.8 & 7.5 & 172.3 \\
\hline ML-1 bed & $95 \%$ & 224.2 & 31.7 & 29.5 & 3.3 & 156.6 & 51.1 & 427.1 \\
\hline & $\%$ Contri. $^{a}$ & 47.1 & 6.7 & 4.3 & 0.6 & 37.0 & 4.4 & 100.0 \\
\hline & Mean & 79.4 & 10.0 & 8.2 & 0.9 & 110.0 & 7.4 & 215.8 \\
\hline ML-2 beds & $95 \%$ & 189.2 & 26.9 & 20.9 & 2.9 & 266.9 & 47.1 & 501.3 \\
\hline & $\%$ Contri. & 36.8 & 4.6 & 3.8 & 0.4 & 51.0 & 3.4 & 100.0 \\
\hline & Mean & 47.6 & 4.4 & 6.7 & 0.6 & 36.6 & 10.5 & 106.5 \\
\hline SH-1 bed & $95 \%$ & 198.6 & 20.8 & 29.5 & 2.7 & 150.9 & 45.9 & 436.8 \\
\hline & $\%$ Contri. & 44.7 & 4.2 & 6.3 & 0.6 & 34.4 & 9.9 & 100.0 \\
\hline & Mean & 43.9 & 3.9 & 7.3 & 0.5 & 49.9 & 5.7 & 111.2 \\
\hline SH-2 beds & $95 \%$ & 191.0 & 16.8 & 32.0 & 2.7 & 219.0 & 35.4 & 475.9 \\
\hline & $\%$ Contri. & 39.5 & 3.5 & 6.6 & 0.4 & 44.9 & 5.2 & 100.0 \\
\hline & Mean & 101.9 & 6.2 & 12.3 & 0.9 & 60.1 & 16.7 & 198.2 \\
\hline LH-1 bed & $95 \%$ & 230.5 & 15.1 & 35.7 & 2.7 & 128.5 & 39.4 & 443.0 \\
\hline & $\%$ Contri. & 51.4 & 3.1 & 6.2 & 0.5 & 30.3 & 8.4 & 100.0 \\
\hline & Mean & 104.8 & 7.0 & 15.4 & 1.0 & 88.3 & 19.3 & 235.8 \\
\hline LH-2 beds & $95 \%$ & 195.9 & 15.0 & 40.7 & 2.1 & 170.7 & 44.0 & 458.6 \\
\hline & $\%$ Contri. & 44.4 & 3.0 & 6.5 & 0.4 & 37.5 & 8.2 & 100.0 \\
\hline & Mean & 23.2 & 1.2 & 2.1 & 0.2 & 23.9 & 0.0 & 50.6 \\
\hline Suite-1 bed & $95 \%$ & 207.1 & 7.1 & 18.5 & 1.2 & 223.4 & 0.0 & 440.0 \\
\hline & $\%$ Contri. & 45.8 & 2.3 & 4.2 & 0.5 & 47.1 & 0.0 & 100.0 \\
\hline & Mean & 16.7 & 1.5 & 2.0 & 0.3 & 23.3 & 0.0 & 43.8 \\
\hline Suite- 2 beds & $95 \%$ & 199.8 & 15.5 & 20.7 & 3.1 & 288.3 & 0.0 & 545.9 \\
\hline & $\%$ Contri. & 38.2 & 3.4 & 4.5 & 0.7 & 53.1 & 0.0 & 100.0 \\
\hline & Mean & 18.5 & 3.8 & 1.9 & 0.1 & 0.0 & 6.6 & 31.0 \\
\hline LR & $95 \%$ & 115.2 & 27.1 & 4.4 & 0.6 & 0.0 & 34.9 & 188.3 \\
\hline & $\%$ Contri. & 59.7 & 12.4 & 6.3 & 0.4 & 0.0 & 21.2 & 100.0 \\
\hline & Mean & 17.9 & 1.2 & 1.2 & 0.2 & 6.2 & 3.1 & 29.7 \\
\hline BR \& LR & $95 \%$ & 137.6 & 9.1 & 8.7 & 1.7 & 70.6 & 32.0 & 274.3 \\
\hline & $\%$ Contri. & 60.2 & 4.0 & 3.9 & 0.5 & 21.0 & 10.4 & 100.0 \\
\hline
\end{tabular}

a $\%$ contribution in the table: percentage of contribution to mean value of each category. 


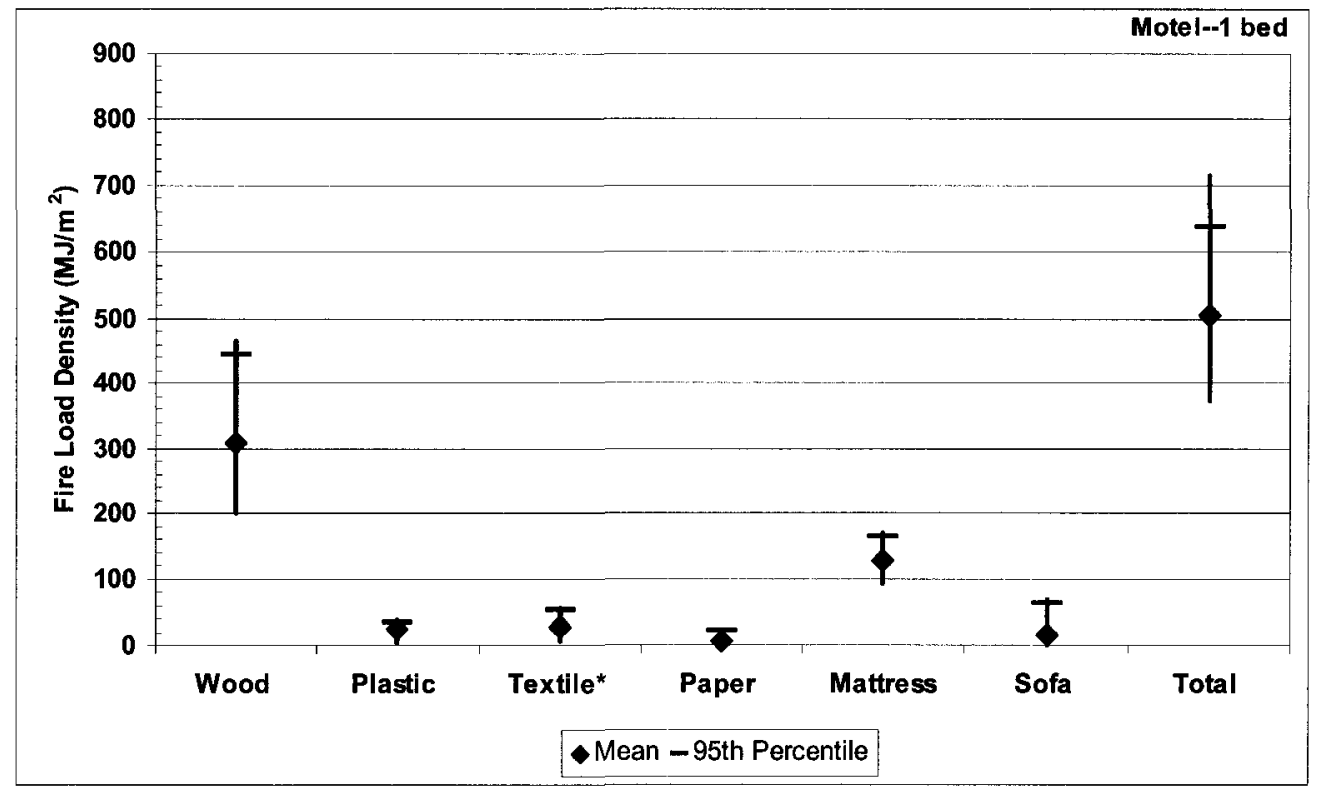

Figure 42 Fire load density of different combustibles in motel bedrooms with one bed [* Textile includes leather]

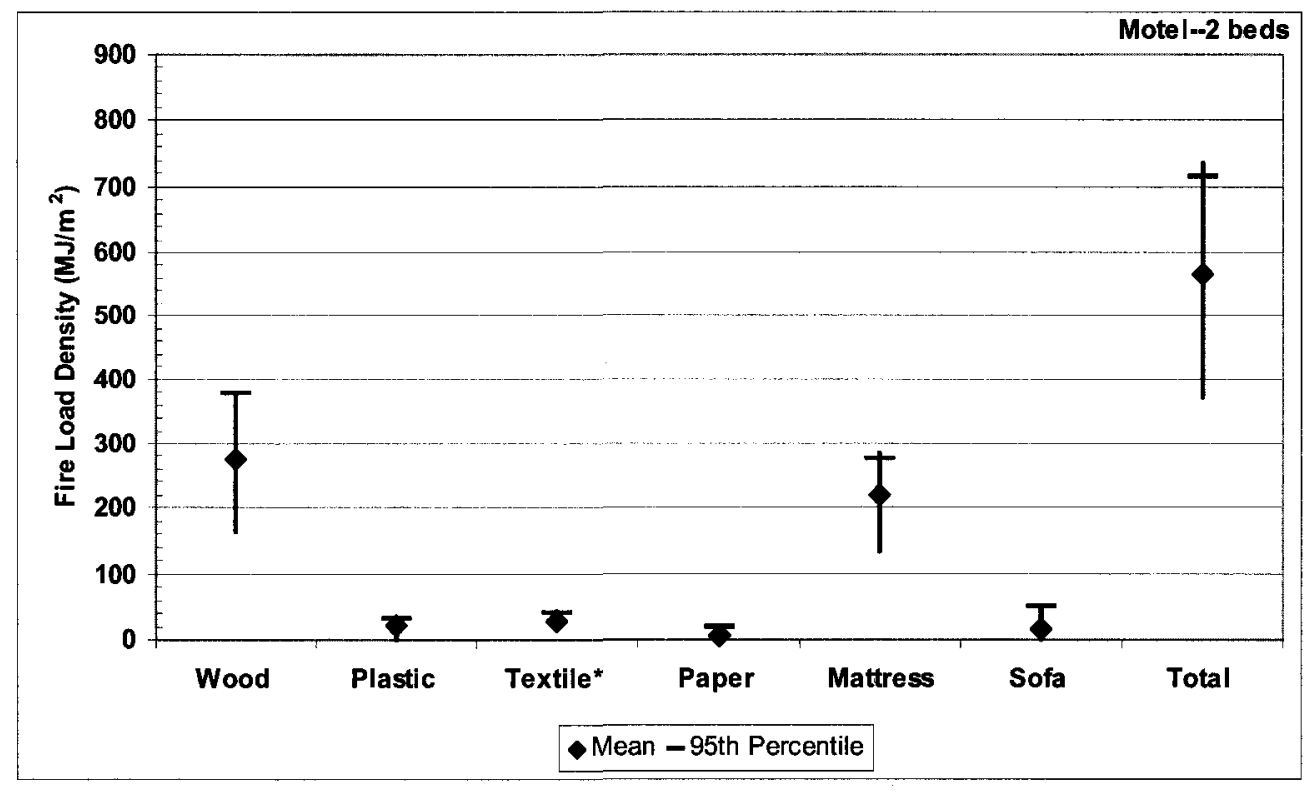

Figure 43 Fire load density of different combustibles in motel bedrooms with two beds [* Textile includes leather] 


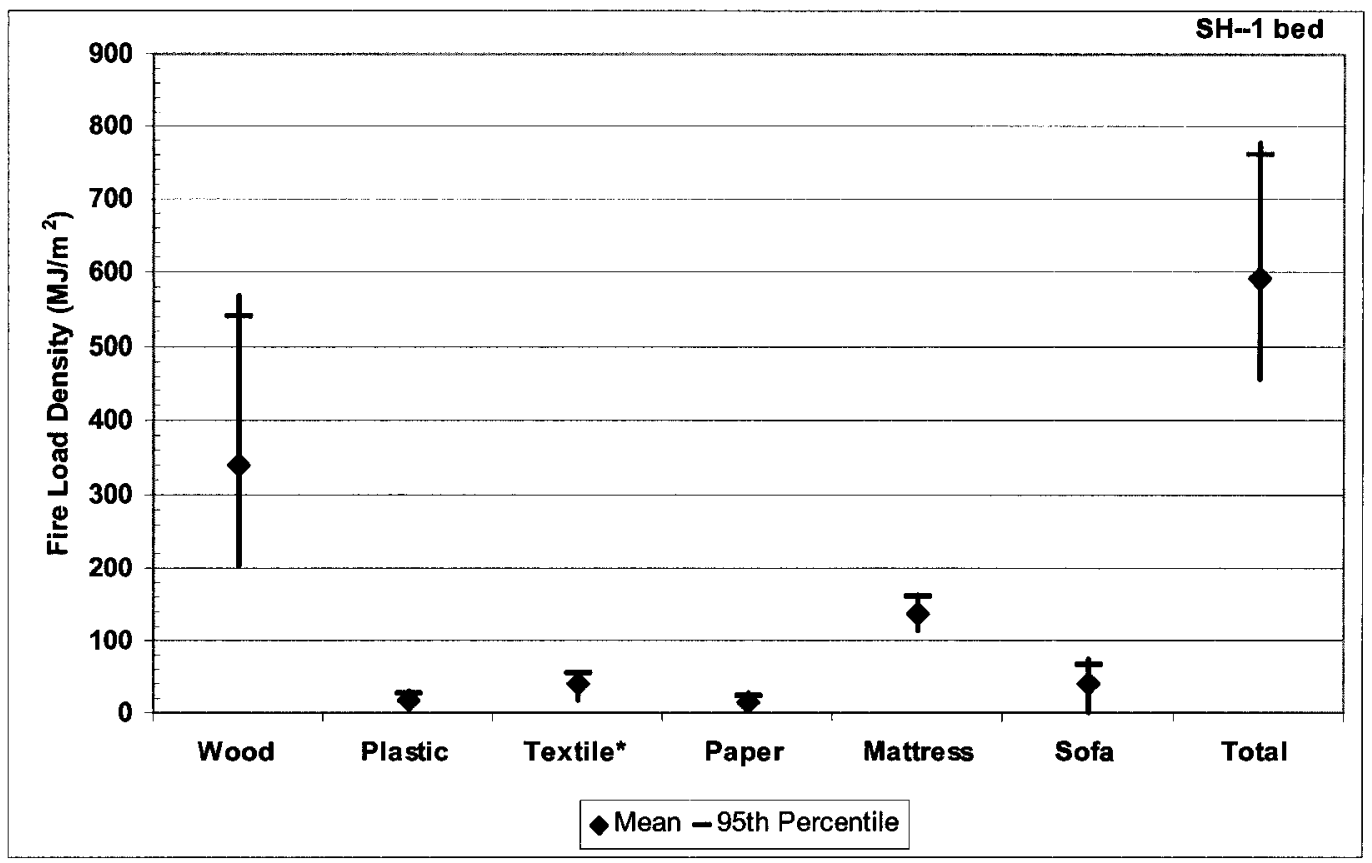

Figure 44 Fire load density of different combustibles in standard hotel bedrooms with one bed [* Textile includes leather]

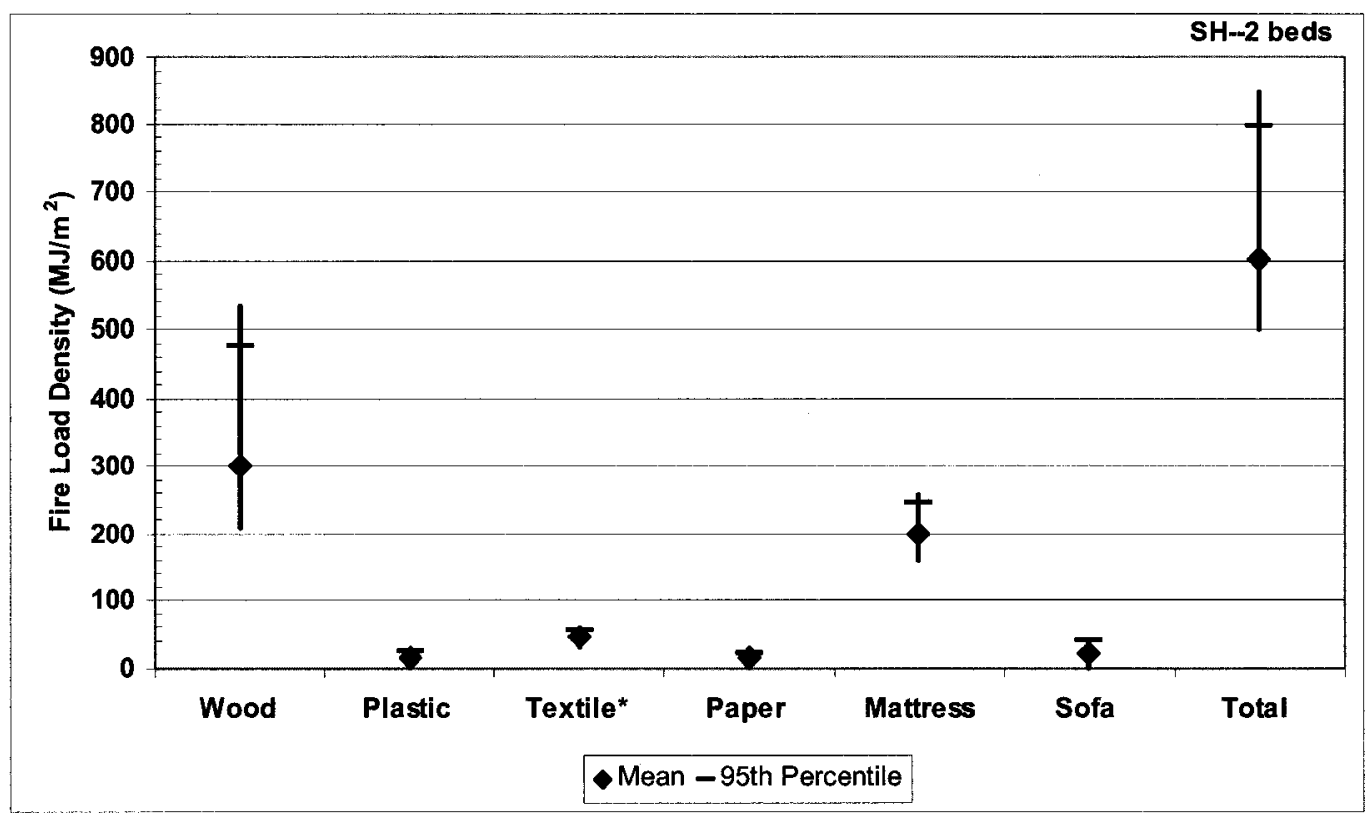

Figure 45 Fire load density of different combustibles in standard hotel bedrooms with two beds [* Textile includes leather]

80 


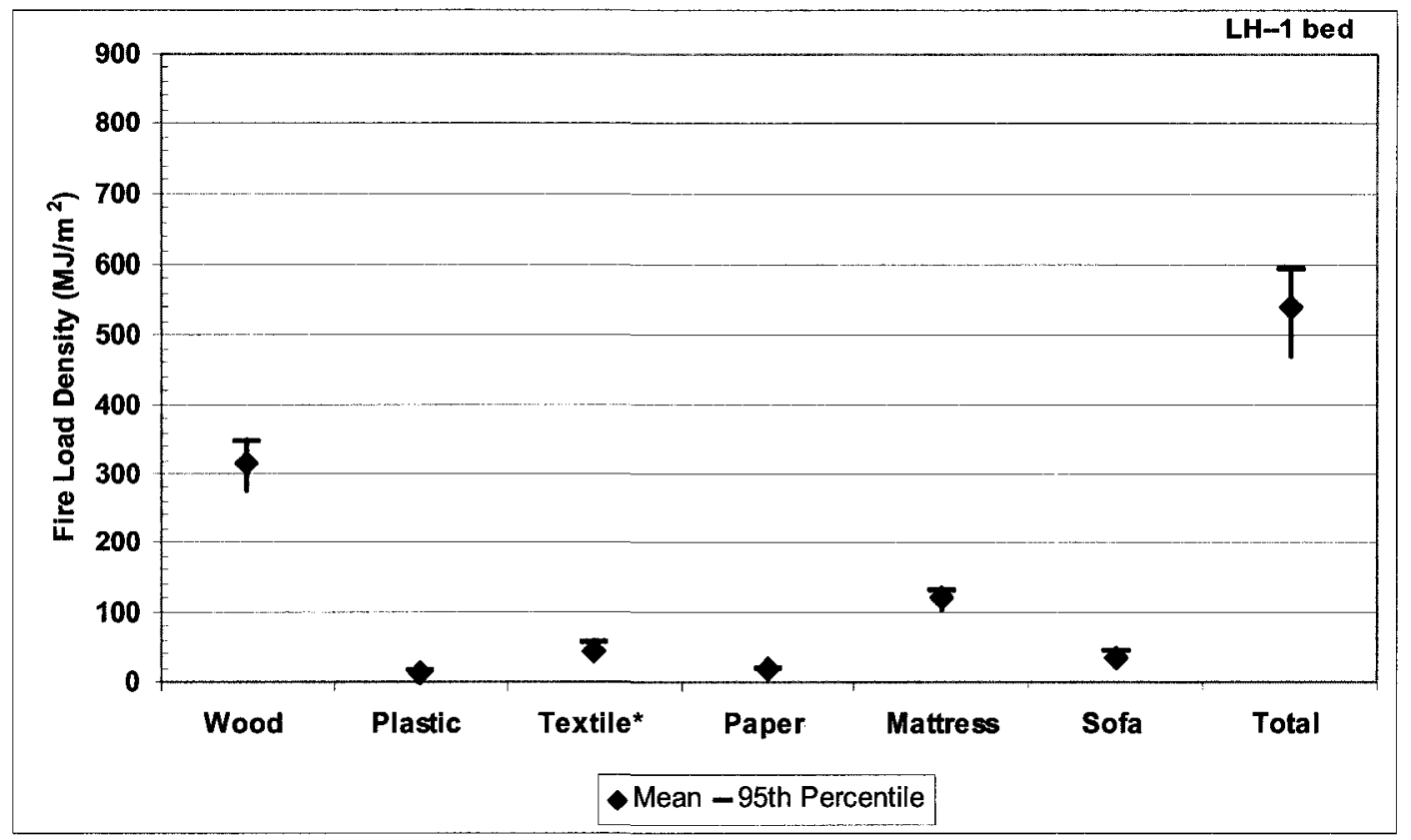

Figure 46 Fire load density of different combustibles in luxury hotel bedrooms with one bed [* Textile includes leather]

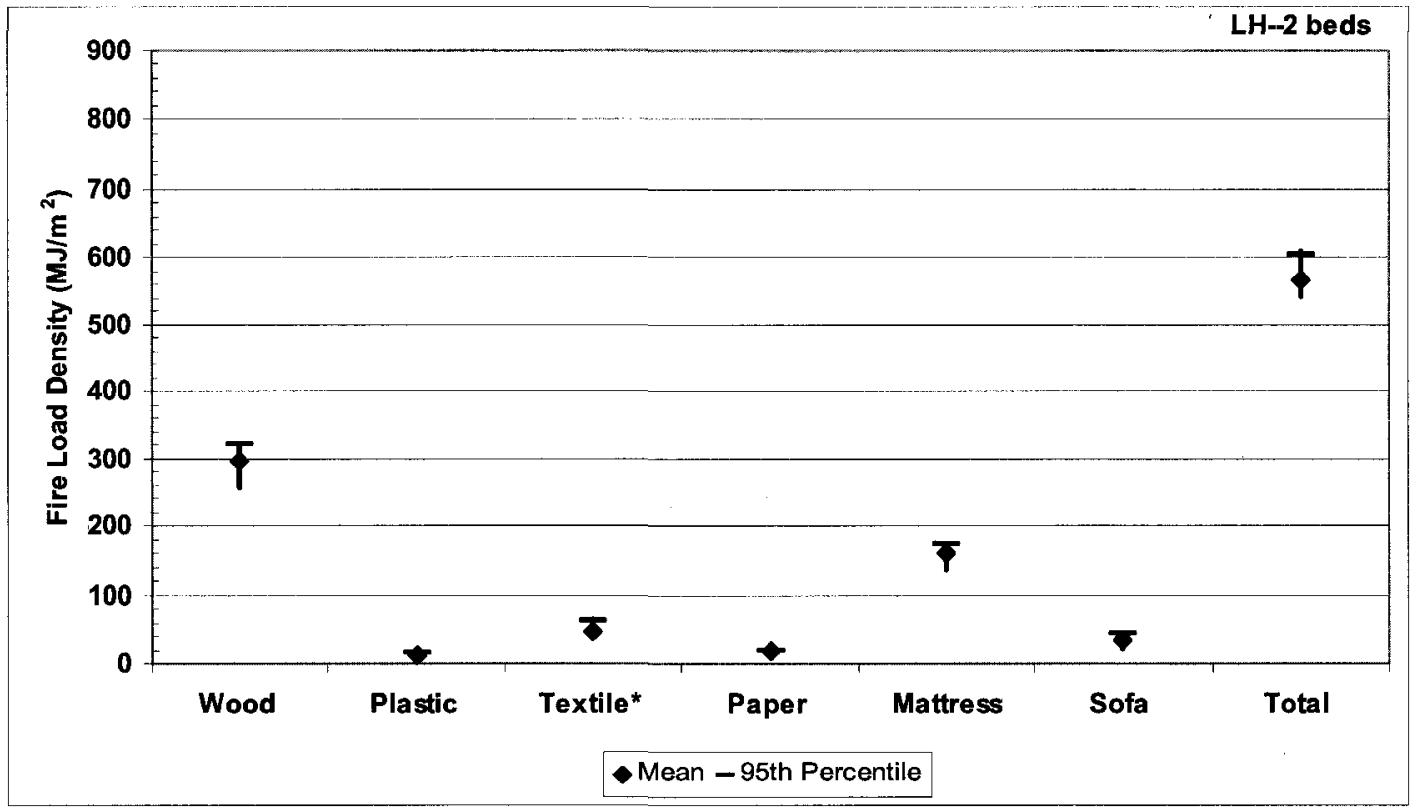

Figure 47 Fire load density of different combustibles in luxury hotel bedrooms with two beds $[*$ Textile includes leather $]$ 


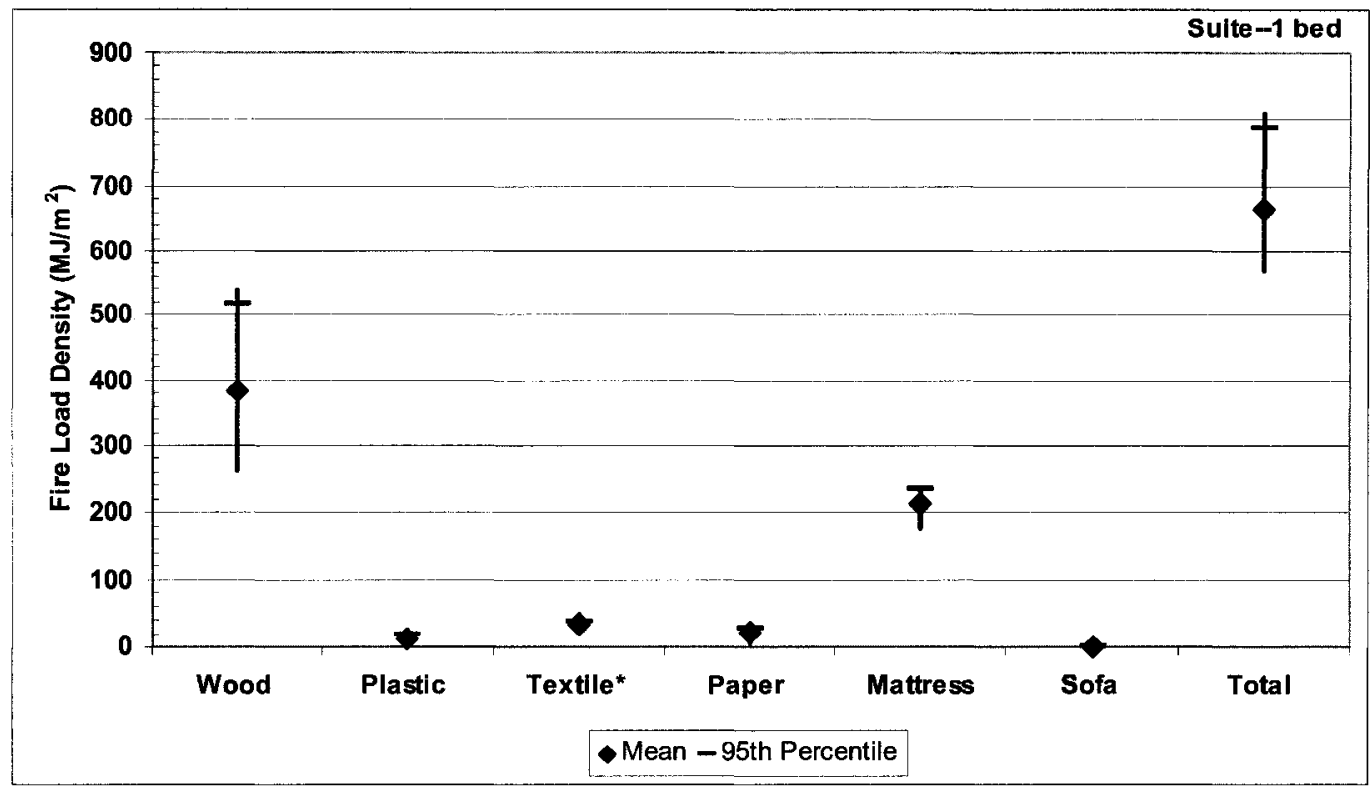

Figure 48 Fire load density of different combustibles in hotel suite bedrooms with one bed [* Textile includes leather]

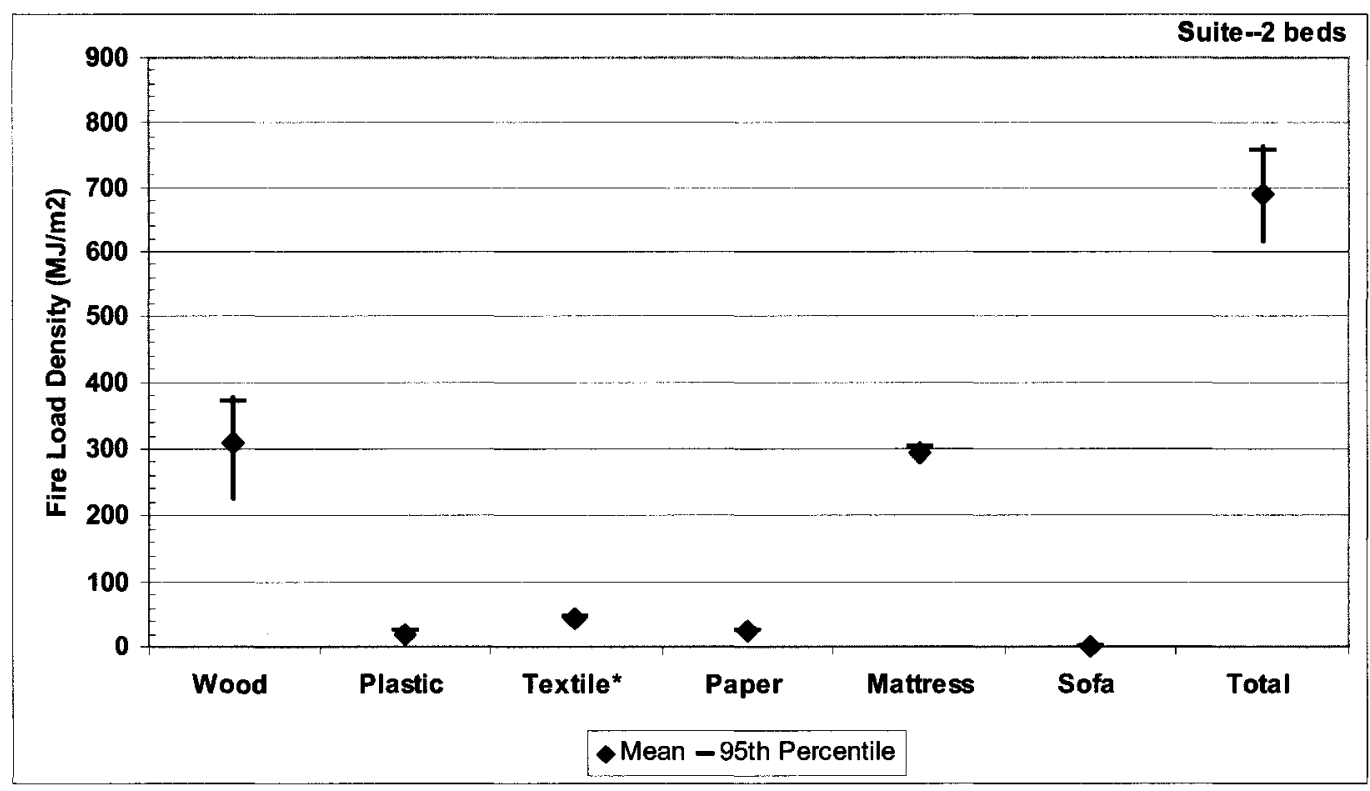

Figure 49 Fire load density of different combustibles in hotel suite bedrooms with two beds [* Textile includes leather] 


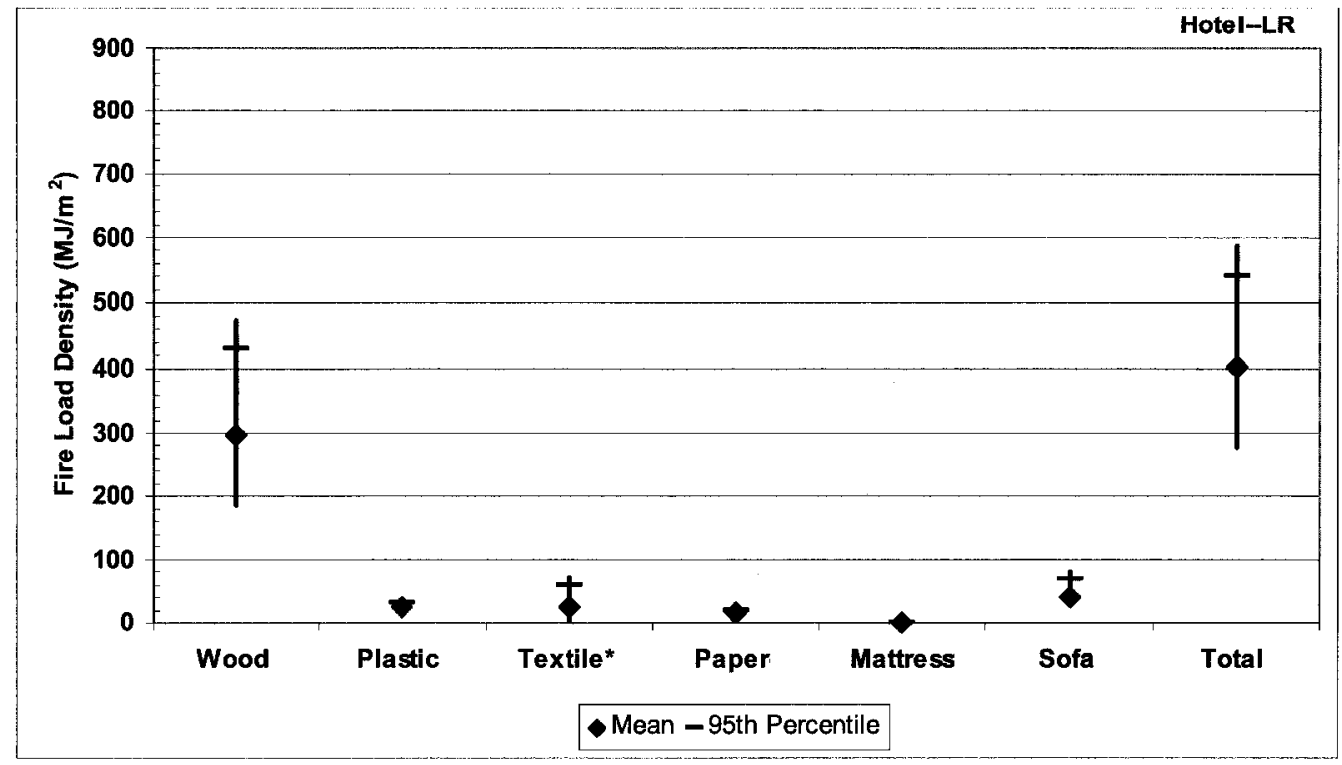

Figure 50 Fire load density of different combustibles in hotel living rooms

[* Textile includes leather]

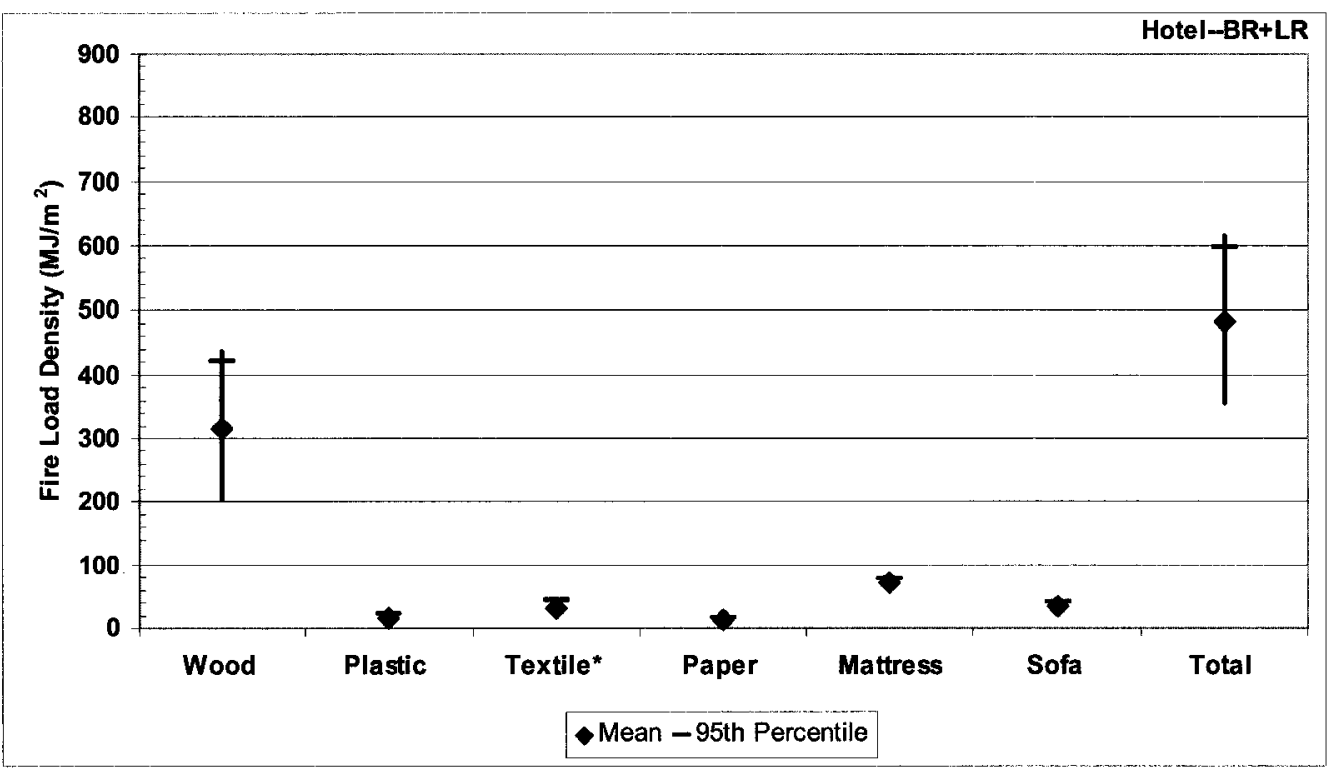

Figure 51 Fire load density of different combustibles in hotel bedrooms plus living rooms without doors in between [* Textile includes leather] 
From Figure 42 to Figure 51, and Table 20, wood has the highest contribution to the total fire load density in all types of motel and hotel guest rooms. Mattresses also provide a high contribution to total fire load density in all of the bedrooms. Textiles (including leather) and sofas each contribute less than $100 \mathrm{MJ} / \mathrm{m}^{2}$ to the total fire load density. Plastic and paper provide less than $50 \mathrm{MJ} / \mathrm{m}^{2}$ each to the total fire load density.

\subsection{Summary and Recommendations}

This chapter presented a description, methodology, and data analysis of a fire load survey, conducted in 10 motels and 12 hotels in Canada's National Capital Region (Ottawa and Gatineau area), from March 2007 to August 2007. The fire load density of different types of motel and hotel guest rooms in different hotel categories was computed. Typical values for floor area, area of openings and percentage of floor area covered by furnishings were reported for different types of guest rooms and hotel categories. The summary of fire load survey data for motels and hotels is given in Table 22 . The results and analysis can be used to develop fuel packages and design fires representing hotels and motels.

The average total fire load density for all the surveyed motels and hotels is $550 \mathrm{MJ} / \mathrm{m}^{2}$, and the standard deviation is $115 \mathrm{MJ} / \mathrm{m}^{2}$. Both types of bedrooms in hotel suites have the highest average total fire load density ranging from 664 to $691 \mathrm{MJ} / \mathrm{m}^{2}$, and the living rooms have the lowest mean value of $401 \mathrm{MJ} / \mathrm{m}^{2}$. Wood provides the highest contribution to the fire load density in all the surveyed guest rooms. 
Table 22 Summaries of Fire load survey data for motels and hotels

\begin{tabular}{|c|c|c|c|c|c|}
\hline \multicolumn{2}{|c|}{ Categories } & \multirow{2}{*}{$\begin{array}{c}\begin{array}{c}\text { Floor Area } \\
\left(\mathrm{m}^{2}\right)\end{array} \\
20.4\end{array}$} & \multirow{2}{*}{$\begin{array}{c}\text { Window Area } \\
\left(\mathrm{m}^{2}\right) \\
2.5\end{array}$} & \multirow{2}{*}{$\begin{array}{c}\text { Floor Coverage } \\
(\%)\end{array}$} & \multirow{2}{*}{$\begin{array}{l}\text { Total Fire Load Density } \\
\qquad\left(\mathrm{MJ} / \mathrm{m}^{2}\right) \\
506.0\end{array}$} \\
\hline ML-1 bed & Mean & & & & \\
\hline & $95 \%$ & 29.4 & 3.3 & 40.2 & 636.8 \\
\hline \multirow{2}{*}{ ML-2 beds } & Mean & 22.9 & 2.5 & 40.3 & 565.5 \\
\hline & $95 \%$ & 29.8 & 3.4 & 48.2 & 714.9 \\
\hline \multirow[t]{2}{*}{ SH-1 bed } & Mean & 22.8 & 4.0 & 34.5 & 590.3 \\
\hline & $95 \%$ & 28.3 & 6.4 & 40.0 & 758.2 \\
\hline \multirow{2}{*}{ SH-2 beds } & Mean & 26.0 & 2.9 & 38.1 & 600.5 \\
\hline & $95 \%$ & 31.9 & 5.2 & 43.3 & 795.4 \\
\hline \multirow[t]{2}{*}{ LH-1 bed } & Mean & 26.2 & 5.9 & 35.3 & 542.6 \\
\hline & $95 \%$ & 32.1 & 9.2 & 40.8 & 593.8 \\
\hline \multirow[t]{2}{*}{ LH-2 beds } & Mean & 28.4 & 5.3 & 34.5 & 567.0 \\
\hline & $95 \%$ & 32.2 & 9.3 & 36.0 & 604.1 \\
\hline \multirow[t]{2}{*}{ Suites-1 bed } & Mean & 13.2 & 1.9 & 37.5 & 663.6 \\
\hline & $95 \%$ & 15.0 & 2.8 & 39.8 & 786.1 \\
\hline \multirow[t]{2}{*}{ Suite- 2 beds } & Mean & 14.6 & 2.0 & 47.1 & 690.9 \\
\hline & $95 \%$ & 17.0 & 2.6 & 49.7 & 756.8 \\
\hline \multirow[t]{2}{*}{ Living Room } & Mean & 29.9 & 3.8 & 28.4 & 401.0 \\
\hline & $95 \%$ & 39.2 & 4.9 & 32.6 & 541.5 \\
\hline \multirow[t]{2}{*}{ BR \& LR } & Mean & 38.7 & 13.2 & 34.8 & 481.7 \\
\hline & $95 \%$ & 51.8 & 22.2 & 41.3 & 596.0 \\
\hline
\end{tabular}

The surveyed bedrooms in motels, standard hotels, and luxury hotels have the $95^{\text {th }}$ percentile of the floor areas ranging from 28 to $32 \mathrm{~m}^{2}$ (excluding bathrooms), and the floor area covered by furnishings ranges from $35.9 \%$ to $48.2 \%$. The bedrooms in hotel 
suites have the lowest $95^{\text {th }}$ percentile of floor areas ranging from 15 to $17 \mathrm{~m}^{2}$ (excluding bathrooms). The 95 percent of hotel living rooms is less than the floor area of $39 \mathrm{~m}^{2}$ (excluding bathrooms, and kitchens with doors), and less than $32 \%$ floor area covered by furnishings.

Most of the surveyed rooms were already cleaned and ready for rent. Guest luggage was not considered in this research. Guest clothes and belongings need to be added to the fuel package to get the total fire load density. 


\section{Chapter 4: Full-Scale Fire Tests}

\subsection{Introduction}

Fire load surveys for motels and hotels have been conducted in Canada's National Capital Region---Ottawa and Gatineau, from March 2007 to August 2007. The surveyed motels included one-storey, two-storey, and three-storey buildings. The surveyed hotels covered hotel ratings from 2-star to 5-star, building ages from 6 years to over 100 years, and storeys from 3 to 24 . All of the surveyed motels and hotels have two main types of bedrooms: bedrooms with one bed and bedrooms with two beds.

Two full-scale fire tests, one representing a bedroom with one bed and the other representing a bedroom with two beds, were conducted at the NRCC/Carleton (National Research Council of Canada/Carleton University) Fire Research Lab. The date of the first

test was October $10^{\text {th }}$ of 2008 , and the second test was conducted on November $12^{\text {th }}$ of 2008. The design of the tests was based on the survey of fire loads and their distribution. The dimensions of the test room for both tests were $3.77 \mathrm{~m} \mathrm{x} 4.17 \mathrm{~m} \mathrm{x} 2.37 \mathrm{~m}$. The room had a smaller floor area than most of the mean values of those in the surveyed bedrooms. For both tests, the room had a window opening with dimensions of $1.5 \mathrm{~m} \mathrm{x} 1.5 \mathrm{~m}$. 
A large hood with dimensions $6.0 \mathrm{~m} \times 6.0 \mathrm{~m}$ was placed above the window soffit to collect the exhaust gases. The mass flow rate, gas temperature, and concentrations of oxygen, carbon dioxide, and carbon monoxide were measured in the exhaust duct for heat release rate calculation, based on the oxygen consumption method. In the test room, thermocouple trees, heat flux gauges, bidirectional probes, and gas analysers were used to measure temperature, heat flux, pressure, and gas concentration.

\subsection{Test Room}

The test room for the two full-scale fire tests was located in the northwest corner of a large burn-hall with dimensions of $52.0 \mathrm{~m} \times 28.5 \mathrm{~m} \mathrm{x} 12.2 \mathrm{~m}$ at the NRCC/Carleton Fire Research Fire Lab. The test room was originally designed for the "Characterization of Fires in Multi-Suite Residential Dwellings (CFMRD)" project, which was initiated by the National Research Council of Canada (NRCC or NRC-IRC) in 2006 for the study of fires in low-rise multi-suite residential dwellings of light-frame construction [63].

The test room was built on a concrete slab with a thickness of $15.2 \mathrm{~cm}$. The walls and roof were constructed using lightweight steel frame. In the CFMRD project, the walls and floor were lined with a layer of cement board, and the ceiling with two layers of gypsum board. The interior dimensions of the test room were $3.8 \mathrm{~m} \mathrm{x} 4.2 \mathrm{~m} \times 2.37 \mathrm{~m}$. Figure 52 shows the construction details of the roof, and Table 23 presents the framing and lining materials used in the CFMRD project [63]. 


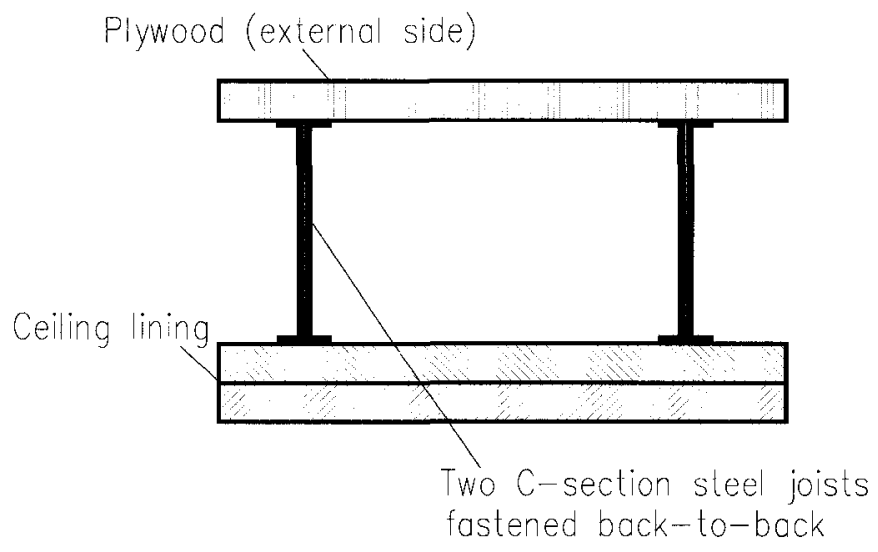

Figure 52 Construction details of the roof in the CFMRD project [63]

Table 23 Framing and lining materials used in the CFMRD project [63]

\begin{tabular}{llll}
\hline & Framing & Interior lining & Exterior lining \\
& Members & & \\
\hline Walls & $\begin{array}{l}152.4 \mathrm{~mm} 14 \text { gauge steel } \\
\text { studs @ 406.4 mm 0.c. }\end{array}$ & $\begin{array}{l}12.7 \mathrm{~mm} \text { cement } \\
\text { board (one layer) }\end{array}$ & $\begin{array}{l}12.7 \mathrm{~mm} \text { cement } \\
\text { board (one layer) }\end{array}$ \\
& $\begin{array}{l}\text { Ceiling / Roof } \\
\text { 152.4 mm steel joists* } 14\end{array}$ & Gypsum board & $15.9 \mathrm{~mm}$ plywood \\
& gauge @ 406.4 mm 0.c. & (two layers) $^{6}$ & (one layer) \\
& none & 12.7 mm cement & Concrete slab \\
& & board (one layer) & \\
\hline
\end{tabular}

* Two joists were fastened back-to-back to strengthen the ceiling and provide an extra flange for attaching the ceiling; ${ }^{6}$ Two layers of $15.9 \mathrm{~mm}$ Type-X gypsum boards

For the two full-scale fire tests in this project, the same test room was used with the same lightweight steel frame, and the same ceiling and floor lining materials as the one used in the CFMRD project. An additional layer of $15.7 \mathrm{~mm}$ Type-X gypsum board was used for the walls on the top of the layer of cement board, due to the severity concern of 
the expected post-flashover fire. The final interior dimensions of the test room for the two full-scale fire tests were $3.77 \mathrm{~m} \mathrm{x} 4.17 \mathrm{~m} \mathrm{x} 2.37 \mathrm{~m}$.

There was a $2.0 \mathrm{~m} \times 0.9 \mathrm{~m}$ doorway in the middle of the north wall, which was closed by a removable door without hinges in both tests. A layer of $15.7 \mathrm{~mm}$ Type-X gypsum board was placed on the inside surface of the door. One window opening with a size of $1.5 \mathrm{~m} \times 1.5 \mathrm{~m}$ was located on the south wall for the two full-scale fire tests.

\subsection{Test Instrumentation and Set-up}

The two full-scale fire tests were designed to simulate two fire scenarios, one in a bedroom with one bed, and another in a bedroom with two beds. The test measurements were categorized into three major parts: instrumentation for the measurement of the heat release rate, instrumentation in the test room, and instrumentation facing the window opening.

\subsubsection{Heat Release Rate (HRR) Measurement}

Heat release rate is one of the most important factors in the study of fire phenomena, and has been widely used to quantify the size of fires. The heat release rate calculation was based on the classical principle of oxygen consumption which states that the same amount of heat is produced per unit mass of oxygen consumed in the fires of many organic materials [43-47]. In this research, Janssen's [47] method was used in the heat release rate calculation for the two full-scale fire tests. 
For heat release rate measurement and calculation, a hood with a dimension of $6.0 \mathrm{x}$ $6.0 \mathrm{~m}$ was built above the window to collect exhaust gases, and a vertical exhaust duct with a diameter of $1.32 \mathrm{~m}(52$ ") was connected to the hood. Figure 53 shows the hood and the exhaust duct. All of the parameters used for heat release rate calculation, such as the mass flow rate, gas temperature, pressure, and concentrations of oxygen, carbon dioxide, and carbon monoxide, were measured in the vertical exhaust duct at about $10 \mathrm{~m}$ height from the top of the window opening, as shown in Figure 54.

The exhaust gases were drawn by three fans, which were located at about $50 \mathrm{~m}$ away from the test room. Each exhaust fan had the capacity of $44 \mathrm{~m}^{3} / \mathrm{s}$. In the two full-scale fire tests, all of the three exhaust fans were set at $75 \%$ of maximum speed. 


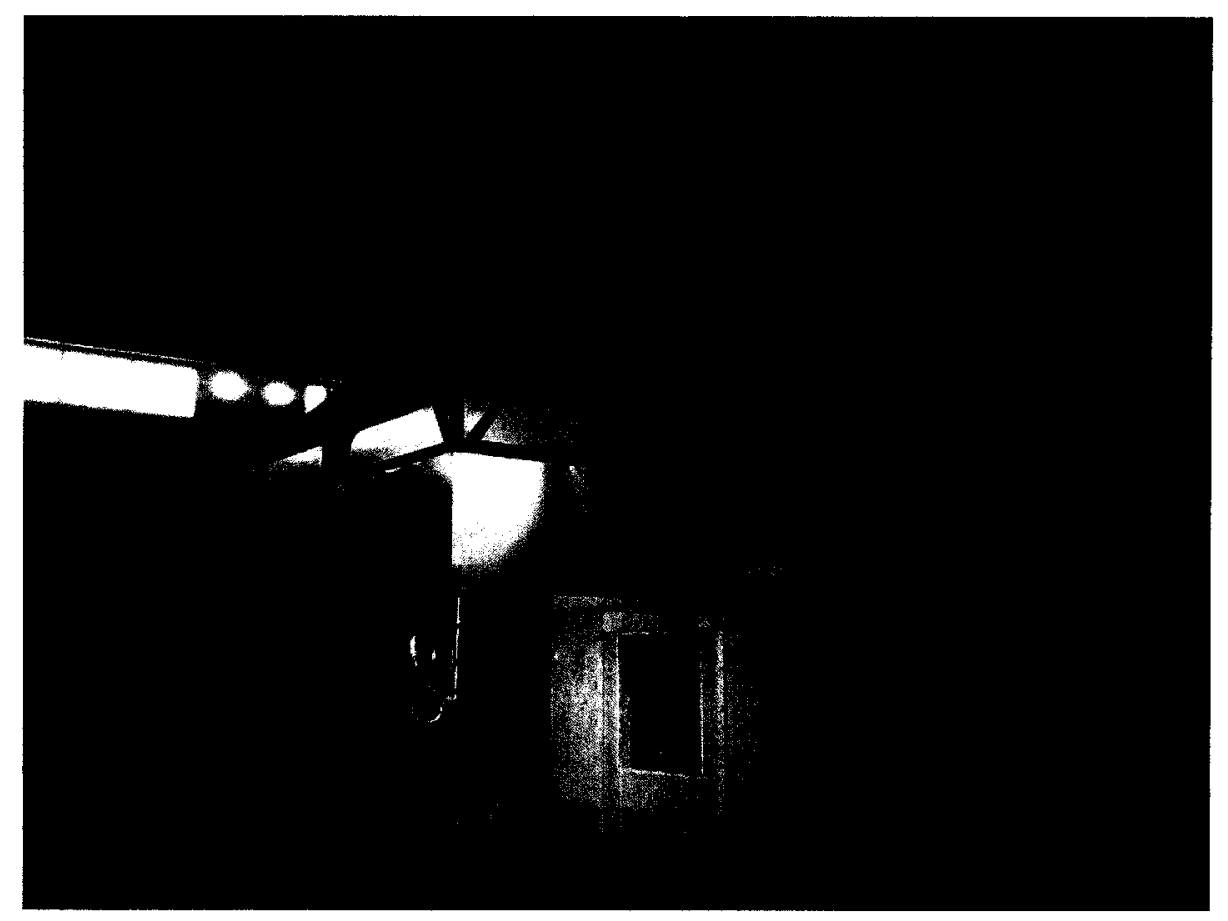

Figure 53 Hood and exhaust duct for heat release rate measurement

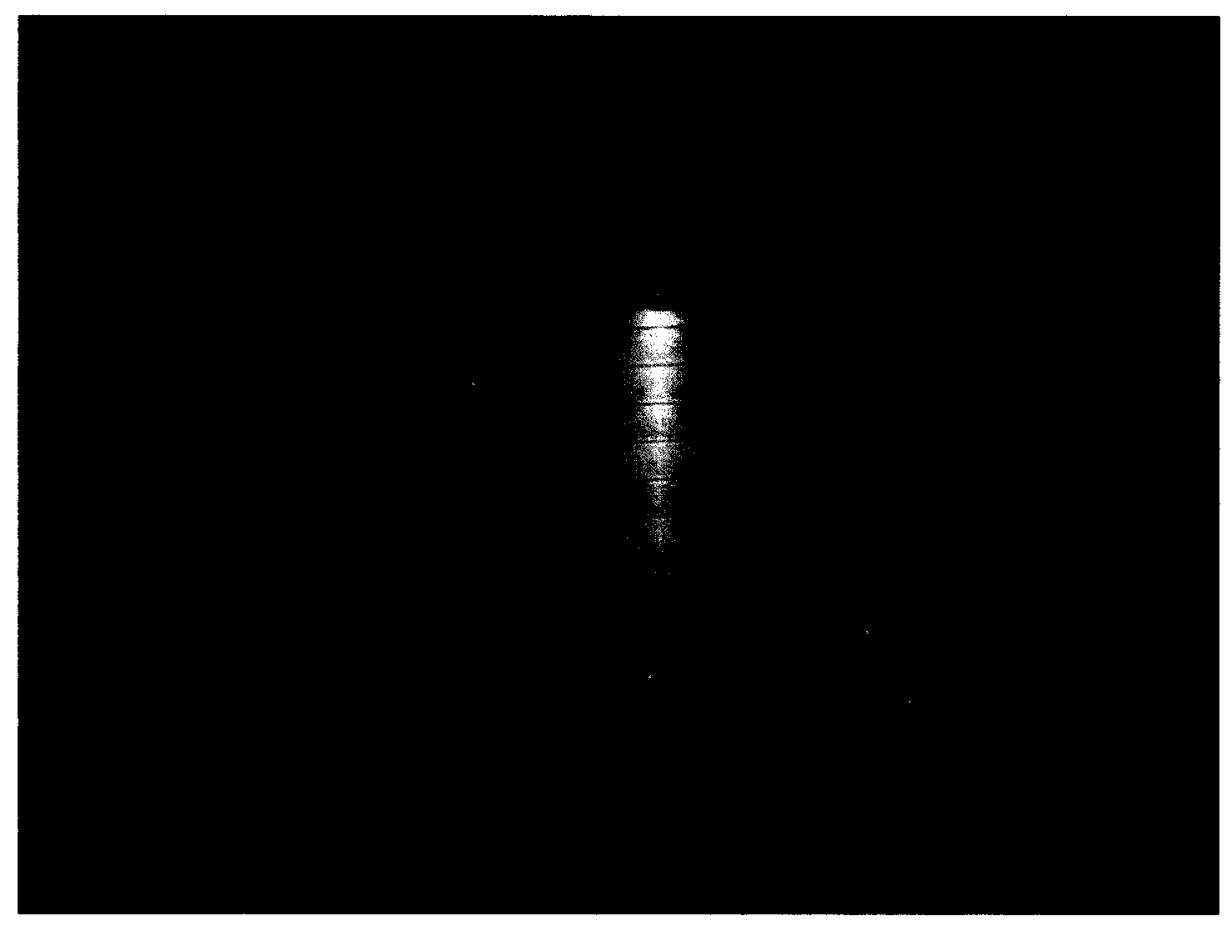

Figure 54 Measurement locations for heat release rate 92 


\subsubsection{Instrumentation in the Test Room}

In the two full-scale tests, a total of eight thermocouple trees, five single thermocouples, six heat flux gauges, four bidirectional probes, and two gas sampling probes were installed in the test room. Figure 55 presents the layout of instrumentation installed inside the room (including the ceiling), on the wall, at the window opening and outside the test room. For the $2^{\text {nd }}$ test, two single beds with a separated distance of $0.67 \mathrm{~m}$ were used instead of one double bed in the $1^{\text {st }}$ test. Figure 56 provides the section view of the instrumentation installed at the window opening.

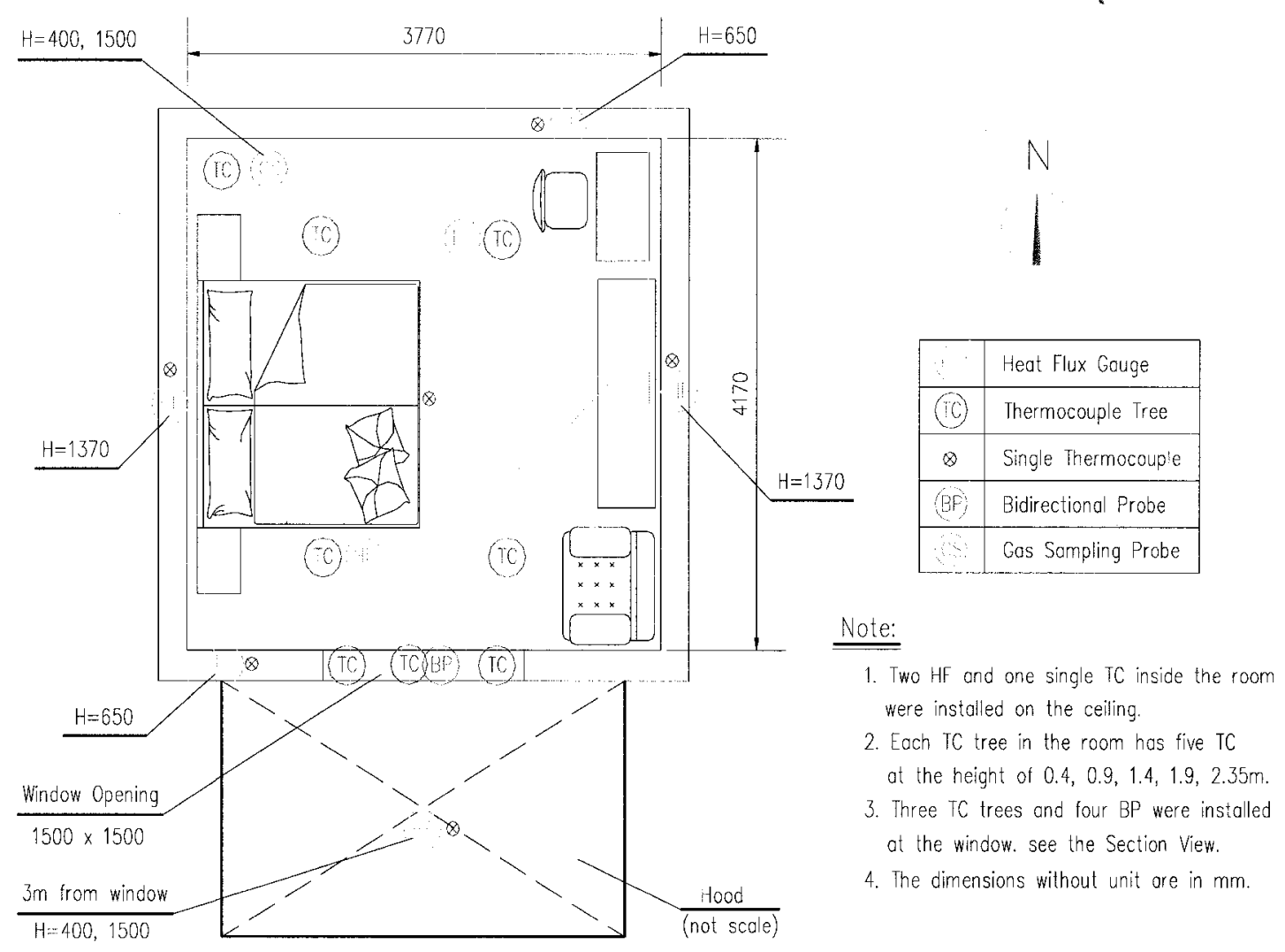

Figure 55 Layout of instrumentation in the test room 


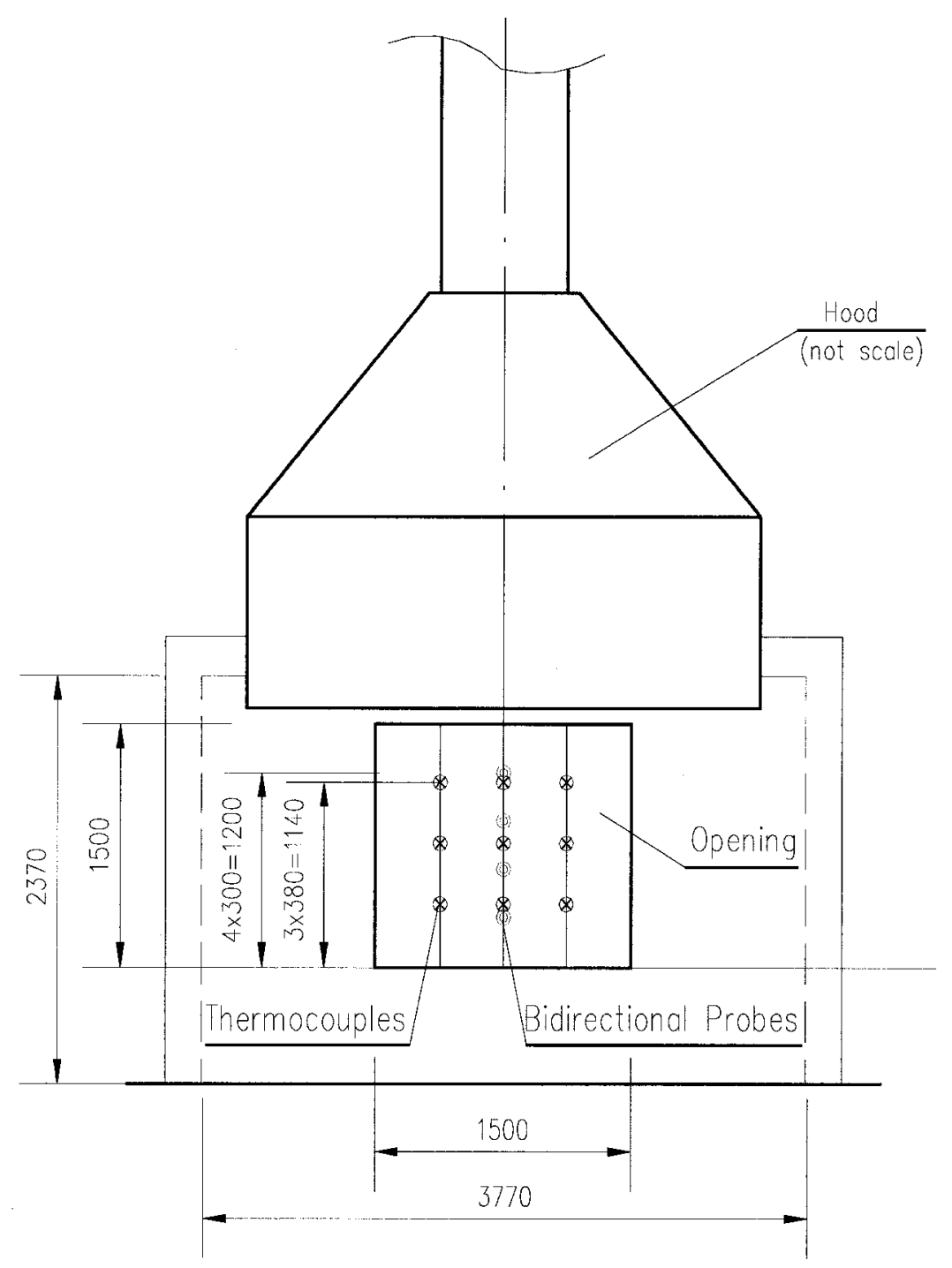

Figure 56 Section view of instrumentation at window opening

\subsubsection{Thermocouples}

The temperature development in the test room during fire tests was measured by five thermocouple trees inside the room, three thermocouple trees at the window opening, one thermocouple in the middle of the room beneath the ceiling, and another four 
thermocouples on the walls attached with heat flux gauges. The locations of the thermocouple trees and the single thermocouples are shown in Figure 55 and Figure 56.

The five thermocouple trees inside the room are labelled as SW (southwest), NW (northwest), NE (northeast), SE (southeast), and NW corner (northwest corner). All of them were suspended from the ceiling, and each thermocouple tree had five thermocouples with an elevation of $0.4 \mathrm{~m}, 0.9 \mathrm{~m}, 1.4 \mathrm{~m}, 1.9 \mathrm{~m}$, and $2.35 \mathrm{~m}$ from the floor. The three thermocouple trees, NE, SE, and NW corner, had the same locations in the two tests, but the location of the other two thermocouple trees, SW and NW, were slightly changed in the north-south direction in the two tests, due to the conflict with the beds. In the first test, the room had one bed, and the thermocouple threes, SW and NW, were located at the two sides of the bed at the same distance from the south and the north wall. In the second test, the room had two beds, and the SW thermocouple tree was located between the window and one of the beds, and the NW thermocouple tree was located between the two beds and close to the middle line of the room.

One single thermocouple was located in the middle of the room and $0.02 \mathrm{~m}$ beneath the ceiling, and four other single thermocouples were located on the walls and mounted with heat flux gauges. Each of the three thermocouple trees at the window opening had three thermocouples, and the section view of their locations is given in Figure 56. All of them were kept at the same locations for the two tests.

Type-K thermocouples were used which have a measuring range of -200 to $1200^{\circ} \mathrm{C}$. The temperature data was directly recorded by the data acquisition system. 


\subsubsection{Heat Flux Gauges}

The rates of heat transfer can be measured by using heat flux gauges. On the ceiling of the test room, two heat flux gauges were installed at locations close to the SW and NE thermocouple trees.

A total of four heat flux gauges were mounted separately on the south, east, north, and west walls. Their locations and elevations are shown in Figure 55. The two heat flux gauges on the east wall and the west wall were placed at the same height of $1.2 \mathrm{~m}$ from the floor, and in the centre line of the wall. The heat flux gauge on the east wall was located above the headboard in the first test and between the two beds in the second test. The heat flux gauge on the west wall was above the TV sets in both tests. The heat flux gauges on the south and north walls were placed at the same height of $0.6 \mathrm{~m}$ from the floor, and $0.8 \mathrm{~m}$ from the west wall and the east wall.

In the first test, one heat flux gauge was placed on the floor to monitor the heat flux to the floor; however, due to the severity of the fire in the first test, the heat flux gauge was damaged, so it was not used in the second test. The damaged heat flux gauge in the first test is shown in Figure 57.

Gardon heat flux gauges were used which have a measuring range of 0 to 10 millivolts. The measured voltage data were converted to heat flux values using the certified calibration factor for each heat flux gauge that has been provided by the manufacturer. 


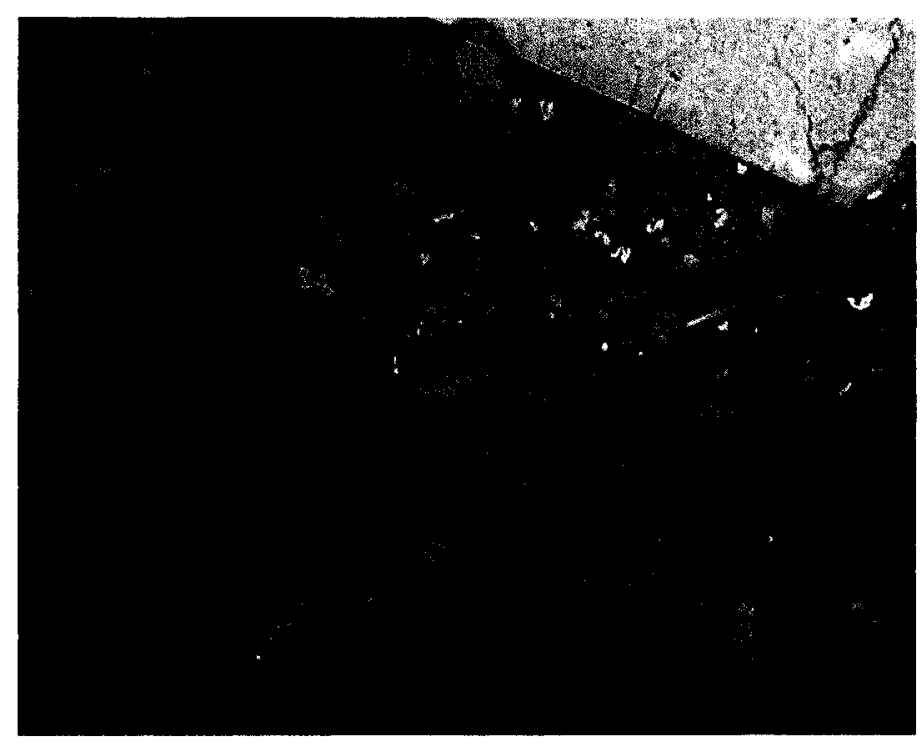

Figure 57 Damaged heat flux gauge on the floor

\subsubsection{Bidirectional Probes}

Four bidirectional probes were installed in the middle line of the window opening, in order to monitor gas movement through the opening. Their locations and elevations are given in Figure 55 and Figure 56.

TT series Autozeroing Micromanometers were used to measure the differential pressures with a measuring range of 0 to 1 volts. The measured voltage data were converted to the pressure in Pascal by using the correlation factors derived from the operating manual for the TT series instruments.

\subsubsection{Gas Analysers}

Two gas analysis probes, at heights of $0.4 \mathrm{~m}$, and $1.5 \mathrm{~m}$ from the floor, were installed on the north wall $0.9 \mathrm{~m}$ deep inside the room. The mole concentrations of oxygen, carbon 
dioxide, and carbon monoxide were measured at these two locations, so that the changes of gas concentrations at the two different smoke layer heights can be compared.

The range of the gas analysers was set at 4 to 20 millivolts, and the different conversion factors were used to calculate the mole concentrations of oxygen, carbon dioxide, and carbon monoxide.

\subsubsection{Instrumentation facing the Window Opening}

Two heat flux gauges combined with two thermocouples were placed outside the test room at a distance of $3 \mathrm{~m}$ from the window. In addition, two infrared cameras and one digital video camera were set outside the test room at a distance of about 5 to 6 metres. The layout of instrumentation outside the test room is shown in Figure 55.

\subsubsection{Heat Flux Gauges and Thermocouples}

To measure the heat flux from the flame exiting the window opening, two heat flux gauges were installed on a moveable steel post at a height of $1.45 \mathrm{~m}$ and $2.08 \mathrm{~m}$ from the room floor level, and the steel post was placed outside the test room and opposite to the middle line of the window opening at a distance of $3 \mathrm{~m}$.

Gardon heat flux gauges were also used with a measuring range of 0 to 10 millivolts. The measured voltage data were converted to the heat flux values by using the certified calibration factor for each heat flux gauge that has been provided by the manufacturer. 
Each heat flux gauge was attached with a Type-K thermocouple to measure the temperature. The measuring range of the thermocouples was from -200 to $1200^{\circ} \mathrm{C}$. The temperature data were directly recorded by the data acquisition system.

\subsubsection{Infrared Camera}

Two FLIR infrared cameras (model: P640 \& SC640) were used to take thermo-pictures and monitor temperature developments of the flame and the south exterior wall. The infrared cameras can measure temperatures at a range of -40 to $2000^{\circ} \mathrm{C}$.

\subsubsection{Digital Video Camera and Still Camera}

One Sony digital video (model: HDR-SR7) camera and two digital still cameras were used to take videos and pictures during the tests.

\subsection{Furnishings Used in the Two Tests}

Two full-scale fire tests were designed to simulate hotel room fires in a bedroom with one bed and a bedroom with two beds. The $3 \mathrm{D}$ views of the two tests from Smokeview software [64] are given in Figure 58 and Figure 59. The items used in the two tests include mattress, mattress boxes, headboards, footboards, dressers, desks, chairs, sofas, beddings, and TV etc, which are listed in Table 24 and Table 25. A total of 25 items with a total weight of $330.8 \mathrm{~kg}$ were used in the first test, and a total of 22 items with a total weight of $318.5 \mathrm{~kg}$ were used in the second test. 
The fire loads for wood, textile, plastic, paper, and carpets were kept approximately the same for the two tests. The major difference of the two tests is that one double bed with a top surface area of $3.04 \mathrm{~m}^{2}$ was used in the first test, and two single beds with a total top surface area of $3.57 \mathrm{~m}^{2}$ and a separate distance of $0.65 \mathrm{~m}$ were used in the second test. Another difference is the weights of the two upholstered single sofas, which had similar polyurethane foam as the mattresses. The first test had a fire load density of 397.2 $\mathrm{MJ} / \mathrm{m}^{2}$, and the second test had a fire load density of $366.1 \mathrm{MJ} / \mathrm{m}^{2}$, details of which are given in Table 26.

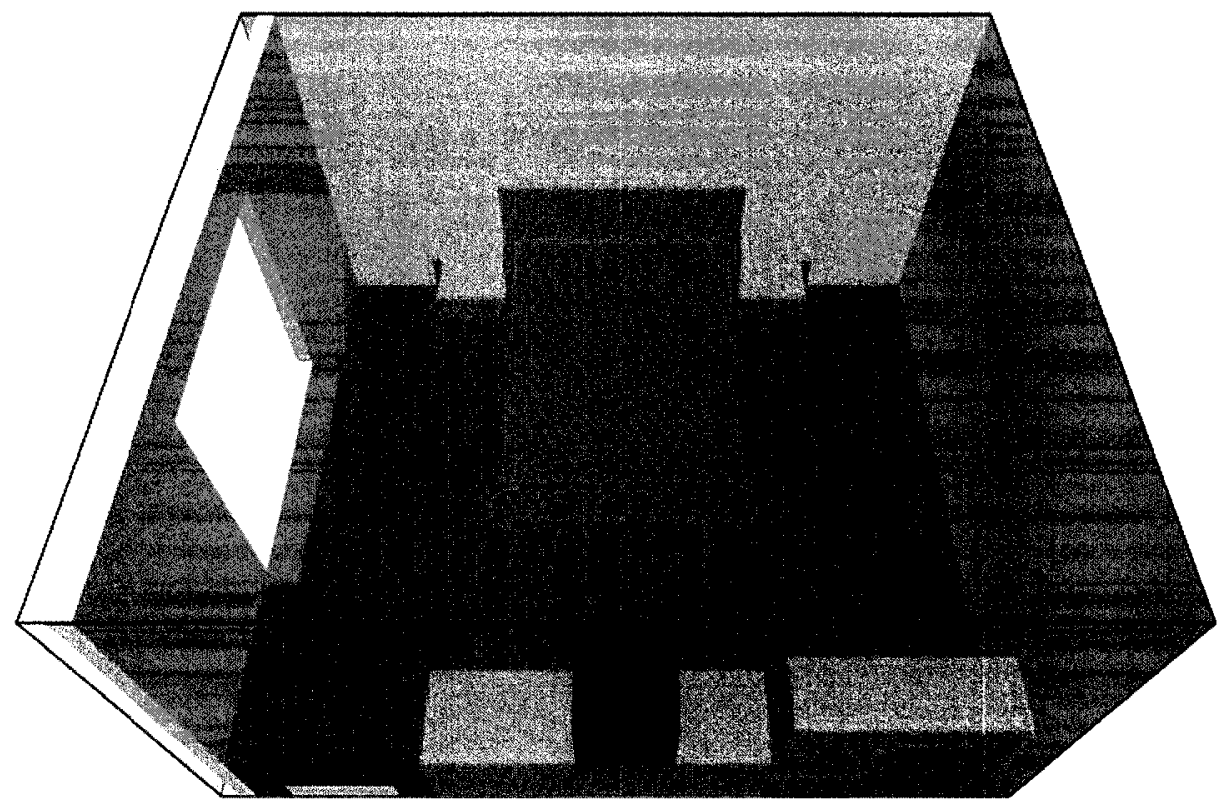

Figure 58 3D layout of the test room for the $1^{\text {st }}$ test 


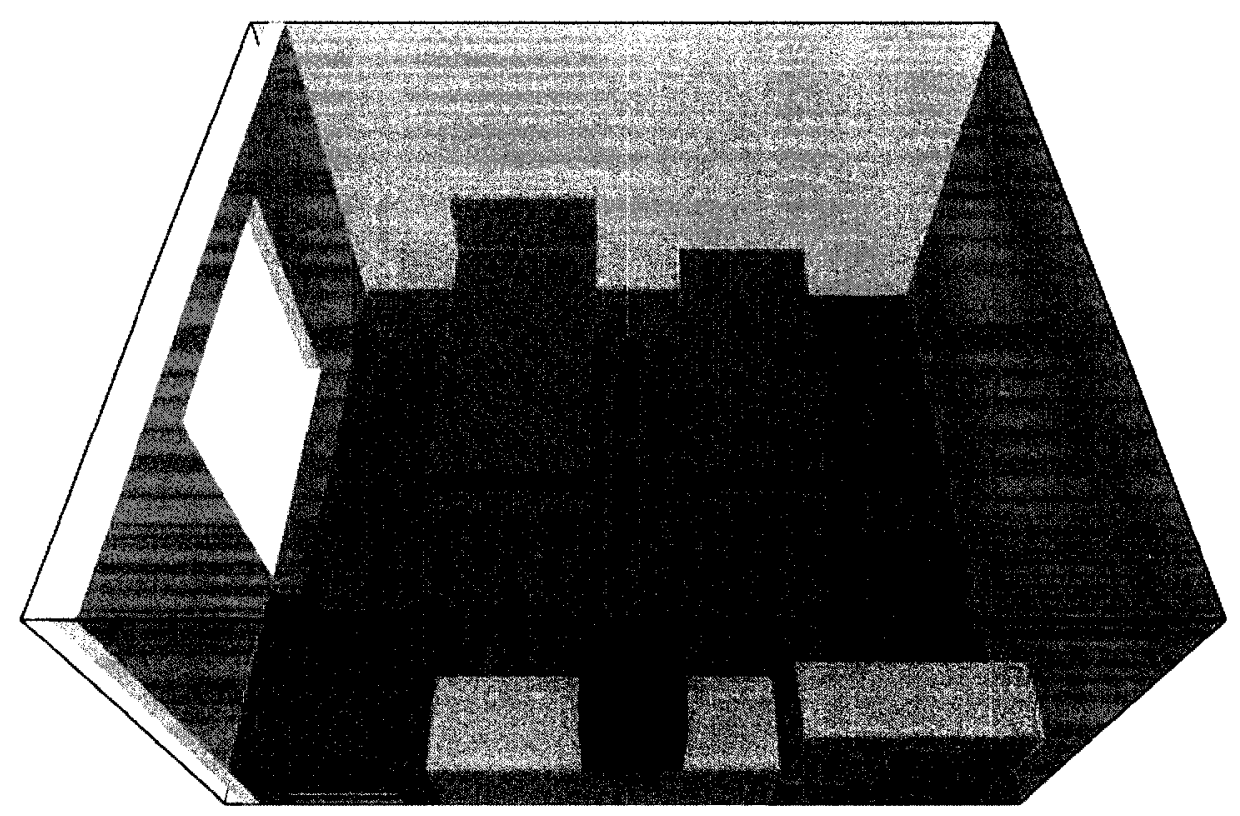

Figure 59 3D layout of the test room for the $2^{\text {nd }}$ test

Table 24 Items used in the first test

\begin{tabular}{lccc}
\hline \multicolumn{1}{c}{ Items } & Qty & Dimensions (m) & Mass (kg) \\
\hline Furniture: & & & \\
Double Bed headboard & 1 & $1.68 \times 1.20 \times 0.045$ & 14.8 \\
Double Bed footboard & 1 & $1.64 \times 0.6 \times 0.055$ & 10.0 \\
Double Mattress & 1 & $2.00 \times 1.52 \times 0.24$ & 36.8 \\
Double Mattress Box & 1 & $2.01 \times 1.52 \times 0.25$ & 37.5 \\
Sofa Chairs & 1 & $1.02 \times 0.97 \times 0.80$ & 38.0 \\
Nightstands & 2 & $0.52 \times 0.37 \times 0.58$ & 15.2 \\
Desks & 1 & $1.22 \times 0.44 \times 0.77$ & 27.5 \\
Chairs & 1 & $0.55 \times 0.59 \times 0.81$ & 11.3 \\
Dressers & 1 & $1.83 \times 0.46 \times 0.61$ & 61.5 \\
\hline Beddings: & & & 2.6 \\
Quilts & 1 & & 2.0 \\
Pillows & 3 & & 4.2 \\
Bed Covers \& Sheets & 1 & & 30.8 \\
\hline Electronics: & & & 0.1 \\
Televisions & 1 & $0.65 \times 0.50 \times 0.58$ & 6.2 \\
Telephone--handset & 1 & $0.16 \times 0.05 \times 0.03$ & \\
Printer & 1 & $0.45 \times 0.24 \times 0.18$ & \\
\hline & & 101 & \\
& & & \\
\hline
\end{tabular}




\begin{tabular}{lccc}
\hline Others: & & & \\
Telephone books & 2 & & 3.8 \\
Rubbish Bins & 1 & & 0.3 \\
Carpet-1 & 1 & $2.40 \times 1.56 \times 0.003$ & 8.6 \\
Carpet-2 & 1 & $2.45 \times 1.53 \times 0.003$ & 6.3 \\
Carpet-3 & 1 & $2.33 \times 1.68 \times 0.003$ & 9.6 \\
Carpet-4 & 1 & $1.66 \times 1.14 \times 0.003$ & 3.7 \\
\hline Sum: & 25 & & 330.8 \\
\hline
\end{tabular}

Table 25 Items used in the second test

\begin{tabular}{lccc}
\hline \multicolumn{1}{c}{ Items } & Qty & Dimensions (m) & Mass $(\mathrm{kg})$ \\
\hline Furniture: & & & \\
Single Bed headboard & 1 & $1.02 \times 0.86 \times 0.055$ & 6.1 \\
Single Mattress-1 & 1 & $1.88 \times 0.95 \times 0.18$ & 14.8 \\
Single Mattress-2 & 1 & $1.88 \times 0.95 \times 0.18$ & 17.0 \\
Single Mattress Box-1 & 1 & $1.83 \times 0.98 \times 0.19$ & 18.5 \\
Single Mattress Box-2 & 1 & $1.83 \times 0.98 \times 0.19$ & 18.2 \\
Sofa Chairs & 1 & $0.82 \times 0.70 \times 1.00$ & 23.7 \\
Nightstands & 2 & $0.59 \times 0.48 \times 0.56$ & 39.4 \\
TV stand & 1 & $0.80 \times 0.45 \times 0.60$ & 27.9 \\
Desks & 1 & $1.07 \times 0.60 \times 0.74$ & 29.3 \\
Chairs & 1 & $0.55 \times 0.58 \times 0.81$ & 11.3 \\
Dressers & 1 & $1.39 \times 0.48 \times 0.41$ & 28.3 \\
\hline Bedding: & & & 1.5 \\
Pillows & 2 & & 7.5 \\
Bed Covers \& sheets & 2 & & \\
Blankets & & & \\
\hline Electronics: & & & 13.1 \\
Televisions & 1 & $0.76 \times 0.48 \times 0.59$ & 318.5 \\
\hline Others: & & & 3.8 \\
Telephone books & 2 & & 0.3 \\
Rubbish Bins & 1 & & \\
Carpet-1 & 1 & $3.15 \times 1.22 \times 0.003$ & \\
Carpet-2 & 1 & $1.80 \times 1.58 \times 0.003$ & \\
\hline Sum: & 22 & & \\
\hline & & & \\
\hline
\end{tabular}

102 
Table 26 Fire load density for the two tests

\begin{tabular}{lcccccccc}
\hline & Wood & Plastic & Textile & Paper & Mattress & Sofa & Carpet & Sum \\
\hline Test 1-FLD $\left(\mathrm{MJ} / \mathrm{m}^{2}\right)$ & 210.4 & 18.8 & 10.5 & 4.1 & 74.0 & 45.7 & 33.7 & 397.2 \\
Test 2-FLD $\left(\mathrm{MJ} / \mathrm{m}^{2}\right)$ & 211.8 & 17.3 & 10.8 & 4.1 & 63.9 & 28.5 & 29.7 & 366.1 \\
\hline
\end{tabular}

\subsection{Test Results and Data Analysis}

\subsubsection{Test Observation and Record}

Two full-scale fire tests were conducted in a test room with interior dimensions of $3.77 \mathrm{~m}$ x $4.17 \mathrm{~m} \times 2.37 \mathrm{~m}$ at NRCC/Carleton (National Research Council of Canada/Carleton University) Fire Research Lab. The date of the first test was October 10, 2008, and the date of the second test was November 12, 2008.

In both tests, the exhaust fans were set at $75 \%$ of the maximum speed. All of the doors in the burning-hall were closed, except the door at the south end, which is about $45 \mathrm{~m}$ from the test room. The gas analysers were calibrated on the test day by NRCC staff, and the other instruments, such as thermocouples, heat flux gauges, were checked with the data acquisition system one and two days before the test day.

For the two tests, the same propane burner was used as the ignition source at a flow rate of $6.6 \mathrm{~L} / \mathrm{min}$ for 50 seconds. The burner was vertically placed beside the beds, at the side close to the window opening. The burner was located at a distance of $0.03 \mathrm{~m}$ from the side of the beds, and a distance of $0.85 \mathrm{~m}$ from the foot end of the beds. Figure 60 shows the start of the fire of the first test. 
A test record sheet was prepared for the test day to record main observations during the tests. This information was also verified by reviewing digital videos and photos. Table 27 provides the time frames of fire development in the two tests.

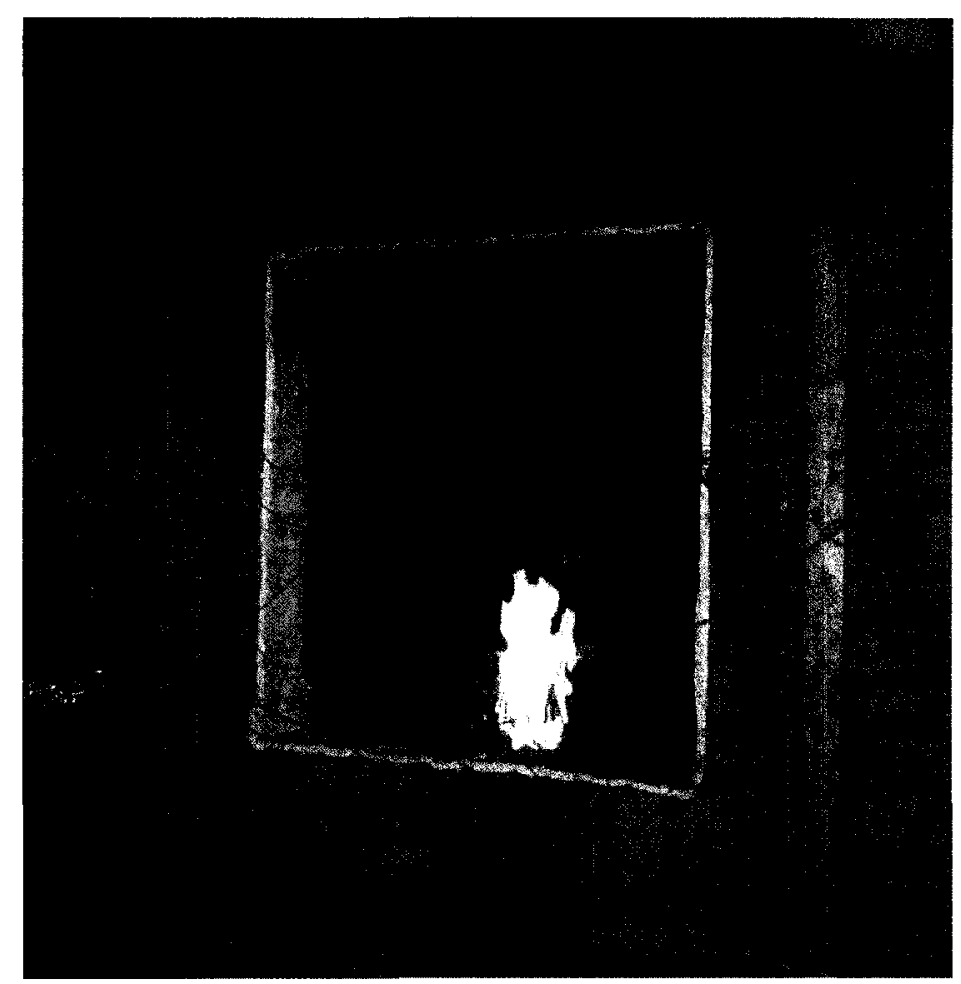

Figure 60 The start of the fire in the $\mathbf{1}^{\text {st }}$ test

Table 27 Records of the two tests

\begin{tabular}{lccc}
\hline \multirow{2}{*}{ Test Record } & Test 1 & & Test 2 \\
\cline { 2 - 3 } Burner ignites & $(\mathrm{sec})$. & $(\mathrm{sec})$. \\
Burner turn off & 00 & 000 \\
Flame reach ceiling & 50 & 50 \\
Smoke flow out of window & 195 & 140 \\
Flame issues out of window & 210 & 160 \\
Second item ignites & 240 & 180 \\
Flashover & Could not see & & Could not see \\
TV explosion & 240 & & 180 \\
\hline
\end{tabular}

104 


\begin{tabular}{lcc}
\hline Decay starts & 780 & 900 \\
Fire comes out of the door & $\sim 1500$ & No \\
Test terminated & 1785 & 1325 \\
\hline
\end{tabular}

\subsubsection{Heat Release Rate}

Heat release rate calculation was based on the oxygen consumption principle, using the equations developed by Janssen [47]. The input data include temperature, mass flow rate, and gas concentration that were measured in the exhaust system. The delay times of the gas analysers were estimated by comparing the two curves of gas temperature and oxygen concentration. The estimated delay time for both tests was 26 seconds. Figure 61 , Figure 62, Figure 63 and Figure 64 present the curves of gas temperature and oxygen concentration before and after using delay time in the two tests.

The same pilot burner was ignited for 50 seconds in both tests. The following test description and plotted figures use the start time of pilot ignition as the start of the test. The calculated heat release rates for the two full-scale tests are presented in Figure 65. 


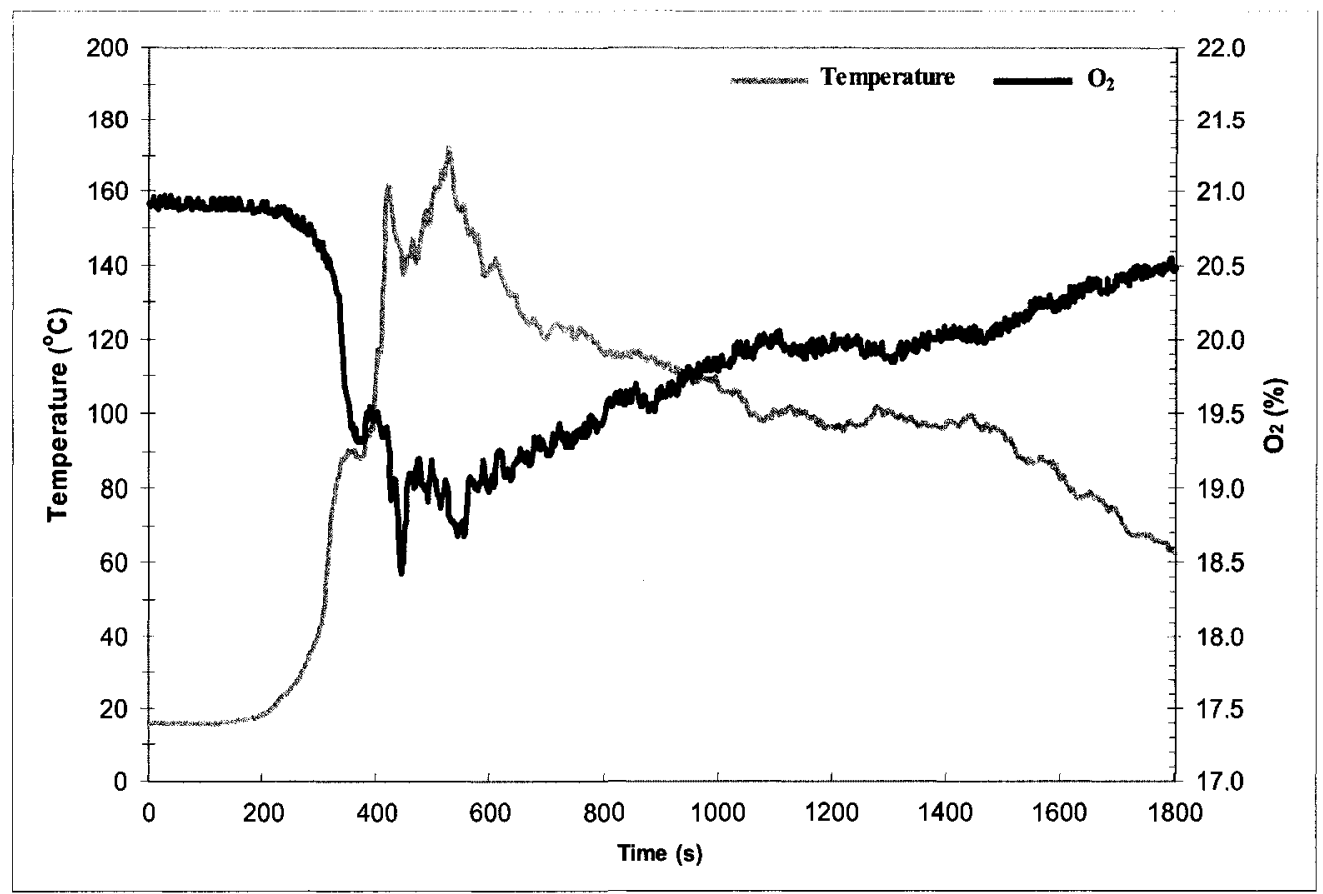

Figure 61 Temperature and $\mathrm{O}_{2}$ concentration before using the delay time for $1^{\text {st }}$ test

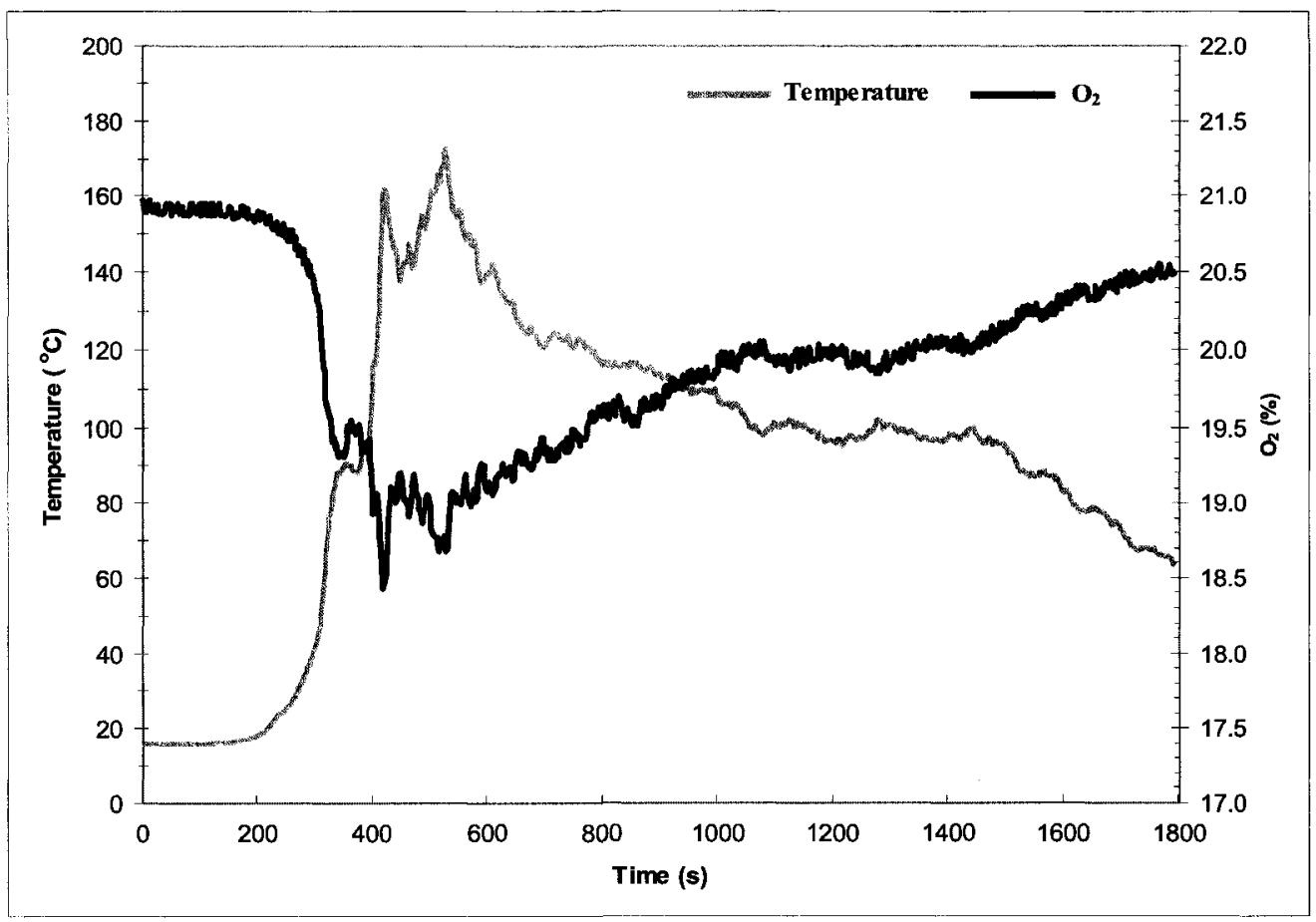

Figure 62 Temperature and $\mathrm{O}_{2}$ concentration after using the delay time for $1^{\text {st }}$ test 106 


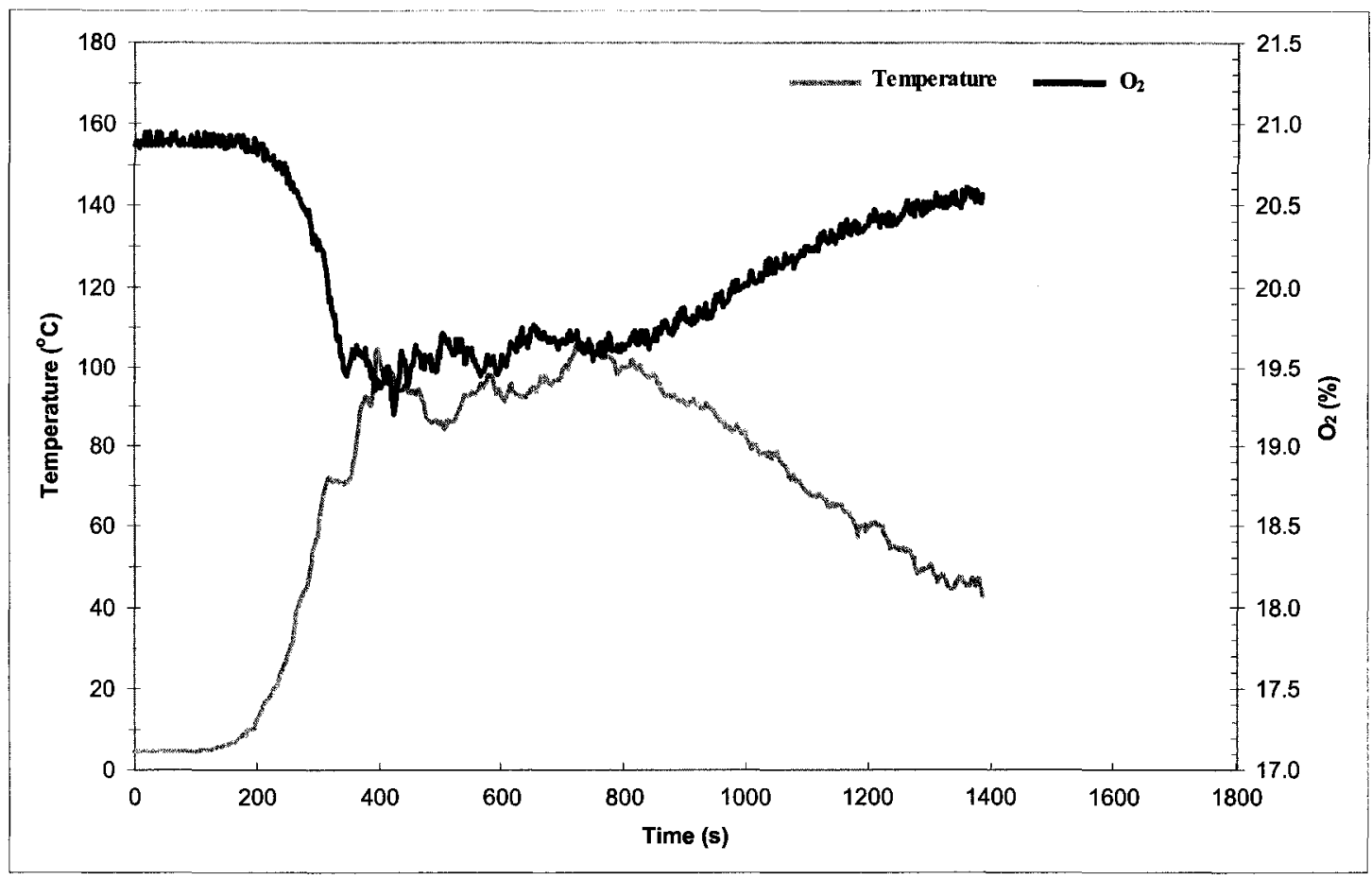

Figure 63 Temperature and $\mathrm{O}_{2}$ concentration before using the delay time for $2^{\text {nd }}$ test

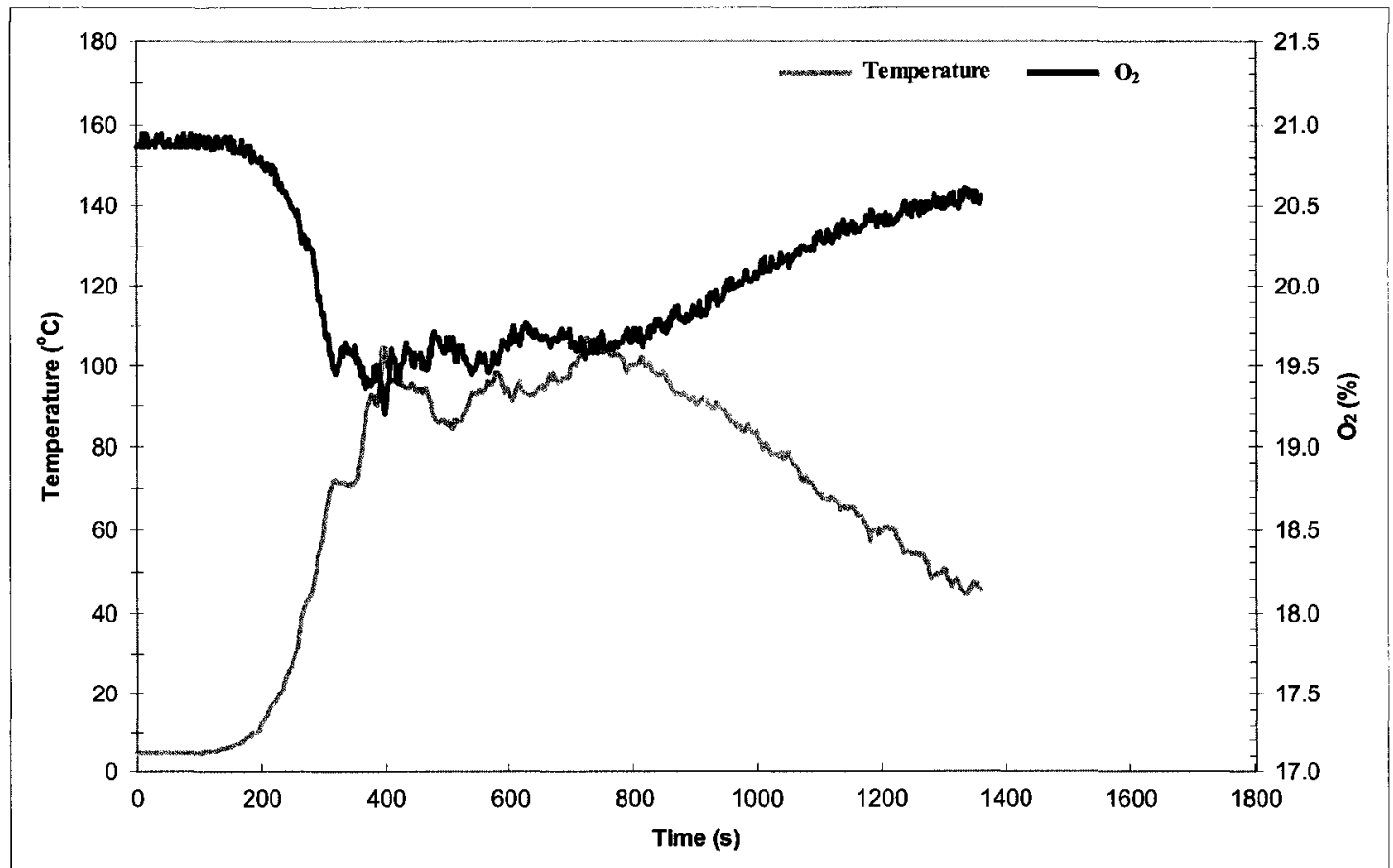

Figure 64 Temperature and $\mathrm{O}_{2}$ concentration after using the delay time for $2^{\text {nd }}$ test 107 


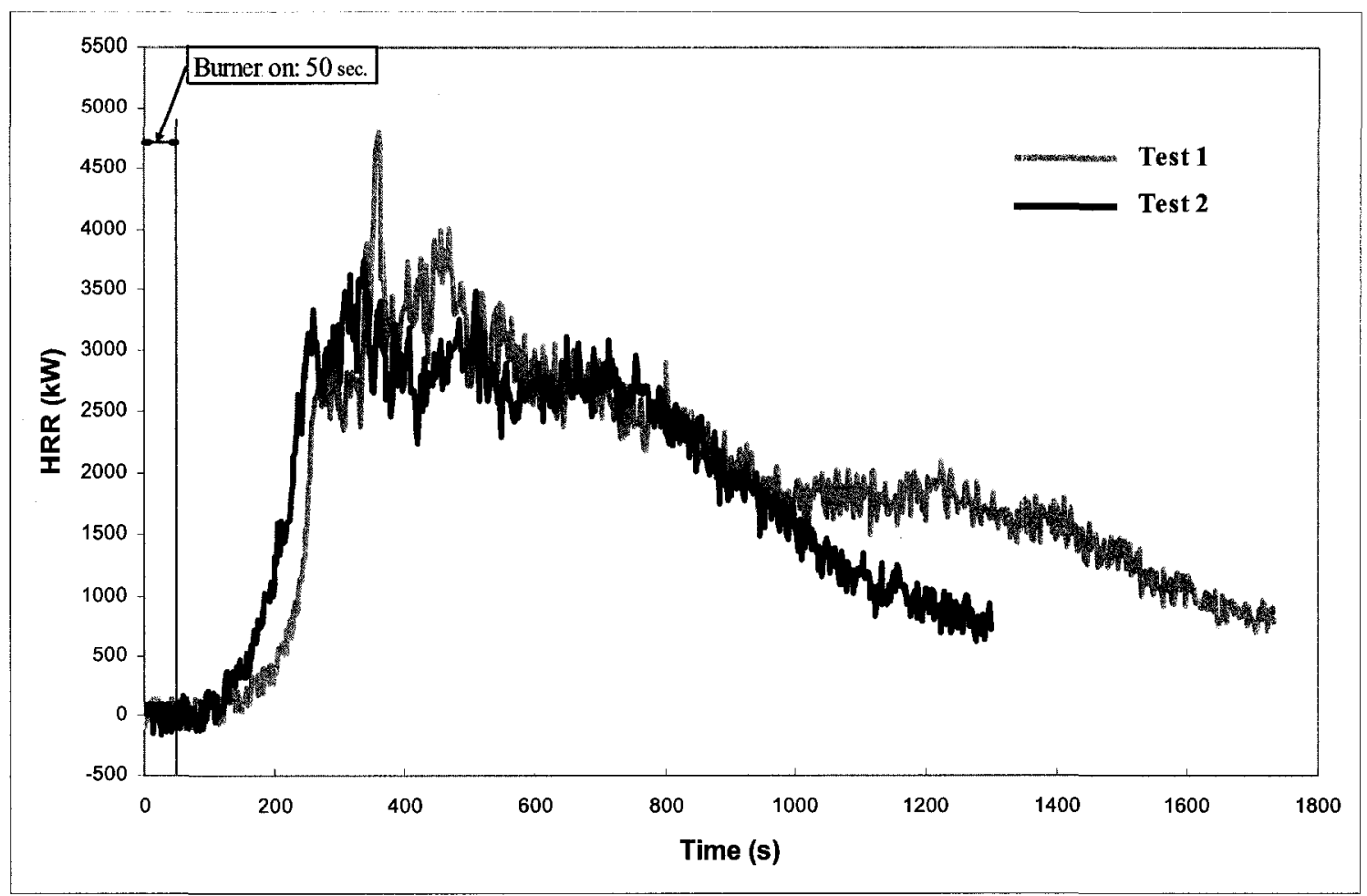

Figure 65 Heat release rates for the two full-scale tests

The plot of the heat release rates of the two tests depicted in Figure 65 shows that the fire in the first test developed faster than the fire in the second test in the early stage. The time that the heat release rate reached $500 \mathrm{~kW}, 1000 \mathrm{~kW}$, and $1500 \mathrm{~kW}$ in the first test was about 30 to 50 seconds earlier than that in the second test. The reason could be the different material layers of the ignited side of the mattresses.

For both tests, the maximum values of heat release rates occurred at the second peak. The maximum value of the heat release rate in the first test reached $4809 \mathrm{~kW}$ at 360 seconds (6 minutes), which is about $1 \mathrm{MW}$ higher than the maximum value of the heat release rate in the second test that was $3735 \mathrm{~kW}$ at 338 seconds (5.6 minutes). In comparison with the two single beds in the second test, the one double bed in the first test 108 
had a higher and more condensed fire load, which could contribute to the higher maximum value of the heat release rate. The third peak value of heat release rate in the first test is also higher than that in the second test by about $0.5 \mathrm{MW}$. This is reasonable as the fire load of the sofa chair in the first test was higher than that of the sofa used in the second test.

In the first test, there is a period of 400 seconds during which the heat release rate levels off during the decay stage. This phenomenon does not appear in the second test. This may be due to the type of furniture used in the first test, which had a dresser made of heavy solid timber. The characteristic heat release rate values for the two tests are listed in Table 28.

Table 28 Characteristic values of heat release rate in the two tests

\begin{tabular}{lccccc}
\hline & \multicolumn{2}{c}{ Time (s) } & & \multicolumn{2}{c}{ HRR (kW) } \\
\cline { 2 - 3 } \cline { 5 - 6 } & Test 1 & Test 2 & & Test 1 & Test 2 \\
\hline HRR at $500 \mathrm{~kW}$ & 210 & 156 & & 518 & 528 \\
HRR at $1000 \mathrm{~kW}$ & 236 & 194 & & 1033 & 1007 \\
HRR at $1500 \mathrm{~kW}$ & 250 & 218 & & 1511 & 1527 \\
1st peak HRR & 292 & 260 & & 2965 & 3326 \\
2nd peak HRR & 360 & 338 & & 4809 & 3735 \\
3rd peak HRR & 468 & 510 & & 4006 & 3470 \\
1st decay starts & 550 & 772 & & 3250 & 2714 \\
2nd decay starts & 1392 & no & & 1612 & no \\
Record ends & 1792 & 1360 & & 767 & 715 \\
\hline
\end{tabular}

\subsubsection{Temperature}

Temperature changes during the two full-scale fire tests were measured by using thermocouples, and were also monitored by an infrared camera. The same thermocouples 
were used in both tests with a total of 45 thermocouples in the first test, and a total of 44 in the second test. One thermocouple that was attached to the heat flux gauge on the floor was not used in the second test, because this heat flux gauge was not employed in the second test.

Table 29 and Table 30 provide the number and height of thermocouples attached to the five thermocouple trees in the room, and three thermocouple trees at the window opening. Temperature measurements obtained from these thermocouples are shown in the Figures 66 to 70 , and 75 to 81 .

Table 29 Thermocouple number and height for five thermocouple trees in the room

\begin{tabular}{cccccc}
\hline $\begin{array}{c}\text { Height } \\
(\mathrm{m})\end{array}$ & $\begin{array}{c}\text { Southwest } \\
(\mathrm{SW})\end{array}$ & $\begin{array}{c}\text { Northwest } \\
(\mathrm{NW})\end{array}$ & $\begin{array}{c}\text { Northeast } \\
(\mathrm{NE})\end{array}$ & $\begin{array}{c}\text { Southeast } \\
(\mathrm{SE})\end{array}$ & $\begin{array}{c}\text { Northwest Corner } \\
(\mathrm{NW} \text { Corner) }\end{array}$ \\
\hline 2.35 & TC5 & TC10 & TC15 & TC20 & TC25 \\
1.90 & TC4 & TC9 & TC14 & TC19 & TC24 \\
1.40 & TC3 & TC8 & TC13 & TC18 & TC23 \\
0.90 & TC2 & TC7 & TC12 & TC17 & TC22 \\
0.40 & TC1 & TC6 & TC11 & TC16 & TC21 \\
\hline
\end{tabular}

Table 30 Thermocouple number and height for three thermocouple trees at the window

\begin{tabular}{cccc}
\hline $\begin{array}{c}\text { Height* } \\
(\mathrm{m})\end{array}$ & West Line & Centre Line & East Line \\
\hline 1.14 & WL T & CL T & EL T \\
0.76 & WL M & CL M & EL M \\
0.38 & WL B & CL B & EL B \\
\hline
\end{tabular}

* From bottom of the window opening 


\subsubsection{The First Test}

The room temperatures were mainly measured by the five thermocouple trees, marked as SW (southwest), NW (northwest), NE (northeast), SE (southeast), and NW corner (northwest corner). There was also one thermocouple located in the centre of the room $0.02 \mathrm{~m}$ below the ceiling. Other single thermocouples were attached with heat flux gauges mounted on the wall, ceiling and floor.

The measured temperatures of the five thermocouples are presented in Figures 66 to 70. Almost all of the temperature curves reached the first peak value at about 300 seconds, when the heat release rate also reached the first peak value. Most of the thermocouples had their highest temperature at about 600 seconds, which corresponds to the start time of the decay phase from the heat release rate curve, but not the time that the maximum value of the heat release rate was reached. The measured temperature from the bottom thermocouple, 'TC11' of the NE thermocouple tree was unexpectedly higher after 608 seconds. The peak values of the room temperature from the SE thermocouple tree and NE thermocouple tree (except 'TC11') were $1060^{\circ} \mathrm{C}$ and $1091^{\circ} \mathrm{C}$. These maximum temperatures have also been observed by the infra camera (Figure 73 and Figure 74). 


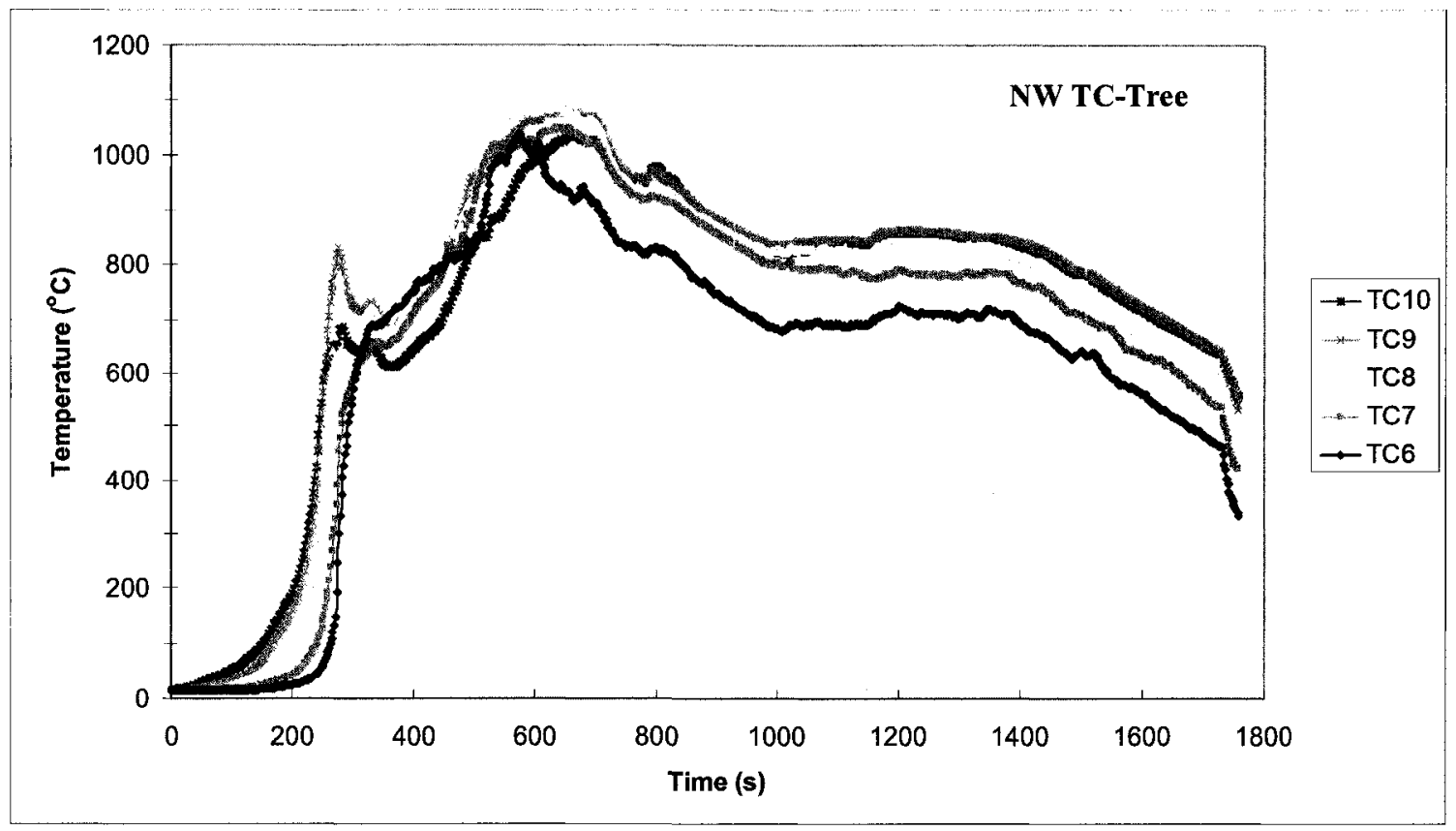

Figure 66 Temperatures of TC tree at northwest in the $1^{\text {st }}$ test

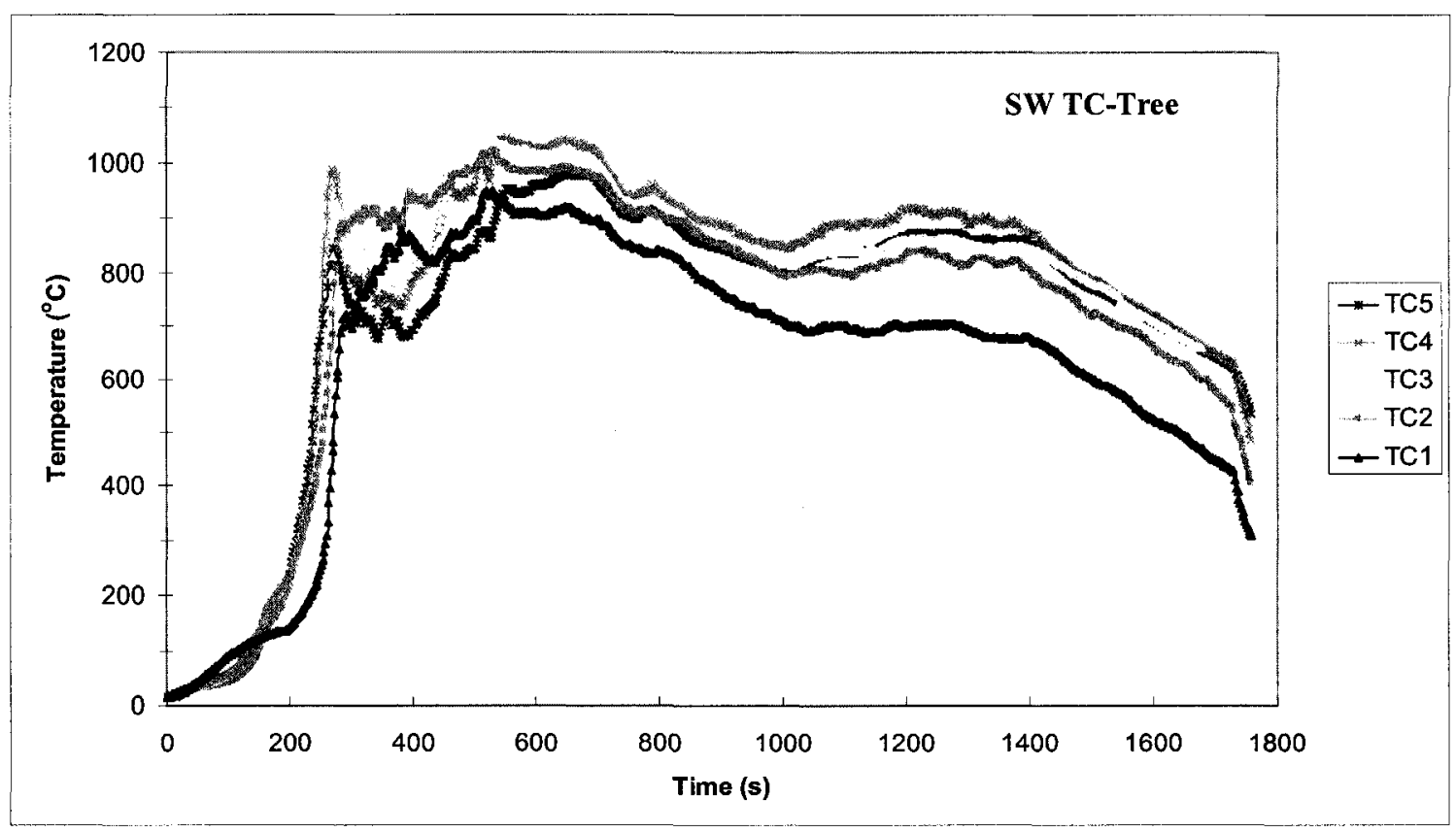

Figure 67 Temperatures of TC tree at southwest in the $1^{\text {st }}$ test 


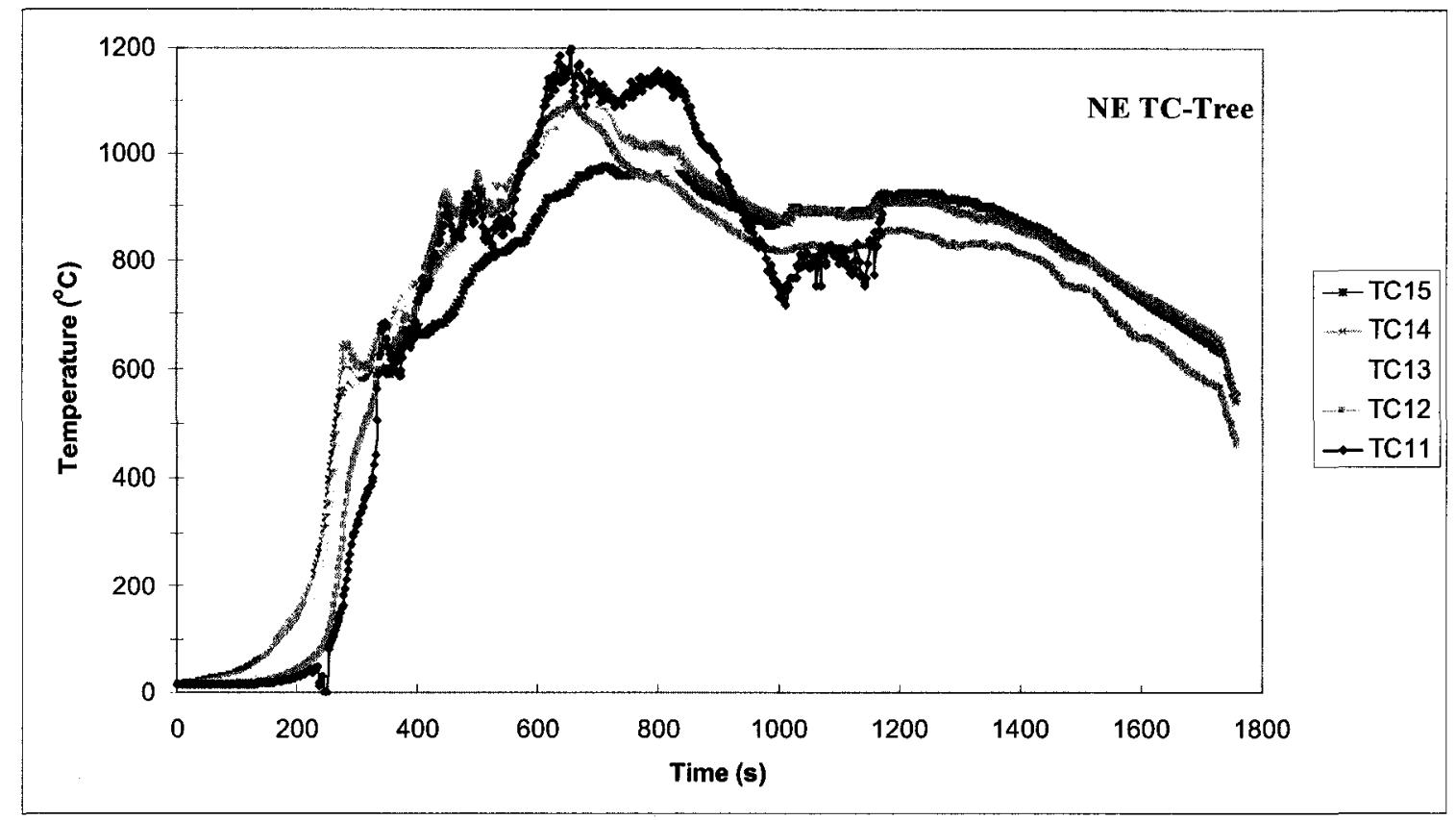

Figure 68 Temperatures of TC tree at northeast in the $1^{\text {st }}$ test

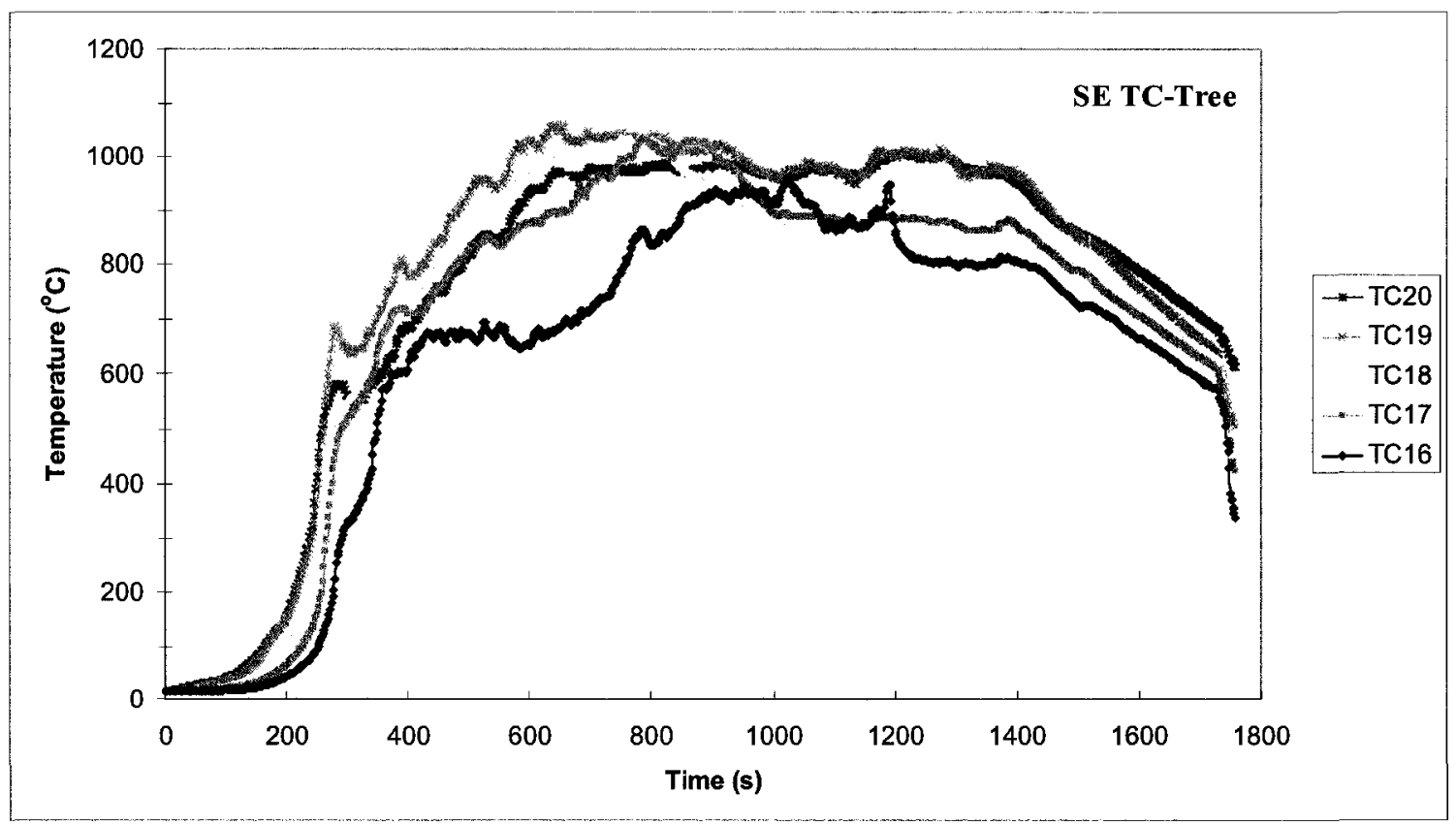

Figure 69 Temperatures of TC tree at southeast in the $1^{\text {st }}$ test 


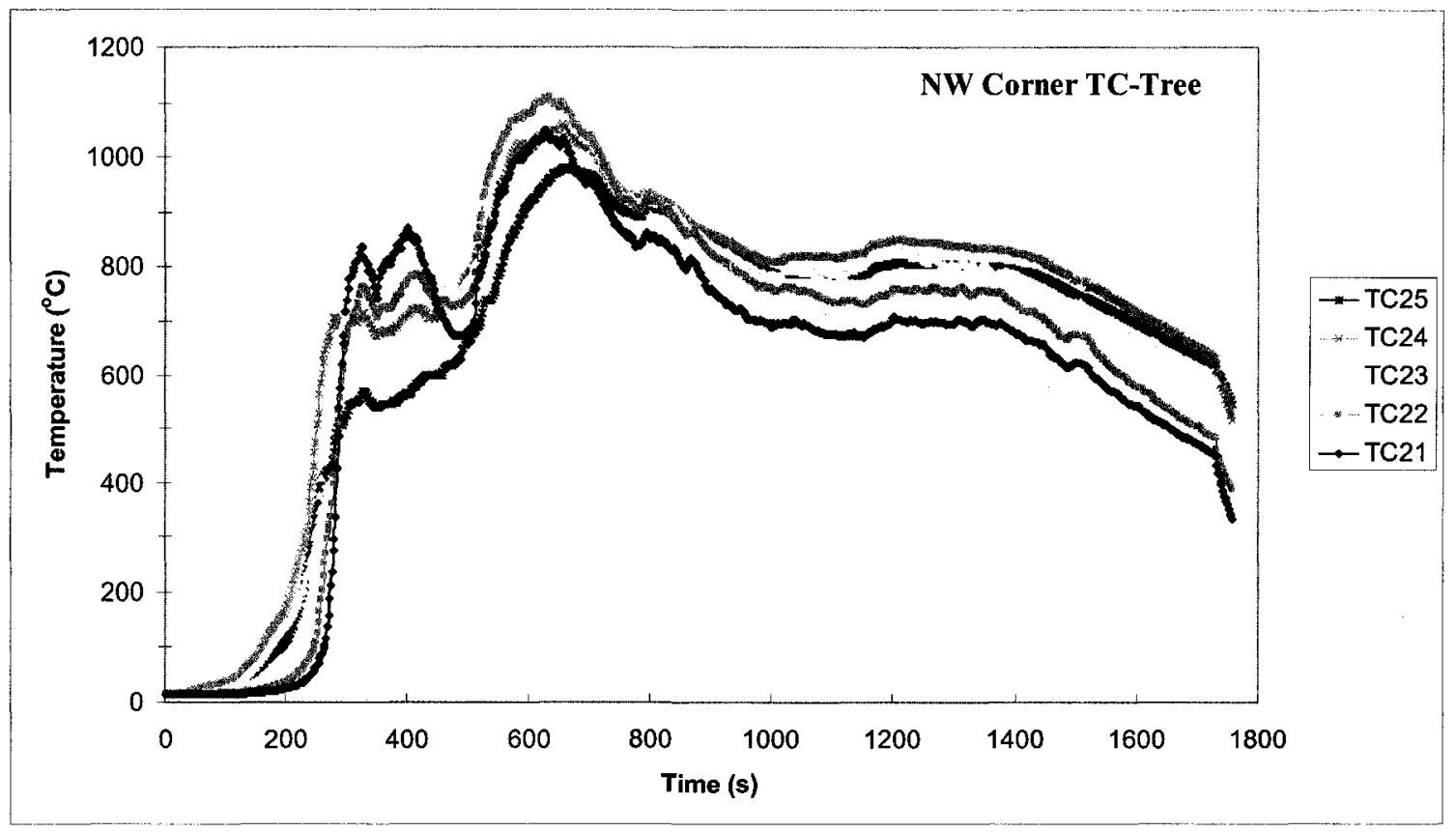

Figure 70 Temperatures of TC tree at northwest corner in the $1^{\text {st }}$ test

It was interesting to notice that the three thermocouple trees on the west, SW, NW, and NW corner, have very similar shape of the curves, which are different than another similar shape of the curves that the two thermocouple trees on the east, SE and NE have. It seems that the fire development in the room was divided into two zones, west zone (bed) and east zone (wood furniture and sofa chair), which can also be seen in the digital videos, photos (Figure 71 and Figure 72), and infrared pictures (Figure 73 and Figure 74). 


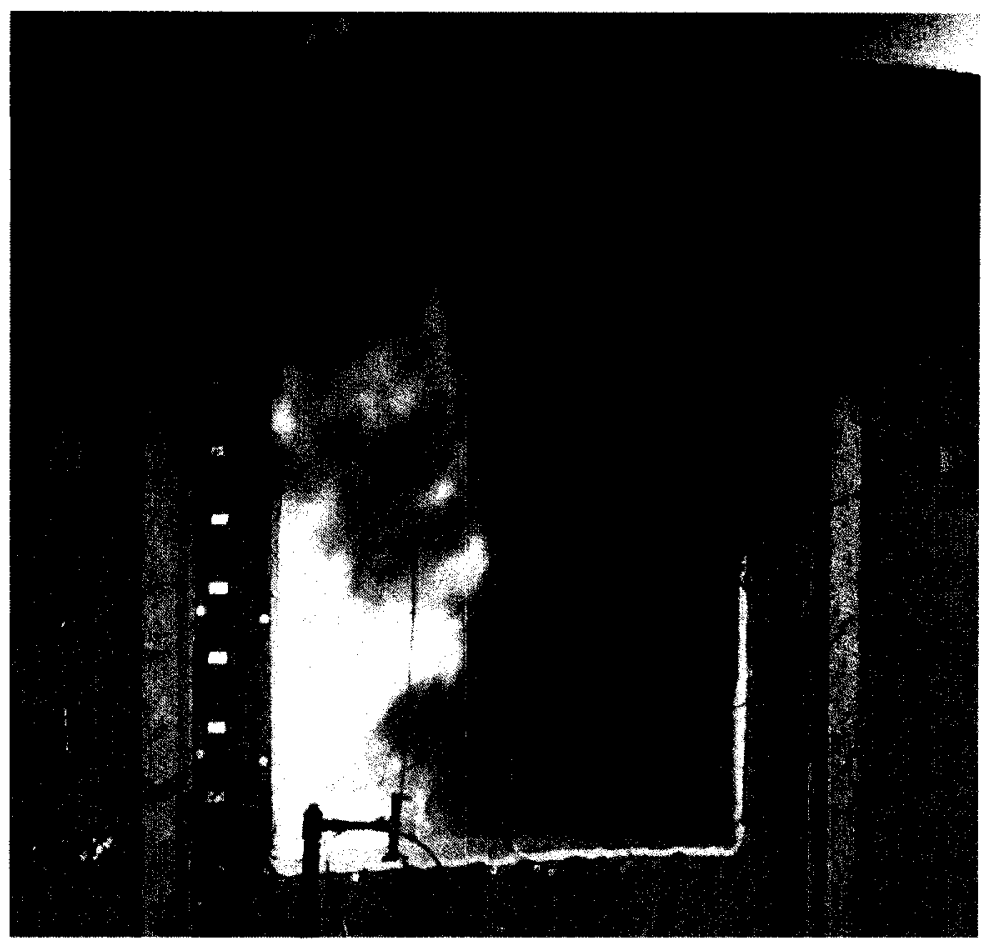

Figure 71 Test picture at 300 seconds in the $1^{\text {st }}$ test

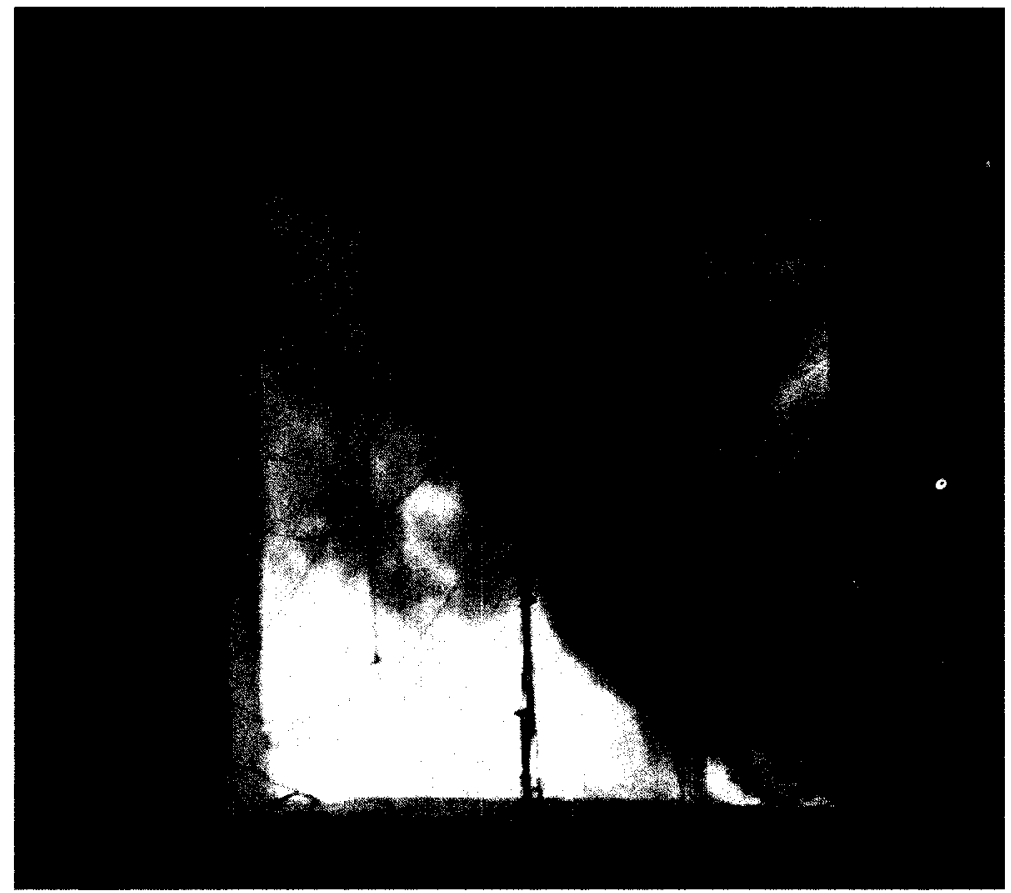

Figure 72 Test picture at 600 seconds in the $1^{\text {st }}$ test

\section{5}




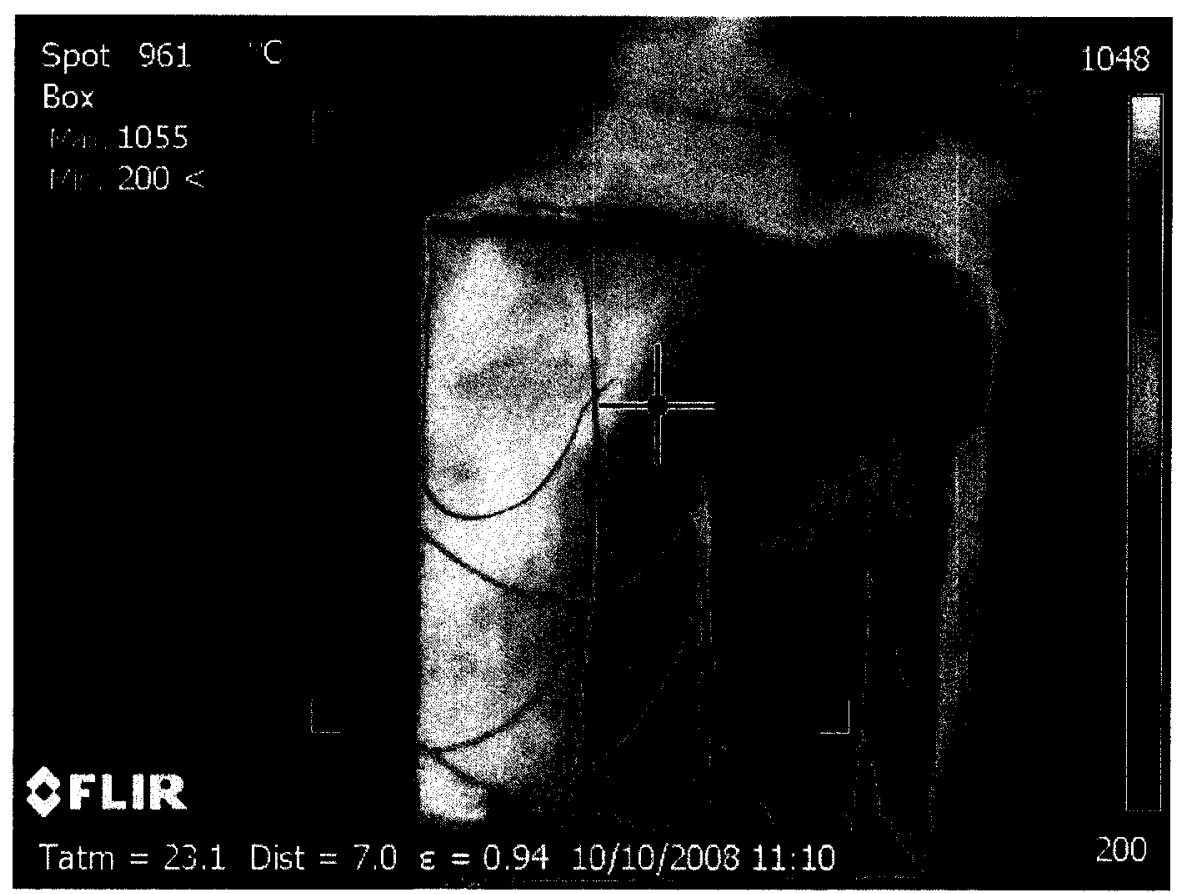

Figure 73 Infrared picture in the $1^{\text {st }}$ test

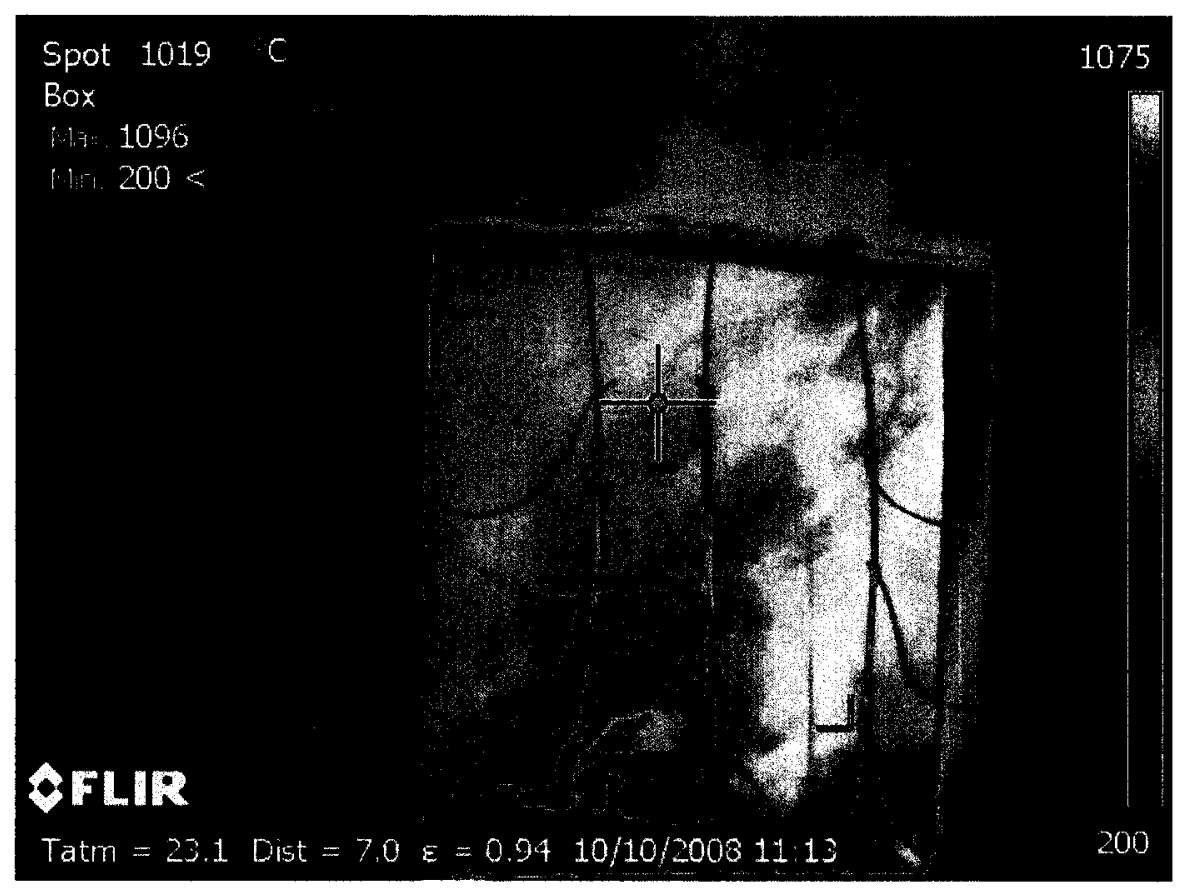

Figure 74 Infrared picture in the $1^{\text {st }}$ test 
Three thermocouple trees with a total of nine thermocouples were placed at the window opening. Figure 75 presents the temperature changes of the nine thermocouples in the first test. The three thermocouples on the top row, WL-T (West Line-Top), CL-T (Centre Line-Top), and EL-T (East Line-Top) have very similar temperature development. Also the three thermocouples of the bottom row (WL-B, CL-B, and EC-B) have similar results. The thermocouple in the middle of the west line had a lower temperature than the other two in the middle of the center line and east line during the decay stage.

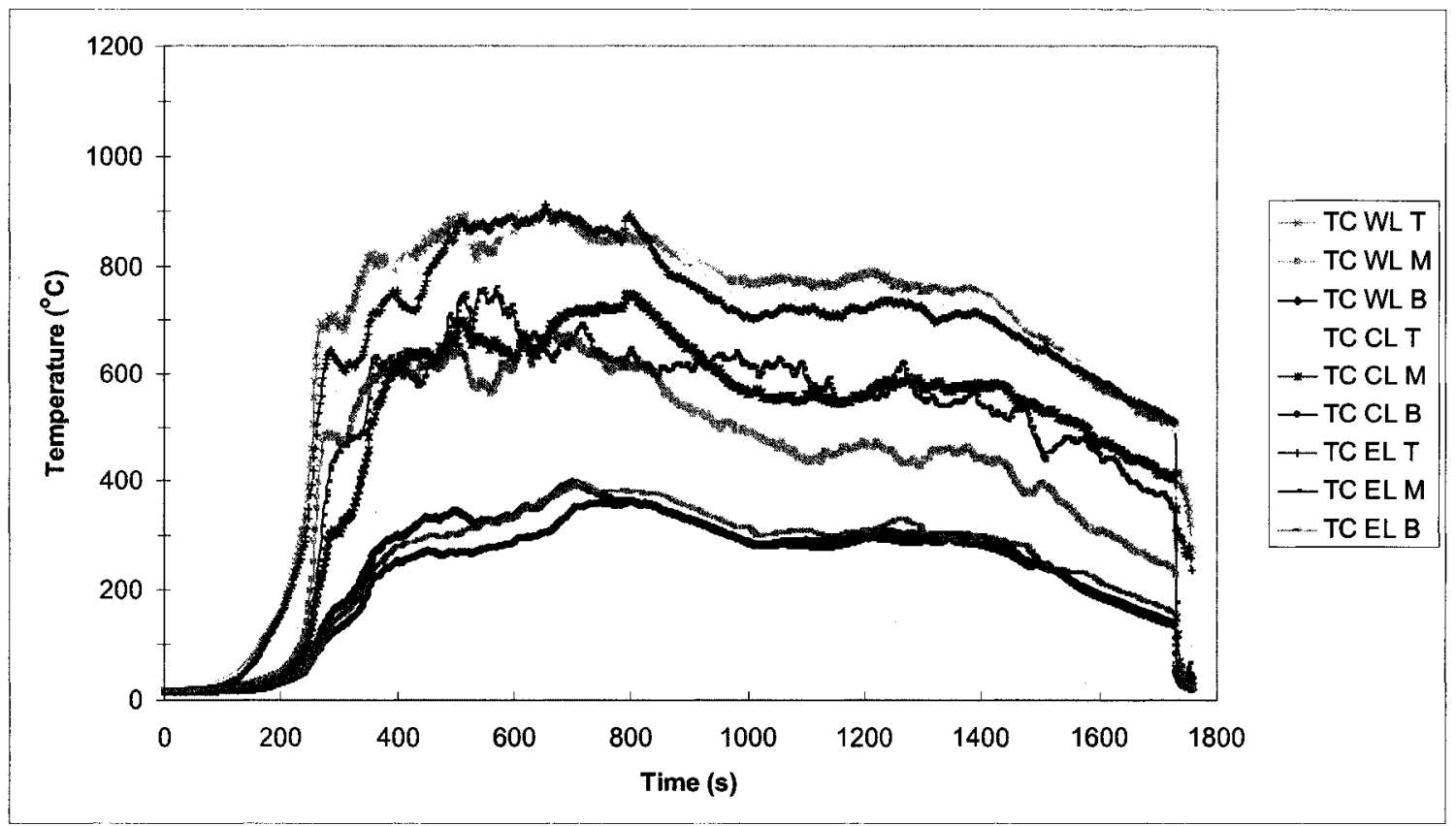

Figure 75 Temperatures of TC trees at the window opening in the $1^{\text {st }}$ test 


\subsubsection{The Second Test}

The temperature development of the five thermocouple trees in the second test is presented in Figures 76 to 80 . The figures also show the two different shapes of temperature curves that one group is the thermocouples at the west side of the room, and another group is the thermocouples at the east side of the room, which was noticed in the first test.

The temperatures measured by the five thermocouple trees during the second test increase faster than during the first test. This is consistent with the development of the heat release rates in both tests. Most of the thermocouples had the highest temperature at about 700 seconds, which correspond to the start time of the decay in the heat release rate curve that was also noticed during the first test.

The temperatures of the three thermocouple trees at the window opening are given in Figure 81 . The three thermocouples at the middle height had temperatures closer to the temperatures of the thermocouples at the top than those at the bottom. Figure 81 also shows two thermocouple trees (WL and CL) fell at about 700 to 800 seconds when the decay started, which was also seen on the test site and the digital video. 


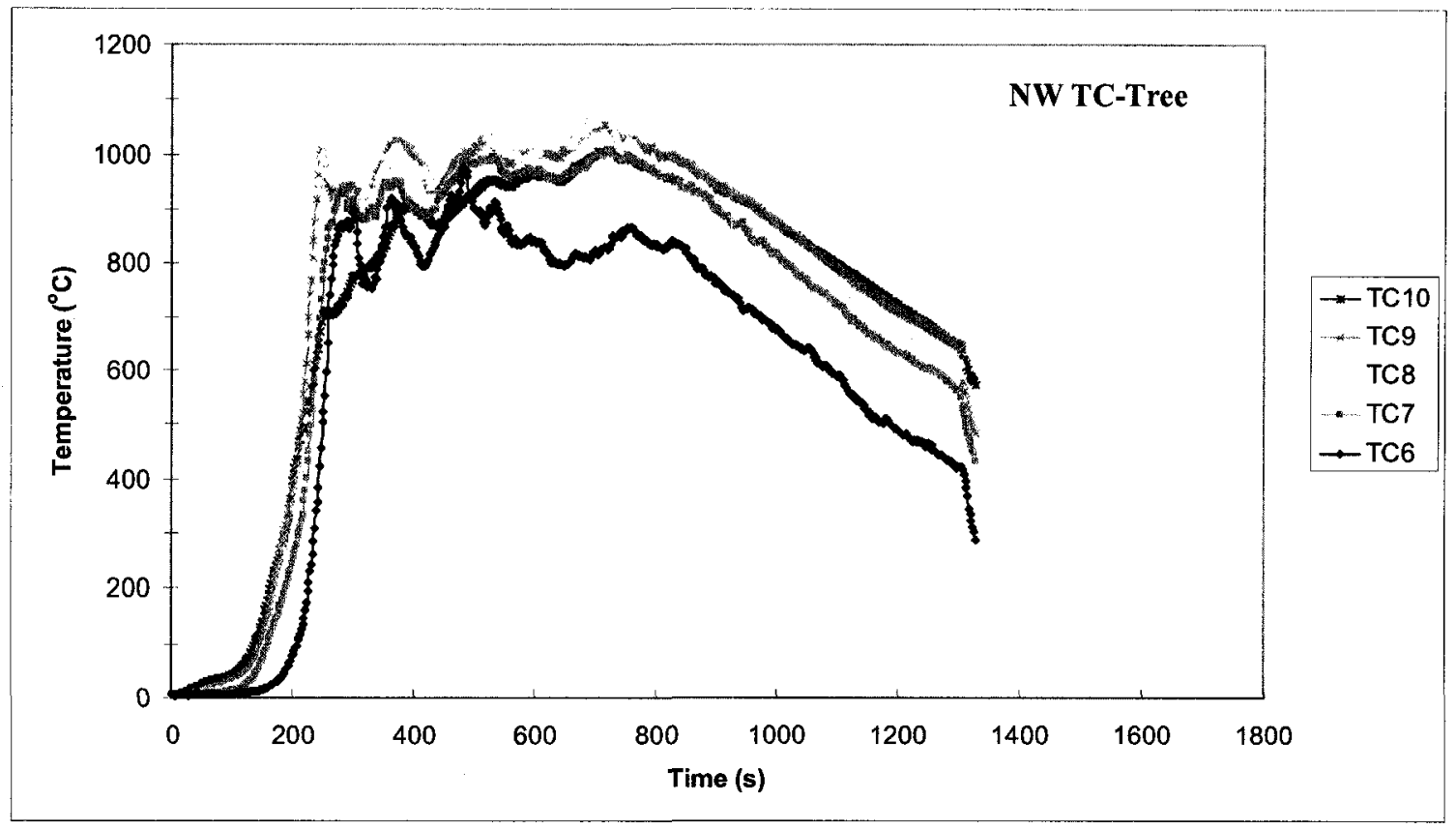

Figure 76 Temperature of TC tree at northwest in the $2^{\text {nd }}$ test

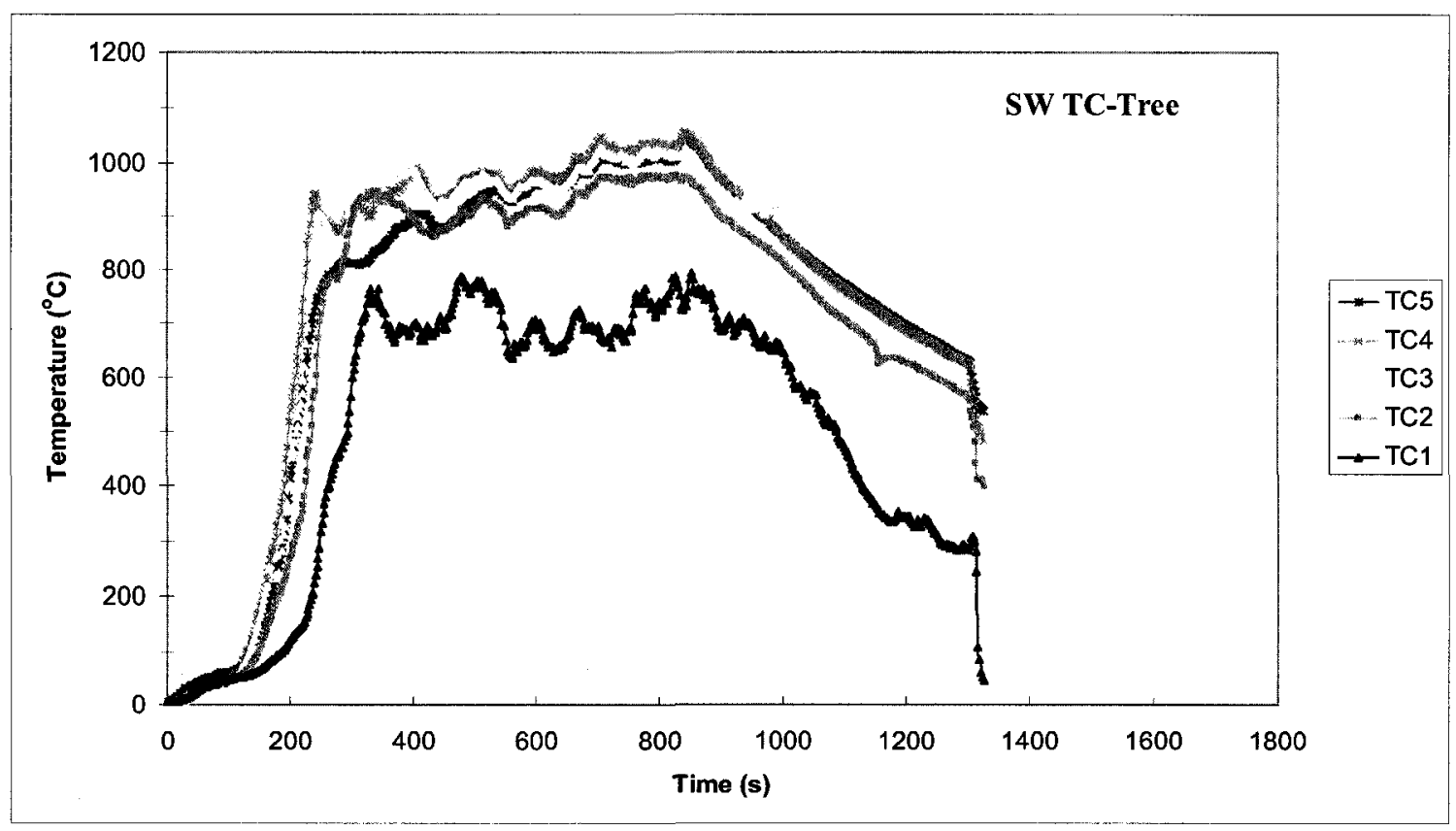

Figure 77 Temperature of TC tree at southwest in the $2^{\text {nd }}$ test 


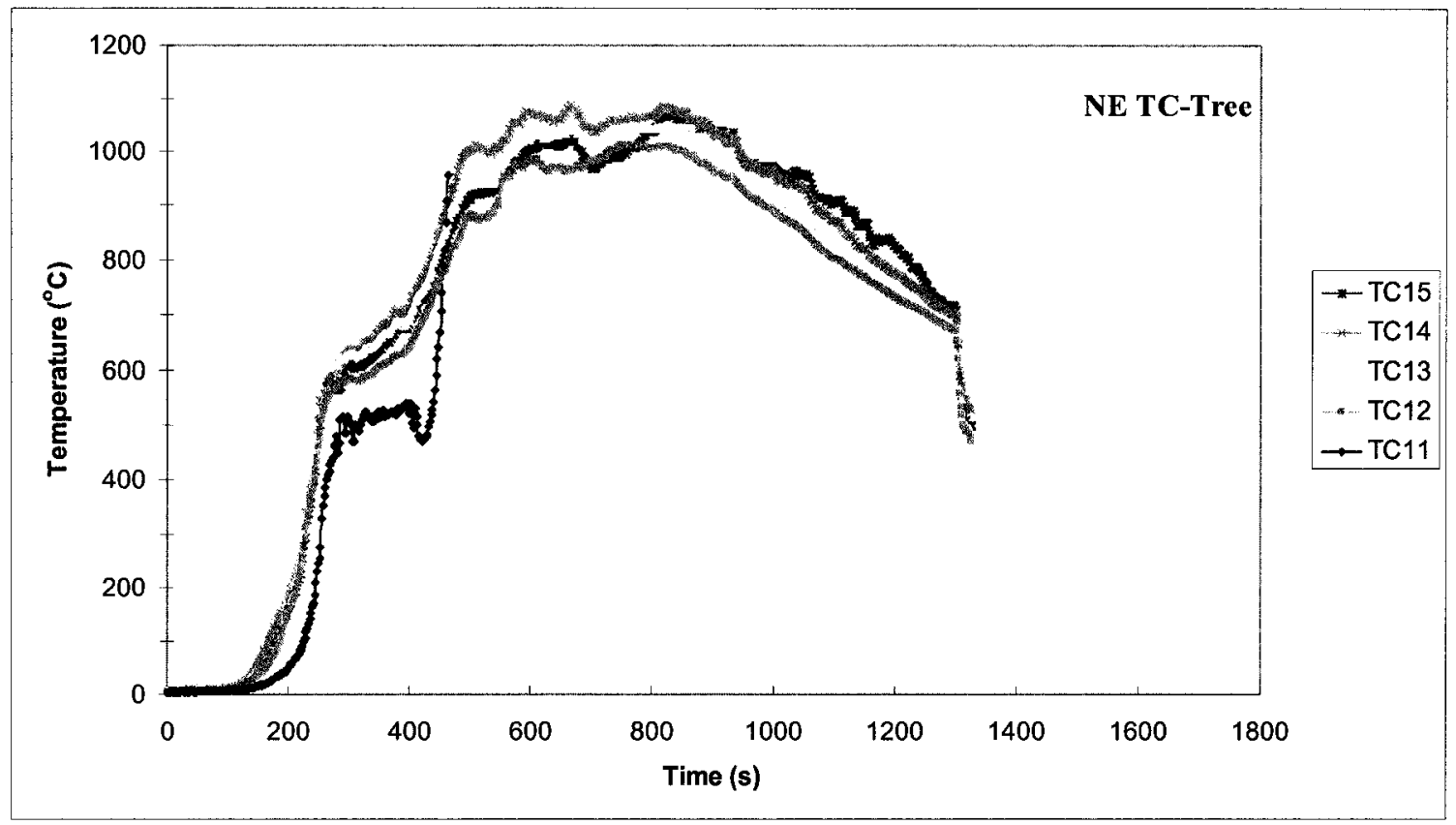

Figure 78 Temperature of TC tree at northeast in the $2^{\text {nd }}$ test

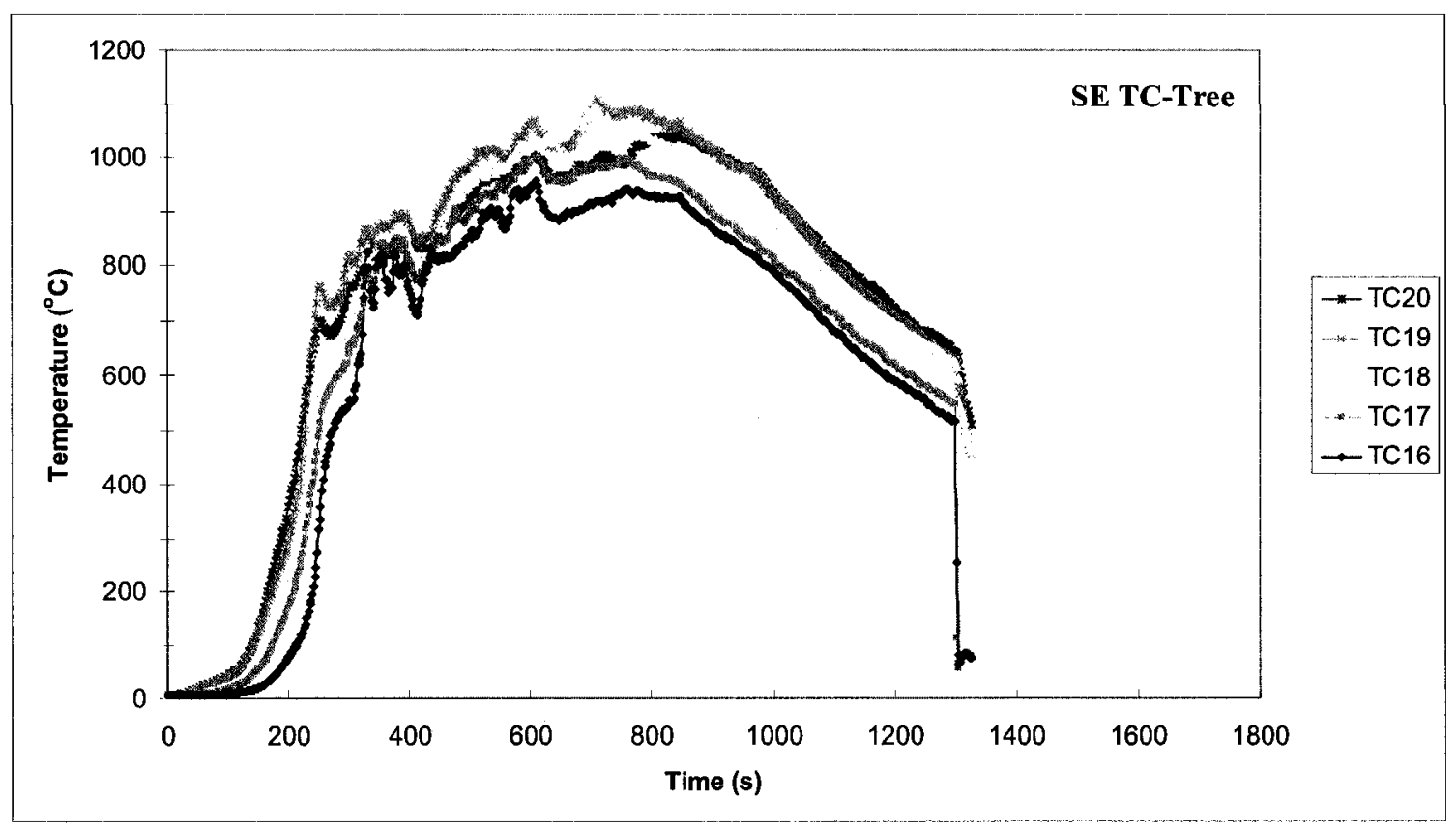

Figure 79 Temperature of TC tree at southeast in the $2^{\text {nd }}$ test 


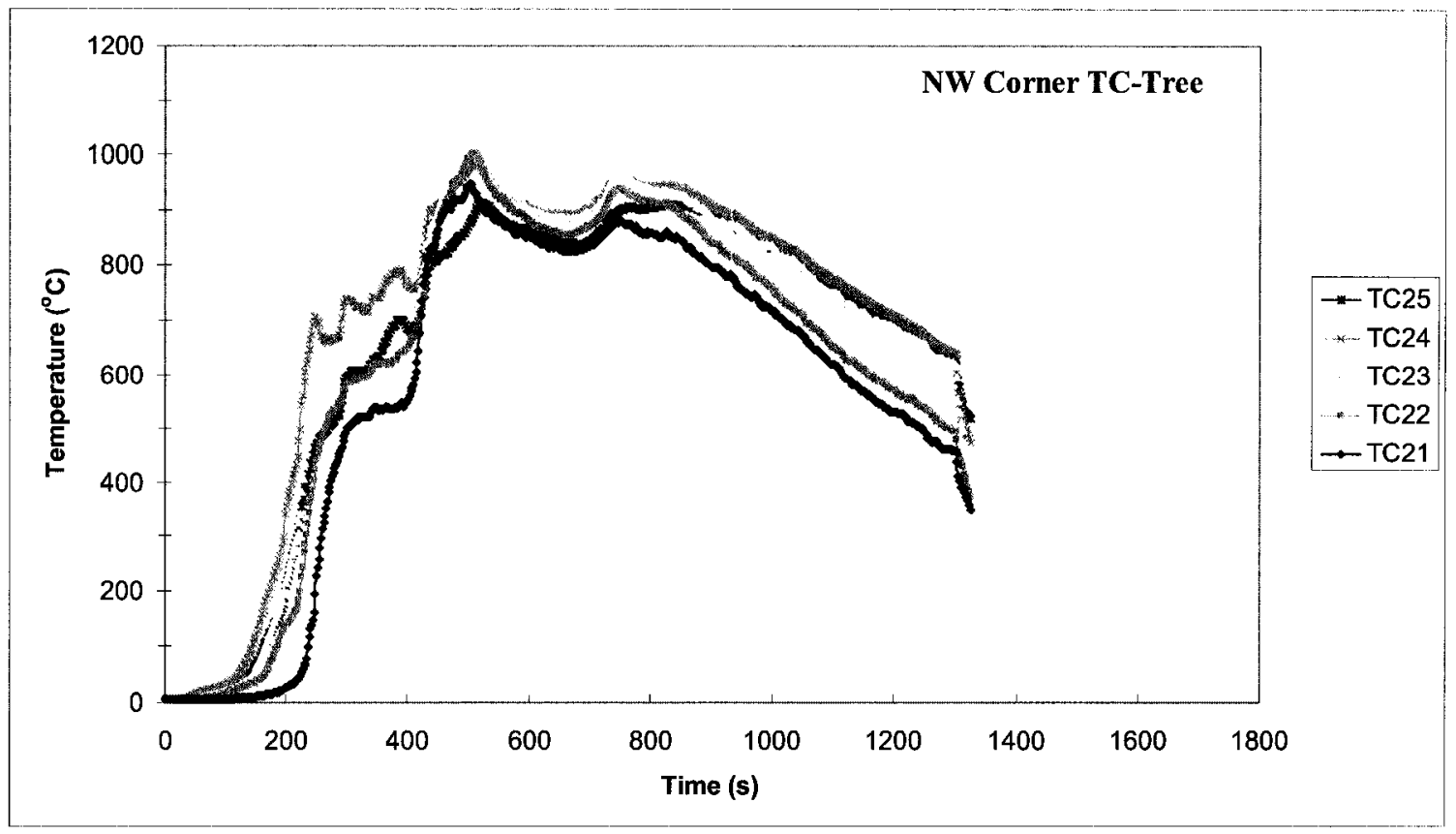

Figure 80 Temperatures of TC tree at northwest corner in the $2^{\text {nd }}$ test

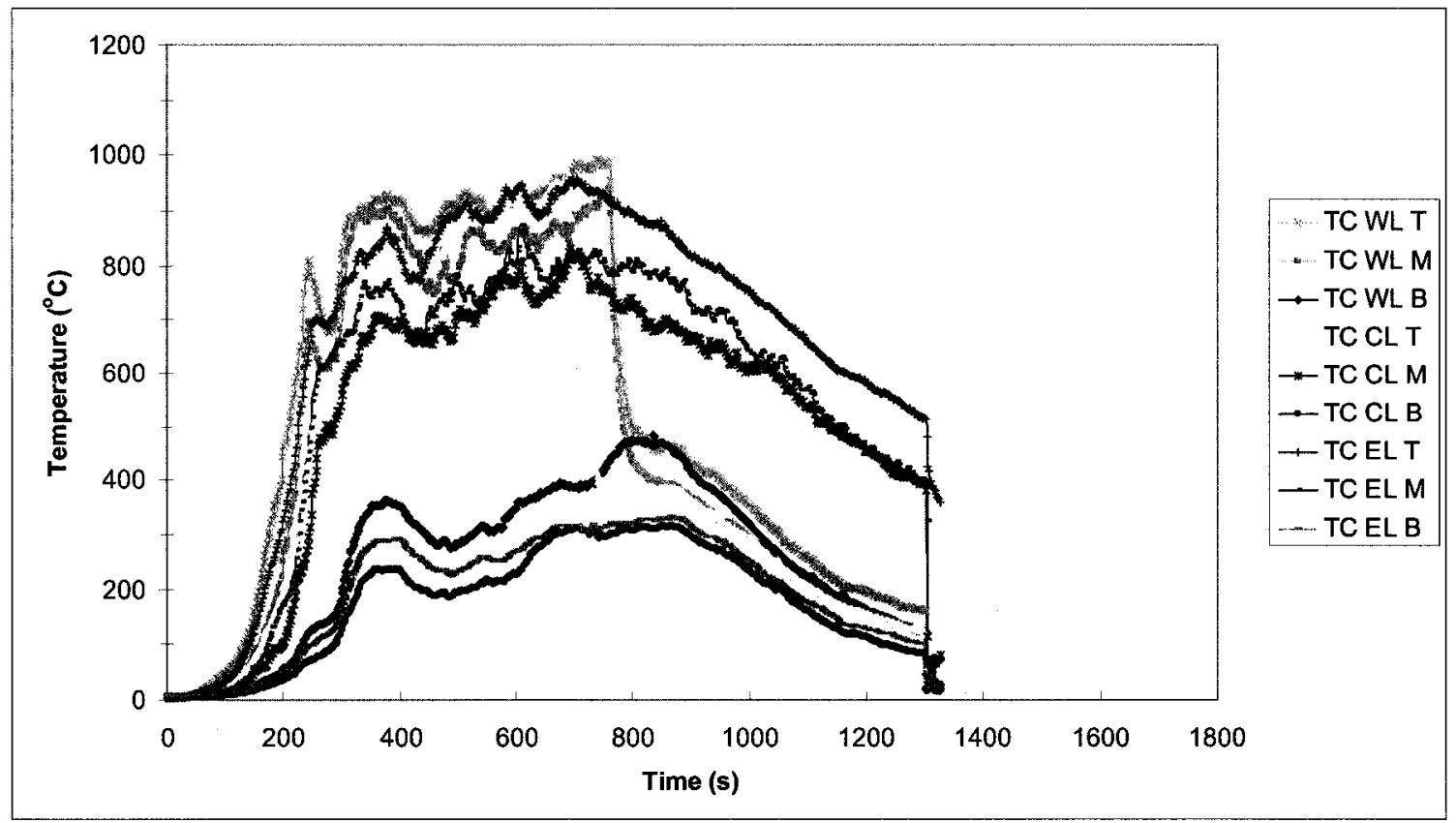

Figure 81 Temperatures of TC trees at the window opening in the $2^{\text {nd }}$ test 


\subsubsection{Heat Flux}

A total of nine heat flux gauges were installed in the first test, and a total of eight heat flux gauges were used in the second test. The floor heat flux gauge was not used in the second test because it was damaged during the first test.

Figure 82 and Figure 83 present heat flux as measured on the north, south, west, and east walls of the test room during the tests. Figure 84 and Figure 85 present the heat flux measured at the northwest and southeast of the ceiling. In the first test, the damage of the cooling system for the heat flux gauges led to the damage of six heat flux gauges, and Table 31 provides the time when the data of "over range" appeared. The six damaged heat flux gauges were replaced in the second test, and the same installation locations were used in the second test.

Table 31 The time of "over range" appeared to HF gauges in the 1st test

\begin{tabular}{llc}
\hline Heat Flux Gauge location & "over range" at (sec.) \\
\hline \multirow{4}{*}{ Walls } & North & 962 \\
& South & no \\
& West & 750 \\
& East & 884 \\
\hline \multirow{2}{*}{ Ceiling } & Northeast & 1206 \\
& Southwest & 674 \\
\hline
\end{tabular}




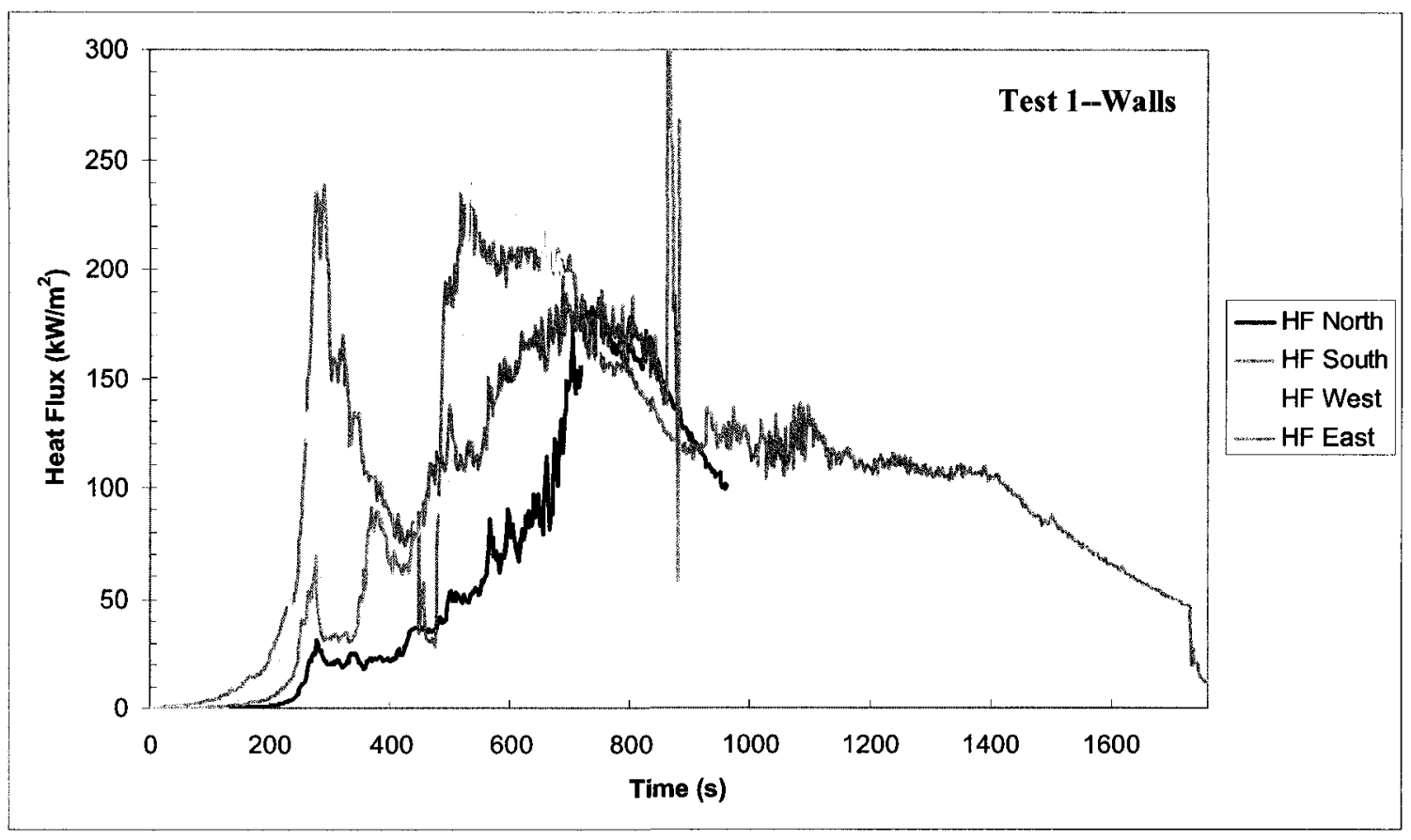

Figure 82 Heat flux on the walls in the $1^{\text {st }}$ test

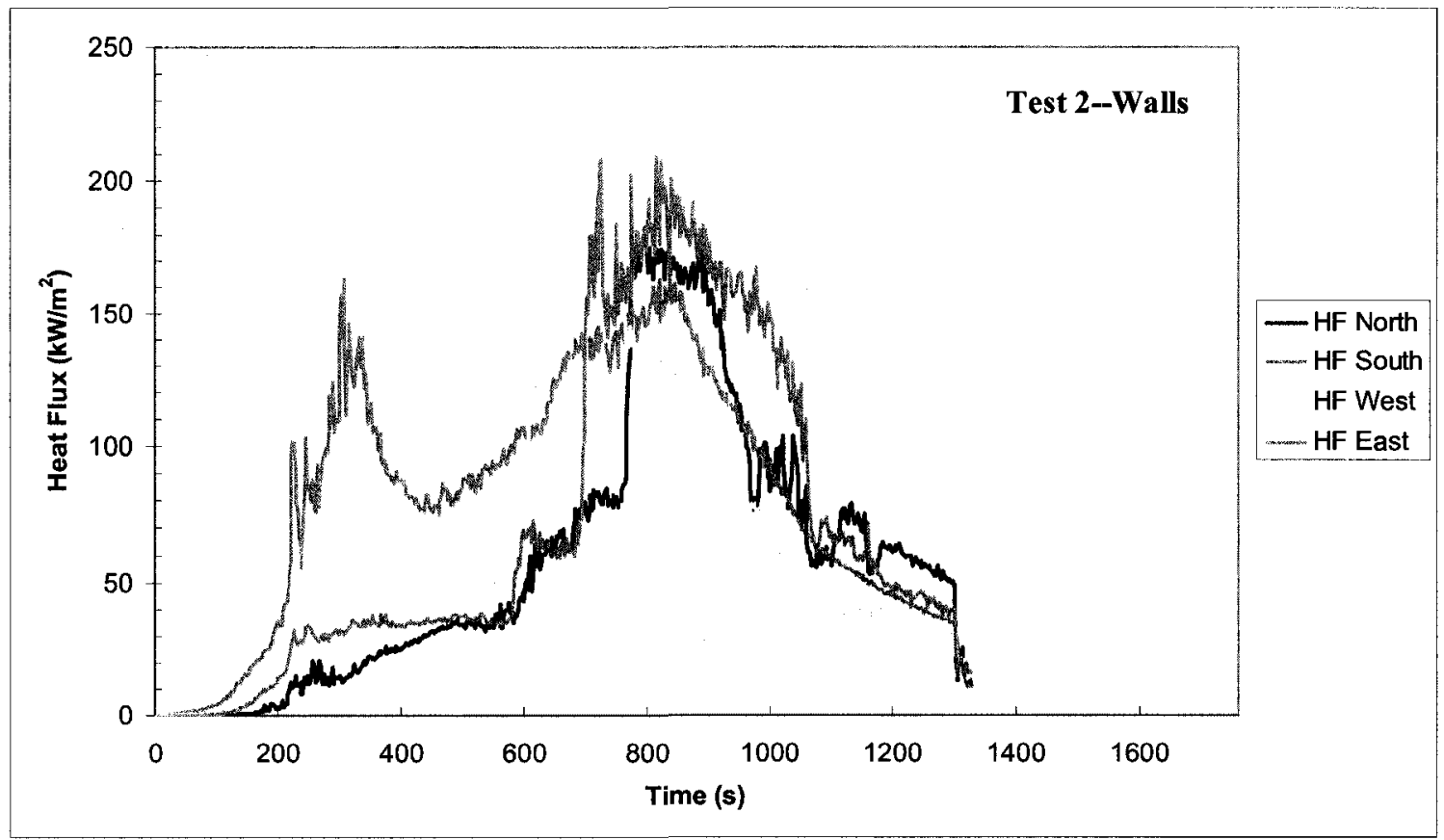

Figure 83 Heat flux on the walls in the $2^{\text {nd }}$ test

123 


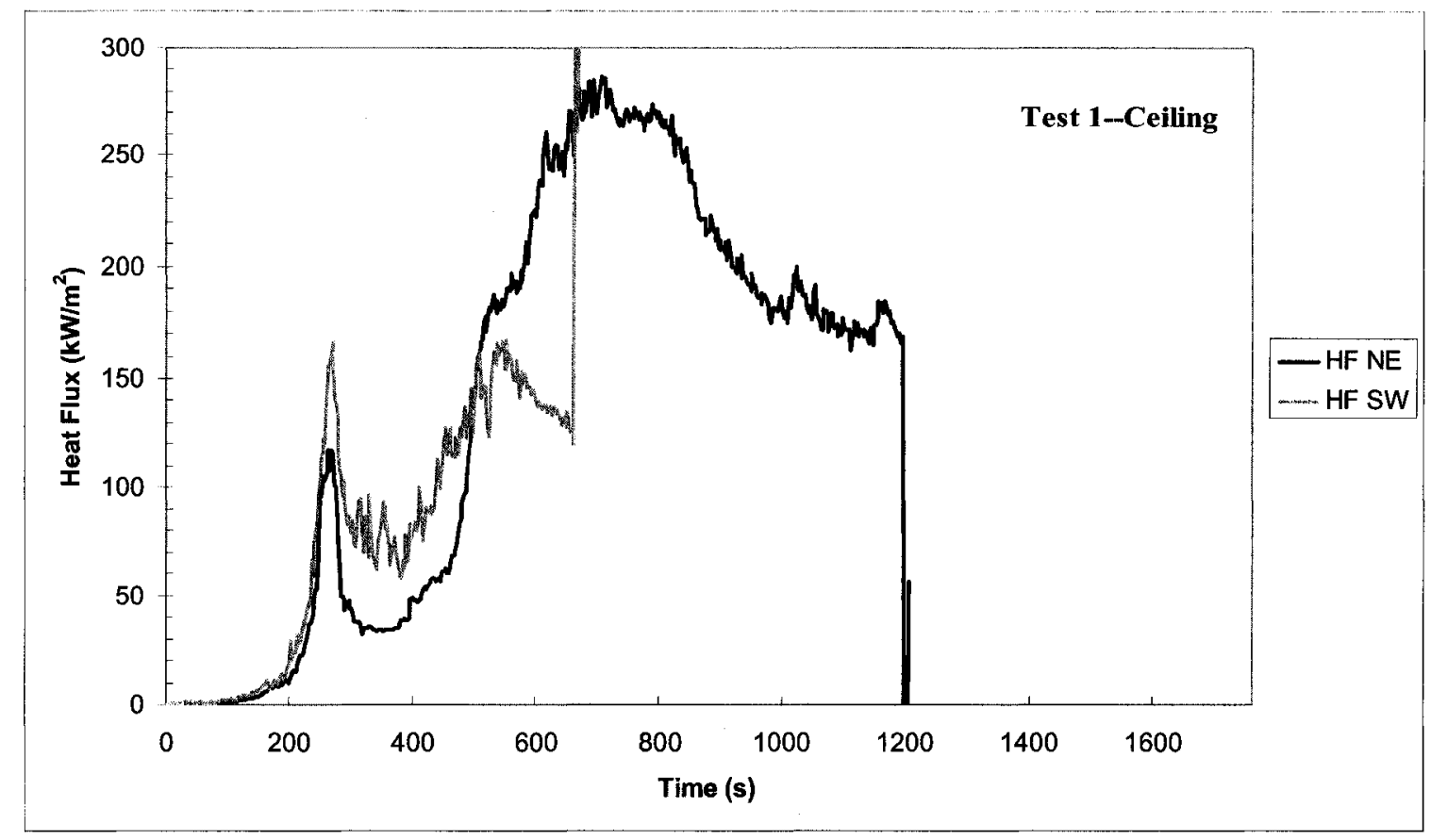

Figure 84 Heat flux on the ceiling in the $1^{\text {st }}$ test

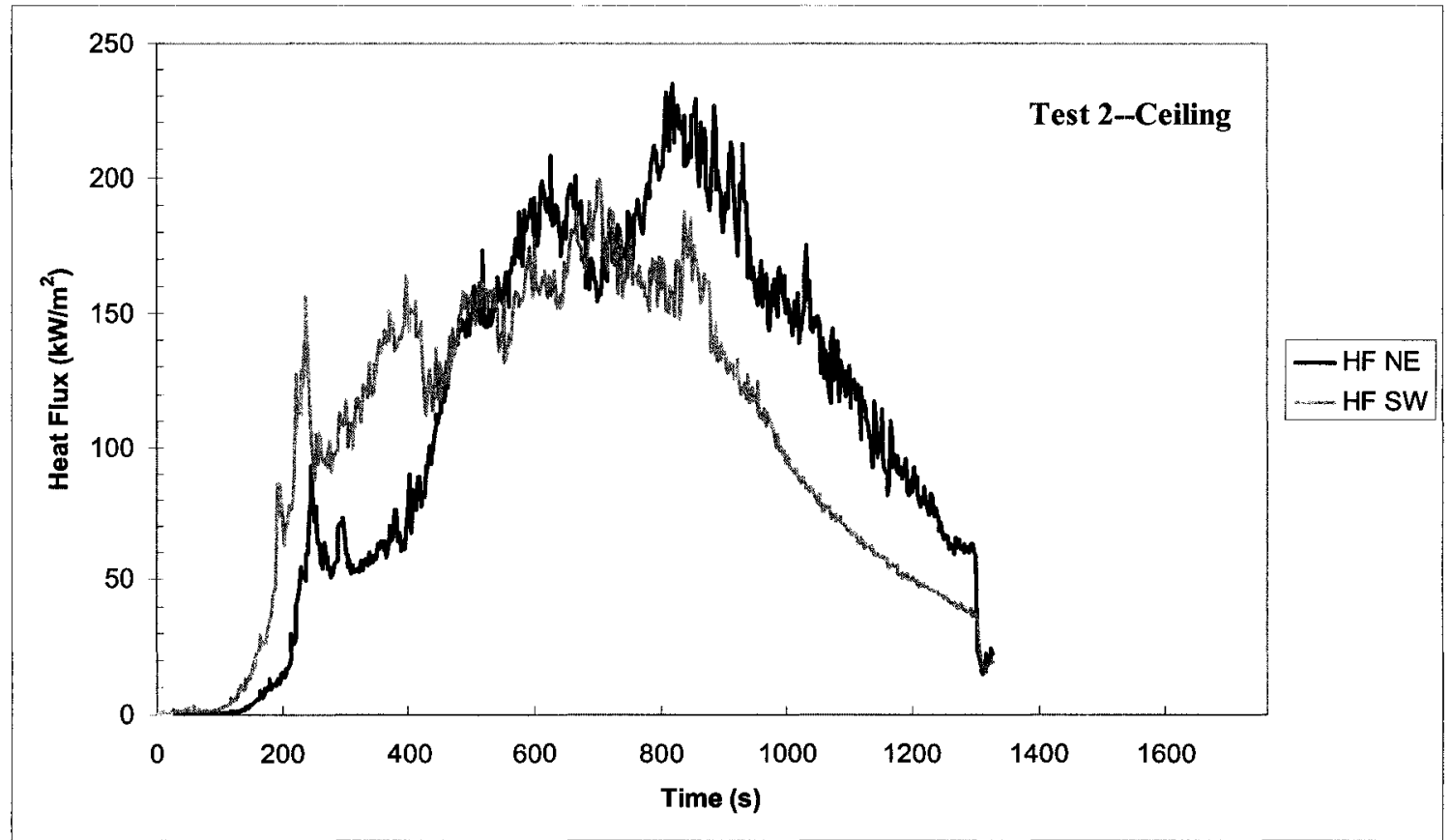

Figure 85 Heat flux on the ceiling in the $2^{\text {nd }}$ test 
From Figure 82 and Figure 83, the heat fluxes on the walls in both tests have two peak values. The first peak value for both tests was recorded by the heat flux gauge at the south wall $163 \mathrm{~kW} / \mathrm{m}^{2}$ (306 s) for the $1^{\text {st }}$ test, and $236 \mathrm{~kW} / \mathrm{m}^{2}(278 \mathrm{~s})$ for the $2^{\text {nd }}$ test. The heat flux gauge at the south wall was the nearest to the pilot burner. The second peak value was recorded by the heat flux gauge at the west wall in the $1^{\text {st }}$ test, which was located above the headboard of the double bed, at $258 \mathrm{~kW} / \mathrm{m}^{2}(552 \mathrm{~s})$, and by the heat flux gauge at the east wall in the $2^{\text {nd }}$ test, which was located above the TV, at $208 \mathrm{~kW} / \mathrm{m}^{2}$ (816 s). The time of the second peak corresponds to the time of the maximum heat release rates and maximum temperature in the room.

The heat fluxes measured at the ceiling have three peak values in the $2^{\text {nd }}$ test, which is shown in Figure 85, but two peak values in the $1^{\text {st }}$ test are shown in Figure 84. The first peak values were recorded by the heat flux gauge at the southwest of the ceiling in the two tests at about $160 \mathrm{~kW} / \mathrm{m}^{2}$. The second peak values were recorded by the heat flux gauge at the northeast of the ceiling with values of $286 \mathrm{~kW} / \mathrm{m}^{2}(706 \mathrm{~s})$ for the $1^{\text {st }}$ test, and $207 \mathrm{~kW} / \mathrm{m}^{2}(626 \mathrm{~s})$ for the $2^{\text {nd }}$ test.

Figure 86 and Figure 87 present the heat flux measured $3 \mathrm{~m}$ outside the window opening with a highest value of about $13 \mathrm{~kW} / \mathrm{m}^{2}$ for both tests. 


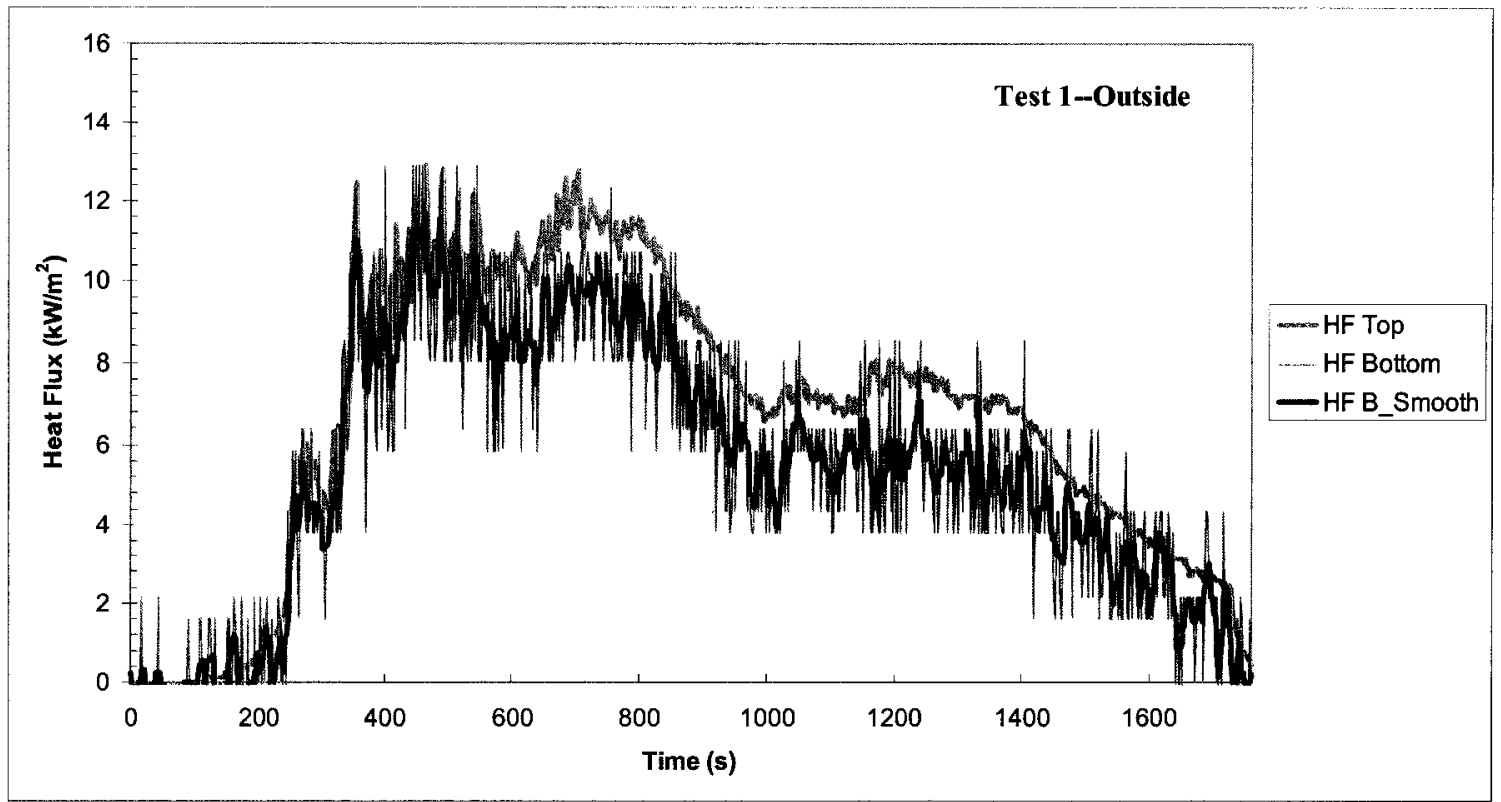

Figure 86 Heat flux measured $3 \mathrm{~m}$ outside the window opening in the $1^{\text {st }}$ test

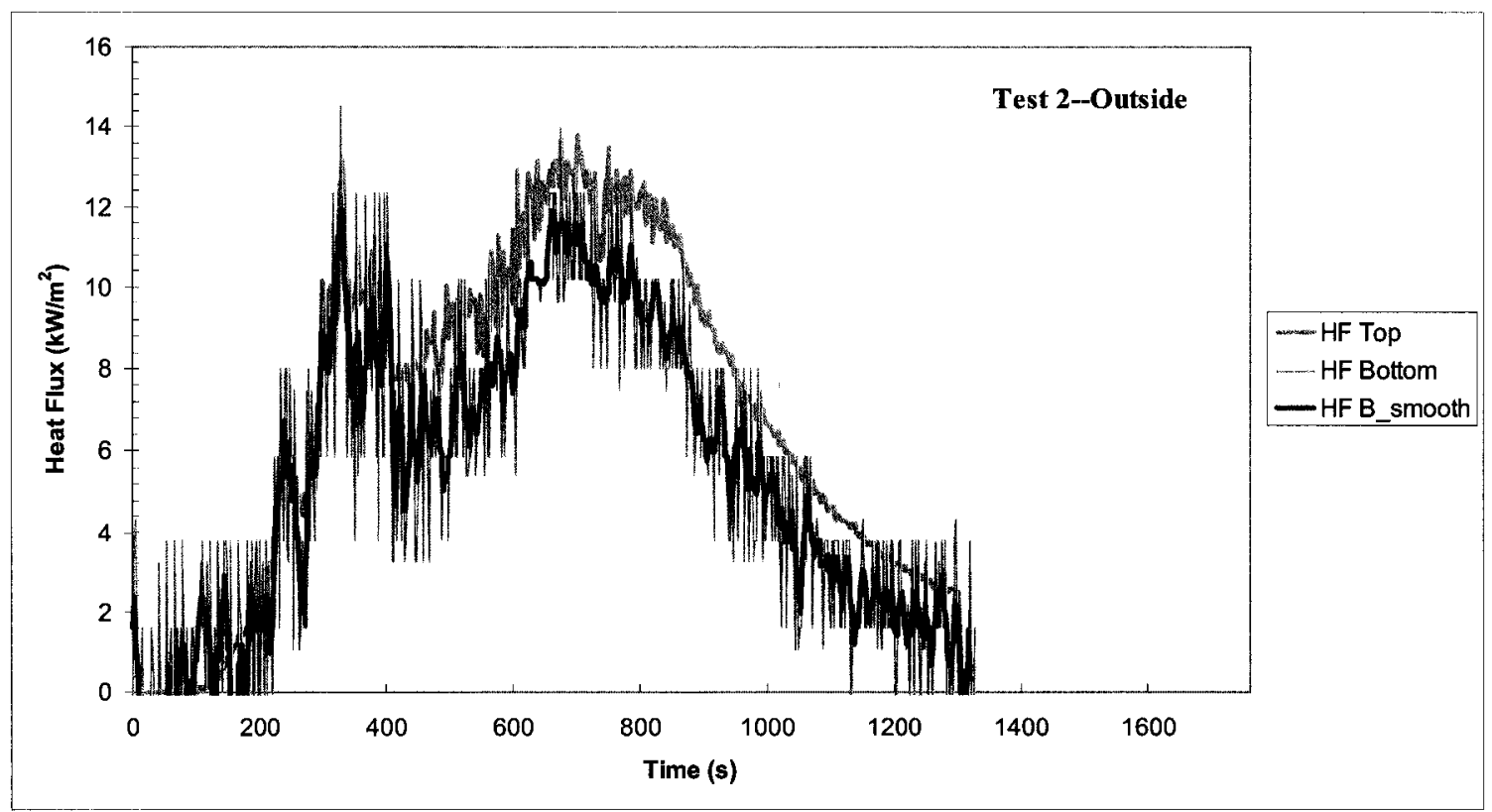

Figure 87 Heat flux measured $3 \mathrm{~m}$ outside the window opening in the $2^{\text {nd }}$ test 


\subsubsection{Pressure Difference at the Window Opening}

Figure 88 presents the pressure difference at the window opening measured in the $1^{\text {st }}$ test. It shows positive pressure difference at the top of the window indicating that gases flow out of the room, and negative pressure difference at the bottom indicating that fresh air flow into the room. The curves of the top, H1.7 and H1.4, have more fluctuation than the curves of the bottom, $\mathrm{H} 1.1$ and $\mathrm{H} 0.8$, which might be due to the high turbulence of the hot gases. The bidirectional probes failed to give good measurements in the second test.

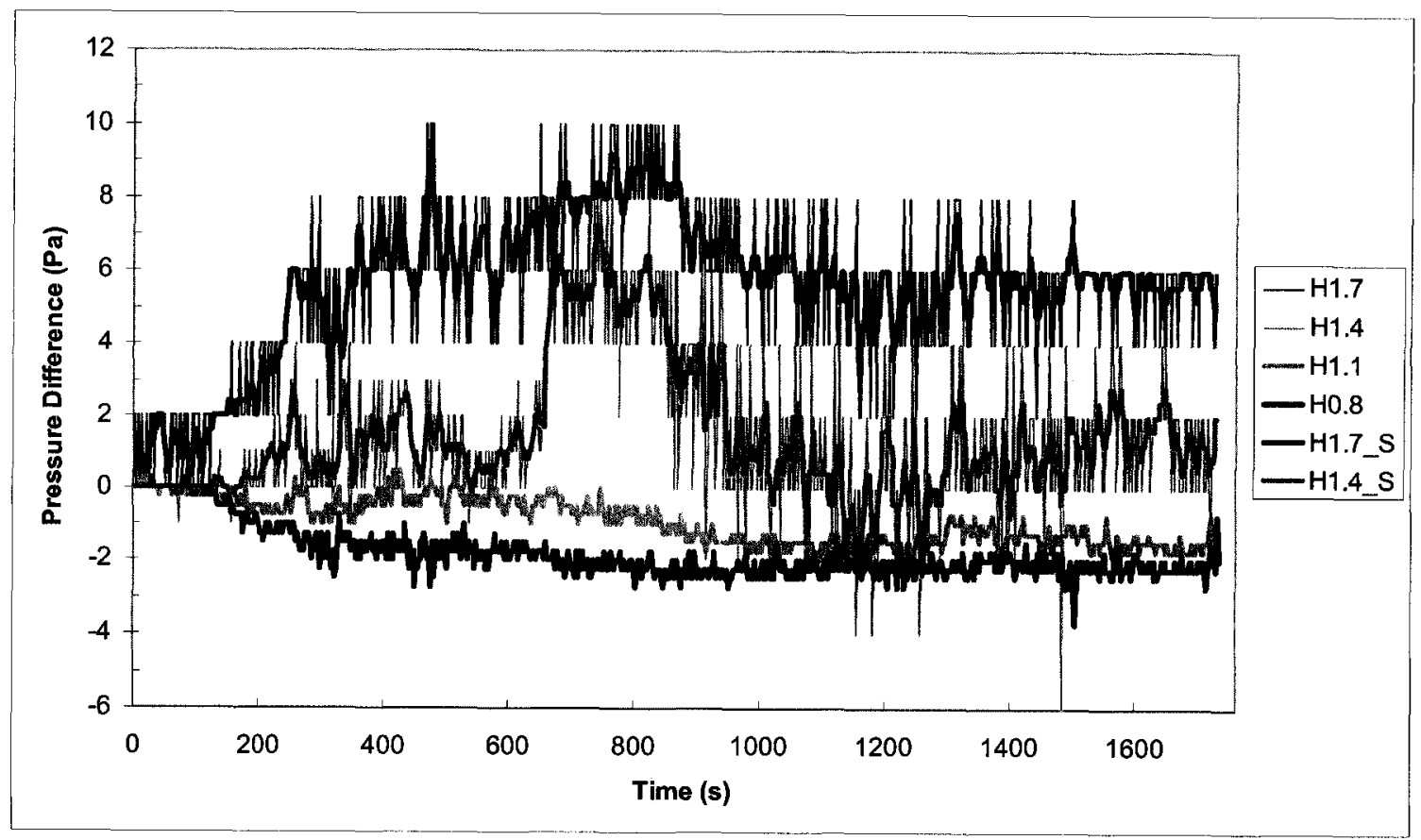

Figure 88 Pressure difference at the window opening in the $1^{\text {st }}$ test 


\subsubsection{Gas Concentration in the Test Room}

The gas concentrations in the test room were measured by two gas analysis probes, located at $0.5 \mathrm{~m}$, and $1.5 \mathrm{~m}$ height from the floor, and at a distance of $0.9 \mathrm{~m}$ from the north wall for both probes. Figure 89 and Figure 91 present the mole concentrations of oxygen in the two tests, and Figure 90 and Figure 92 present the mole concentrations of carbon oxide, and carbon monoxide in the two tests.

In the two tests, the mole percentage of oxygen dropped to zero at about 300 seconds and stayed at zero for about 250 seconds for both tests. The reason could be the measuring locations of the gas probes, which were at the back corner of the room where fresh air could not easily flow.

The maximum values of $\mathrm{CO}_{2}$ measured in the tests were $17.9 \%$ for the $1^{\text {st }}$ test, and $18.3 \%$ for the second test. For both tests, the high value of $\mathrm{CO}_{2}$ in the room started to drop at about 730 seconds, and they levelled offat about $7 \%$.

The maximum values of $\mathrm{CO}$ could not be measured in the two tests, due to the higher values of $\mathrm{CO}$ over the maximum range of the instrument setting. The durations that the values are over range lasted 148 seconds for the $1^{\text {st }}$ test, and 190 seconds for the $2^{\text {nd }}$ test. The over range durations correspond to the periods where oxygen values dropped to zero. 


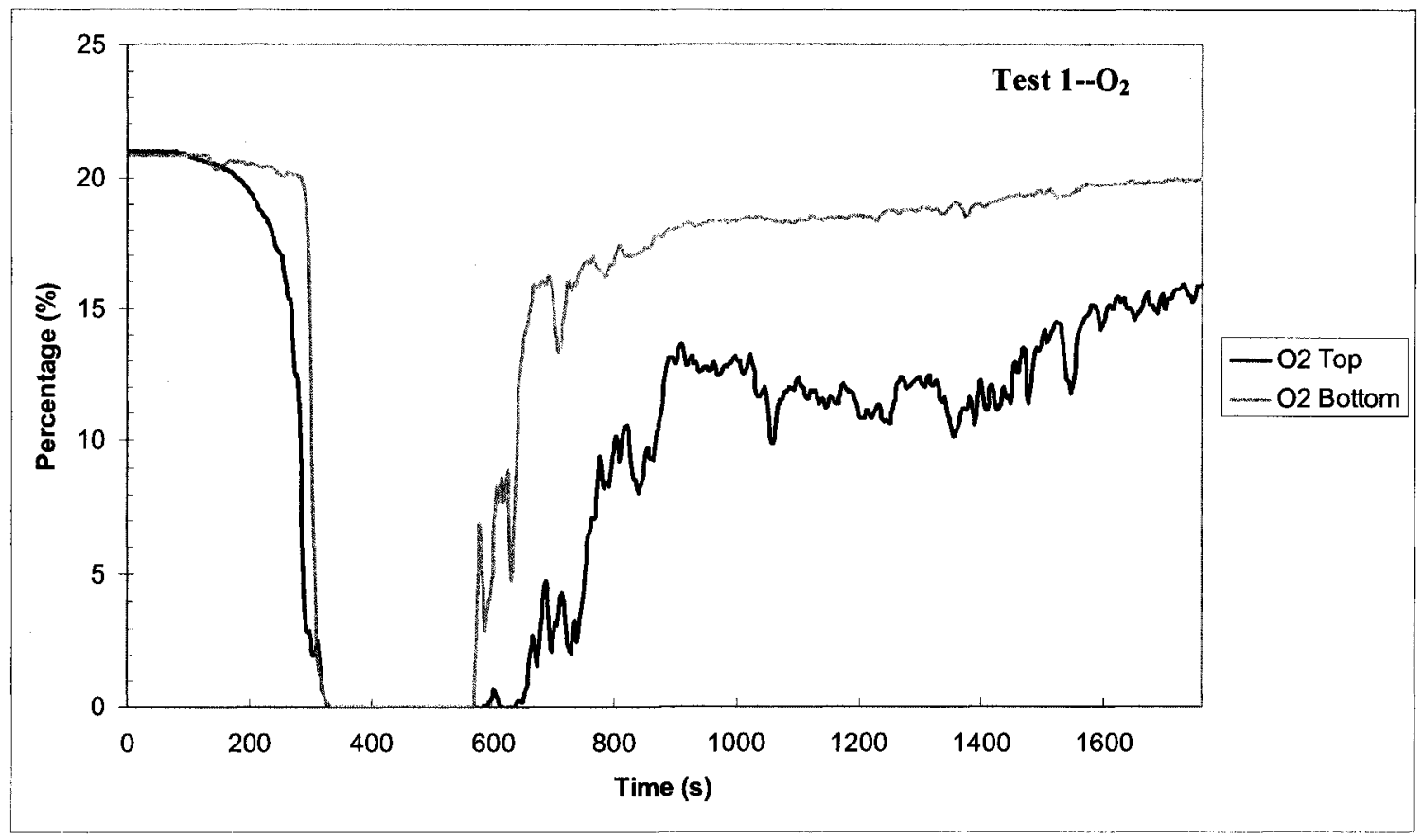

Figure 89 Concentration of $\mathrm{O}_{2}$ in the test room in the $1^{\text {st }}$ test

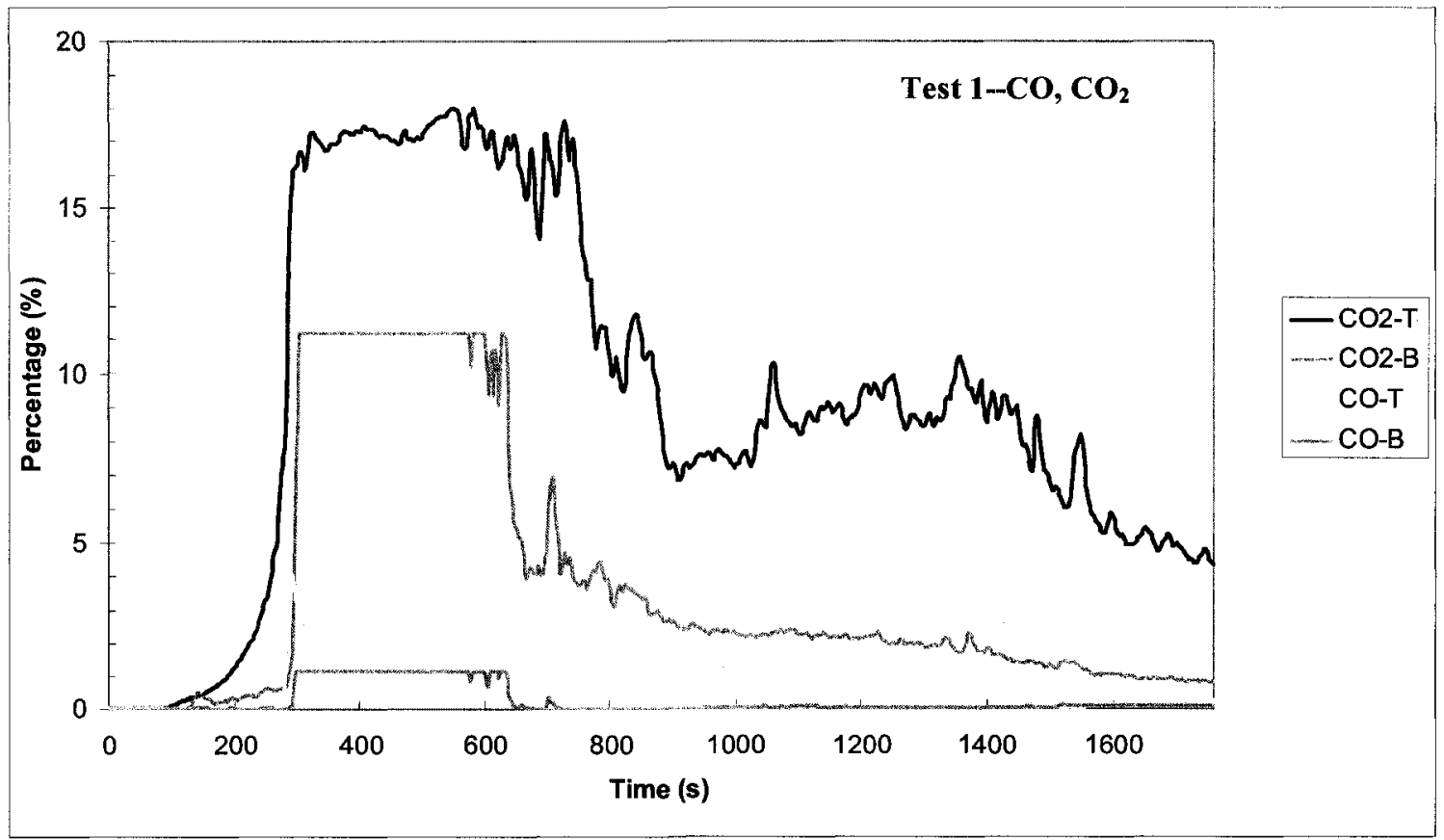

Figure 90 Concentration of $\mathrm{CO}$ and $\mathrm{CO}_{2}$ in the test room in the $1^{\text {st }}$ test

[*T-op; B-Bottom]

129 


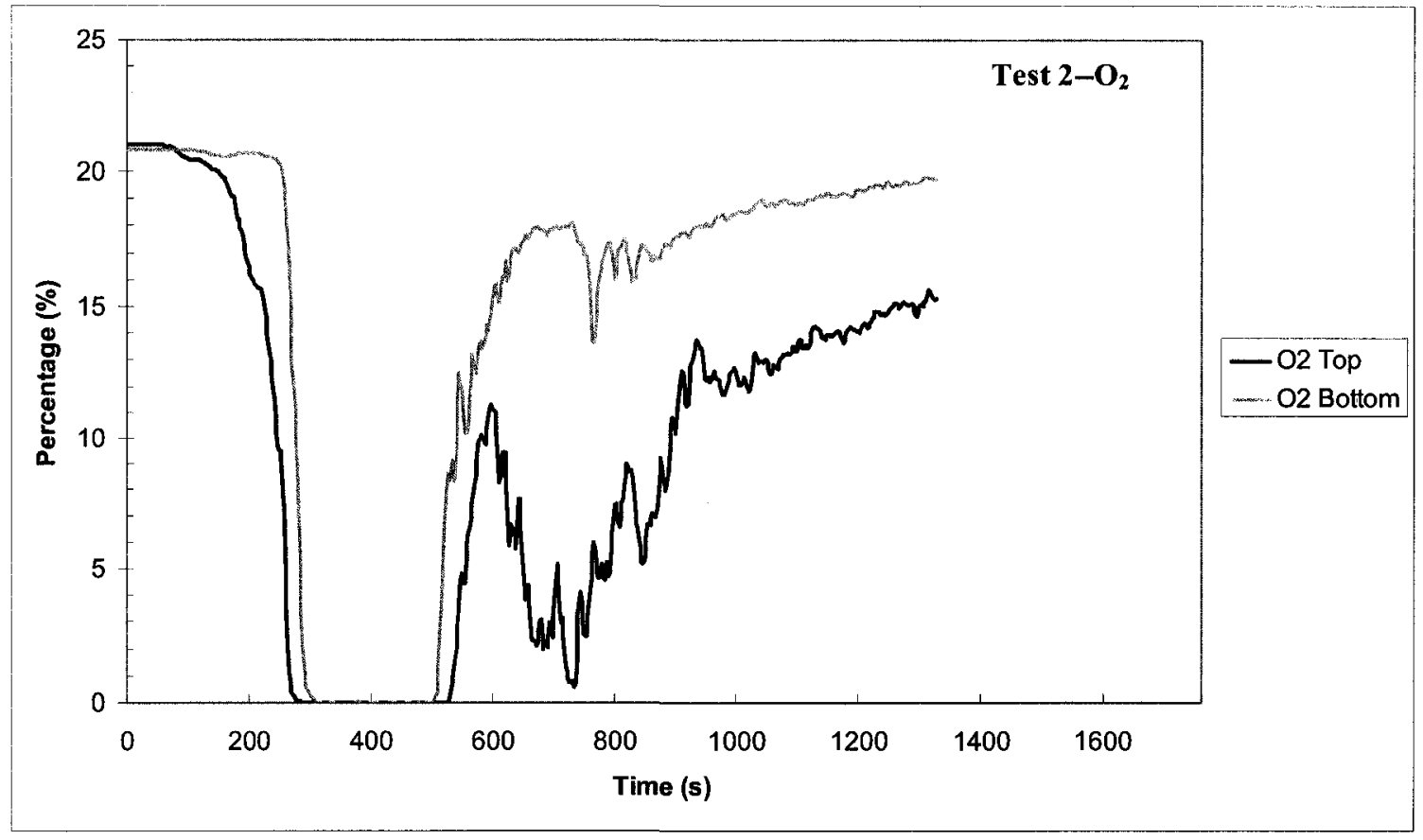

Figure 91 Concentration of $\mathrm{O}_{2}$ in the test room in the $2^{\text {nd }}$ test

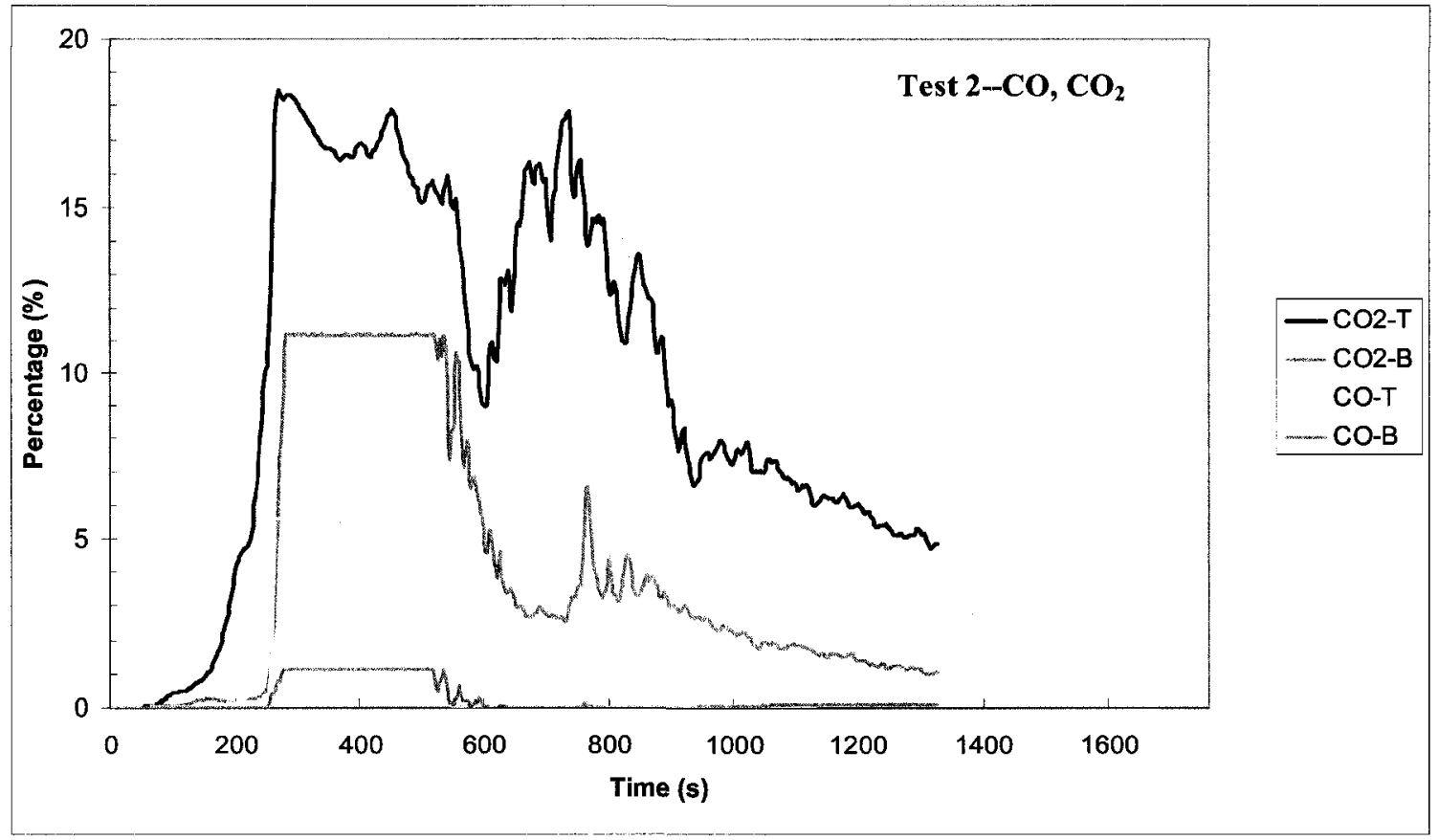

Figure 92 Concentration of $\mathrm{CO}$ and $\mathrm{CO}_{2}$ in the test room in the $2^{\text {nd }}$ test

[*T-Top; B-Bottom]

130 


\subsection{Data Derived for Design Fires}

\subsubsection{HRR vs. Time Curves}

In enclosure fires, the maximum heat release rate is governed by the areas of all openings, and the equation [65] is given by:

$$
\dot{Q}=1.5 A \sqrt{H}
$$

Where, $\quad \dot{Q}=$ heat release rate of the fire (MW)

$$
\begin{aligned}
& A=\text { total area of the openings }\left(\mathrm{m}^{2}\right) \\
& H=\text { weighted height of the openings (m) }
\end{aligned}
$$

For this project, one window opening with the same dimensions of $1.5 \mathrm{~m} \times 1.5 \mathrm{~m}$ was used in both tests, and the calculated maximum heat release rate was $4.13 \mathrm{MW}$. In the two experimental tests, the peak values of the heat release rate were $4.8 \mathrm{MW}$ for the first test, and 3.7 MW for the second test, shown in Figure 65.

In design fires for enclosures, some parameters in the different fire development stages need to be quantified, such as the growth rate in the early stage, heat release rate of fully developed fire, duration of fully developed fire, and duration of decay phase. Figure 93 and Figure 94 provide the design fire curves for the two tests. The design curve 1 for both tests simply followed the heat release rate curve derived from experimental tests. The design curve 2 was conservative for fire protection design with a safety factor of 1.15 applied to the heat release rate of fully developed stage, and a longer duration of fully developed stage. 
As shown in Figure 93, for the first test simulating a bedroom with one double bed, the growth rate of the fire matches a $t^{2}$ fire with a growth rate coefficient of 0.055 , which is slightly higher than the value for fast fires $(0.0466)$. In design curve 1 , the heat release rate for the fully developed stage was assumed to be $3.14 \mathrm{MW}$, with a duration of 400 seconds, which is the average value of heat release rate between 290 to 690 seconds. The heat release rate for the second flat period is the average heat release rate between 982 to 1350 seconds. This value is $1.86 \mathrm{MW}$, with a duration of 368 seconds. The duration for the first decay slope is 292 seconds. The second decay slope was determined by extending the heat release rate curve to the horizontal axis, and drawing the line from the start of the second decay phase to that point. The point at which the curve meets the horizontal axis is 2000 seconds. In design curve 2, the same growth rate is used as in design curve 1 . The heat release rate for the fully developed stage was assumed to be 3.61 MW, with a duration of 768 seconds. The value of $3.61 \mathrm{MW}$ was obtained by multiplying the peak value of design curve 1 by 1.15 . The duration of the fully developed phase was computed by adding the duration of the two horizontal portions of the design curve 1 . The slope of design curve 2 was obtained by extending the curve from the end of the fully developed phase to the end of design curve 1 . The slope of the decay is 3.897 with a duration of 926 seconds. 


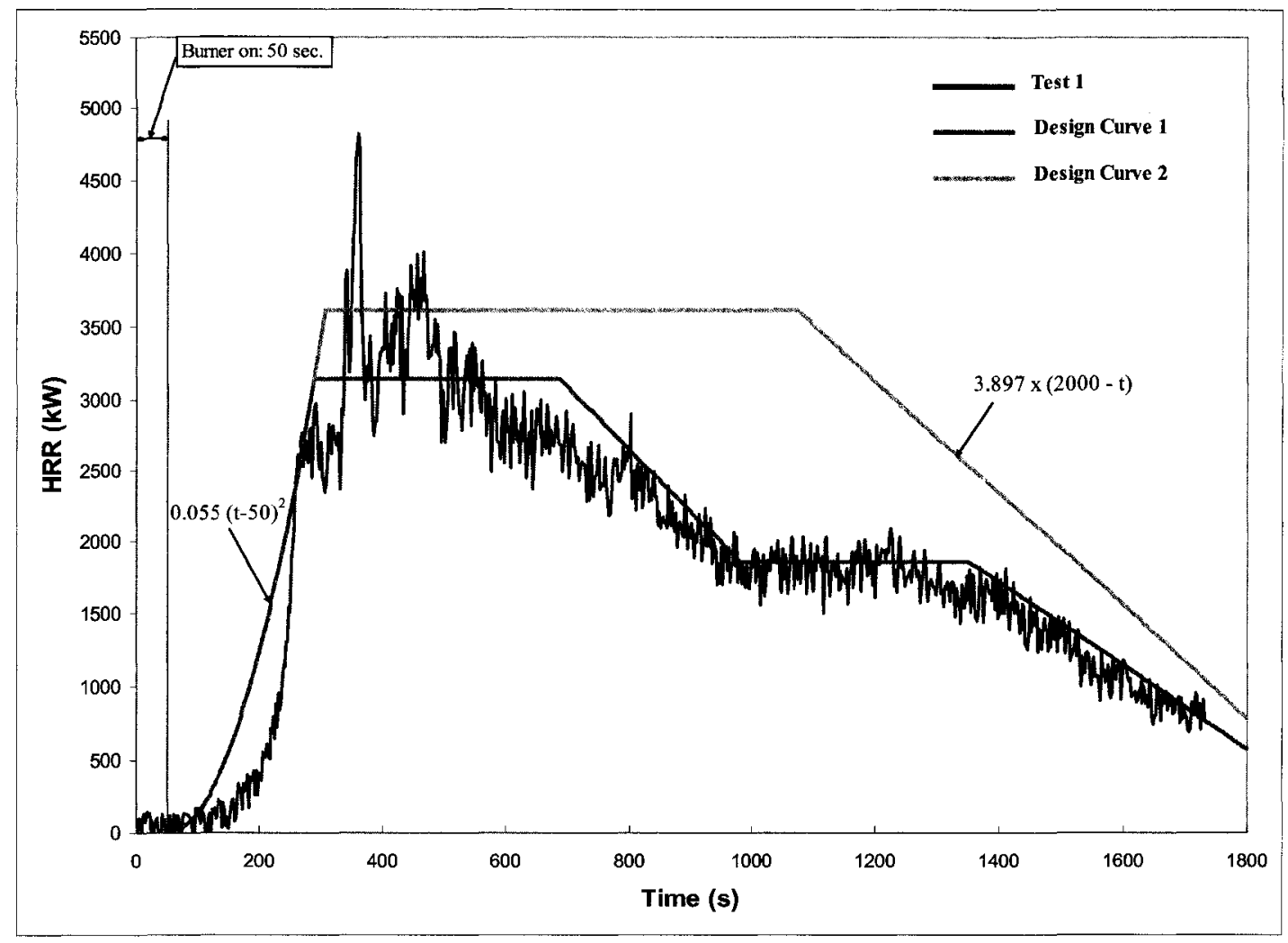

Figure 93 Heat release rate design curves for the $1^{\text {st }}$ test

Figure 94 shows that for the second test, which simulates a bedroom with two single beds, the growth rate coefficient is 0.06 . This value is used for both design curves, and is slightly higher than the characteristic value for fast fires. In design curve 1 , the heat release rate for the fully developed stage is $2.86 \mathrm{MW}$, with a duration of 456 seconds, which is the average value of heat release rate between 268 to 724 seconds. The design curve 1 for the decay stage matches a $\mathrm{t}^{2}$ curve with a coefficient of: 0.00245 , and the duration of the decay stage is approximately 1076 seconds. In design curve 2 , the same growth rate is used as in the design curve 1 . The heat release rate for the fully developed stage of $3.29 \mathrm{MW}$ was determined by multiplying the peak value of design curve 1 by 
1.15. The duration of the fully developed phase is 547 seconds, which is 1.2 times longer than that in design curve 1 . The slope of design curve 2 was obtained by extending the curve from the end of the fully developed phase to the end of design curve 1.

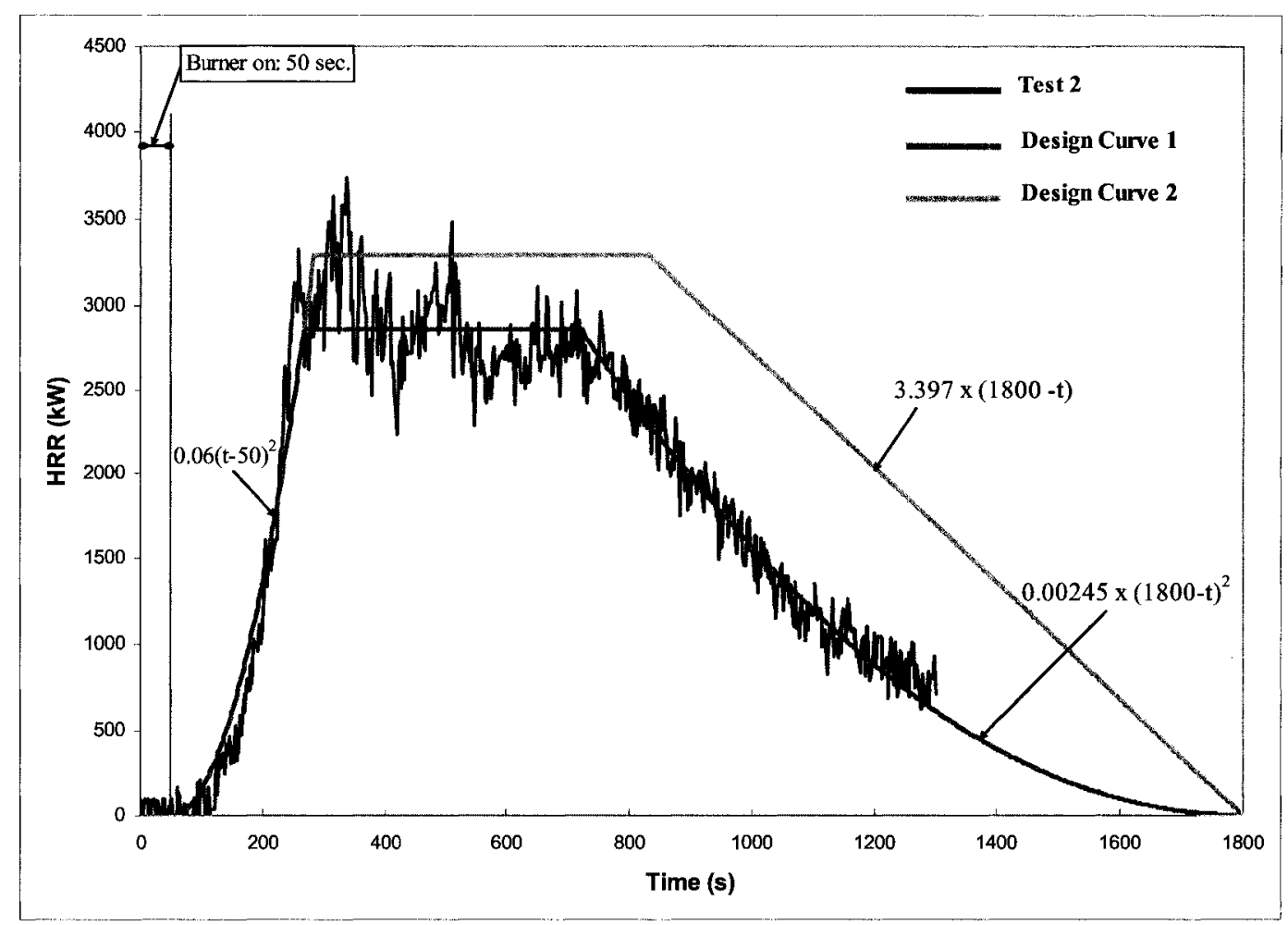

Figure 94 Heat release rate design curves for the 2 nd test

A possible design fire for hotel rooms with the same opening size could be the design curve 2 for the $1^{\text {st }}$ test as it is more severe with higher heat release rate and longer duration.

\subsubsection{Temperature beneath the Ceiling}

In fire protection engineering, the design of many active systems, such as sprinklers and heat detection require knowledge of the temperature beneath the ceiling. In the test room, 134 
five thermocouple trees, and one single thermocouple beneath the centre of the ceiling were used. A total of six thermocouples were located $0.02 \mathrm{~m}$ beneath the ceiling. Figure 95 presents the average temperature of the six thermocouples beneath the ceiling for the two tests. The temperature development of the two tests was very close in the growth stage with the first peak value of about $650^{\circ} \mathrm{C}$ at 286 seconds for the first test, and 262 seconds for the second test. The maximum average ceiling temperatures for the two tests were almost the same at about $990^{\circ} \mathrm{C}$. For both tests, the average ceiling temperatures reached about $950^{\circ} \mathrm{C}$ after 600 seconds. In Test 1 , temperature stayed at values over $600^{\circ} \mathrm{C}$ for close to 25 minutes.

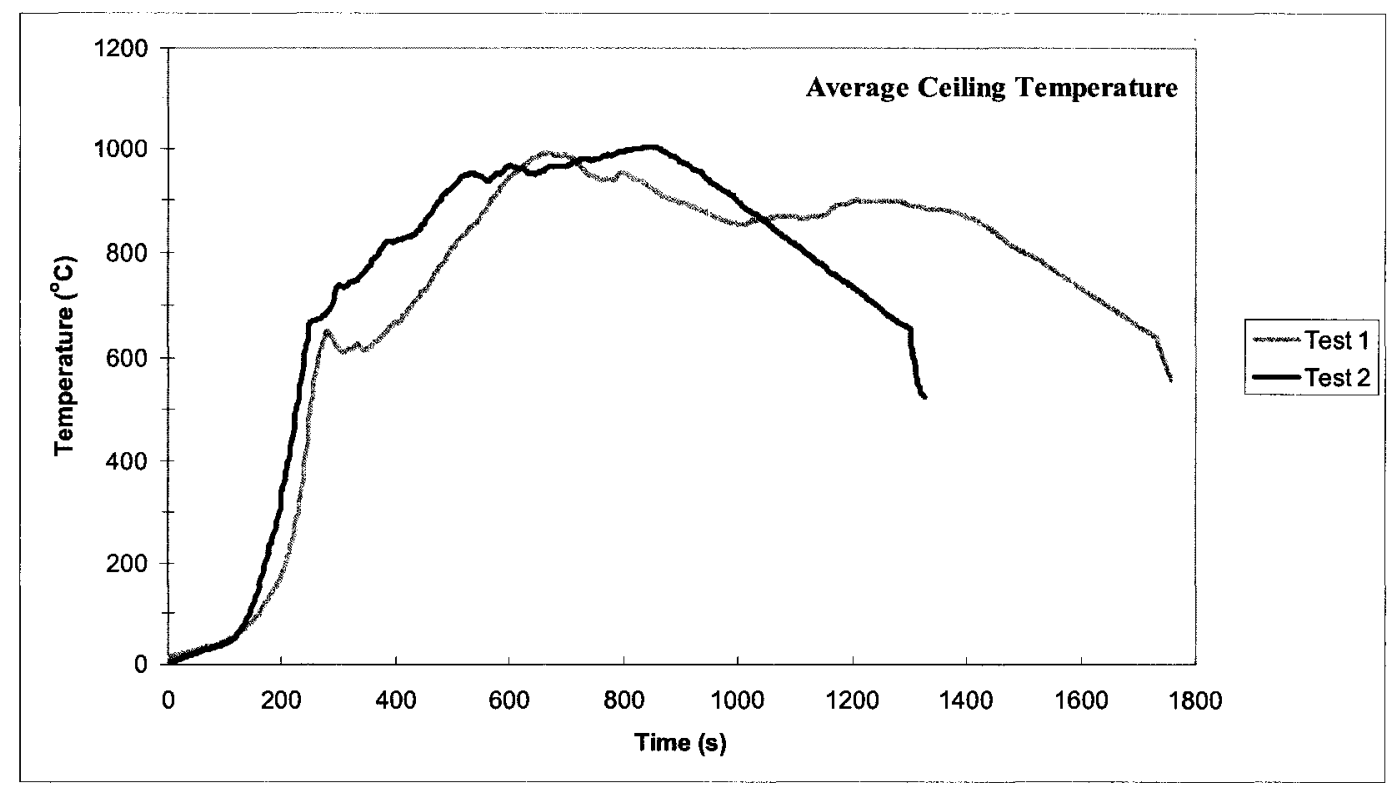

Figure 95 Average ceiling temperature for the two tests 


\subsection{Summary of the Tests}

Two full-scale fire tests have been conducted at the NRCC/Carleton (National Research Council of Canada/Carleton University) Fire Research Lab. The first test, designed to simulate a fire in a hotel bedroom with one bed, was conducted on October $10^{\text {th }}$ of 2008 , and the second test for simulating a fire in a bedroom with two beds, was conducted on November $12^{\text {th }}$ of 2008 . The interior dimensions of the test room for both tests were $3.77 \mathrm{~m} \times 4.17 \mathrm{~m} \times 2.37 \mathrm{~m}$, and the window opening sizes for both tests were $1.5 \mathrm{~m} \mathrm{x}$ $1.5 \mathrm{~m}$.

At the early stage, the fire develops faster in the $2^{\text {nd }}$ test than that in the $1^{\text {st }}$ test. The $1^{\text {st }}$ test had the higher maximum heat release rate of $4.8 \mathrm{MW}$, while the second test reached 3.7 MW. A delay time of 26 seconds was used in the heat release rate calculations for both tests.

In the test room, the highest temperature measured in the $1^{\text {st }}$ test was close to $1200^{\circ} \mathrm{C}$, and that measured in the $2^{\text {nd }}$ test was about $1100^{\circ} \mathrm{C}$, both of which were higher than the maximum average ceiling temperature for the two tests. The highest heat fluxes for both tests were measured at the northeast location of the ceiling, with a value of $286 \mathrm{~kW} / \mathrm{m}^{2}$ (706 s) for the $1^{\text {st }}$ test, and $234 \mathrm{~kW} / \mathrm{m}^{2}(818 \mathrm{~s})$ for the $2^{\text {nd }}$ test.

Two distinguished vertical zones (west and east) of fire development were noticed in the two full-scale fire tests. This phenomenon might be applied to hotel guest rooms and other bedrooms with similar furnishing layout as that for the two tests. Further experimental tests and research on this phenomenon are needed. 
Design fire curves of heat release rate were presented, which could be used as a prescribed fire in FDS input files to simulate smoke movement in the buildings. Average ceiling temperatures for the two tests were also provided, which could be helpful for the design of active and passive fire protection system. 


\section{Chapter 5: FDS Modelling}

\subsection{Introduction}

In this project, the CFD model, FDS was used to simulate hotel fire tests. The Fire Dynamics Simulator (FDS), which is a CFD model developed in the fire community, solves numerically a form of the Navier-Stokes equations, which are appropriate for lowspeed, thermally-driven flow that focuses on smoke and heat transport from fires. Most of the difficulties in simulating fires is to derive a suitable input data file.

\subsection{Data Files Provided in FDS}

In version 4 of FDS, a data file of commonly used materials with material properties and thermal properties was provided, which was quite convenient for fire researchers and engineers to use. However, the new version 5 of FDS does not provide the data file. The reason is that the model developers do not want to (also should not) take the responsibility of people using and quoting the data provided in FDS. Currently, a project was undertaken by WPI (Worcester Polytechnic Institute), the Southwest Research Institute, and the SFPE (Society of Fire Protection Engineers) to develop a standard guide for fire model input parameters, including documentation of the standard test methods used to obtain material properties [66]. 
Actually, in FDS version 5, some examples are also given, which have some data, but most of them are labelled as 'Properties completely fabricated'. The normally used materials for room fire, such as PMMA, upholstery, and spruce, can be found in both the data files of FDS version 4, and the examples of FDS version 5.

In FDS, two burning phases are considered. One is a solid phase pyrolysis, and the other is gas phase combustion. Different materials can have different solid phase pyrolysis, but for the gas phase combustion, only one gaseous fuel can be defined in FDS, due to the cost of solving the transport equations or multiple gaseous fuels [52].

\subsection{Virtual Fuels Developed for FDS Modelling}

Based on the assumption that all of the fuels in compartment are uniformly distributed, a virtual fuel package was used to model the fuels in different commercial stores, such as computer stores, book stores, shoe stores, and toy stores [60]. Virtual fuel packages were developed for the seven types of stores with PMMA as the base material. The material properties of virtual fuel packages for different commercial stores are summarized in Table 32. Properties common to all seven packages were the conductivity 'KS', specific heat 'C_P', maximum burning rate 'BURNING_RATE_MAX', and density 'DENSITY', with the values of $0.19 \mathrm{~W} / \mathrm{m} / \mathrm{K}, 1.42 \mathrm{~kJ} / \mathrm{kg} / \mathrm{K}, 0.028 \mathrm{~s}^{-1}$, and $536 \mathrm{~kg} / \mathrm{m}^{3}$, respectively. Properties, which were different for each fuel package, were the heat of vaporization 'HEAT_OF_VAPORIZATION', heat of combustion 'HEAT_OF_COMBUSTION', and the ignition temperature 'TEMPIGN'. Two values for 'HEAT_OF_VAPORIZATION' were used, $1620 \mathrm{~kJ} / \mathrm{kg}$ for five stores, and $1134 \mathrm{~kJ} / \mathrm{kg}$ for two stores. For 
'HEAT_OF_COMBUSTION', three values were used, $18270 \mathrm{~kJ} / \mathrm{kg}$ for five stores, $20097 \mathrm{~kJ} / \mathrm{kg}$ and $22000 \mathrm{~kJ} / \mathrm{kg}$ for two stores. For ignition temperature, four values were used. They were $285,304,380$ and $383^{\circ} \mathrm{C}$.

Table 32 Virtual fuel packages for different commercial stores (summarized from [60])

\begin{tabular}{lccccccc}
\hline Material properties in solid phase & 'CMP' & 'SA-II' & 'CLC-II' & 'TOY-II' & 'SHO-II' & 'BK-II' & 'FF-II' \\
\hline HEAT_OF_VAPORIZATION & 1134 & 1620 & 1134 & 1620 & 1620 & 1620 & 1620 \\
HEAT_OF_COMBUSTION & 20097 & 18270 & 18270 & 18270 & 18270 & 18270 & 22000 \\
BURNING_RATE_MAX & 0.028 & 0.028 & 0.028 & 0.028 & 0.028 & 0.028 & 0.028 \\
DELTA & 0.012 & 0.02 & 0.01 & 0.02 & 0.0216 & 0.0216 & 0.015 \\
KS & 0.19 & 0.19 & 0.19 & 0.19 & 0.19 & 0.19 & 0.19 \\
C_P & 1.42 & 1.42 & 1.42 & 1.42 & 1.42 & 1.42 & 1.42 \\
DENSITY & 536 & 536 & 536 & 536 & 536 & 536 & 536 \\
BACKING & & \multicolumn{5}{c}{ INSULATED } \\
TMPIGN & 380 & 285 & 380 & 285 & 304 & 304 & 383 \\
\hline
\end{tabular}

[*'CMP' - Computer Store; 'SA-II'-Storage Area; 'CLC-II'—Clothing Store; 'TOY-II'-Toy Store; 'SHOII'-Shoe Store; 'BK-II'-Bookstore; 'FF-II'-Fast Food Outlet]

In the hotel room scenario, the fuels are not uniformly distributed. One important feature for these room fires is that there are two distinguished groups of materials or fuels involved in fire. One group is the foam and fabric of the bed and sofa with lower density and higher heat of combustion, which usually is involved during the early stages of the fire. The other group includes all other materials, such as wood, plastic, paper, foam and fabric, which become involved after flashover. The materials of wood and plastic have higher density and lower heat of combustion than the foam and fabric.

Two virtual fuels were developed for simulating hotel room fires. One virtual fuel that mainly includes foam and fabric is named ' $\mathrm{FF}$ '. The other virtual fuel includes the 
materials of wood, plastic, paper, foam and fabric is named 'WPFF'. The material and thermal properties for the two virtual fuels are given in Table 33.

For gas phase combustion, only one gaseous fuel can be defined in the reaction ID for each FDS modelling. POLYURETHANE was used in the room fire example of FDS version 4 and 5 . The data have a source that is from ' $\mathrm{C} \_6.3 \mathrm{H}$-7.1 $\mathrm{N} \mathrm{O}$ 2.1, NFPA Handbook, Babrauskas' [52]. PROPANE is one of the widely used gaseous fuels in FDS, which is known as 'C_3 $\mathrm{H} \_$'. In order to check the sensitivity of different gaseous fuel used in the FDS modelling, both POLYURETHANE and PROPANE were tried in the same simulation setup.

Table 33 Material and thermal properties for two virtual fuels

\begin{tabular}{lcc}
\hline \&MATL ID & 'FF' & 'WPFF' \\
CONDUCTIVITY & 0.1 & 0.1 \\
SPECIFIC_HEAT & 1.0 & 1.5 \\
DENSITY & 25 & 450 \\
HEAT_OF_REACTION & 1500 & 1500 \\
HEAT_OF_COMBUSTION & 35000 & 18000 \\
REFERENCE_TEMPERATURE & 280 & 320 \\
REFERENCE_RATE & 0.05 & 0.005 \\
N-REACTIONS & 1 & 1 \\
NU_FUEL & 1 & 1 \\
& & \\
\&SURF ID & 'VF-1' & 'VF-2' \\
THICKNESS & 0.1 & 0.02 \\
BURN_AWAY &.$T R U E$. &. TRUE. \\
PART_ID & 'smoke' & 'smoke' \\
MATL_ID & 'FF' & 'WPFF' \\
\hline
\end{tabular}

\subsection{FDS Simulation for the Fire Test 1}

For the virtual fuel ' $\mathrm{FF}$ ', a form of slab was constructed with dimensions of $2.1 \mathrm{~m} \mathrm{x}$ $1.5 \mathrm{~m} \times 0.3 \mathrm{~m}$. For the virtual combined fuel 'WPFF', a form of bar was used with a cross 
section of $0.1 \times 0.1 \mathrm{~m}$, and three lengths of the bars $(1.5 \mathrm{~m}, 2.0 \mathrm{~m}$, and $2.1 \mathrm{~m})$. Two types of fuel layouts were considered. The layout 1 was to put the two virtual fuels in the middle of the room with FF slab on the top and WPFF bar beneath the slab. Layout 2 was to locate the FF slab and one layer of WPFF bar at the place where the bed was located in the test, and place all other WPFF bars at the place close to the middle of the east wall, where the furniture was located in the test. Layout 2 was based on the observation of two vertical zones (west and east) of fire development noticed in the experimental tests. The same total volumes of 'FF' and 'WPFF' were used in the two different fuel layouts. Figure 96 and Figure 97 show the two floor layouts of the two virtual fuels.

In each simulation, one pilot burner was placed beside the FF slab at the side close to window opening. Both burners had the same dimensions of $0.2 \mathrm{~m} \times 0.3 \mathrm{~m}$, the same heat release rate of $60 \mathrm{~kW}$. A grid size of $0.1 \mathrm{~m} \mathrm{x} 0.1 \mathrm{~m}$ was used for all simulations.

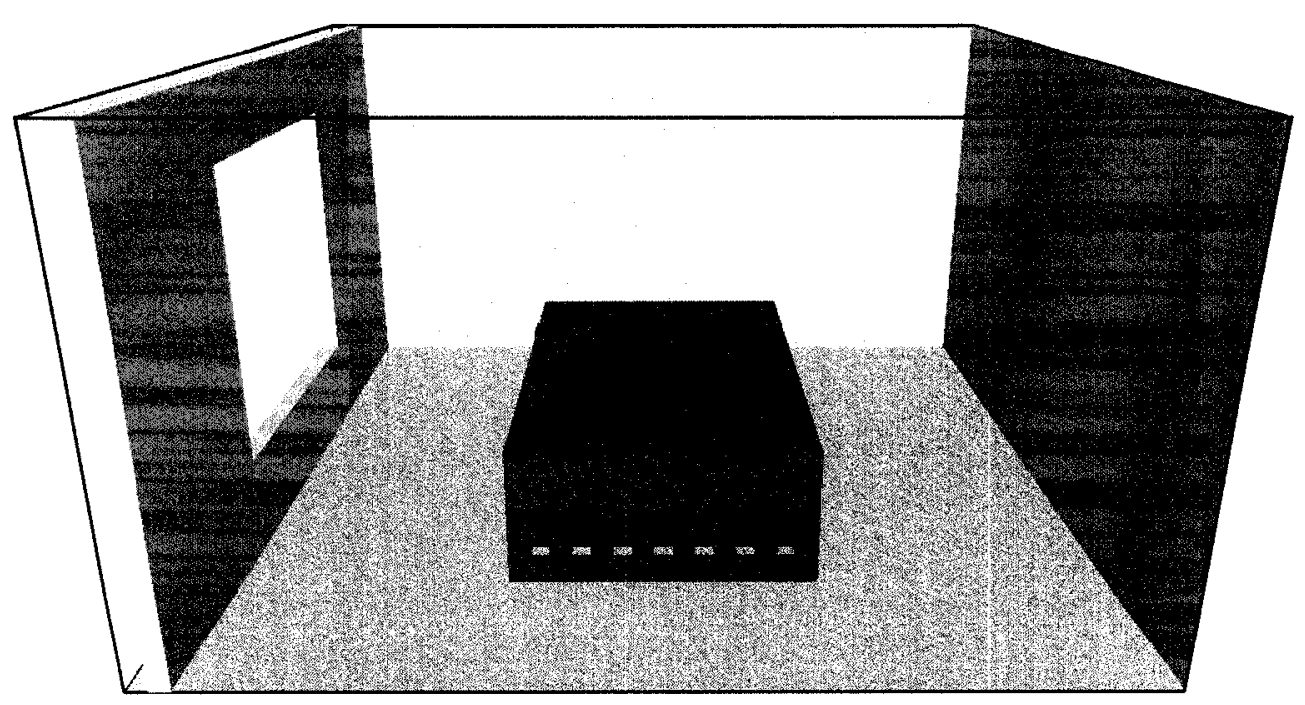

Figure 96 Layout 1 of virtual fuels 


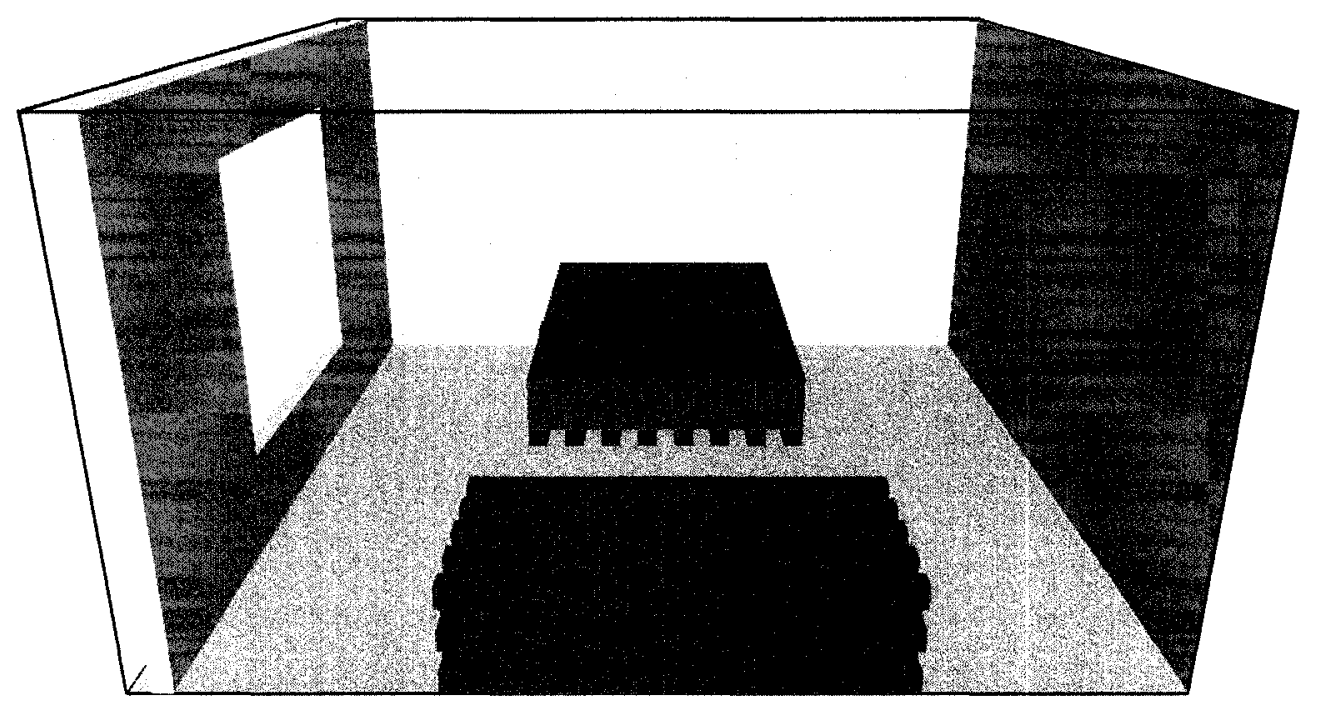

Figure 97 Layout 2 of virtual fuels

\subsubsection{Heat Release Rate Prediction}

Figure 98 and Figure 99 present the simulation results by using different gaseous fuels (PROPANE and POLYURETHANE) for different solid fuel layouts. For the simulations with PROPANE gaseous fuel, the two solid fuel layouts gave good predictions at the early stage of fire development. Both simulations even predicted the first peak value, the maximum values, and their time close to the experimental data. The predicted heat release rates for the fully developed stage were higher than the experimental data. In the decay stage, both simulations had poor prediction with the sharp slope of the decay, and Layout 2 had a slightly better prediction than Layout 1, probably because the two locations of the fuels in the layout 2 prolonged the time of flame spread.

For the simulations with POLYURETHANE gaseous fuel, both solid fuel layouts did not give good predictions. The simulation of Layout 2 predicted the first peak value of heat release rate at about 90 seconds, which was about 145 seconds earlier than the 
simulation result of Layout 1 , and about 200 seconds earlier than the experimental data. In the fully developed stage, the heat release rates for both simulations continued to rise until they reach the maximum values, and then dropped sharply. Almost no decay stages appeared.

Among the four simulation setups, the simulation using propane gaseous fuel and solid fuel layout 2 had a better prediction. The problem of predicting for decay stage, which appeared in all simulations, can be improved in fire protection design by adjusting the slope of the decay curve within a reasonable range. 


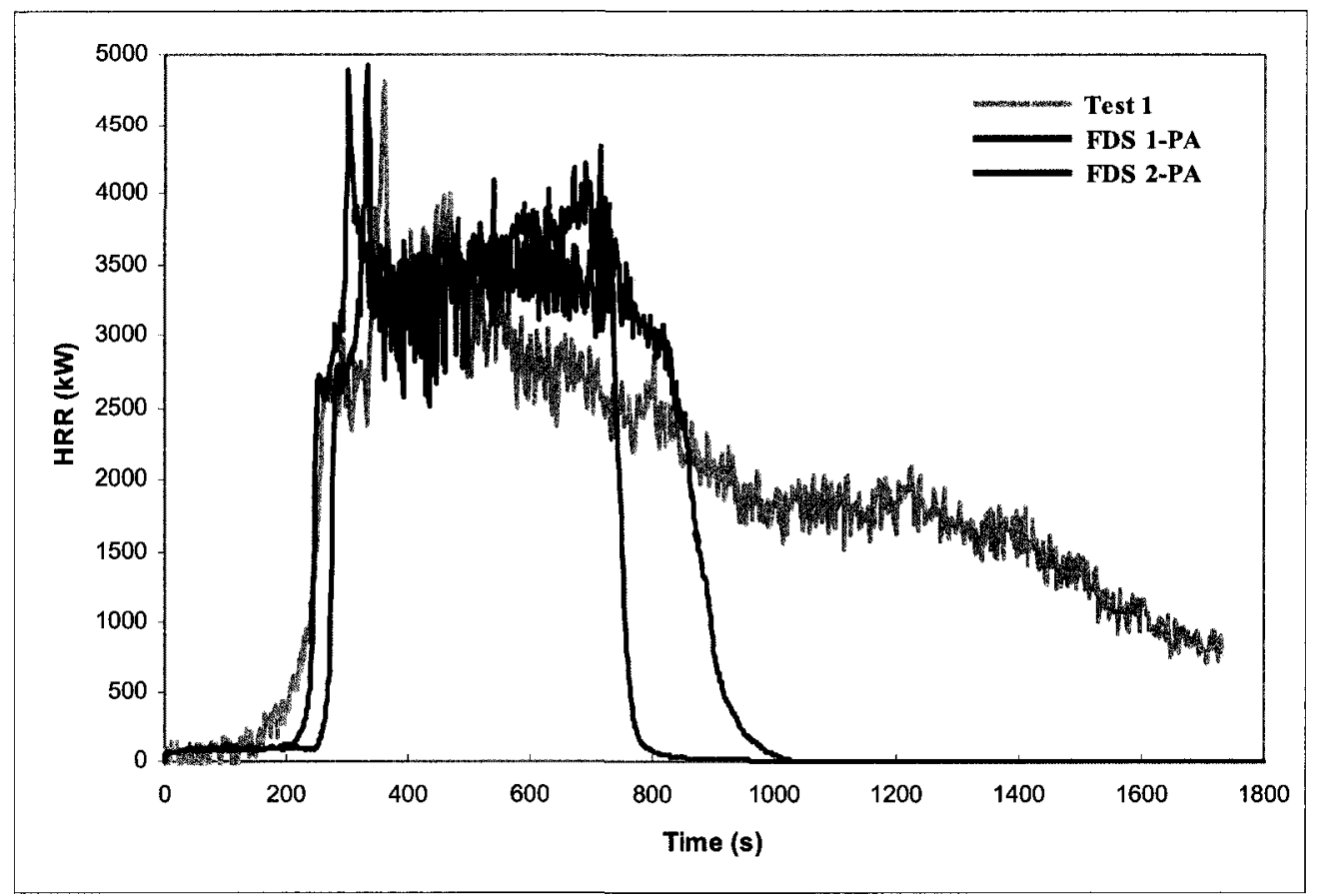

Figure 98 Heat release rate prediction by using PROPANE with two virtual fuel layouts

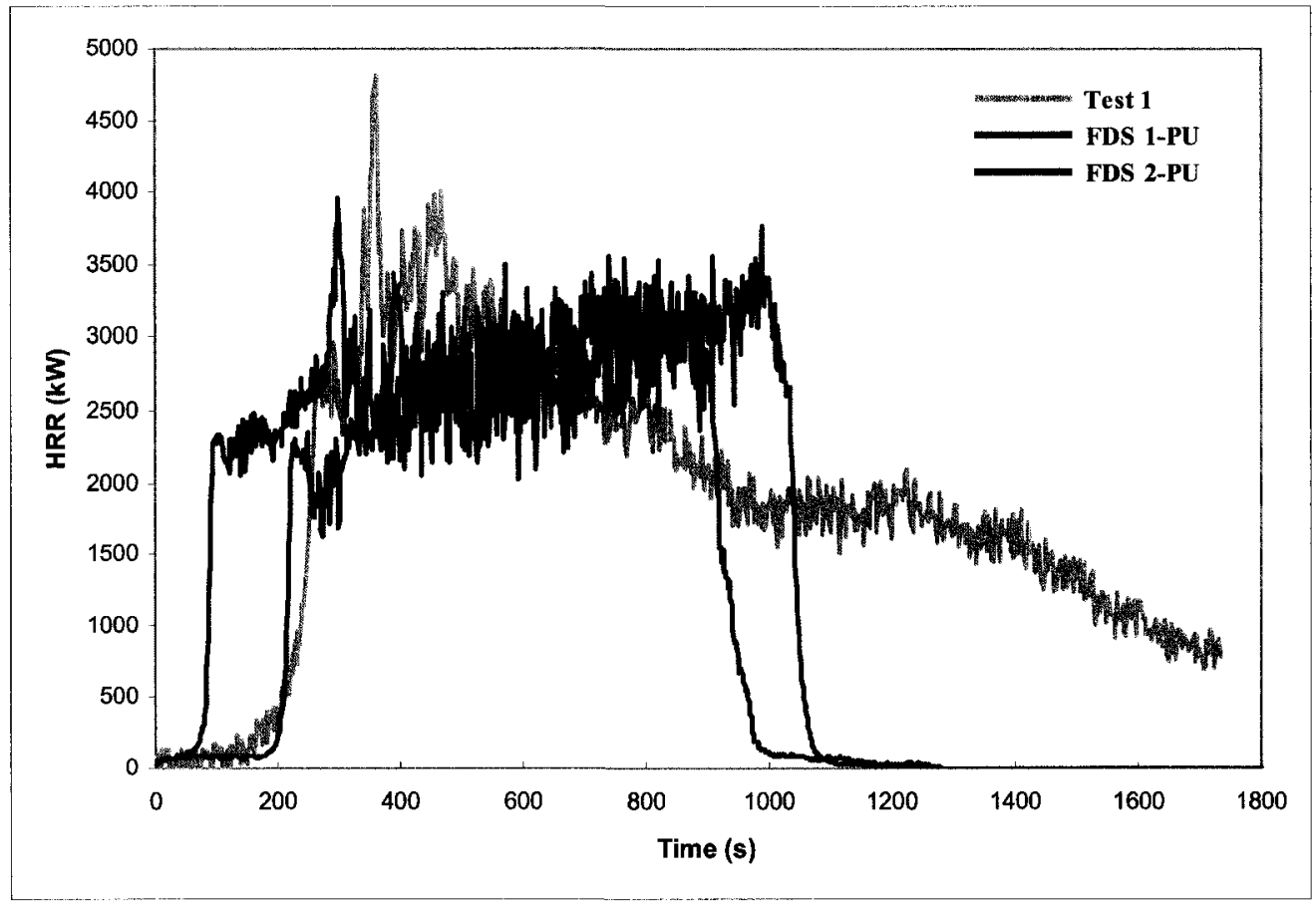

Figure 99 Heat release rate prediction by using PU with two virtual fuel layouts 145 


\subsubsection{Temperature Prediction}

In the two fire tests, five thermocouple trees, SW (southwest), NW (northwest), NE (northeast), SE (southeast), and NW Corner (northwest corner), were used to measure the room temperature. For the FDS simulation using the two different virtual fuel layouts, the temperature measurement of the thermocouple tree at the NW Corner was chosen for comparison with the experimental data.

Figure 100 and Figure 101 present the temperature predictions using PROPANE gaseous fuel with two virtual fuel layouts. Both simulations predicted two peak values, which compared well with experimental data, especially in the early stage of the fire. In the simulation with Layout 2, the two bottom thermocouples of the NW Corner tree measured the second peak value (also maximum value) of $1070^{\circ} \mathrm{C}$ at about $660 \mathrm{~s}$, which was very close to the experimental data. The two simulations had poor predictions in the decay stage, which is similar to heat release rate prediction. Figure 102 and Figure 103 present the temperature predictions by using POLYURETHANE gaseous fuels with two virtual fuel layouts, but both simulations had poor predictions.

Figure 104 and Figure 105 present the temperature in the centre of the room beneath the ceiling measured in the experiments and the simulations with the two different gaseous fuels and two different virtual fuel layouts. The simulation with PROPANE and Layout 2 also had a relatively better prediction than the other three simulations. 


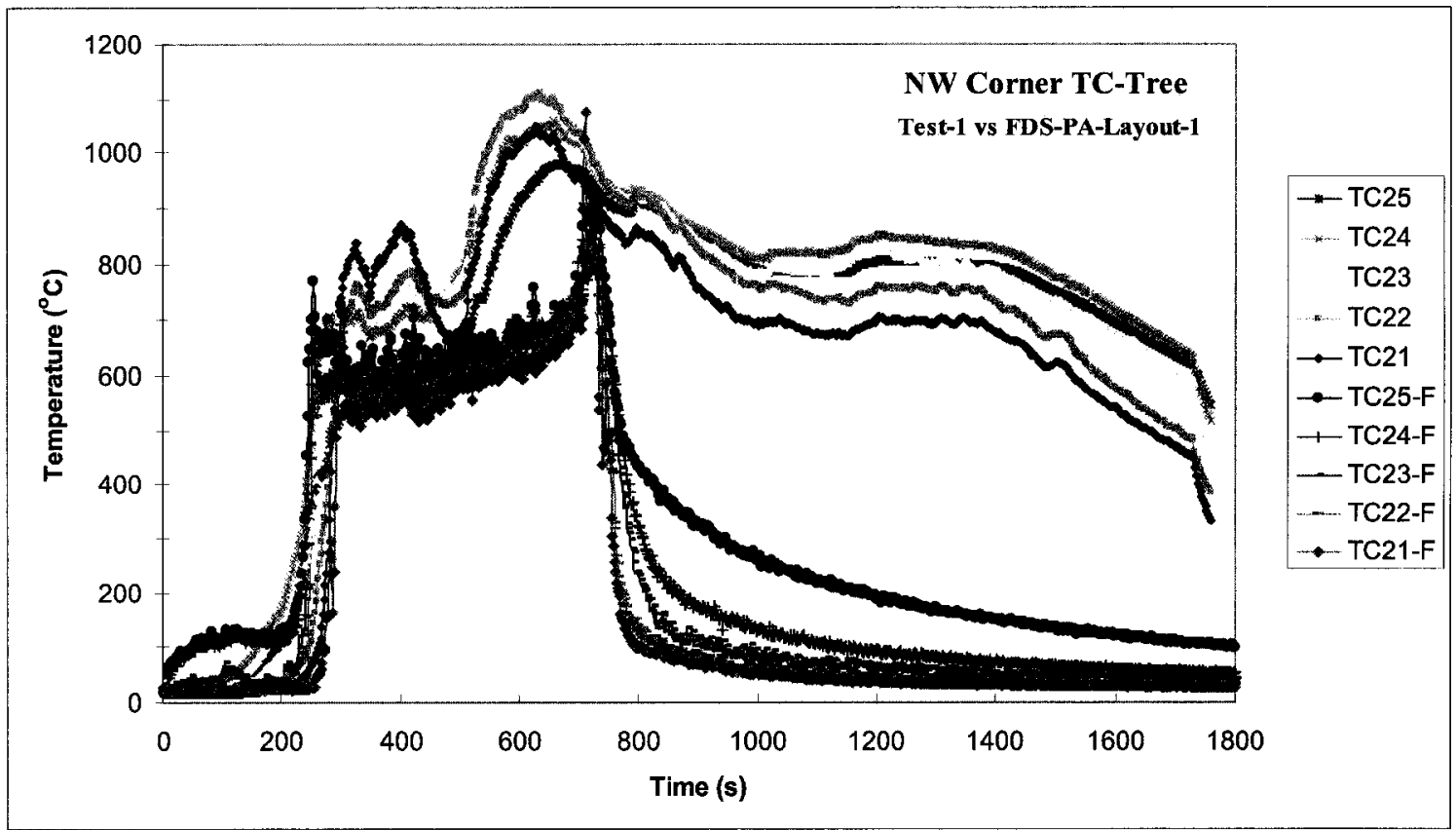

Figure 100 TC tree temperature prediction by using PROPANE and virtual fuel layout 1

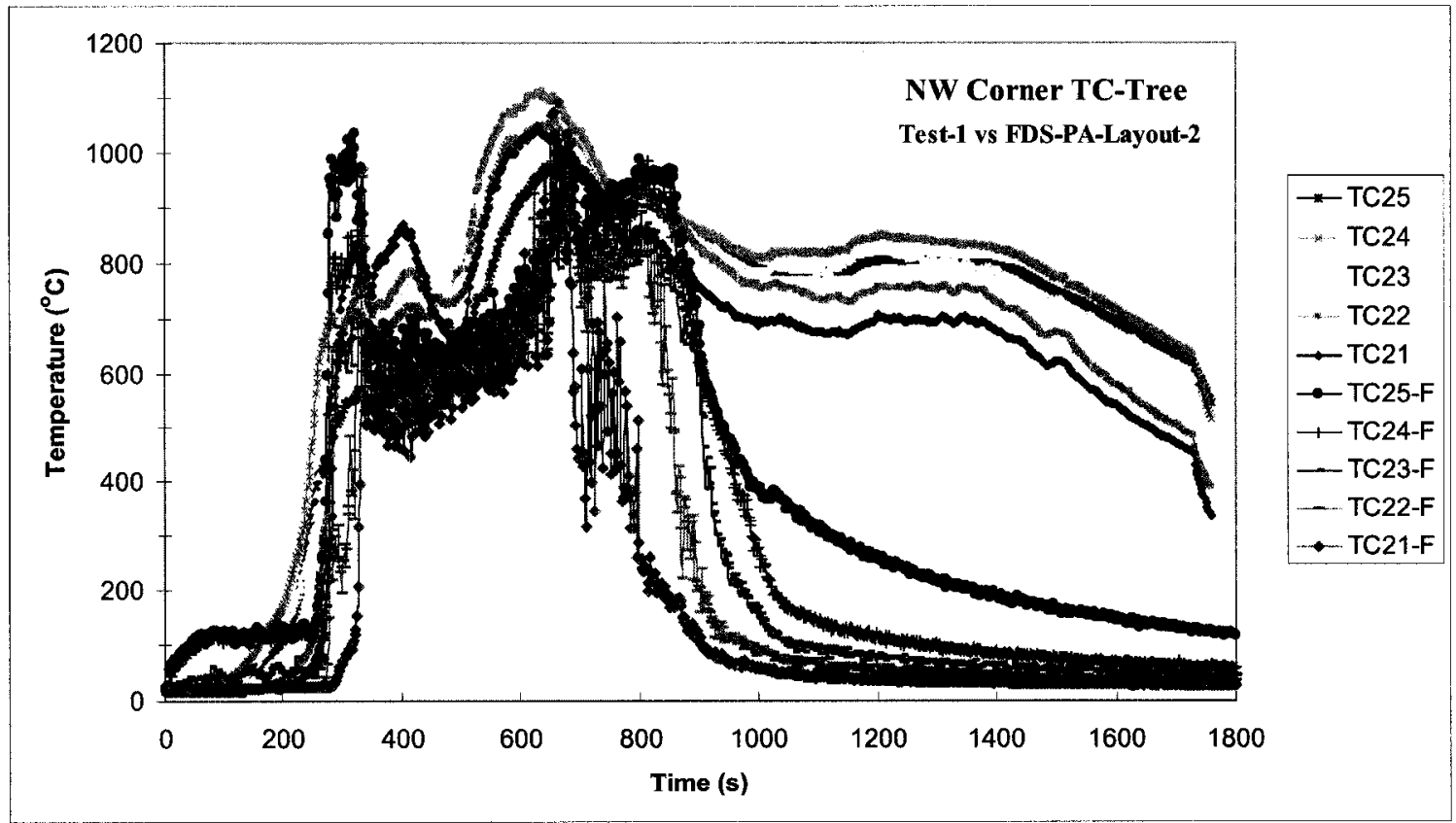

Figure 101 TC tree temperature prediction by using PROPANE and virtual fuel layout 2 


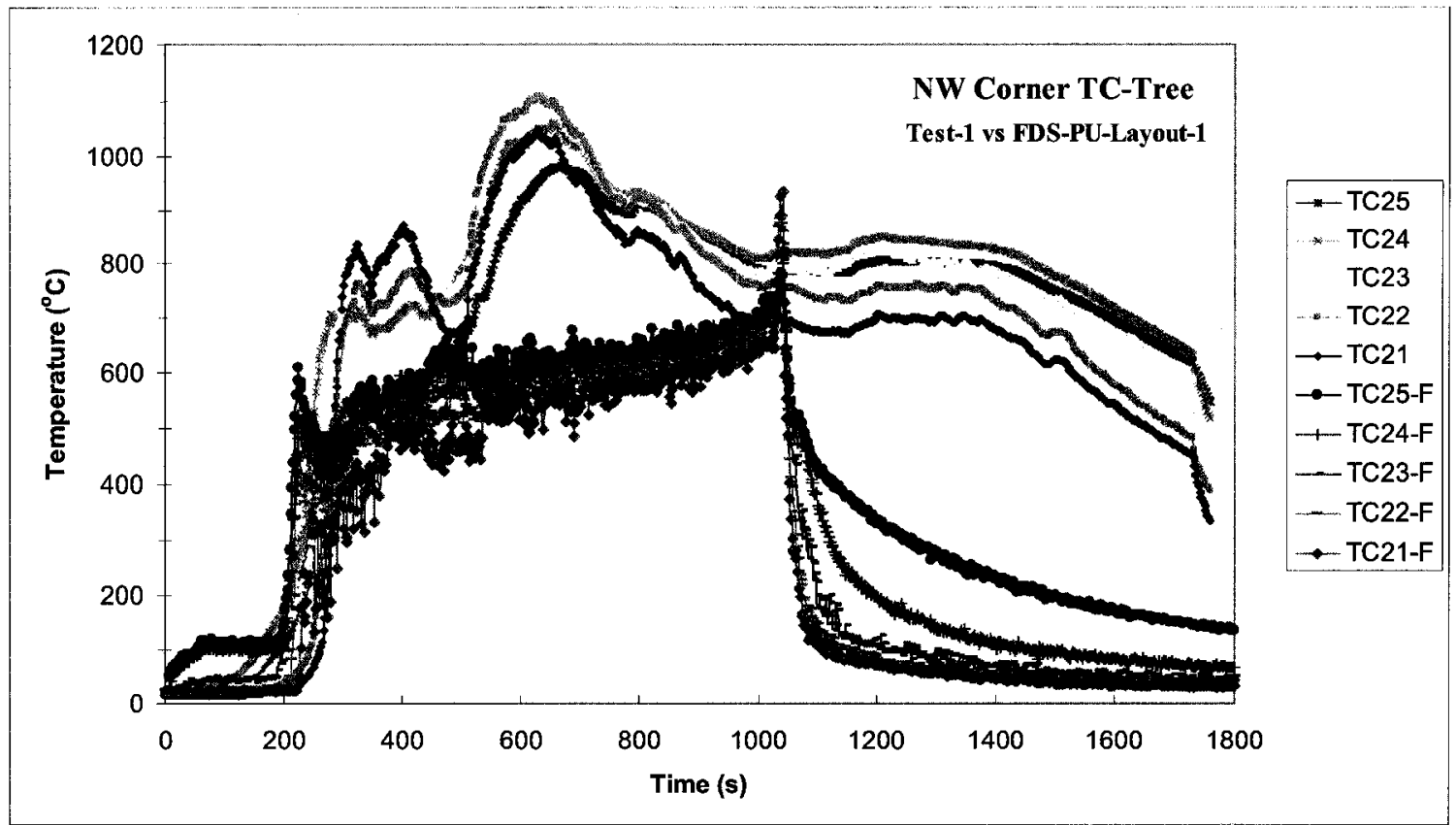

Figure 102 TC tree temperature prediction by using PU and virtual fuel layout 1

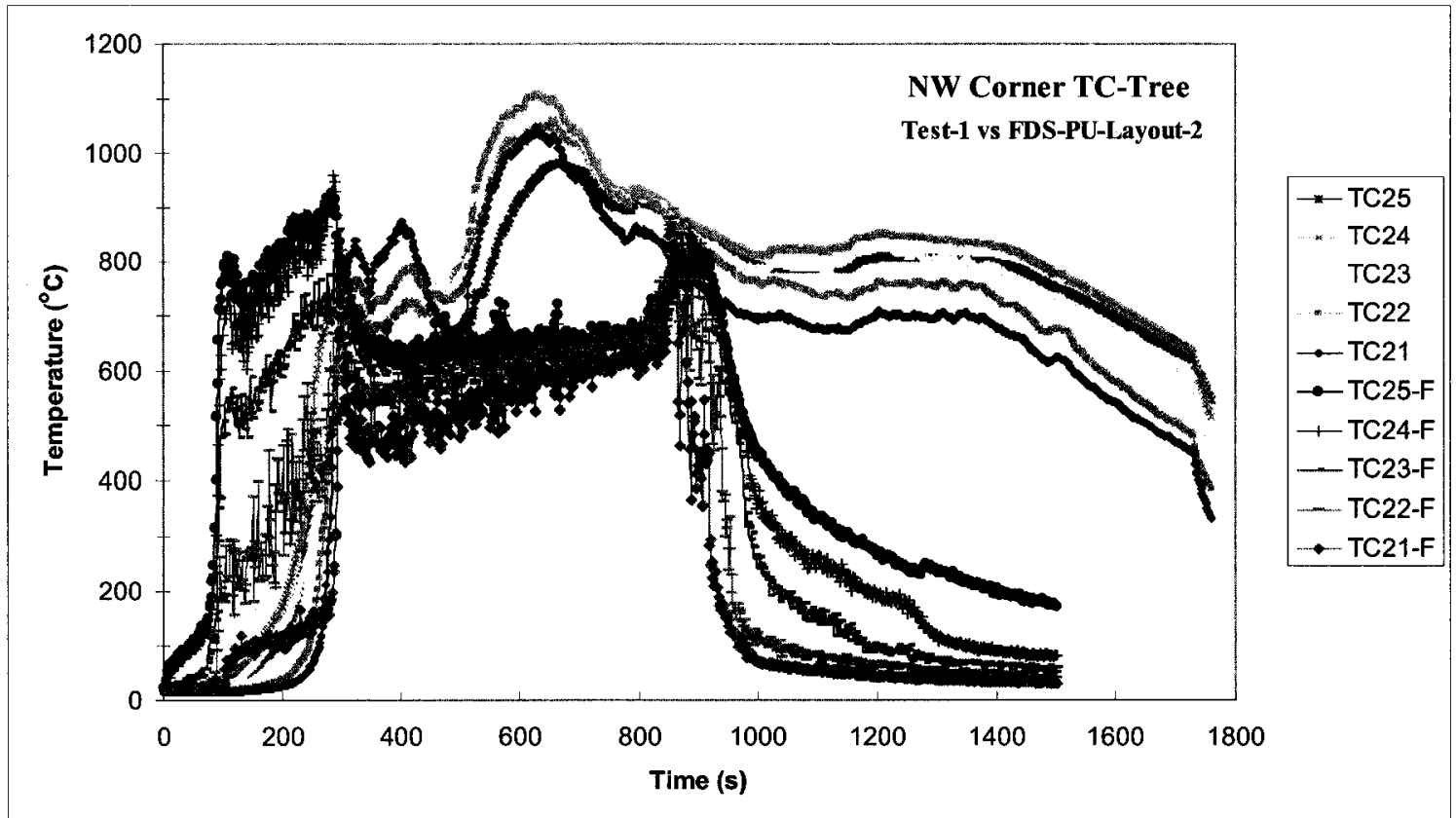

Figure 103 TC tree temperature prediction by using PU and virtual fuel layout 2 


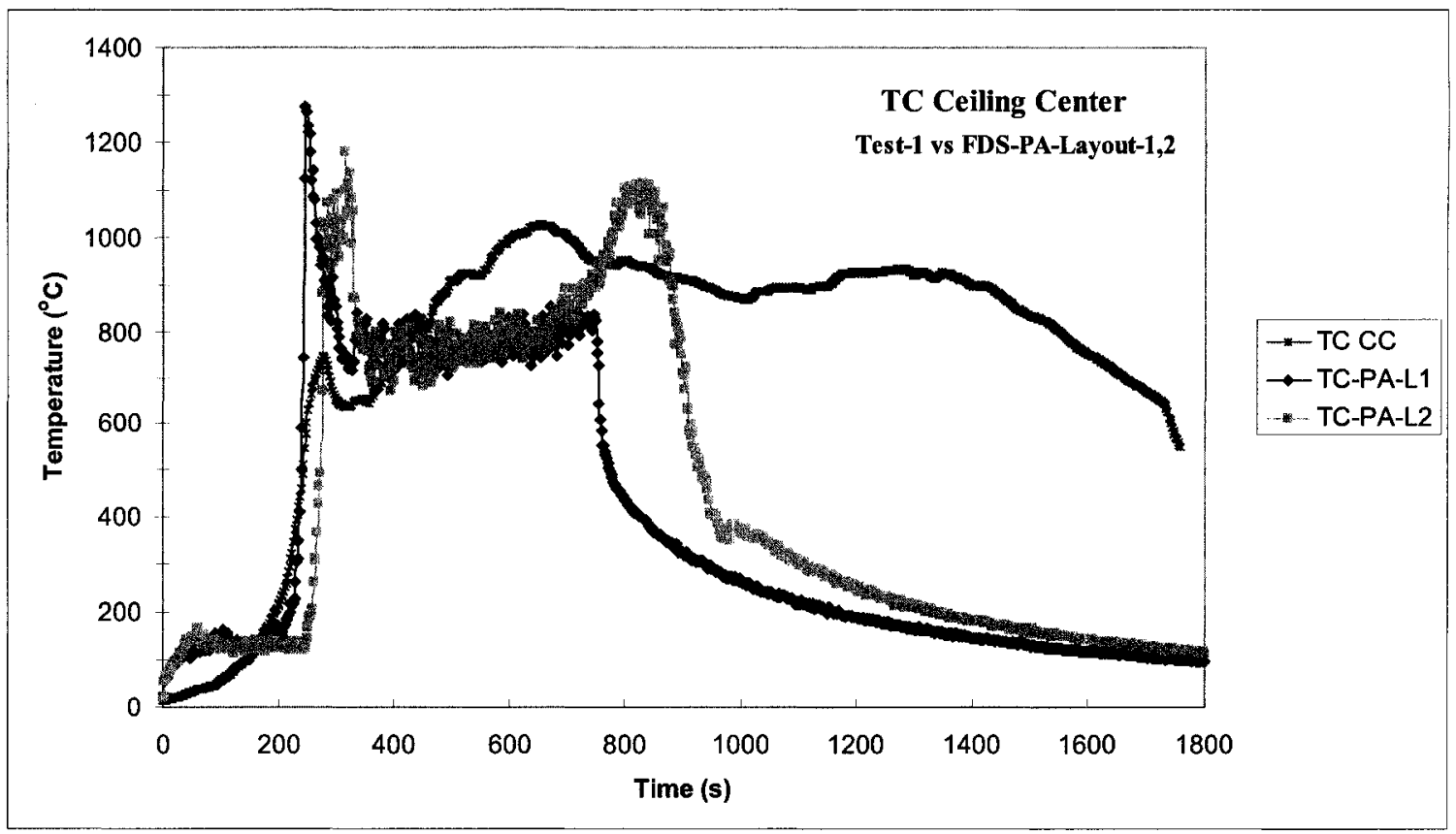

Figure 104 Ceiling center temperature prediction by using PA with two virtual fuel layouts

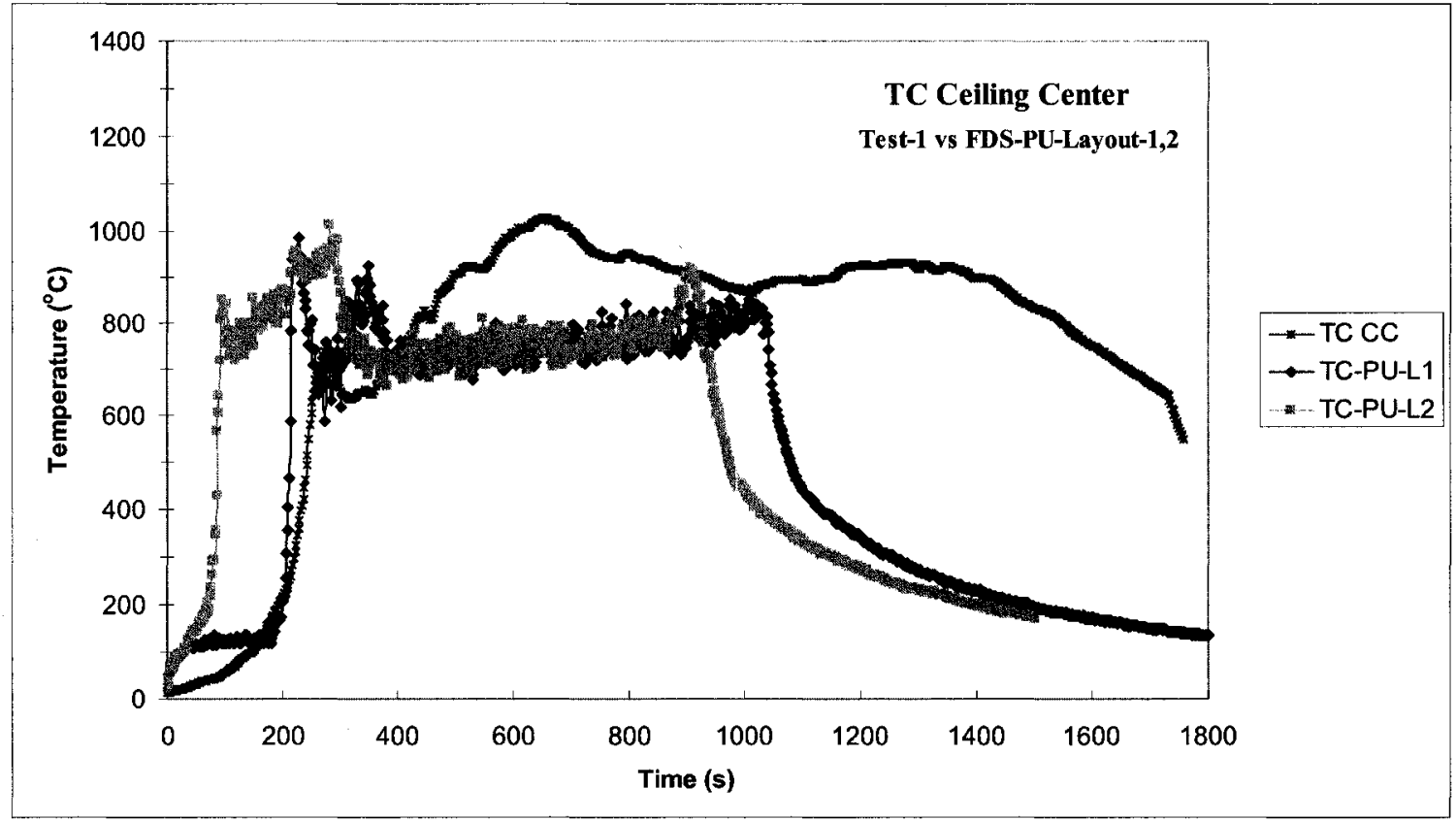

Figure 105 Ceiling center temperature prediction by using PU with two virtual fuel layouts 


\subsubsection{Gas Concentration Prediction}

In the four simulations with two different gaseous fuels and two different virtual fuel layouts, gas concentrations were also measured at the same locations as that in the experiment, which were at heights of $0.4 \mathrm{~m}$, and $1.5 \mathrm{~m}$ from the floor and at the northwest corner of the room. Figures 106 to 109 present the simulation results of $\mathrm{CO}$ and $\mathrm{CO}_{2}$ concentration using two different gaseous fuels (PROPANE and POLYURETHANE) and two different virtual fuel layouts. All of the four simulations did not predict $\mathrm{CO}$ concentration. Except for the simulation with POLYURETHANE and virtual fuel layout 1 , the other three simulations had good predictions of $\mathrm{CO}_{2}$ concentrations. The two simulations using PROPANE gaseous fuel had similar $\mathrm{CO}_{2}$ concentration plateau values at about $10 \%$, and the other two simulations with POLYURETHANE had similar $\mathrm{CO}_{2}$ concentration plateau values at about $13.5 \%$, both of which were lower than the experimental data at the maximum value of $17.9 \%$.

Figures 110 to 113 present the predictions of $\mathrm{O}_{2}$ concentration using two different gaseous fuels and two different virtual fuel layouts. Similar to $\mathrm{CO}_{2}$ prediction, the three simulations, except for the simulation with POLYURETHANE and virtual fuel layout 1 , predicted well $\mathrm{O}_{2}$ concentration. The two simulations using PROPANE gaseous fuel had similar $\mathrm{O}_{2}$ concentration plateau values at about $1.9 \%$, and the other two simulations with POLYURETHANE had similar $\mathrm{O}_{2}$ concentration plateau values at about $2.6 \%$. 


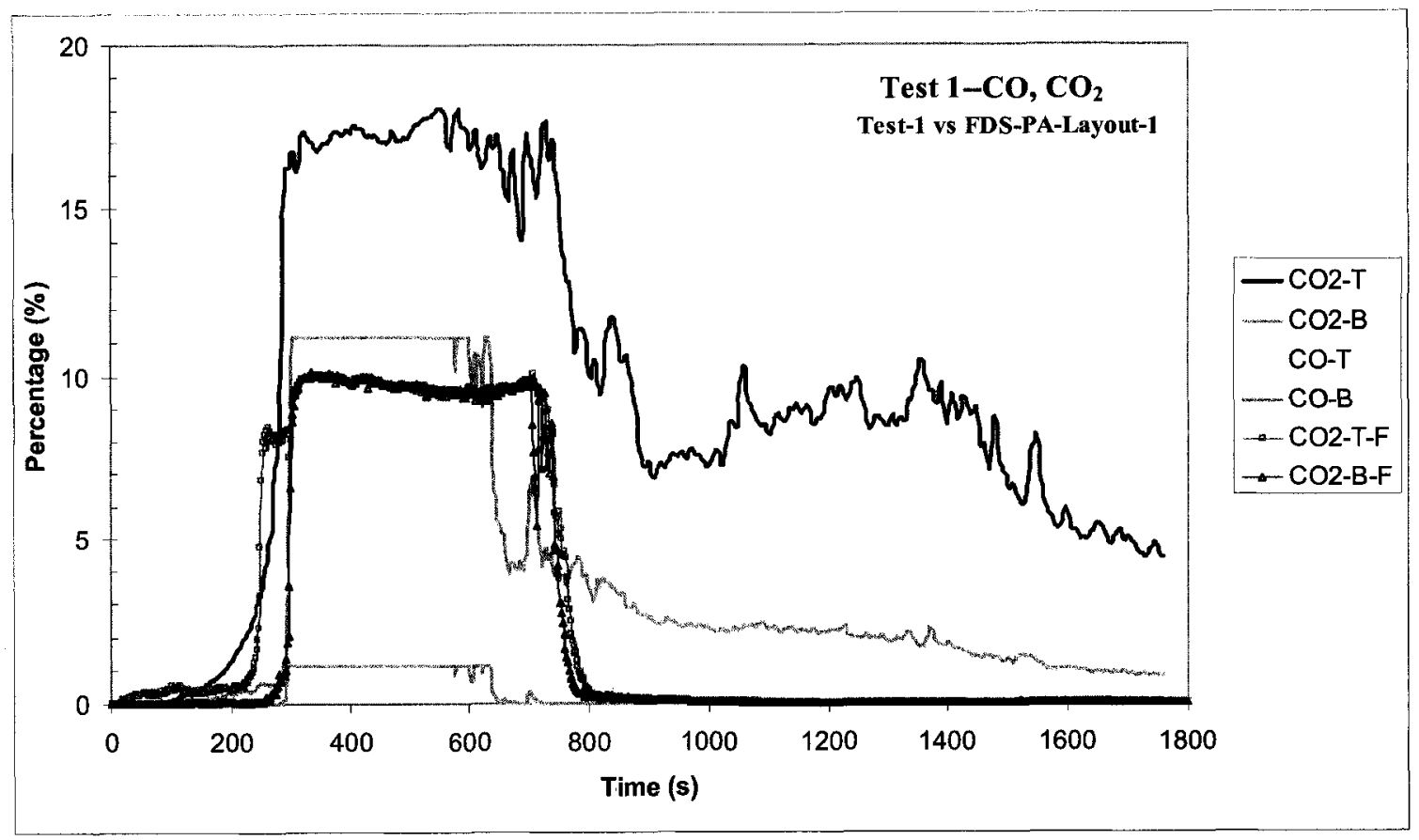

Figure $106 \mathrm{CO}$ and $\mathrm{CO}_{2}$ prediction by using PROPANE and virtual fuel layout 1

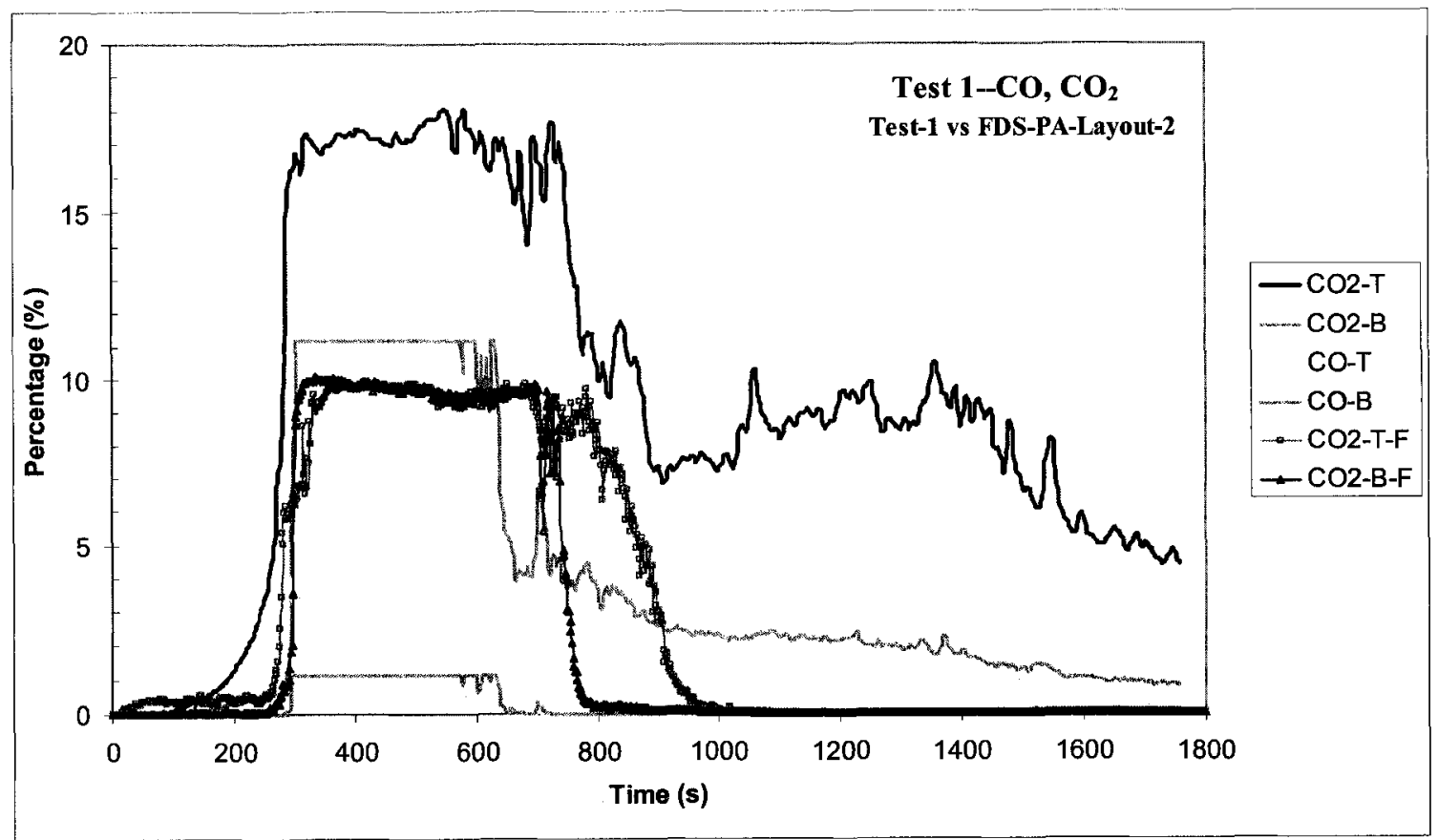

Figure $107 \mathrm{CO}$ and $\mathrm{CO}_{2}$ prediction by using PROPANE and virtual fuel layout 2 


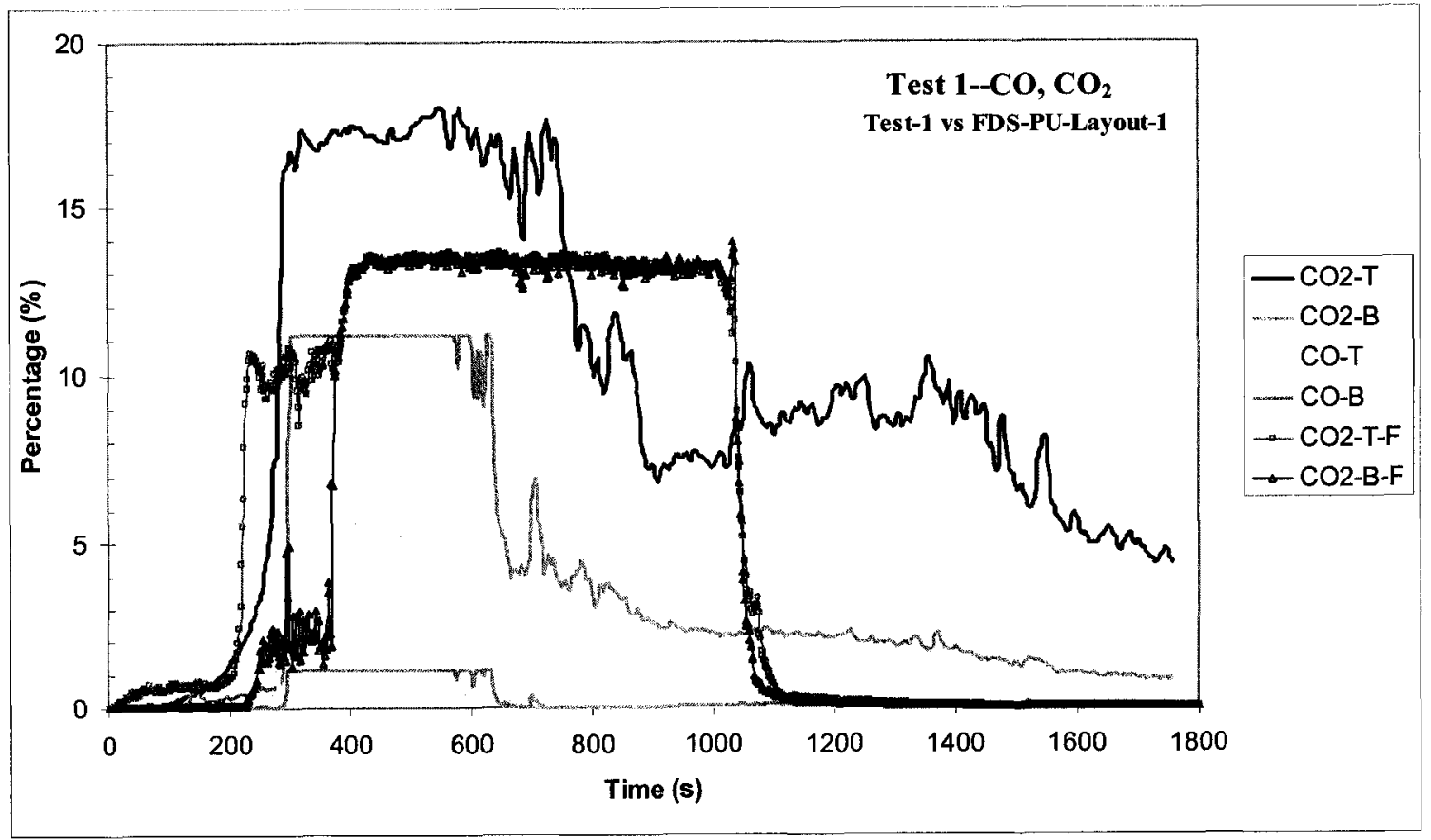

Figure $108 \mathrm{CO}$ and $\mathrm{CO}_{2}$ prediction by using $\mathrm{PU}$ and virtual fuel layout 1

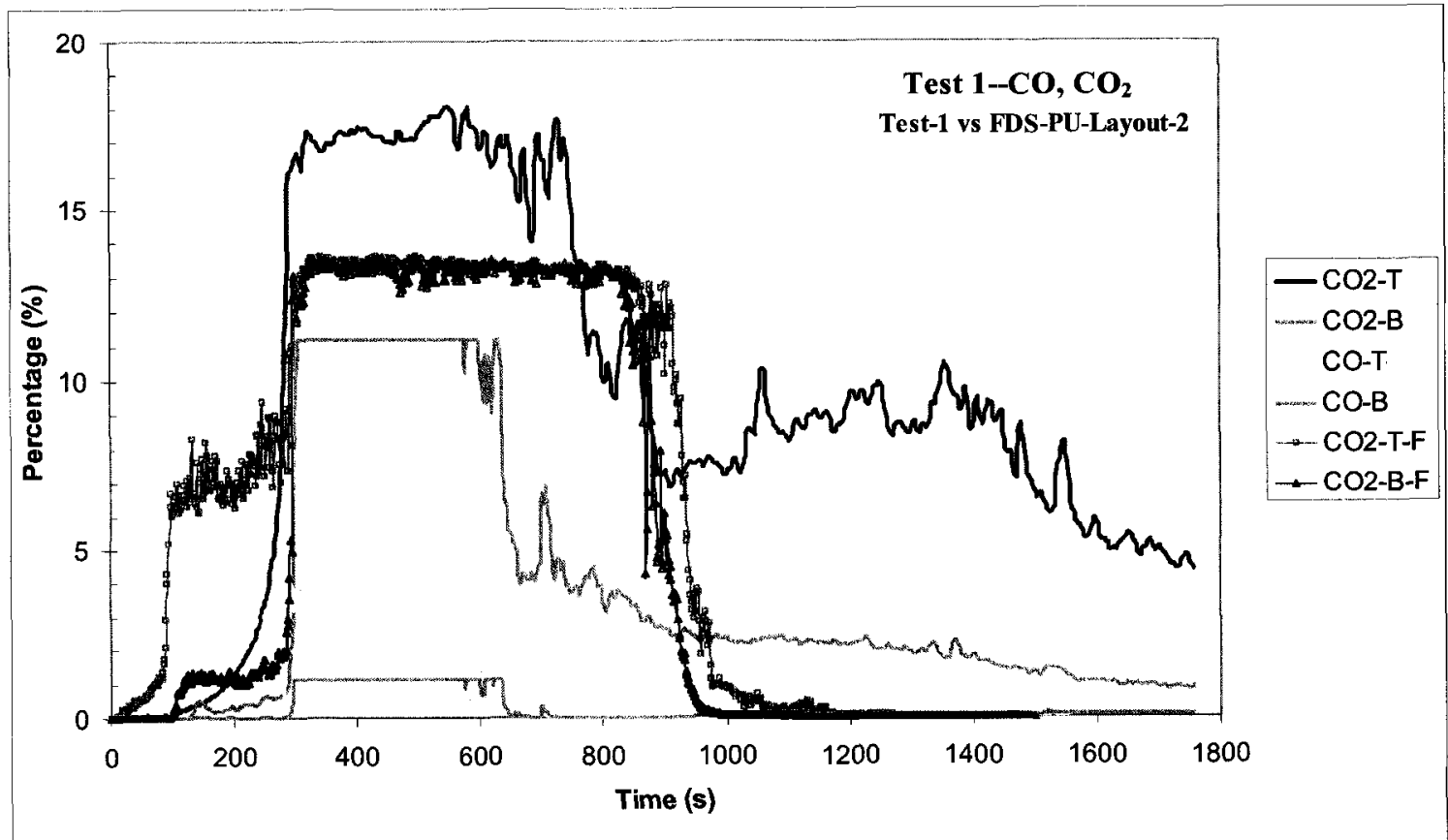

Figure $109 \mathrm{CO}$ and $\mathrm{CO}_{2}$ prediction by using $\mathrm{PU}$ and virtual fuel layout 2 


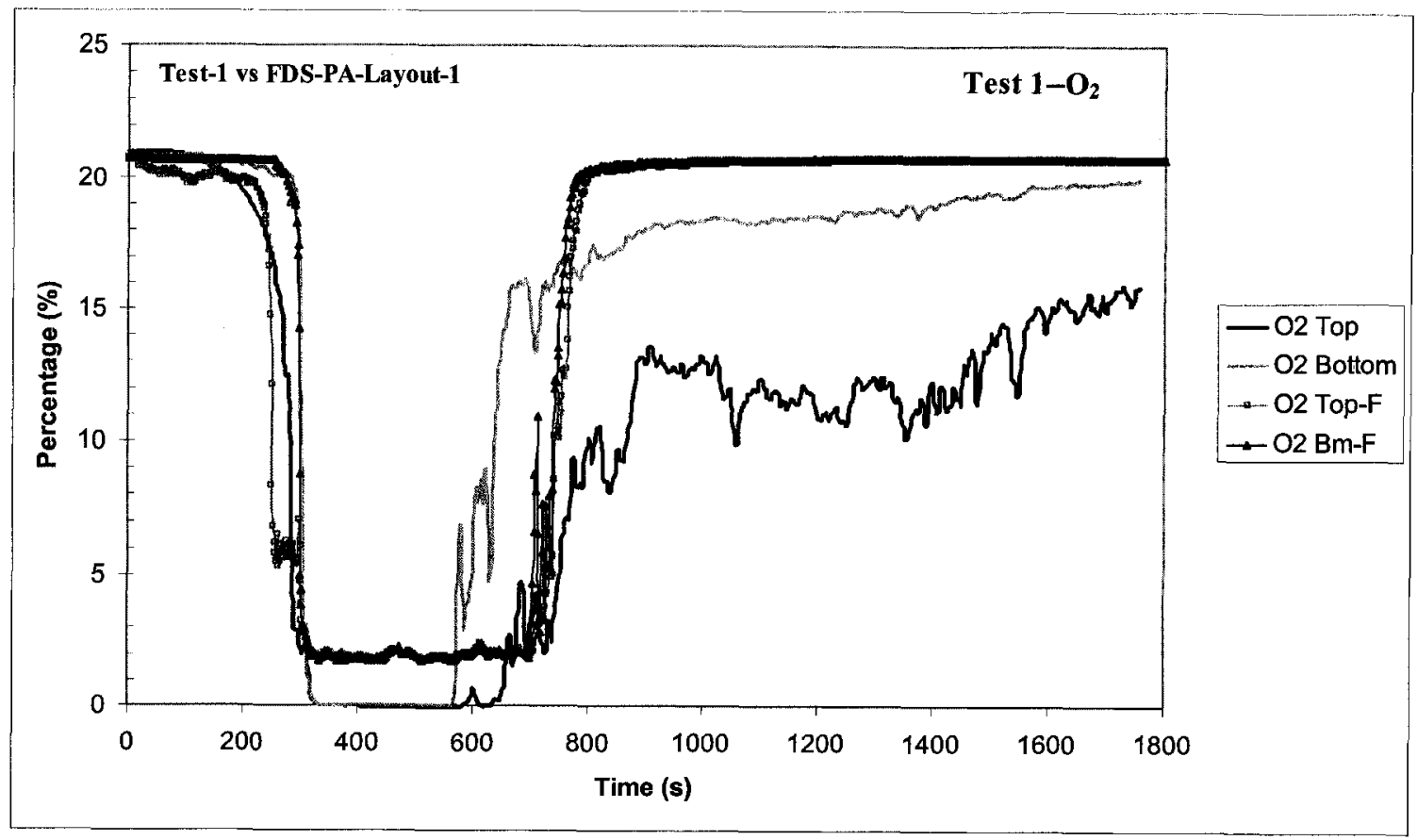

Figure $110 \mathrm{O}_{2}$ prediction by using PROPANE and virtual fuel layout 1

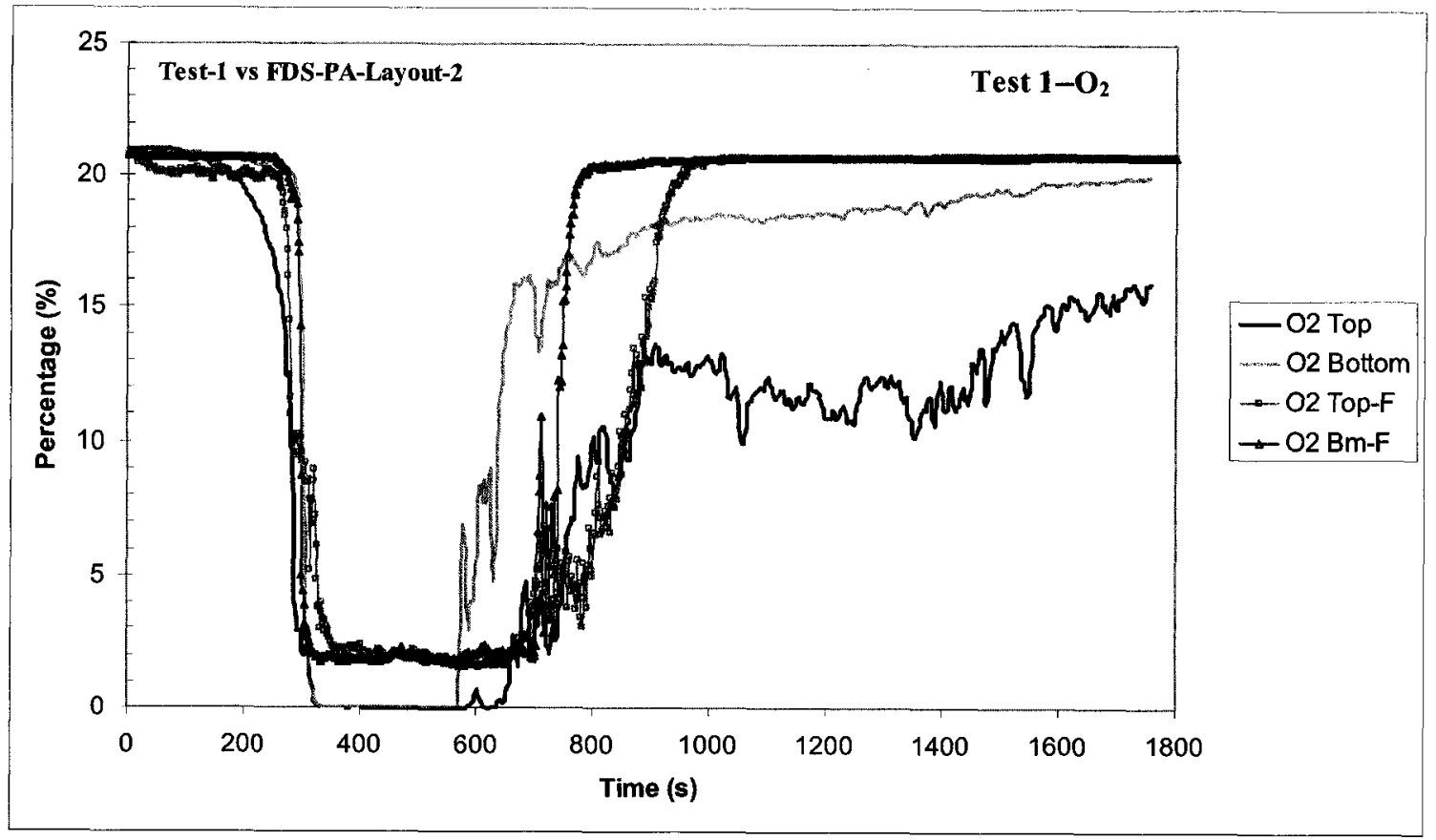

Figure $111 \mathrm{O}_{2}$ prediction by using PROPANE and virtual fuel layout 2 


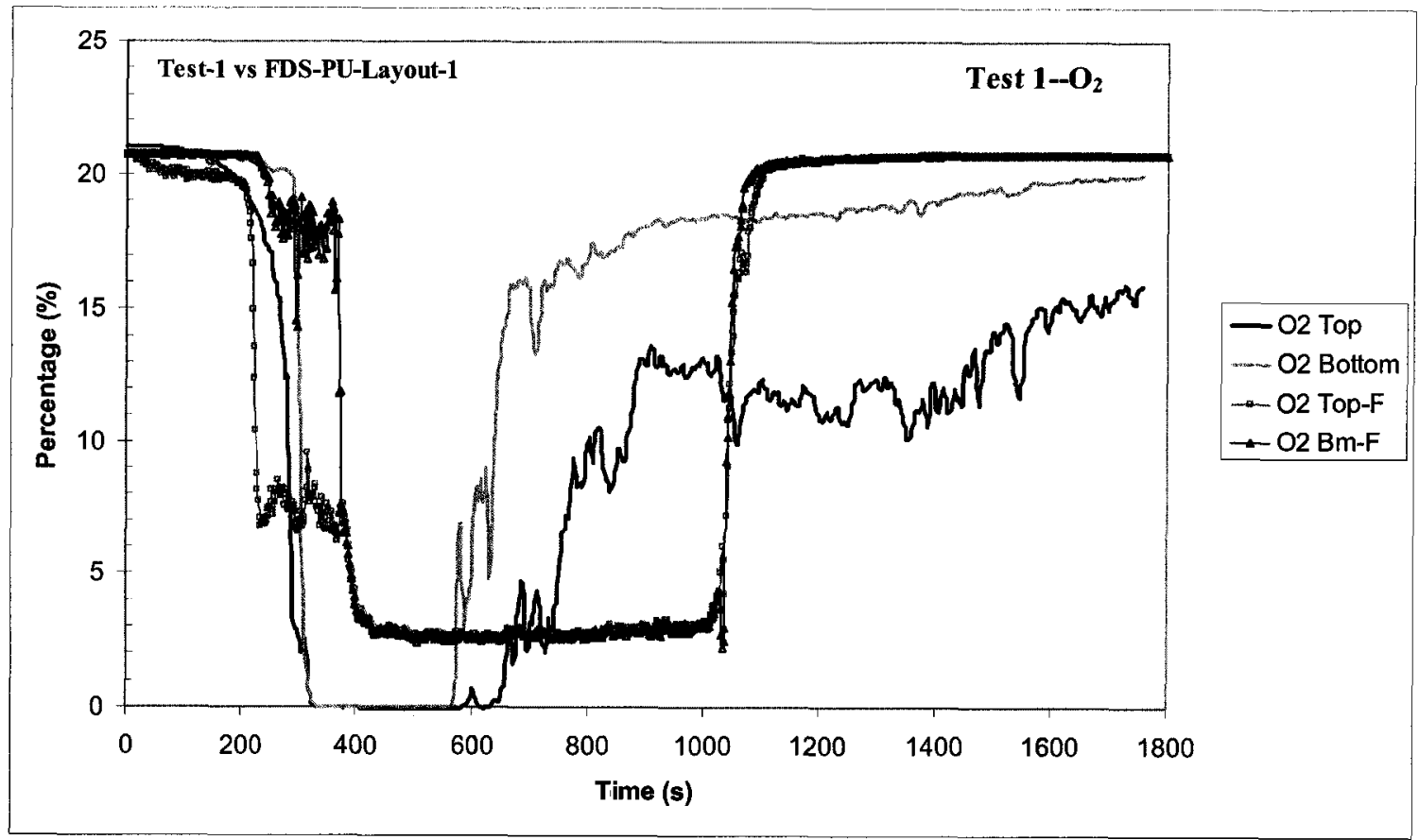

Figure $112 \mathrm{O}_{2}$ prediction by using PU and virtual fuel layout 1

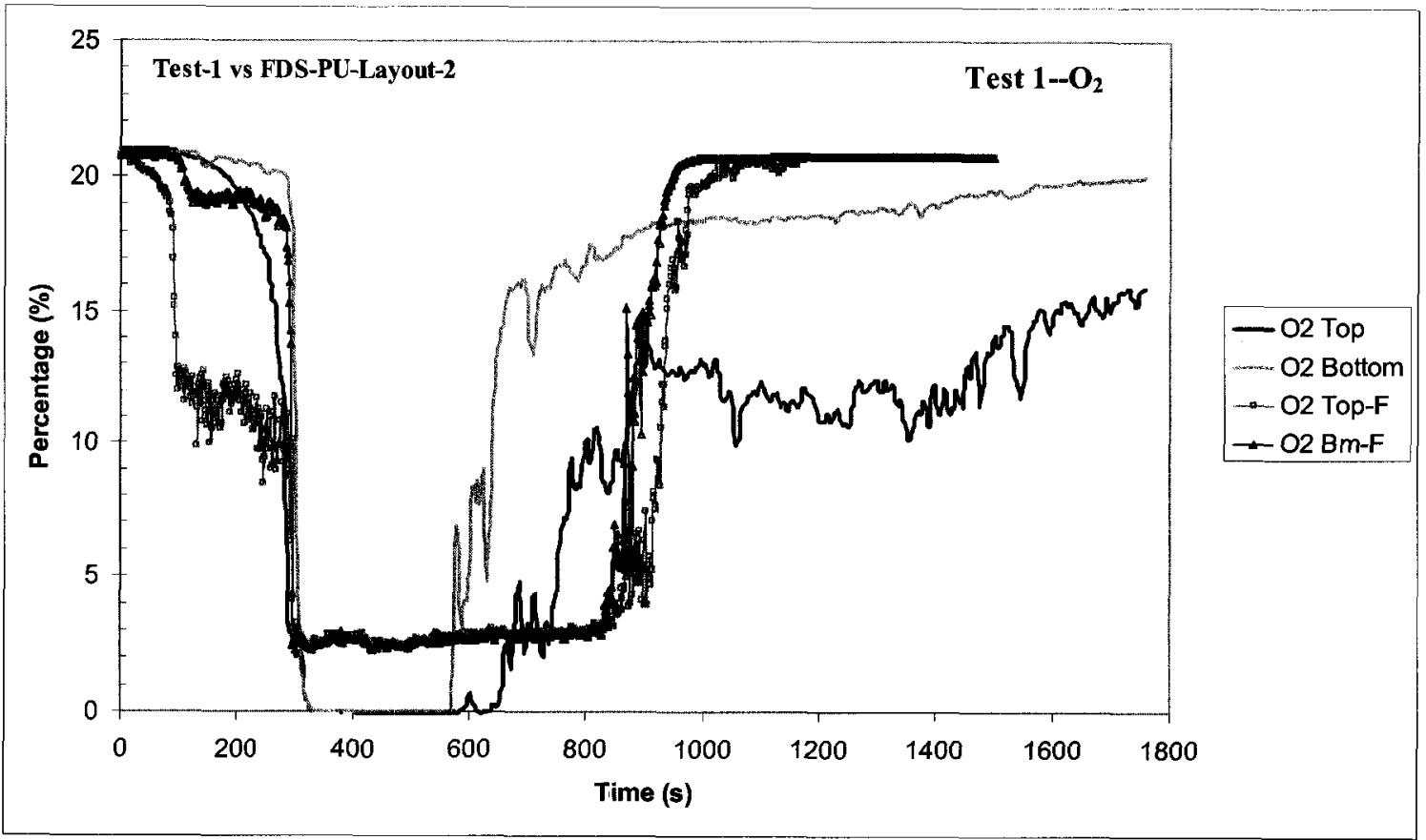

Figure $113 \mathrm{O}_{2}$ prediction by using $\mathrm{PU}$ and virtual fuel layout 2 


\subsubsection{Sensitivity of Reference Rate}

The default value of REFERENCE_RATE (reaction rate) in FDS version 5 is $0.1 \mathrm{~s}^{-1}$. In the FDS user's guide [52], "it is suggested that unless you have information to the contrary, REFERENCE_RATE at its default value and just specify the REFERENCE_TEMPERATURE." In this FDS simulation, different reference rates were tried for both virtual fuels in different fuel layouts. Figure 114 shows the simulation results using the same propane gaseous fuel and the same solid fuel layout 2 with different reference rates. Simulation 'PAL2-RR1' used the FDS default reference rate for both virtual fuels. 'PAL2-RR2' and 'PAL2-RR3' used the same value of $0.05 \mathrm{~s}^{-1}$ for the 'FF' virtual fuel, and different values of 0.002 and $0.005 \mathrm{~s}^{-1}$ for the 'WPFF' virtual fuel. 'PAL2-RR3' resulted in a better prediction.

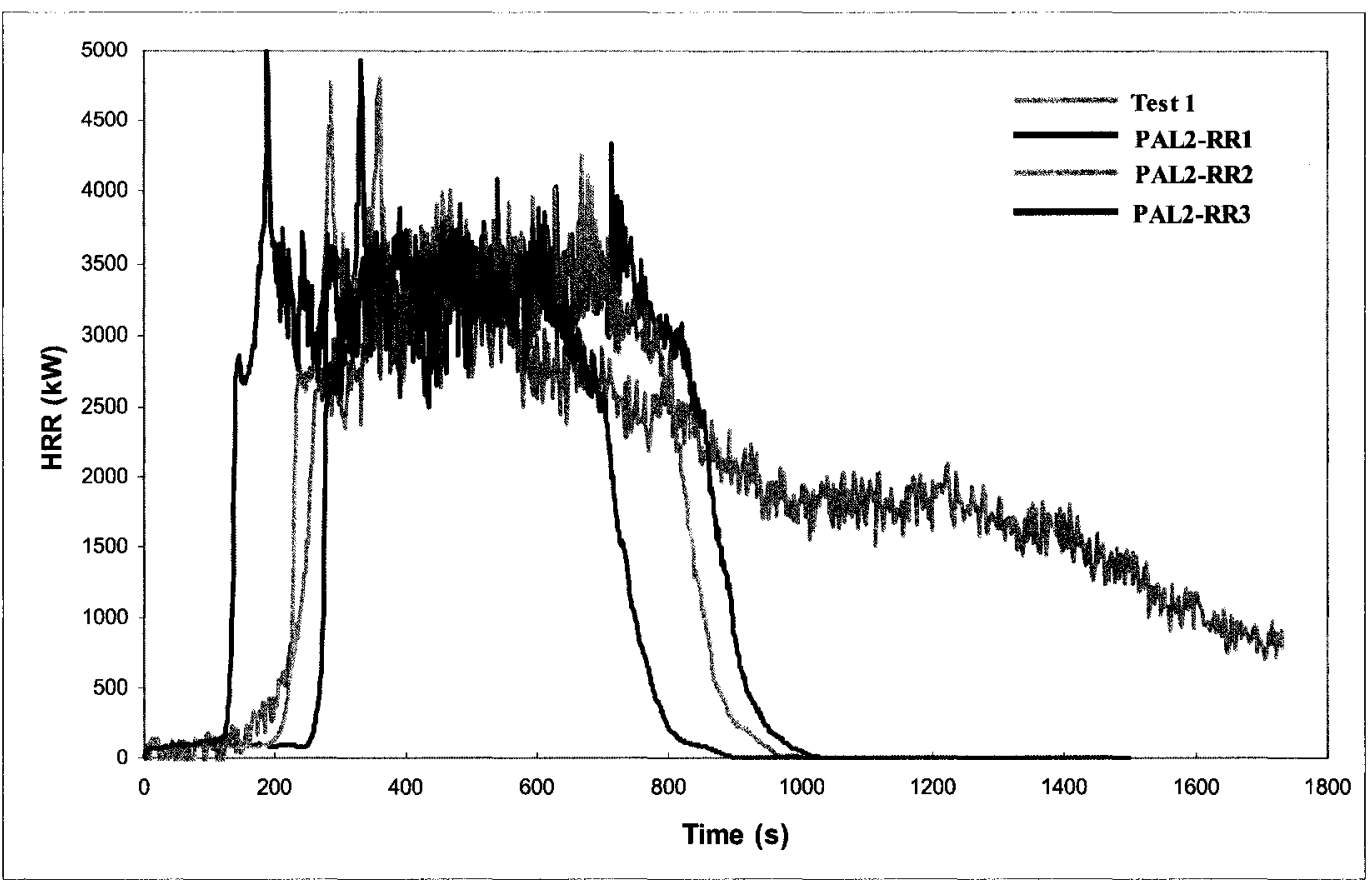

Figure 114 Sensitivity of the Reference Rate 


\subsection{FDS Simulation for the Fire Test 2}

The same material and thermal properties of virtual fuels, 'FF' and 'WPFF', were used to simulate fire test 2. Based on Layout 2 for fire test 1, a Layout 3 was developed to simulate fire test 2. Layout 3 used the same amount and same locations of WPFF virtual fuels that were placed close to the middle of the east wall in Layout 2 . The difference of Layout 3 and Layout 2 is that two small FF slabs with one layer of WPFF bars beneath each FF slab was used in Layout 3 instead of one big FF slab and one layer of WPFF bars as used in Layout 2. Figure 115 provides the 3D view of Layout 3.

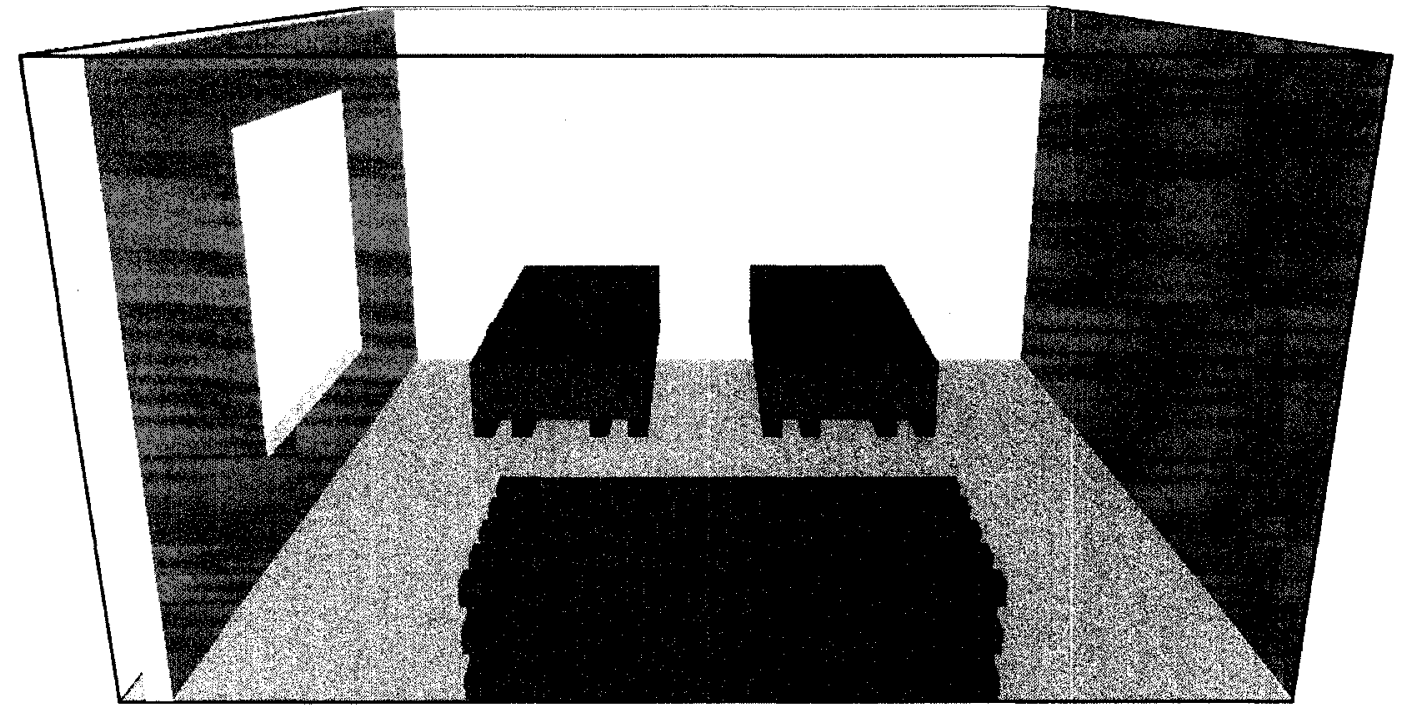

Figure 115 Layout 3 of virtual fuels

Two gaseous fuels, PROPANE and POLYURETHANE, were also used to simulate

fire test 2. Figure 116 presents the simulation results using two gaseous fuels in Layout 3. The simulation with PROPANE gaseous fuel had a better prediction than that with POLYURETHANE in the early stage of fire development. For the simulation with 
PROPANE, the predicted time to reach the first peak heat release rate value was close to that in the experiment, but the predicted first peak heat release value was higher than the experimental data by about $13.8 \%$. For the simulation with POLYURETHANE, the fire developed earlier than in the experiment. This is similar to the simulation results using POLYURETHANE and virtual fuel Layout 2 for fire test 1 . The two simulations with Layout 3 also had poor predictions in the decay stage as the four simulations for fire test 1.

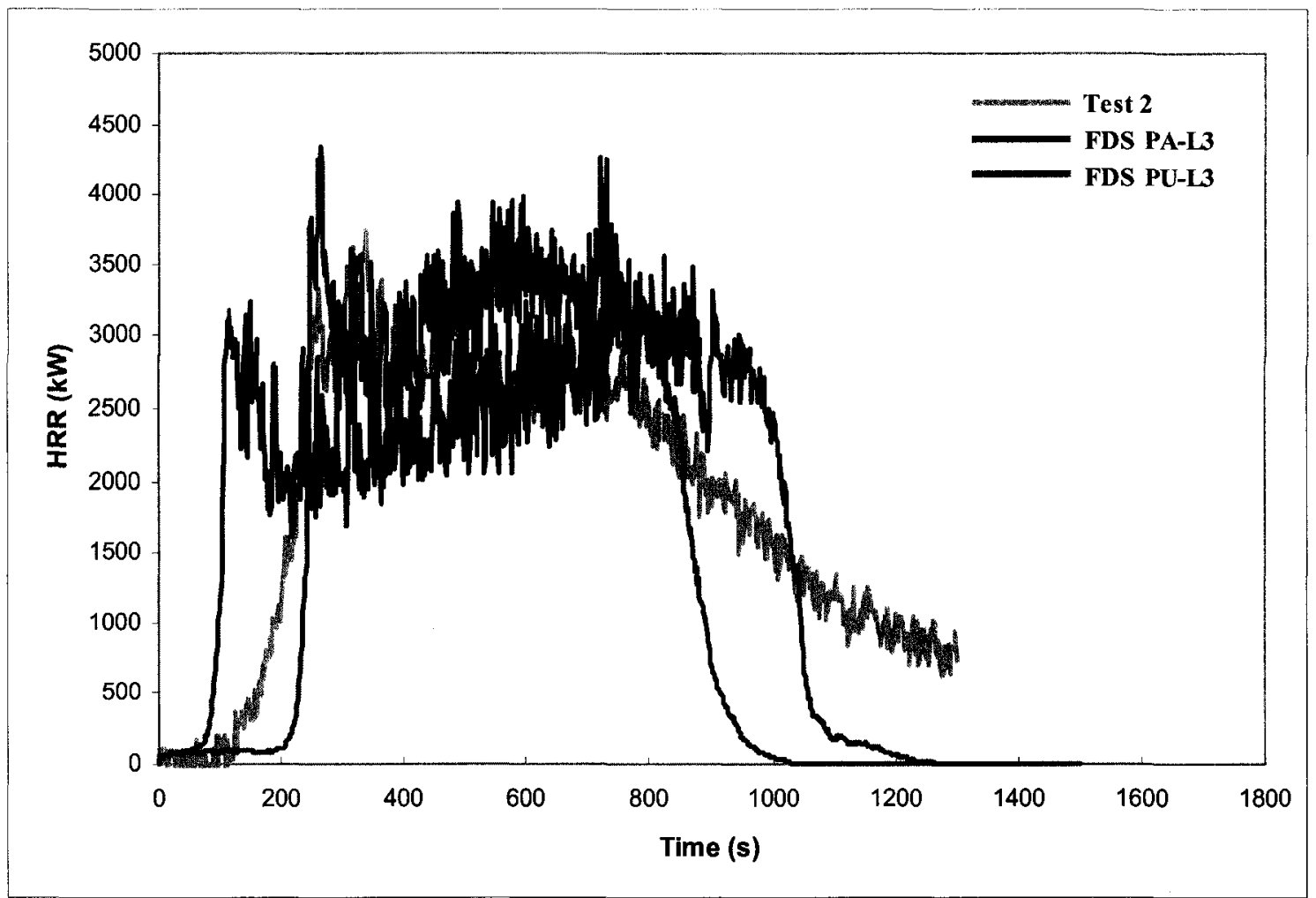

Figure 116 Heat release rate prediction by using two gaseous fuels in layout 3 


\subsection{Summary of the Modelling}

Two groups of materials or fuels with different density and heat of combustion were noticed in different stages of fire development. Based on this, these two virtual fuels were used for the two groups of materials. One virtual fuel, ' $\mathrm{FF}$ ', mainly included foam and fabric, and the other virtual fuel, 'WPFF', included the materials of wood, plastic, paper, foam, and fabric. The material and thermal properties of the two virtual fuels were given.

Two virtual fuel layouts were used to simulate fire test 1 . In one layout, the two virtual fuels were placed in the middle of the room, and in the other layout, the virtual fuels were located separately in two places. A third virtual fuel layout was used to simulate fire test 2 .

In order to check the effect of the burning gaseous fuel on the results, two gaseous fuels, POLYURETHANE and PROPANE were used. For the simulation for fire test 1, the predicted heat release rates, temperature, and gas concentration were compared with experimental data. Different reference rates for the two virtual fuels were also checked. For the simulation for fire test 2 , the predicted heat release rates were compared with experimental data.

For the simulation for fire test 1 , both simulations with PROPANE gaseous fuel had good predictions of heat release rate at the early stage of fire development. The predicted first peak value and the maximum value of heat release rate, and their time were close to the experimental data. The two simulations with POLYURETHANE gaseous fuel did not 
show good results. The poor prediction for the decay stage could be improved in fire protection design by adjusting the slope of the decay curve.

The temperature prediction of fire test 1, shown in Figure 101, with PROPANE and virtual fuel layout 2 had a relatively better result than the other three simulations with different gaseous fuels and different virtual fuel layouts. The two simulations using PROPANE gaseous fuel had similar $\mathrm{CO}_{2}$ and $\mathrm{O}_{2}$ concentration plateau values at about $10 \%$ and $1.9 \%$, respectively, and the other two simulations with POLYURETHANE had similar $\mathrm{CO}_{2}$ and $\mathrm{O}_{2}$ concentration plateau values at about $13.5 \%$ and $2.6 \%$, respectively. The model was not set to predict CO concentrations.

With the third virtual fuel layout for fire test 2 , the simulation with PROPANE gaseous fuel had a better prediction than that with POLYURETHANE in the early stage of fire development.

The virtual fuels provide a simplified way to predict a fire in FDS when many materials are involved with many unknown parameters. It is much easier to set up the input files using representative virtual fuels than using the real materials. The material and thermal properties of the virtual fuels, such as density, ignition temperature, and reference rate, affect the simulation results; hence it is recommended to check the predicted heat release rate with experimental data from literature. 


\section{Chapter 6: Conclusions and Recommendations}

\subsection{Conclusions}

This project included fire load surveys, experimental tests, and fire modelling. The fire load surveys have been conducted in 10 motels and 12 hotels in Canada's National Capital Region---Ottawa and Gatineau, from March 2007 to August 2007. Two full-scale fire tests have been conducted at NRCC/Carleton (National Research Council of Canada/Carleton University) Fire Research Lab. Test 1 was conducted on October $10^{\text {th }}$ of 2008, and Test 2 was conducted on November $12^{\text {th }}$ of 2008 . A field model, Fire Dynamics Simulator (FDS), was used to simulate the fire tests. The major findings and contributions of this project are listed below:

\section{Fire Load Survey:}

1. The fire load survey included a wide range of motels and hotels from one storey to 24 storeys, and from hotel rating of 2-star to 5-star.

2. Three categories were used to report the survey results for hotels: standard hotels, luxury hotels and hotel suites. 
3. Total fire load density and moveable fire load density were analysed for the different types of guest rooms and hotel categories. The average total fire load density for all the surveyed motels and hotels was $550 \mathrm{MJ} / \mathrm{m}^{2}$.

4. Typical values for floor area, area of openings and percentage of floor area covered by furnishings were also provided in terms of different types of guest rooms and hotel categories.

\section{Full-scale Fire Tests:}

5. Two full-scale tests were conducted. One was designed to simulate a fire in a hotel bedroom with one bed, and the other was to simulate a fire in a bedroom with two beds.

6. The heat release rates of the two tests were calculated by using oxygen consumption principle. A delay time of 26 seconds was chosen by comparing the curves of temperature and oxygen concentration. The $1^{\text {st }}$ test had a maximum heat release rate of $4.8 \mathrm{MW}$, and the $2^{\text {nd }}$ test had a maximum value of $3.7 \mathrm{MW}$.

7. Temperature, heat flux and gas concentration in the test room during the tests were also measured and provided.

8. Two distinguished vertical zones (west and east) of fire development were noticed in the two full-scale fire tests, which could be applied to most hotel guest rooms and other bedrooms with the similar furnishing layouts. 
9. Design fire curves of heat release rate were developed from the tests, which could be used as a prescribed fire in FDS input files to simulate smoke movement in the buildings. The average ceiling temperatures for the two tests are provided, which could be helpful for the design of active or passive fire protection system.

\section{FDS Modelling:}

10. Two virtual fuels were designed and used to define two groups of materials or fuels, which had different density and heat of combustion. Their material and thermal properties were provided.

11. The sensitivity of different gaseous fuels was checked by using PROPANE and POLYURETHANE. Two different fuel layouts were used to simulate the $1^{\text {st }}$ fire test, and the simulation results of heat release rate, temperature, and gas concentration were used to compare with experimental data. The simulation using PROPANE gaseous fuel and solid fuel layout 2 had a better prediction in the early stage of the fire development. Different values of REFERENCE_RATE were used to check the sensitivity.

12. A third fuel layout was used to simulate the $2^{\text {nd }}$ fire test. The simulation with PROPANE had a better heat release rate prediction than that with POLYURETHANE in the early stage of the fire development.

This study provides the data obtained from field survey and full-scale fire tests, which will be useful for fire protection engineers to conduct performance-based design. A 
simplified approach of using two virtual fuels in FDS simulation had a good prediction in the early stages of the fires. The predicted heat release rate curves can be checked and verified using the data from literature. The modified heat release rate curve can be prescribed in FDS input files to model the smoke movement in the buildings.

\subsection{Recommendations for future work}

Fire load survey is a tedious and time-consuming work. The survey has been conducted in a wide range of motels and hotels, but some of the categories may not have enough samples due to the difficulty to get the permission to access. The surveyed values of fire load density may change by regions and countries. A round-robin exercise to conduct fire load survey in different countries would be valuable.

For experimental tests, a larger size test room with two double beds is recommended to be used for further research. It will be interesting to see if the two vertical zones still appear in the fire development, when similar furniture layouts are used.

To predict a fire in a room with ordinary furniture is one of the most challenging applications for FDS, due to many unknown parameters, and the sensitivity of the parameters. Using two virtual fuels to predict the room fires provides a simplified approach in FDS application. For different room use and different building categories, the material and thermal properties of the two virtual fuels need to be identified by comparing with the experimental data. 
Tests can be conducted with different ventilation openings to cover the range of openings obtained by the survey. 


\section{References:}

1. Bukowski, R. W., Setting Performance Code Objectives: How Do We Decide What Performance the Codes Intend?, Interflam '96. International Interflam Conference, 7th Proceedings. March 26-28, 1996, Cambridge, England, Interscience Communications Ltd., London, England, Franks, C. A.; Grayson, S., Editor(s), pp.555-561.

2. Meacham, B. (editor), Performance-based Building Design Concepts: A Companion Document to the ICC Performance Code for Buildings and Facilities, International Code Council, Falls Church, Virginia, USA, 2004

3. SFPE Engineering Guide to Performance-Based Fire Protection Analysis and Design of Buildings, Society of Fire Protection Engineers and National Fire Protection Association, USA, 2000

4. Lataille, J. I., Fire Protection Engineering in Building Design, ButterworthHeinemann, USA, 2003

5. Babrauskas, V., Performance-based Building Codes: What will Happen to the Levels of Safety?, Retrieved from: http://doctorfire.com/FSE_codes_story.pdf, Retrieved Date: June 05, 2008

6. Mehaffey, J. R., Regulatory Environment, Short Course: Performance-based Fire Safety Design, March 21-23, 2008, Carleton University, Ottawa, Ontario, Canada, 2008, pp.2.1-2.23

7. Canada Commission on Building and Fire Codes. National Building Code of Canada 2005. National Research Council Canada, Institute for Research in Construction Ottawa, On., 2005

8. Lundin, J., Development of a Framework for Quality Assurance of Performancebased Fire Safety Designs, Journal of Fire Protection Engineering, Vol.15, February, 2005, pp.19-42

9. Hadjiosophocleous, G. V., Benichou, N., Tamim, A. S., Literature Review of Performance-Based Fire Codes and Design Environment, Journal of Fire Protection Engineering, 1998, Vol. 9, No.1, pp.12-40

10. Hadjiosophocleous, G. V., Performance-Based Design Guidelines, Short Course: Performance-based Fire Safety Design, March 21-23, 2008, Carleton University, Ottawa, Ontario, Canada, 2008 
11. Richardson, L. R., Fire Losses in Selected Property Classifications of Nonresidential, Commercial and Residential Wood Buildings. Part 1: Hotels/motels and Care Homes for Aged, Fire and Materials, v 31, n 2, March, 2007, pp.97-123

12. Roberts, D., and Chan, D. H., Fires in Hotel Rooms and Scenario Predictions, International Journal of Contemporary Hospitality Management, 12/1 2000, pp. $37-44$

13. Ahrens, M., Structure Fires in Selected Occupancies: Building Characteristics Causal Factors and Incident Details-1980-1998 Annual Averages, Report prepared for Forintek Canada Corp. by National Fire Protection Association, Fire Analysis and Research Division, Quincy, MA, 2003, pp.245.

14. Best, R., and Demers, D. P., Investigation Report on the MGM Grand Hotel Fire, National Fire Protection Association, 1982, pp.83.

15. Hansell, G. O. and Morgen H. P., Fire Sizes in Hotel Bedrooms-Implications for Smoke Control Design, Fire Safety Journal, 1984/85, v8, pp.177-186

16. Bukowski, R. W., Determining Design Fires for Design-level and Extreme Events, SFPE $6^{\text {th }}$ International Conference on Performance-Based Codes and Fire Safety Design Methods, June 14-16, 2006, Tokyo, pp.1-11

17. Bwalya, A., An Overview of Design Fires for Building Compartment, Fire Technology, 2008, 44, pp.167-184

18. Walton, T. D. and Thomas, P. H., Section 3 Chapter 6 Estimating Temperatures in Compartment Fires, SFPE handbook, pp.3.171-3.188

19. Karlsson, B. and Quintiere, J. G., Chapter 2. A Qualitative Description of Enclosure Fires, Enclosure fire Dynamics, CRC Press, USA, 2000

20. National Fire Protection Association (NFPA), Smoke Management Systems in Malls, Atria, and Large Areas, NFPA Guide, (NFPA92B), 2000

21. Bwalya, A. C., Benichou, N., Sultan, M. A., Literature review on design fires, IRC-RR-137, June 25, 2003

22. McCaffrey, B. J., Quintiere, J. G., and Harkleroad, M. F., Estimating Room Temperatures and the Likelihood of Flashover Using Fire Test Data Correlations, Fire Technology, Vol. 17(2), 1981, pp.98-119

23. Babrauskas, V., Estimating Room Flashover Potential, Fire Technology, Vol.16(2), 1980, pp.94-103

24. Thomas, P. H., Testing Products and Materials for Their Contribution to Flashover in Rooms, Fire and Materials, Vol.5(3), 1981, pp.103-111

25. Babrauskas, V., A Closed-form Approximation for Post-flashover Compartment Fire Temperatures, Fire Safety Journal, 1981, 4, pp.63-73 
26. Babrauskas, V. and Williamson, R. B., Post-flashover Compartment Fires: Basic of a Theoretical Model, Fire and Materials, 1978, 2, 2, pp.39-53

27. Eurocode 1, Basis of Design and Actions on Structures. Part 2-2: Actions on Structures Exposed to Fire, (ENV 1991-2-2: 1995E), 1995

28. Feasey, R., Post-flashover Design Fires, Research project for Master of Engineering, University of Canterbury, New Zealand, February 1999

29. Magnusson, S. E. and Thelandersson, S., Temperature-Time Curves for the Complete Process of Fire Development - A Theoretical Study of Wood Fuels in Enclosed Spaces, Acta Polytechnica Scandinavica, Stockholm, Sweden, 1970

30. Buchanan, A.H., Structure Design for Fire Safety, University of Canterbury, New Zealand, 1998

31. Bwalya, A. C., Sultan, M. A., and Benichou, N., A Pilot Survey of Fire Loads in Canadian Homes, Research report No. 159, National Research Council Canada, March 92004

32. Culver, C. G., Survey Results for Fire Loads and Live Loads in Office Buildings, Building Science Series No. 85, National Bureau of Standards, USA, 1976, pp.1150

33. Bryson, J. O. and Gross, D., Techniques for the Survey and Evaluation of Live Floor Loads and Fire Loads in Modern Office Buildings, National Bureau of Standards Building Science Series 16, USA, 1967, pp.1-30

34. Baldwin, R., Law, M., Allen, G., and Griffiths, L.G., Survey of Fire-Loads in Modern Office Buildings-Some Preliminary Results, Fire Research Note, No.808, March, 1970

35. Kumar, S. and Rao, C. V. S. K., Fire Loads in Office Buildings, J. Structure Engineering, March 1997, Vol.123, No.3, pp.365-368

36. Kumar, S. and Rao C. V. S. K., Fire Loads in Residential Buildings, Building and environmen, 1995, Vol.30, No.2, pp.299-305

37. Chapter 8. Fire Load and Fire Exposure, Fire Safety Journal, Vol.6, No.1, 1983, pp.24-34

38. Yii, H. W., Effect of surface Area and thickness on fire loads, Fire Engineering Research Report 2000/13, University of Canterbury, March 2000

39. Hall, J. R., A Century of Fire Standards, Retrieved from:www.astm.org/SNEWS/ DECEMBER_2004/hall_dec04.html, Retrieved Date: July 12, 2008

40. Babrauskas, V., Chapter 5 Full-scale Heat Release Rate Measurements, Heat Release in Fires, 1992

41. Peacock, R. D., Davis, S., and Babrauskas, V., Data for Room fire Model Comparisons, J. Res. Natl. Inst. Stand. Tehcnol., 1996, Vol.96, No.4, pp.411-462 
42. Milke, J. A., and Hill, S. H., Full-scale Room Fire Experiments Conducted at the University of Maryland, NIST-GCR-96-703, Jun 25, 1996, pp.1-29

43. Thornton, W., The Relation of Oxygen to the Heat of Combustion of Organic Compounds, Philosophical Magazine and Journal of Science, Vol. 33, No.196, 1997

44. Hinkley, P., Wraight, H., and Wadley, A., Rate of Heat Output and Heat Transfer in Fire Propagation Test, Fire Research Note No.709, Fire Research Station, Borehamwood, England, 1968

45. Parker, W., An Investigation of the Fire Environment in the ASTM E-84 Tunnel Test, NBS Technical Note 945, National Bureau of Standards, Gaithersburg, MD, 1977

46. Huggett, C., Estimation of the Rate of Heat Release by Means of Oxygen Consumption, Journal of Fire and Flammability, Vol.12, 1980, pp.61-65

47. Janssens, M. L., Measuring Rate of Heat Release by Oxygen Consumption, Fire Technology, Vol.27, 1991, pp.234-249

48. Stroup, D. W., DeLauter, L., Lee, J., and Roadarmel, G., Large Fire Research Facility (Building 205) Exhaust Hood Heat Release Rate Measurement System, NISTIR 6509, July 2000, pp.1-26

49. Karlsson, B. and Quintiere, J. G., Chapter 10. Computer Modelling of Enclosure Fires, Enclosure fire Dynamics, CRC Press, USA, 2000

50. Jones, W. W., Peacock, R. D., Forney, G. P., and Reneke, P. A., CFASTConsolidated Model of Fire Growth and Smoke Transport (Version 6) Technical Reference Guide, NIST Special Publication 1026, December 2005

51. Cox, C., and Kumar, S., Section 3 Chapter 8 Modeling Enclosure Fires Using CFD, SFPE handbook, pp.3--194-217

52. McGrattan, K., Klein, B., Hostikka, K., and Floyd, J., Fire Dynamics Simulator (Version 5) User's Guide, NIST Special Publication 1019-5, July 30,2008, pp.1188

53. McGrattan, K., Klein, B., Hostikka, K., Floyd, J., Baum, H., Rehm, H., Mell, W., and McDermott, R., Fire Dynamics Simulator (Version 5) Technical Reference Guide, Volume 1: Mathematical Model, NIST Special Publication 1018-5, July 30,2008, pp.1-92

54. FDS/Smokeview Research Plan, FDS Road Map, Retrieved from:http://code. google.com/p/fds-smv/wiki/FDS_Road_Map, Retrieved Date: August 17, 2008

55. McGrattan, K., Fire Modeling. Where Are We? Where Are We going?, Fire Safety Science-proceedings of the Eighth International Symposium, International Association for Fire Safety Science, 2005, pp.33-68 
56. Empis, C. A., Cowlard, A., Welch, S., and Torero, J. L., Chapter 3. Test One: The 'Uncontrolled' Fire, The Dalmarnock Fire Tests: Experiments and Modelling, University of Edinburgh, 2007, pp.63-81

57. Rein, G., Torero, J. L., Jahn, W., Gottfried, J. S., Ryder, N. L., Desanghere, S., Lazaro, M., Mowrer, F., Coles, A., Joyeux, D., Alvear, d., Capote, J. A., Jowsey, A., and Reszka, P., Chapter 10. A Priori Modelling of Fire Test One, The Dalmarnock Fire Tests: Experiments and Modelling, University of Edinburgh, 2007, pp.173-192

58. International Organization for Standardization, ISO/TR 13387-2:1999 (E), Fire safety engineering---Part 2: Design Fire Scenarios and Design Fires, Switzerland, 1999.

59. National Capital Region, Retrieved from: http://en.wikipedia.org/wiki /National Capital_Region_\%28Canada\%29, Retrieved Date: September 06, 2007

60. Zalok, E., Design Fires for Commercial Premises, Ph. D dissertation, Carleton University, 2006.

61. Guest Room Floor plan, Retrived from:http://www.suitedreams.com/English/ suites.html, Retrieved Date: September 13, 2007

62. Zircon Ultrasonic measuring device, Retrived from: http://www. zirccon.com/ sellpages/ Older\%20Products/Dimensionator/DimensionatorSpecs.html, Retrieved Date: September 13, 2007

63. Bwalya, A., Gibbs, E., Lougheed, G., Kashef, A., and Saber, H., Design of a Single-Room Heat Release Calorimeter for the Characterization of Fires in MutiSuite Residential Dwellings Project, NRC-IRC Research Report (in Progress)

64. Forney, G. P., User's Guide for Smokeview Version 5-A Tool for Visualizing Fire Dynamics Simulator Data, NIST Special Publication 1017-1, January, 2008, pp.1-134

65. Mehaffey, J. R., Lecture 11 Post-flashover Fire, Graduate Course: Fire Dynamic II, CIVE5613, Carleton University, 2007

66. McGrattan, K., FDS and Smokeview Discussions, Retrieved from: http://group. google.com/group//fds-smv/browse_thread/thread/d4cd90e26eb68145, Retrieved Date: November 2008

67. Big Hotel Fires, Retrieved from:http:/www.iklimnet.com/hotelfires/bighotelfires. html, Retrieved Date: May 15, 2007.

68. Chen, Z., Hadjiosophocleous, G. V., and Zalok, E., A Survey of Fire Loads in Motels and Hotels, The $21^{\text {st }}$ Century Center of Excellence Program 'Center of Advanced Fire Safety Science and Technology for Building', $3^{\text {rd }}$ International Symposium, Tokyo University of Science, Tokyo, Japan, March 10-11, 2008, pp. $235-246$ 


\section{Appendices:}

\section{Appendix A: Big Hotel Fires}

Table A-1 Big hotel fires in history (modified from [67])

\begin{tabular}{|c|c|c|c|c|c|}
\hline Year & Hotel & Country & $\begin{array}{c}\text { Life } \\
\text { Loss } \\
\end{array}$ & Injured & Damage \\
\hline 2006 & Hotel Fire in Downtown Reno & USA & 12 & 31 & \\
\hline 2006 & Five victims in NE China & China & 5 & & \\
\hline 2006 & Hotel Fire in Atlanta & USA & 1 & 12 & \\
\hline 2005 & Disneyland hotel & USA & & & \\
\hline 2005 & Hilton New York hotel & USA & & 33 & \\
\hline 2005 & Paris Hotel Fire & France & 20 & 50 & \\
\hline 2005 & Grandview Inn & USA,Ohio & & & \\
\hline 2005 & Williamsburg hotel & USA & & & \\
\hline 2005 & Fredericktown hotel & USA & & & \\
\hline 2005 & Schloss Elmau -Bavaria & Germany & & & \\
\hline 2005 & Richmond hotel & Canada & 1 & 14 & \\
\hline 2005 & Lakeview Hotel & $\mathrm{CBC}$ & 5 & & \\
\hline 2005 & Riverside Tower Hotel & USA & 6 & & \\
\hline 2005 & Park Hotel, Broxton & USA & & & \\
\hline 2004 & Sheraton Hotel Fire & USA & & & \\
\hline 2004 & Jinja Hotel Fire & Uganda & & & $\$ 15$ \\
\hline 2004 & Westin Hotel Fire & USA & & & \\
\hline 2004 & San Diego Hotel fire & USA & 1 & 17 & $\$ 1 \mathrm{M}$ \\
\hline 2004 & Houston Hotel Fire & USA & & & \\
\hline 2004 & Maui Hotel Fire. Hawaii & USA & & & $\$ 1 \mathrm{M}$ \\
\hline 2004 & Osceola County Hotel .Florida & USA & & & \\
\hline 2004 & Parco dei Principi Hotel ,Rome & Italy & 3 & & \\
\hline 2004 & Provincial Hotel Fire .Gananoque & Canada & & 1 & $\$ 0.5 \mathrm{M}$ \\
\hline 2004 & Luoyang hotel fire & China & 7 & 17 & \\
\hline 2004 & Greenville Hotel & USA & 6 & & \\
\hline 2003 & Canadian Hotel Fire & Canada & & & \\
\hline
\end{tabular}

170 


\begin{tabular}{|c|c|c|c|c|c|}
\hline 2003 & Rand Inn International Hotel & South Africa & 6 & 67 & \\
\hline 2003 & Tiantan Hotel & Beijing,China & 33 & 16 & \\
\hline 2002 & $\begin{array}{l}\text { Çiragan Palace Hotel } \\
\text { Kempinski,Ist }\end{array}$ & Turkey & & & \\
\hline 2002 & Marriott's Grand Hotel,Alabama & USA & & & $\$ 40$ million. \\
\hline 2002 & Oklahoma City Hotel & USA & & & $\$ 1$ million \\
\hline 2002 & Redding Hotel,San Francisco & USA & & & $\$ 3.5$ million \\
\hline 2002 & Sunset Hotel ,San Bernardino & $\mathrm{USA}, \mathrm{Ca}$ & 4 & 18 & $\$ 150,000$ \\
\hline 2002 & Pretoria & South Africa & 2 & 20 & \\
\hline 2002 & Days Inn Hotel, Wisconsin & USA & & & $\$ 1$ million \\
\hline 2001 & $\begin{array}{l}\text { Holiday Inn,Kansas City } \\
\text { International }\end{array}$ & USA & 4 & & $\$ 35,000$ \\
\hline 2001 & Palomar Hotel & USA,La & 2 & 6 & \\
\hline 2001 & Louvre,Paris & France & 4 & 18 & \\
\hline 2001 & Kazakhstan Hotel in Alma Ata & Kazakhistan & 4 & 14 & \\
\hline 2001 & Greater Manchester,Bolton & GB & 2 & 6 & \\
\hline 2001 & $\begin{array}{l}\text { Gold Strike Hotel-Casino,Las } \\
\text { Vegas }\end{array}$ & USA & & & $\$ 30$ million \\
\hline 2001 & Manor Hotel & Philippine & 70 & 50 & \\
\hline 2001 & South Valley Hotel & USA & & & $\$ 300,000$ \\
\hline 2001 & Kashmir & India & 14 & & \\
\hline 2000 & Childers & Australia & 15 & & \\
\hline 2000 & Marriott Vail Mountain Resort & USA & & & $\$ 20$ million \\
\hline 1999 & West Side Transient Hotel & USA & & 15 & \\
\hline 1999 & Crown Plaza Hotel,Madison & USA & & & $\$ 20,000$ \\
\hline 1999 & Mars Hotel ,Seattle & USA & & & $\$ 3$ million \\
\hline 1999 & Beijing Hotel & China & 9 & 14 & \\
\hline 1998 & Days Inn,Oregon & USA & & & $\$ 500,000$ \\
\hline 1998 & Hotel Vintage Plaza,Oregon & USA & & & $\$ 400,000$ \\
\hline 1997 & Delta Hotel.San Fransisco & USA & 6 & & \\
\hline 1997 & Yanshan Hotel i,Changsha & China & 30 & 24 & \\
\hline 1997 & Shenzen Hotel & China & 29 & 13 & \\
\hline 1997 & Pattaya Royal Resort & Thailand & 91 & 51 & $\$ 40$ million. \\
\hline 1996 & Tozbey Hotel,Istanbul & Turkey & 18 & 41 & \\
\hline 1995 & St. George Hotel Fire & USA & & & \\
\hline 1994 & Antwerp Switel hotel & Belgium & 15 & 160 & \\
\hline 1994 & Hotel Wakagi & Japan & 5 & & \\
\hline 1993 & Paxton Hotel,Chicago & USA & 19 & & \\
\hline 1990 & Sheraton, Cairo & Egypt & 18 & 70 & \\
\hline
\end{tabular}

171 


\begin{tabular}{|c|c|c|c|c|c|}
\hline 1990 & Miami Beach Hotel & USA & 9 & 24 & \\
\hline 1989 & Sydney & Australia & 6 & & \\
\hline 1987 & Ramada Inn Fire & USA & 10 & 11 & \\
\hline 1987 & La Posada Hotel Fire Texas & USA & & 1 & $\$ 150,000$ \\
\hline 1986 & Hotel Caledonian & Norway & 14 & & $£ 3.8$ million \\
\hline 1986 & Dupont Plaza Hotel & Puerto Rico & 96 & 140 & \\
\hline 1986 & New Delhi & India & 38 & & \\
\hline 1986 & Daitokan Hotel & Japan & 24 & & \\
\hline 1985 & Regent Hotel,Manila & Philippine & 17 & & \\
\hline 1984 & Pusan & Japan & 36 & & \\
\hline 1983 & Washington Hotel,Istanbul & Turkey & 38 & 56 & \\
\hline 1982 & Houston Hilton, Westchase & USA & 12 & 5 & \\
\hline 1982 & Zao Kanko hotel & Japan & 11 & & \\
\hline 1982 & Hotel New Japan ,Akasaka & Japan & 33 & 29 & 3 billion yen \\
\hline 1981 & Hilton,Las Vegas & USA & 8 & 252 & \\
\hline 1980 & Stouffer's Inn & USA & 26 & & \\
\hline 1980 & Prince Hotel & Japan & 44 & & \\
\hline 1980 & MGM Grand Hotel,Las Vegas & USA & 84 & 679 & $\$ 300$ million \\
\hline 1979 & Zaragoza & Spain & 76 & & \\
\hline 1978 & Coates Hause Hotel,Kansas & USA & 16 & & \\
\hline 1977 & Duc Del brabant Hotel,Brusseles & Belgium & 302 & & \\
\hline 1977 & Beverly Hills Supper Club & USA & 165 & 116 & \\
\hline 1977 & Hotel Polen,Amsterdam & Holland & 33 & 21 & \\
\hline 1974 & Duluth,Minnesota & USA & 4 & 4 & \\
\hline 1974 & Seoul & South Korea & 88 & & \\
\hline 1973 & Copenhagen & Danemark & 35 & & \\
\hline 1972 & Vendome Hotel,Boston & USA & & & \\
\hline 1971 & New Orleans, Louisiana & USA & 6 & & \\
\hline 1971 & Taeyokale Hotel in Seoul & South Korea & 166 & & \\
\hline 1970 & Chicago, Illinois & USA & & & \\
\hline 1970 & Pioneer Internatioanal,Tucson & USA & 49 & 69 & \\
\hline 1970 & Ozark Hotel ,Seatle & USA & 19 & 10 & \\
\hline 1966 & The Paramount Hotel Fire & USA & 11 & 57 & \\
\hline 1963 & Hotel Roosevelt fire & USA & 22 & & \\
\hline 1960 & Long Beach Hotel & USA & & & $\$ 5,5$ million \\
\hline 1946 & Winecoff Hotcl & USA & 119 & & \\
\hline 1943 & Gulf Hotel Fire & USA & 55 & 36 & \\
\hline 1934 & Kern Hotel Fire & USA & 34 & 44 & \\
\hline 1909 & Windsor (Williams ) Hotel & USA & & & \\
\hline
\end{tabular}




\section{Appendix B: Fire Load Survey Form}

\section{Fire Load Survey Form}

Hotel/Motel:

Number of Rooms:

Number of Floors:

Survey Room:
Address:

Building Age:

Survey Date:

Surveyor:

\section{Room Dimensions:}

\begin{tabular}{|l|l|l|l|l|l|l|}
\hline Rooms & L1 (m) & W 1(m) & L2 (m) & W2 (m) & H (m) & Area (m) \\
\hline Bedroom-1 & & & & & & \\
\hline Bedroom-2 & & & & & & \\
\hline Living room & & & & & & \\
\hline Bathroom & & & & & & \\
\hline Kitchen & & & & & & \\
\hline
\end{tabular}

2. Opening Dimensions:

\begin{tabular}{|l|l|l|l|l|}
\hline Openings & $\mathbf{W}(\mathbf{m})$ & $\mathbf{H}(\mathbf{m})$ & $\mathbf{H}_{\mathbf{0}}(\mathbf{m})$ & Area $\left(\mathbf{m}^{2}\right)$ \\
\hline Window-1 & & & & \\
\hline Window-2 & & & & \\
\hline Door-1 & & & & \\
\hline Door-2 & & & & \\
\hline
\end{tabular}

$\mathrm{H}_{0}$ : height from floor to the bottom of windows, doors.

\section{Floor Plan:}


4. Fixed fire load: (all combustibles in or on the walls, floor and ceiling)

\begin{tabular}{|l|l|l|l|l|l|l|l|}
\hline Combustibles & No & Yes, Qty & L (m) & W (m) & H (m) & Material & Mass(kg) \\
\hline Extension Cords & & & & & & & \\
\hline Window Frames & & & & & & & \\
\hline Door Frames & & & & & & & \\
\hline Doors & & & & & & & \\
\hline Wall Lining & & & & & & & \\
\hline Wall Decoration & & & & & & & \\
\hline Cupboards & & & & & & & \\
\hline Bookshelves & & & & & & & \\
\hline Floor Covering & & & & & & & \\
\hline Telephones & & & & & & & \\
\hline
\end{tabular}

5. Moveable Fire Load: (all items that are bought into the compartment)

\begin{tabular}{|l|l|l|l|l|l|l|l|}
\hline Furniture: & No & Yes, Qty & L (m) & W (m) & H (m) & Material & Mass(kg) \\
\hline Double Beds & & & & & & & \\
\hline Single Beds & & & & & & & \\
\hline Double Bed Frame & & & & & & & \\
\hline Single Bed Frame & & & & & & & \\
\hline Mattresses--1 & & & & & & & \\
\hline Mattresses--2 & & & & & & & \\
\hline Mattresses Boxes & & & & & & & \\
\hline Nightstands & & & & & & & \\
\hline Sofas & & & & & & & \\
\hline Tables & & & & & & & \\
\hline Desks--1 & & & & & & & \\
\hline Desks--2 & & & & & & & \\
\hline Chairs--1 & & & & & & & \\
\hline Chairs--2 & & & & & & & \\
\hline Chairs--3 & & & & & & & \\
\hline Chests & & & & & & & \\
\hline
\end{tabular}




\begin{tabular}{|l|l|l|l|l|l|l|l|}
\hline Dressers & & & & & & & \\
\hline Cabinets-1 & & & & & & & \\
\hline Cabinets--2 & & & & & & & \\
\hline & & & & & & & \\
\hline
\end{tabular}

\begin{tabular}{|l|l|l|l|l|l|l|l|}
\hline Bedding: & No & Yes, Qty & L (m) & W (m) & H (m) & Material & Mass(kg) \\
\hline Quilts & & & & & & & \\
\hline Pillows & & & & & & & \\
\hline Sheets & & & & & & & \\
\hline Bed Covers & & & & & & & \\
\hline Blankets & & & & & & & \\
\hline & & & & & & & \\
\hline
\end{tabular}

\begin{tabular}{|l|l|l|l|l|l|l|l|}
\hline Electronics: & No & Yes, Qty & L (m) & W (m) & H (m) & Material & Mass(kg) \\
\hline Televisions & & & & & & & \\
\hline Computers & & & & & & & \\
\hline CD/DVD & & & & & & & \\
\hline Refrigerators & & & & & & & \\
\hline Coffee Makers & & & & & & & \\
\hline Microwaves & & & & & & & \\
\hline & & & & & & & \\
\hline
\end{tabular}

\begin{tabular}{|l|l|l|l|l|l|l|l|}
\hline Others: & No & Yes, Qty & L (m) & W (m) & H (m) & Material & Mass(kg) \\
\hline Papers/Books & & & & & & & \\
\hline Curtains & & & & & & & \\
\hline Cover of Lamps & & & & & & & \\
\hline Frame of Pictures & & & & & & & \\
\hline Rubbish Bins & & & & & & & \\
\hline & & & & & & & \\
\hline
\end{tabular}




\section{Appendix C: Assumptions for fire load calculation}

Table C-1 Calorific value of different materials

\begin{tabular}{lccc}
\hline Items & $\mathbf{H}_{\mathbf{c}}$ & Unit & Reference \\
\hline Wood & 18.6 & $\mathrm{MJ} / \mathrm{Kg}$ & {$[35]$} \\
Plastic & 22.1 & $\mathrm{MJ} / \mathrm{Kg}$ & {$[35]$} \\
Textile & 18.8 & $\mathrm{MJ} / \mathrm{Kg}$ & {$[60]$} \\
Paper & 17 & $\mathrm{MJ} / \mathrm{Kg}$ & {$[35],[60]$} \\
Leather & 19 & $\mathrm{MJ} / \mathrm{Kg}$ & {$[35],[60]$} \\
Mattress & 35.9 & $\mathrm{MJ} / \mathrm{Kg}$ & Calculated from [38] \\
Sofa & 18.9 & $\mathrm{MJ} / \mathrm{Kg}$ & {$[60]$} \\
Carpet (wool) & 23 & $\mathrm{MJ} / \mathrm{Kg}$ & {$[60]$} \\
Carpet (PU)) & 36 & $\mathrm{MJ} / \mathrm{Kg}$ & Calculated from [38] \\
\hline
\end{tabular}

Table C-2 Electronics or items containing plastics

\begin{tabular}{lccc}
\hline Items & Value & Unit & Reference \\
\hline Extension Cords & 0.03 & $\mathrm{Kg} / \mathrm{m}$ & Lab results 2007 \\
Television & 10.2 & $\mathrm{Kg} /$ piece & {$[60]$} \\
Data projector & 1 & $\mathrm{Kg} /$ piece & estimated \\
DVD player & 1 & $\mathrm{Kg} /$ piece & estimated \\
Computer & 3 & $\mathrm{Kg} /$ piece & {$[60]$} \\
Keyboard & 0.5 & $\mathrm{Kg} /$ piece & estimated \\
Air Conditioner & 1 & $\mathrm{Kg} /$ piece & estimated \\
Fridge---1 door & 10 & $\mathrm{Kg} /$ piece & {$[60]$} \\
Fridge---2 door & 15 & $\mathrm{Kg} /$ piece & estimated \\
Coffee Makers & 1 & $\mathrm{Kg} /$ piece & {$[60]$} \\
Microwaves & 1 & $\mathrm{Kg} /$ piece & {$[60]$} \\
Dish Washers & 5 & $\mathrm{Kg} /$ piece & {$[60]$} \\
Hairdryers---small & 0.4 & $\mathrm{Kg} /$ piece & weighted \\
Hairdryers---large & 1.5 & $\mathrm{Kg} /$ piece & {$[60]$} \\
Alarm Clock & 0.5 & $\mathrm{Kg} /$ piece & estimated \\
\hline
\end{tabular}




\begin{tabular}{lcll}
\hline Telephone & 0.5 & $\mathrm{Kg} /$ piece & estimated \\
Lamp shade & 0.3 & $\mathrm{Kg} /$ piece & estimated \\
Cloth hangers (plastic) & 0.05 & $\mathrm{Kg} /$ piece & weighted \\
Wastebasket & 0.7 & $\mathrm{Kg} /$ piece & weighted \\
Ice container & 0.5 & $\mathrm{Kg} /$ piece & estimated \\
\hline
\end{tabular}

Table C-3 Density of wood and mass of furniture or other items

\begin{tabular}{lccc}
\hline Items & Value & Unit & Reference \\
\hline wood density & 550 & $\mathrm{Kg} / \mathrm{m}^{3}$ & estimated \\
Thickness of hardwood floor & 0.02 & $\mathrm{~m}$ & estimated \\
Sofa Stud & 15 & $\mathrm{Kg} / \mathrm{piece}$ & estimated \\
Sofa--1 seat & 25 & $\mathrm{Kg} /$ piece & {$[60]$} \\
Sofa--2 seat & 35 & $\mathrm{Kg} /$ piece & estimated $^{\text {a }}$ \\
Sofa--3 seat & 50 & $\mathrm{Kg} /$ piece & estimated \\
Frame of Pictures (small) & 2 & $\mathrm{Kg} /$ piece & estimated \\
Frame of Pictures (large) & 4 & $\mathrm{Kg} /$ piece & {$[38]$} \\
Frame of Mirrors & 3 & $\mathrm{Kg} /$ piece & estimated \\
Trees (small) & 2 & $\mathrm{Kg} / \mathrm{piece}$ & estimated \\
Trees (medium) & 4 & $\mathrm{Kg} /$ piece & estimated \\
Christmas Trees (regular) & 7 & $\mathrm{Kg} /$ piece & {$[60]$} \\
cloth hangers (wood) & 0.16 & $\mathrm{Kg} /$ piece & weighted \\
\hline
\end{tabular}

${ }^{a}$ estimated by reference of item weights obtained from Internet 
Table C-4 Mass of textile and leather

\begin{tabular}{lccc}
\hline Items & Value & Unit & Reference \\
\hline Carpet & 1 & $\mathrm{Kg} / \mathrm{m}^{2}$ & {$[38],[60]$} \\
Quilts (small) & 2 & $\mathrm{Kg} /$ piece & weighted \\
Quilts (medium) & 4 & $\mathrm{Kg} /$ piece & estimated \\
Quilts (large) & 6.4 & $\mathrm{Kg} /$ piece & weighted \\
Pillows & 0.8 & $\mathrm{Kg} /$ piece & weighted \\
Sheets & 1 & $\mathrm{Kg} /$ piece & weighted \\
Bed Covers & 3 & $\mathrm{Kg} /$ piece & weighted \\
Blankets & 1.5 & $\mathrm{Kg} /$ piece & weighted \\
Mattress Cover & 1.2 & $\mathrm{Kg} /$ piece & weighted \\
Mattress box Cover & 1 & $\mathrm{Kg} /$ piece & weighted \\
Curtains & 0.5 & $\mathrm{Kg} / \mathrm{m}^{2}$ & estimated \\
Curtain--Silk & 0.1 & $\mathrm{Kg} / \mathrm{m}^{2}$ & estimated \\
Towel (small) & 0.2 & $\mathrm{Kg} / \mathrm{piece}$ & weighted \\
Towel (large) & 0.5 & $\mathrm{Kg} /$ piece & weighted \\
Bath gown & 1 & $\mathrm{Kg} /$ piece & estimated \\
Chair (leather) & 18 & $\mathrm{Kg} /$ piece & estimated \\
Brochures (Leather) & 0.5 & $\mathrm{Kg} /$ piece & weighted \\
\hline
\end{tabular}

a estimated by reference of item weights obtained from Internet

Table C-5 Mass of paper

\begin{tabular}{lccc}
\hline Items & Value & Unit & Reference \\
Wall Paper & 0.5 & $\mathrm{Kg} / \mathrm{m}^{2}$ & estimated \\
Telephone books & 1.5 & $\mathrm{Kg} /$ piece & weighted \\
Brochures (paper) & 0.3 & $\mathrm{Kg} /$ piece & weighted \\
Newspaper & 0.2 & $\mathrm{Kg} /$ piece & estimated \\
\hline
\end{tabular}




\section{Appendix D: Calibration of the ultrasonic measuring device}

Table D Calibration test on the ultrasonic measuring device

\begin{tabular}{|c|c|c|c|c|c|c|}
\hline \multirow{2}{*}{ Tape Rule (m) } & \multicolumn{4}{|c|}{ Ultrasonic Measuring Tool (m) } & \multirow{2}{*}{ Difference (m) } & \multirow{2}{*}{ Accuracy $(\%)$} \\
\hline & Wall 1 & Wall 2 & Wall 3 & Average & & \\
\hline 0.6 & 0.6 & 0.61 & 0.6 & 0.603 & 0.003 & 0.556 \\
\hline 1.0 & 1.00 & 1.01 & 1.01 & 1.007 & 0.007 & 0.667 \\
\hline 1.5 & 1.52 & 1.5 & 1.51 & 1.510 & 0.010 & 0.667 \\
\hline 2.0 & 2.02 & 2.01 & 2.02 & 2.017 & 0.017 & 0.833 \\
\hline 2.5 & 2.52 & 2.52 & 2.52 & 2.520 & 0.020 & 0.800 \\
\hline 3.0 & 3.02 & 3.01 & 3.02 & 3.017 & 0.017 & 0.556 \\
\hline 3.5 & 3.53 & 3.51 & 3.53 & 3.523 & 0.023 & 0.667 \\
\hline 4.0 & 4.04 & 4.03 & 4.03 & 4.033 & 0.033 & 0.833 \\
\hline 4.5 & 4.53 & 4.51 & 4.52 & 4.520 & 0.020 & 0.444 \\
\hline 5.0 & 5.03 & 5.03 & 5.02 & 5.027 & 0.027 & 0.533 \\
\hline 5.5 & 5.55 & 5.53 & & 5.540 & 0.040 & 0.727 \\
\hline 6.0 & 6.04 & 6.02 & & 6.030 & 0.030 & 0.500 \\
\hline 6.5 & 6.55 & 6.52 & & 6.535 & 0.035 & 0.538 \\
\hline 7.0 & 7.04 & 7.02 & & 7.030 & 0.030 & 0.429 \\
\hline 7.5 & 7.54 & 7.52 & & 7.530 & 0.030 & 0.400 \\
\hline 8.0 & 8.05 & 8.03 & & 8.040 & 0.040 & 0.500 \\
\hline 8.5 & 8.53 & 8.54 & & 8.535 & 0.035 & 0.412 \\
\hline 9.0 & 9.02 & 9.05 & & 9.035 & 0.035 & 0.389 \\
\hline
\end{tabular}

179 


\section{Appendix E: FDS (Version 5.2.0) Input Files}

\section{E-1: Propane gaseous fuel and virtual fuel layout 1}

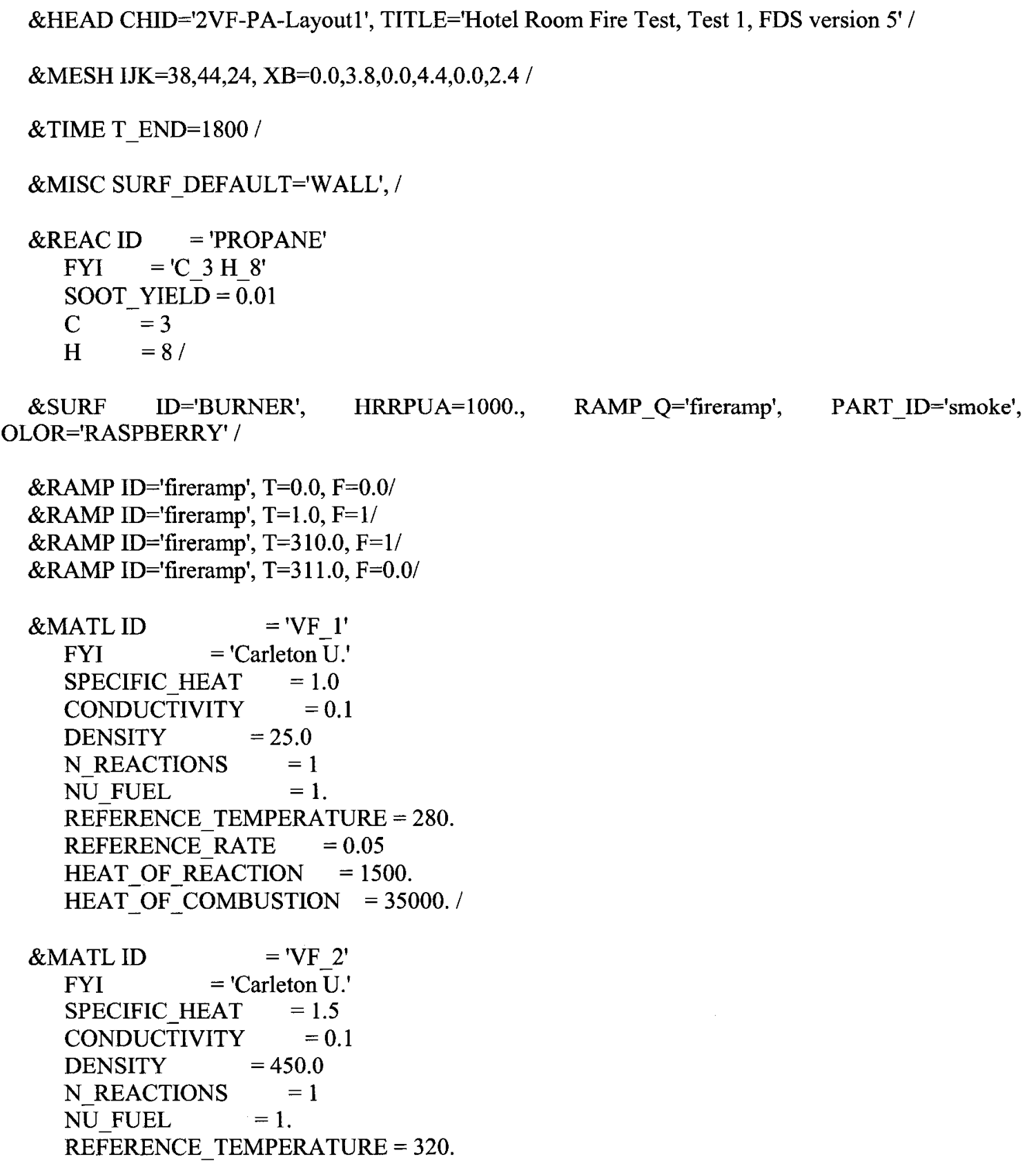




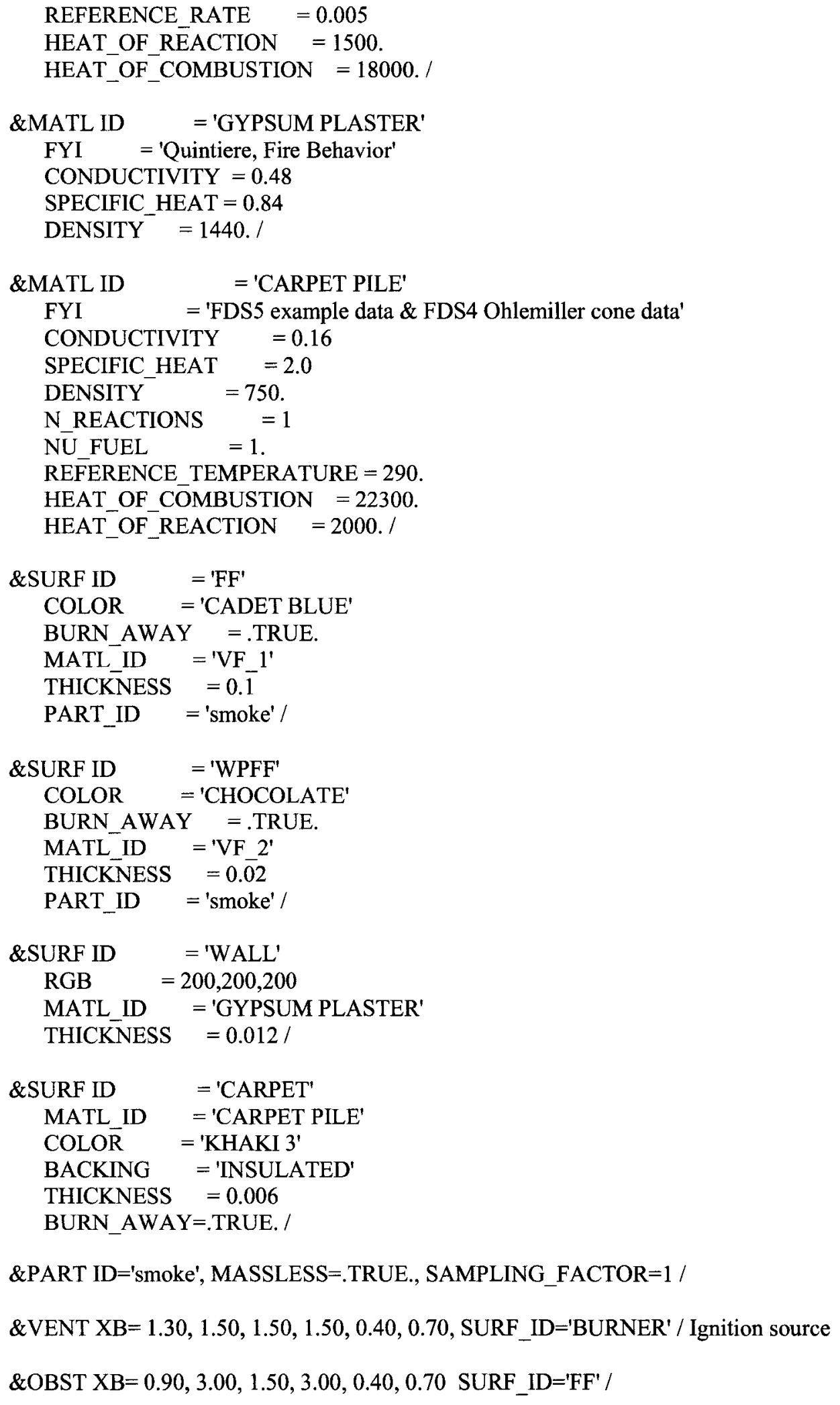


\&OBST $X B=0.90,3.00,1.50,1.60,0.30,0.40$ SURF_ID='WPFF' / \&OBST $\mathrm{XB}=0.90,3.00,1.70,1.80,0.30,0.40 \mathrm{SURF}{ }^{-} \mathrm{ID}={ }^{\prime} \mathrm{WPFF}^{\prime} /$ \&OBST XB $=0.90,3.00,1.90,2.00,0.30,0.40$ SURF_ID='WPFF' \&OBST XB $=0.90,3.00,2.10,2.20,0.30,0.40 \mathrm{SURF}^{-} \mathrm{ID}={ }^{\prime} W \mathrm{WFF}^{\prime} /$ \&OBST XB $=0.90,3.00,2.30,2.40,0.30,0.40 \mathrm{SURF}^{-} \mathrm{ID}={ }^{\prime} W \mathrm{WFF}^{\prime} /$ \&OBST $\mathrm{XB}=0.90,3.00,2.50,2.60,0.30,0.40 \mathrm{SURF}{ }^{-} \mathrm{ID}={ }^{\prime} W P F F^{\prime} /$ \&OBST $X B=0.90,3.00,2.70,2.80,0.30,0.40 \mathrm{SURF}$ ID $={ }^{\prime} \mathrm{WPFF}^{\prime} /$ \&OBST XB $=0.90,3.00,2.90,3.00,0.30,0.40 \mathrm{SURF}$ ID $={ }^{\prime} W P F F^{\prime} /$

\&OBST XB $=0.90,1.00,1.50,3.00,0.20,0.30$ SURF_ID='WPFF' \&OBST $\mathrm{XB}=1.10,1.20,1.50,3.00,0.20,0.30 \mathrm{SURF}$ ID $={ }^{\prime} W \mathrm{WFF}^{\prime} /$ $\& O B S T$ XB $=1.30,1.40,1.50,3.00,0.20,0.30 \mathrm{SURF}^{-} \mathrm{ID}={ }^{\prime} W \mathrm{WFF}^{\prime} /$ \&OBST XB $=1.50,1.60,1.50,3.00,0.20,0.30 \mathrm{SURF}^{-} \mathrm{ID}={ }^{\prime} W \mathrm{WFF}^{\prime} /$ \&OBST XB $=1.70,1.80,1.50,3.00,0.20,0.30 \mathrm{SURF}$ ID $={ }^{\prime} W P F F^{\prime} /$ \&OBST XB $=1.90,2.00,1.50,3.00,0.20,0.30 \mathrm{SURF}_{-}^{-} \mathrm{ID}=$ 'WPFF' $^{\prime}$ \&OBST $X B=2.10,2.20,1.50,3.00,0.20,0.30 \mathrm{SURF}^{-} \mathrm{ID}=\mathrm{WPFF}^{\prime} /$ \&OBST $X B=2.30,2.40,1.50,3.00,0.20,0.30 \mathrm{SURF}$ ID $=$ 'WPFF' \&OBST XB $=2.50,2.60,1.50,3.00,0.20,0.30 \mathrm{SURF}$ ID='WPFF' / \&OBST $\mathrm{XB}=2.70,2.80,1.50,3.00,0.20,0.30 \mathrm{SURF}{ }^{-} \mathrm{ID}={ }^{\prime} W \mathrm{WFF}^{\prime} /$ \&OBST XB $=2.90,3.00,1.50,3.00,0.20,0.30$ SURF_ID='WPFF' /

\&OBST $\mathrm{XB}=0.90,3.00,1.50,1.60,0.10,0.20 \mathrm{SURF}$ ID='WPFF' $/$ \&OBST $X B=0.90,3.00,1.70,1.80,0.10,0.20$ SURF $^{-}$ID $={ }^{\prime} W P F F^{\prime} /$ \&OBST XB $=0.90,3.00,1.90,2.00,0.10,0.20 \mathrm{SURF}^{-} \mathrm{ID}={ }^{\prime} W \mathrm{WFF}^{\prime} /$ \&OBST $\mathrm{XB}=0.90,3.00,2.10,2.20,0.10,0.20 \mathrm{SURF}{ }^{-} \mathrm{ID}={ }^{\prime} \mathrm{WPFF} /$ \&OBST $X B=0.90,3.00,2.30,2.40,0.10,0.20 \mathrm{SURF} I D={ }^{-} \mathrm{WPFF}^{\prime} /$ \&OBST $X B=0.90,3.00,2.50,2.60,0.10,0.20$ SURF_ID='WPFF' / \&OBST $\mathrm{XB}=0.90,3.00,2.70,2.80,0.10,0.20 \mathrm{SURF}^{-} \mathrm{ID}={ }^{\prime} W \mathrm{WFF}^{\prime} /$ \&OBST $\mathrm{XB}=0.90,3.00,2.90,3.00,0.10,0.20 \mathrm{SURF}$ ID $={ }^{\prime} W \mathrm{WFF}^{\prime} /$

\&OBST $\mathrm{XB}=0.90,1.00,1.50,3.00,0.00,0.10 \mathrm{SURF} I \mathrm{D}={ }^{\prime} W \mathrm{WFF}^{\prime} /$ \&OBST $X B=1.50,1.60,1.50,3.00,0.00,0.10 S \mathrm{SRF}^{-} \mathrm{ID}={ }^{\prime} \mathrm{WPFF} \mathrm{F}^{\prime} /$ \&OBST $X B=2.30,2.40,1.50,3.00,0.00,0.10 \mathrm{SURF}^{-} \mathrm{ID}={ }^{\prime} \mathrm{WPFF}$ '

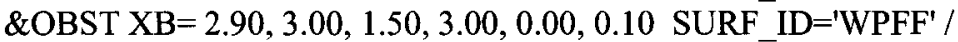

\&OBST XB $=0.00,3.80,0.10,0.20,0.00,2.40 /$ Front wall \&HOLE XB $=1.15,2.65,0.11,0.21,0.50,2.00 /$ Window

\&VENT MB='YMIN',SURF_ID='OPEN' /

\&VENT XB $=0.00,3.80,0.20, \overline{4} .40,0.00,0.00, \mathrm{SURF}_{-}$ID='CARPET' /

\&DEVC XYZ=1.0,3.4,1.5, QUANTITY='carbon dioxide' ID='CO2-Top'/ \&DEVC XYZ=1.0,3.4,0.4, QUANTITY='carbon dioxide' ID='CO2-Bottom'/

\&DEVC XYZ=1.0,3.4,1.5, QUANTITY='carbon monoxide' ID='CO-Top'/ \&DEVC XYZ=1.0,3.4,0.4, QUANTITY='carbon monoxide' ID='CO-Bottom'/

\&DEVC XYZ=1.0,3.4,1.5, QUANTITY='oxygen' ID='O2-Top'/ \&DEVC XYZ=1.0,3.4,0.4, QUANTITY='oxygen' ID='O2-Bottom'/

\&DEVC XYZ=0.3,3.9,2.3, QUANTITY='TEMPERATURE' ID='TC-NW Corner'/ 
\&DEVC XYZ=0.3,3.9,1.9, QUANTITY $=$ 'TEMPERATURE' ID='TC-NW Corner'/ \&DEVC XYZ $=0.3,3.9,1.4$, QUANTITY='TEMPERATURE' ID='TC-NW Coner'/ $\&$ DEVC XYZ $=0.3,3.9,0.9$, QUANTITY='TEMPERATURE' ID='TC-NW Corner'/ \&DEVC XYZ=0.3,3.9,0.4, QUANTITY='TEMPERATURE' ID='TC-NW Corner'/

\&DEVC XYZ=1.9,2.3,2.3, QUANTITY='TEMPERATURE' ID='TC-CC'/middle of room

\&TAIL /

\section{E-2: Propane gaseous fuel and virtual fuel layout 2}

\&HEAD CHID='2VF-PA-Layout2', TITLE='Hotel Room Fire Test, Test 1, FDS version 5' /

\&MESH IJK $=38,44,24, \mathrm{XB}=0.0,3.8,0.0,4.4,0.0,2.4 /$

\&TIME T_END $=1800 /$

\&MISC SURF_DEFAULT $=$ 'WALL', /

\&REAC ID = 'PROPANE'

FYI $=$ ' $\mathrm{C} 3 \mathrm{H} 8$ '

SOOT_YIELD $=\overline{0} .01$

$\mathrm{C} \quad=3$

$\mathrm{H}=8 /$

\&SURF ID='BURNER', HRRPUA=1000., RAMP_Q='fireramp', $\quad$ PART_ID='smoke', COLOR='RASPBERRY' /

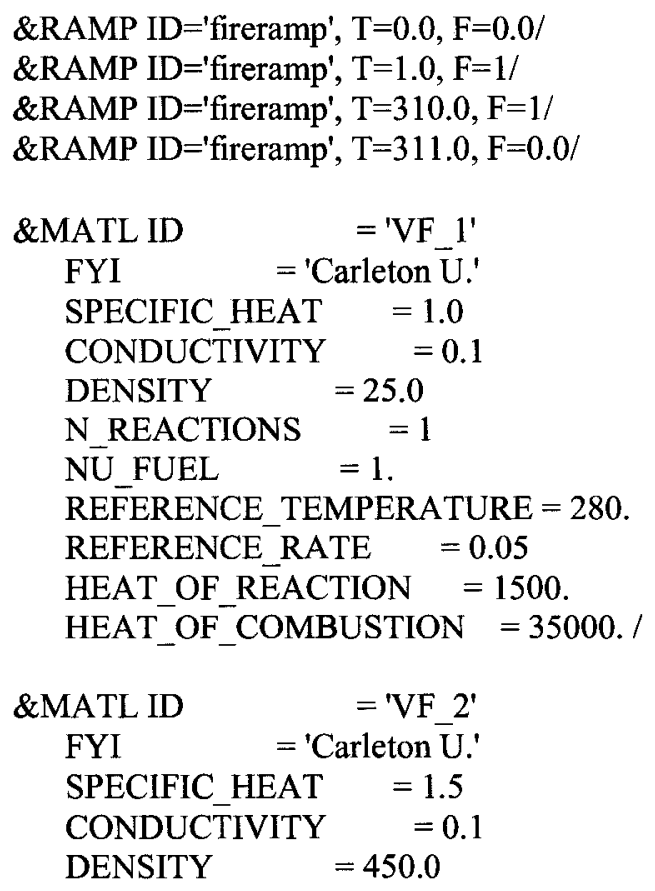




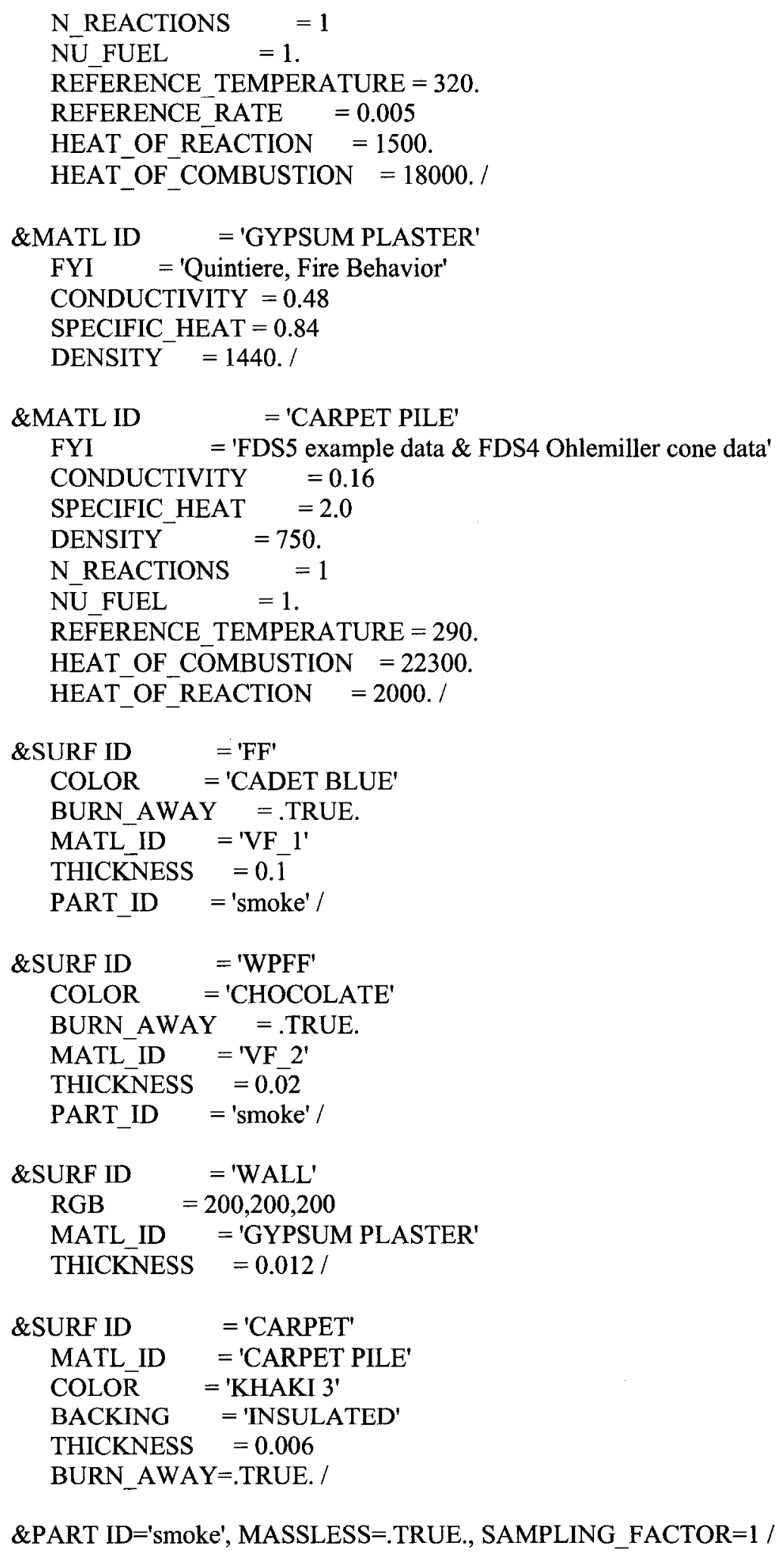


\&VENT XB $=1.30,1.50,1.50,1.50,0.40,0.70, \mathrm{SURF}$ _ID $=$ 'BURNER' $/$ Ignition source

\&OBST XB= $0.10,2.20,1.50,3.00,0.40,0.70$ SURF_ID='FF' /

\&OBST XB=0.10, 2.20, 1.50, 1.60, 0.30, 0.40 SURF_ID='WPFF' / \&OBST $\mathrm{XB}=0.10,2.20,1.70,1.80,0.30,0.40 \mathrm{SURF}{ }^{-} \mathrm{ID}={ }^{\prime} \mathrm{WPFF}^{\prime} /$ \&OBST $\mathrm{XB}=0.10,2.20,1.90,2.00,0.30,0.40 \mathrm{SURF}^{-} \mathrm{ID}={ }^{\prime} \mathrm{WPFF}^{\prime} /$ \&OBST $\mathrm{XB}=0.10,2.20,2.10,2.20,0.30,0.40 \mathrm{SURF}$ ID $=$ 'WPFF' / \&OBST XB= $0.10,2.20,2.30,2.40,0.30,0.40 \mathrm{SURF}_{-} \mathrm{ID}=\mathrm{WWPFF}^{\prime} /$ \&OBST XB=0.10, 2.20, 2.50, 2.60, 0.30, 0.40 SURF ID='WPFF' / \&OBST XB=0.10, 2.20, 2.70, 2.80, 0.30, 0.40 SURF_ID='WPFF' / \&OBST XB=0.10, 2.20, 2.90, 3.00, 0.30, 0.40 SURF_ID='WPFF' /

\&OBST XB $=2.90,3.00,1.30,3.30,0.00,0.10$ SURF ID='WPFF' / $\&$ OBST XB $=3.70,3.80,1.30,3.30,0.00,0.10 \mathrm{SURF}_{-} \mathrm{ID}={ }^{\prime} \mathrm{WPFF}$ '

\&OBST XB $=3.00,3.10,1.30,3.30,0.10,0.20 \mathrm{SURF} I \mathrm{ID}={ }^{\prime} \mathrm{WPFF} /$ \&OBST $\mathrm{XB}=3.20,3.30,1.30,3.30,0.10,0.20 \mathrm{SURF}_{-} \mathrm{ID}={ }^{\prime} \mathrm{WPFF}^{\prime} /$ $\&$ OBST XB $=3.40,3.50,1.30,3.30,0.10,0.20 \mathrm{SURF} I \mathrm{ID}=$ 'WPFF' $^{\prime}$ $\&$ OBST XB=3.60, 3.70, 1.30, 3.30, 0.10, 0.20 SURF_ID='WPFF' /

\&OBST $\mathrm{XB}=2.90,3.00,1.30,3.30,0.20,0.30 \mathrm{SURF}$ ID $=$ 'WPFF' / \&OBST XB $=3.10,3.20,1.30,3.30,0.20,0.30 \mathrm{SURF}_{-} \mathrm{ID}={ }^{\prime} \mathrm{WPFF} /$ \&OBST XB $=3.30,3.40,1.30,3.30,0.20,0.30 \mathrm{SURF}_{-} \mathrm{ID}={ }^{\prime} \mathrm{WPFF}$ ' \&OBST XB $=3.50,3.60,1.30,3.30,0.20,0.30 \mathrm{SURF}_{-} \mathrm{ID}={ }^{\prime} \mathrm{WPFF}{ }^{\prime} /$ \&OBST XB= 3.70, 3.80, 1.30, 3.30, 0.20, 0.30 SURF_ID='WPFF' /

\&OBST XB $=3.00,3.10,1.30,3.30,0.30,0.40$ SURF_ID='WPFF' / \&OBST XB $=3.20,3.30,1.30,3.30,0.30,0.40 \mathrm{SURF}_{-} \mathrm{ID}={ }^{\prime} \mathrm{WPFF}^{\prime} /$ \&OBST XB $=3.40,3.50,1.30,3.30,0.30,0.40 \mathrm{SURF}_{\mathrm{ID}} \mathrm{ID}=\mathrm{\prime WPFF}^{\prime} /$ $\&$ OBST $\mathrm{XB}=3.60,3.70,1.30,3.30,0.30,0.40 \mathrm{SURF}_{-} \mathrm{ID}={ }^{\prime} \mathrm{WPFF}{ }^{\prime} /$

\&OBST XB $=2.90,3.00,1.30,3.30,0.40,0.50$ SURF ID='WPFF' / \&OBST XB $=3.10,3.20,1.30,3.30,0.40,0.50 \mathrm{SURF}_{-} \mathrm{ID}=\mathrm{W}^{\prime} \mathrm{WPF}{ }^{\prime} /$ \&OBST $\mathrm{XB}=3.30,3.40,1.30,3.30,0.40,0.50 \mathrm{SURF}\left[\mathrm{D}={ }^{\prime} \mathrm{WPFF}{ }^{\prime} /\right.$ \&OBST XB $=3.50,3.60,1.30,3.30,0.40,0.50 \mathrm{SURF}_{-}^{-} \mathrm{ID}={ }^{\prime} \mathrm{WPFF}^{\prime} /$ \&OBST $\mathrm{XB}=3.70,3.80,1.30,3.30,0.40,0.50 \mathrm{SURF}_{-} \mathrm{ID}={ }^{\prime} \mathrm{WPFF}^{\prime} /$

\&OBST XB $=0.00,3.80,0.10,0.20,0.00,2.40 /$ Front wall $\&$ HOLE XB $=1.15,2.65,0.11,0.21,0.50,2.00 /$ Window

\&VENT MB='YMIN',SURF_ID='OPEN' /

$\&$ VENT XB $=0.00,3.80,0.20,4.40,0.00,0.00, S_{U R} I D={ }^{\prime} C A R P E T ' /$

\&DEVC XYZ=1.0,3.4,1.5, QUANTITY='carbon dioxide' ID='CO2-Top'/ \&DEVC XYZ=1.0,3.4,0.4, QUANTITY='carbon dioxide' ID='CO2-Bottom'/

\&DEVC XYZ=1.0,3.4,1.5, QUANTITY='carbon monoxide' ID='CO-Top'/ \&DEVC XYZ=1.0,3.4,0.4, QUANTITY='carbon monoxide' ID='CO-Bottom'/

\&DEVC XYZ=1.0,3.4,1.5, QUANTITY='oxygen' ID='O2-Top'/

\&DEVC XYZ=1.0,3.4,0.4, QUANTITY='oxygen' ID='O2-Bottom'/

185 
\&DEVC XYZ=0.3,3.9,2.3, QUANTITY='TEMPERATURE' ID='TC-NW Corner'/ $\& D E V C$ XYZ $=0.3,3.9,1.9$, QUANTITY $=$ 'TEMPERATURE' ID='TC-NW Corner'/ \&DEVC XYZ=0.3,3.9,1.4, QUANTITY='TEMPERATURE' ID='TC-NW Corner'/ \&DEVC XYZ $=0.3,3.9,0.9$, QUANTITY='TEMPERATURE' ID='TC-NW Corner'/ $\& D E V C X Y Z=0.3,3.9,0.4$, QUANTITY $=$ 'TEMPERATURE' ID='TC-NW Corner'/

\&DEVC XYZ=1.9,2.3,2.3, QUANTITY='TEMPERATURE' ID='TC-CC'/middle of room \&TAIL /

\section{E-3: Polyurethane gaseous fuel and virtual fuel layout 1}

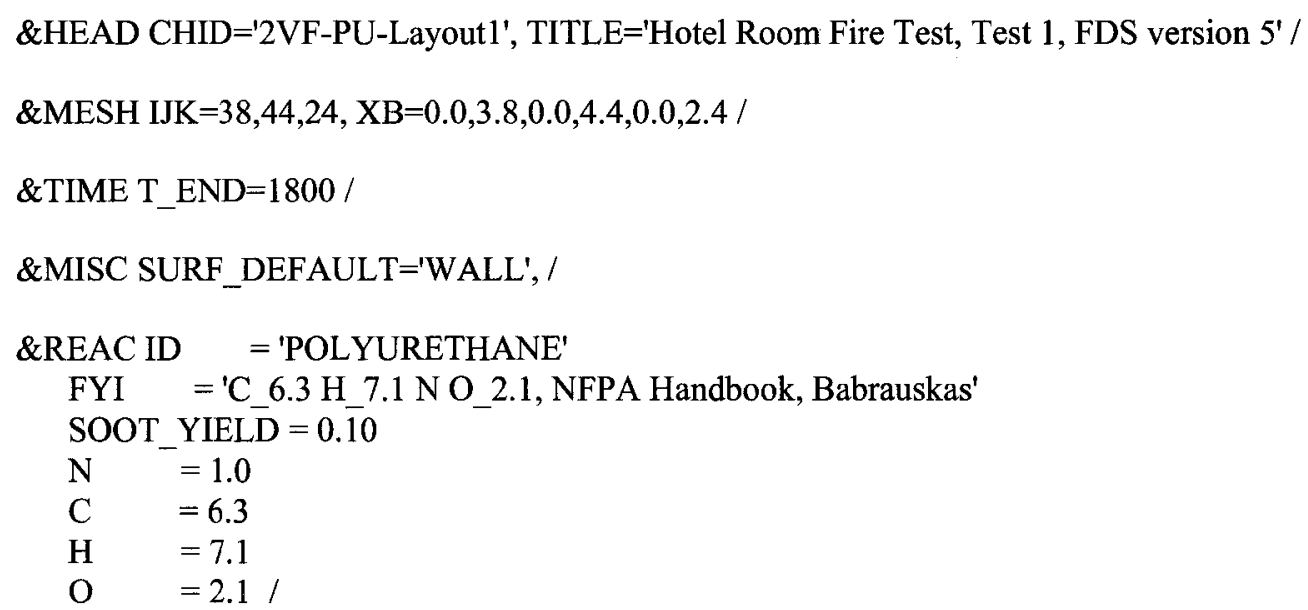




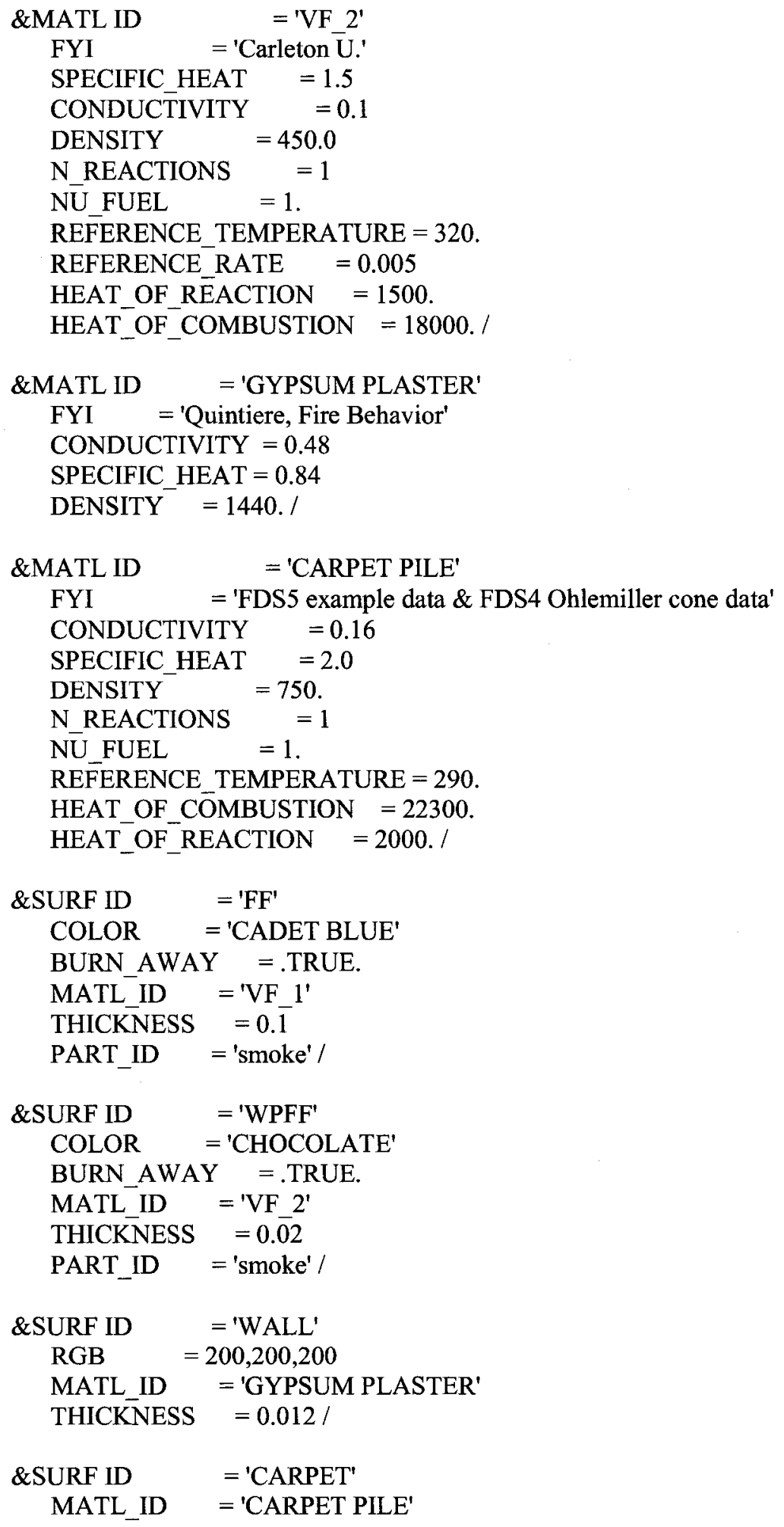




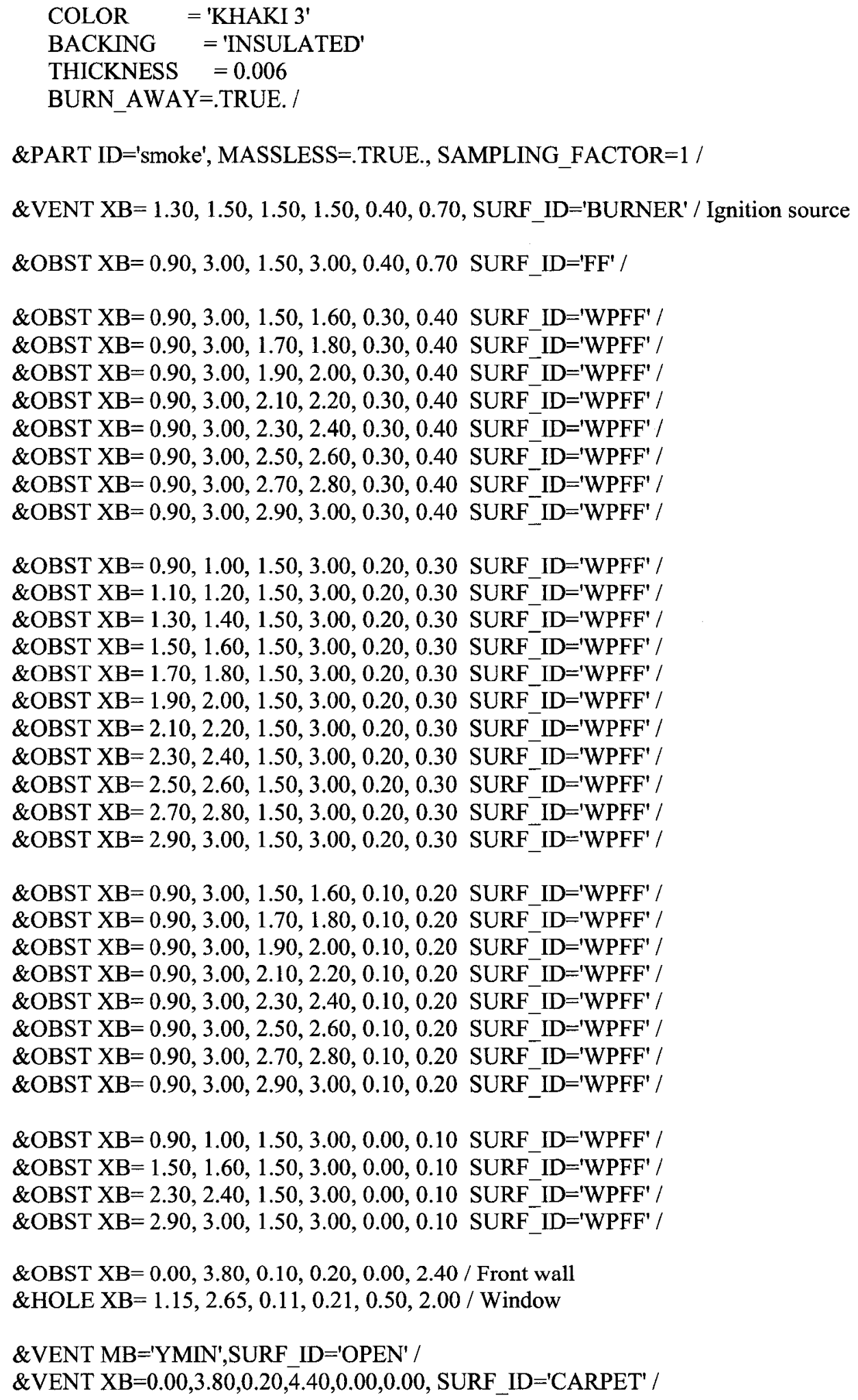


\&DEVC XYZ $=1.0,3.4,1.5$, QUANTITY $=$ 'carbon dioxide' ID='CO2-Top'/

$\& D E V C X Y Z=1.0,3.4,0.4$, QUANTITY $=$ 'carbon dioxide' $I D=' C O 2-B o t t o m ' /$

\&DEVC XYZ=1.0,3.4,1.5, QUANTITY='carbon monoxide' ID='CO-Top'/

\&DEVC XYZ=1.0,3.4,0.4, QUANTITY='carbon monoxide' ID='CO-Bottom'/

\&DEVC XYZ=1.0,3.4,1.5, QUANTITY='oxygen' ID='O2-Top'/

\&DEVC XYZ $=1.0,3.4,0.4$, QUANTITY $=$ 'oxygen' ID='O2-Bottom'/

\&DEVC XYZ=0.3,3.9,2.3, QUANTITY='TEMPERATURE' ID='TC-NW Corner'/ \&DEVC XYZ $=0.3,3.9,1.9$, QUANTITY $=$ 'TEMPERATURE' ID='TC-NW Corner'/ \&DEVC XYZ=0.3,3.9,1.4, QUANTITY='TEMPERATURE' ID='TC-NW Corner'/ \&DEVC XYZ =0.3,3.9,0.9, QUANTITY='TEMPERATURE' ID='TC-NW Corner'/ \&DEVC XYZ $=0.3,3.9,0.4$, QUANTITY='TEMPERATURE' ID='TC-NW Corner'/

$\& D E V C X Y Z=1.9,2.3,2.3$, QUANTITY='TEMPERATURE' ID='TC-CC'/middle of room \&TAIL /

\section{E-4: Polyurethane gaseous fuel and virtual fuel layout 2}

\&HEAD CHID='2VF-PU-Layout2', TITLE='Hotel Room Fire Test, Test 1, FDS version 5' /

\&MESH IJK $=38,44,24, \mathrm{XB}=0.0,3.8,0.0,4.4,0.0,2.4$ /

\&TIME T_END $=1800 /$

\&MISC SURF_DEFAULT $=$ 'WALL', /

\&REAC ID $=$ 'POLYURETHANE'

FYI = 'C_6.3 H_7.1 N O_2.1, NFPA Handbook, Babrauskas'

SOOT_YIELD $=0 . \overline{10}$

$\mathrm{N} \quad=1.0$

$\mathrm{C}=6.3$

$\mathrm{H} \quad=7.1$

$\mathrm{O}=2.1 /$

\&SURF ID='BURNER', HRRPUA=1000., RAMP_Q='fireramp', PART_ID='smoke', COLOR='RASPBERRY' /

\&RAMP ID $=$ 'fireramp', $\mathrm{T}=0.0, \mathrm{~F}=0.0 /$

\&RAMP ID='fireramp', $\mathrm{T}=1.0, \mathrm{~F}=1 /$

\&RAMP ID='fireramp', $\mathrm{T}=310.0, \mathrm{~F}=1 /$

$\&$ RAMP ID $=$ 'fireramp', $\mathrm{T}=311.0, \mathrm{~F}=0.0 /$

\&MATL ID $\quad=$ 'VF 1 '

FYI = 'Carleton U.'

SPECIFIC_HEAT $=1.0$ 


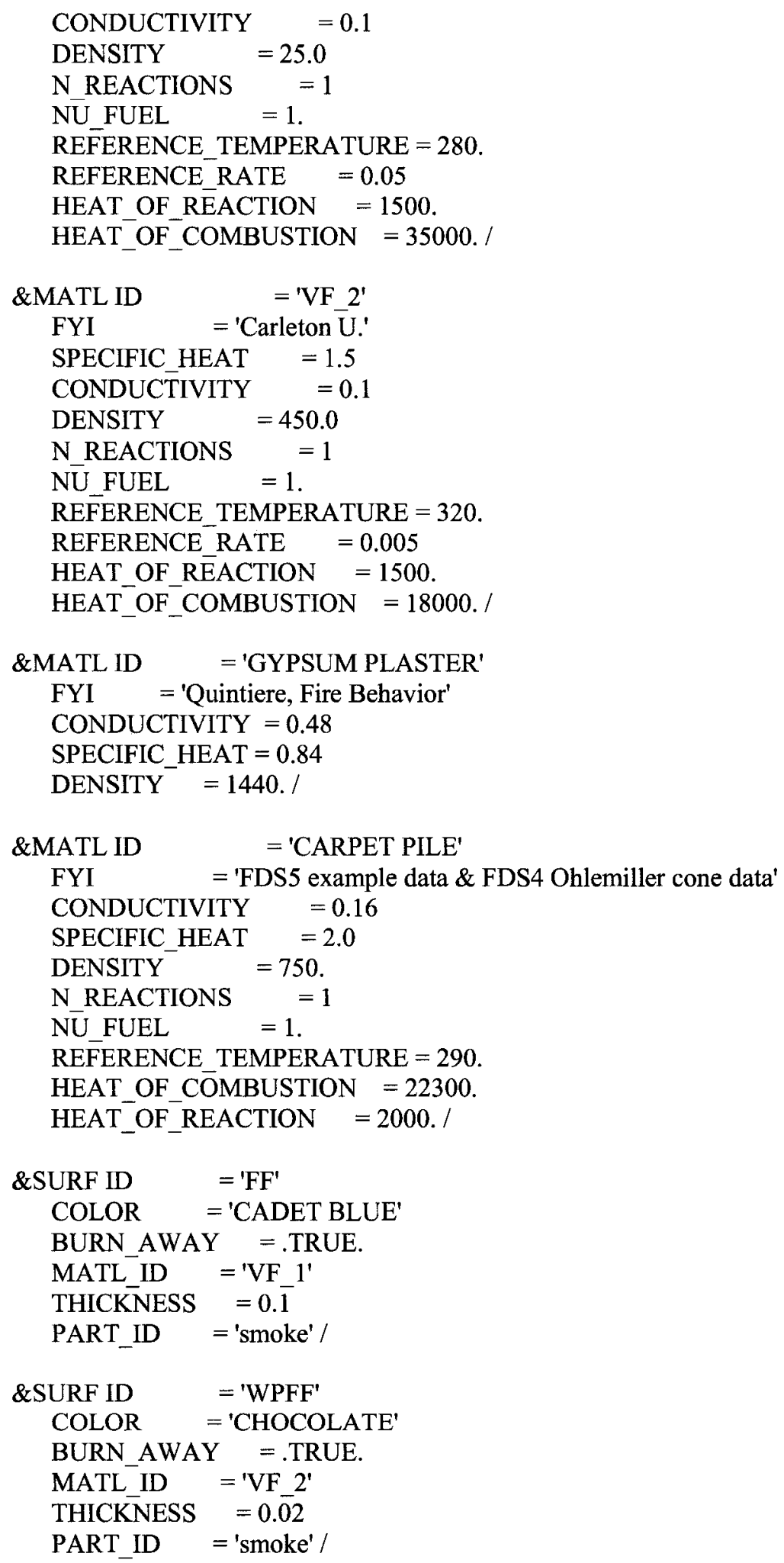




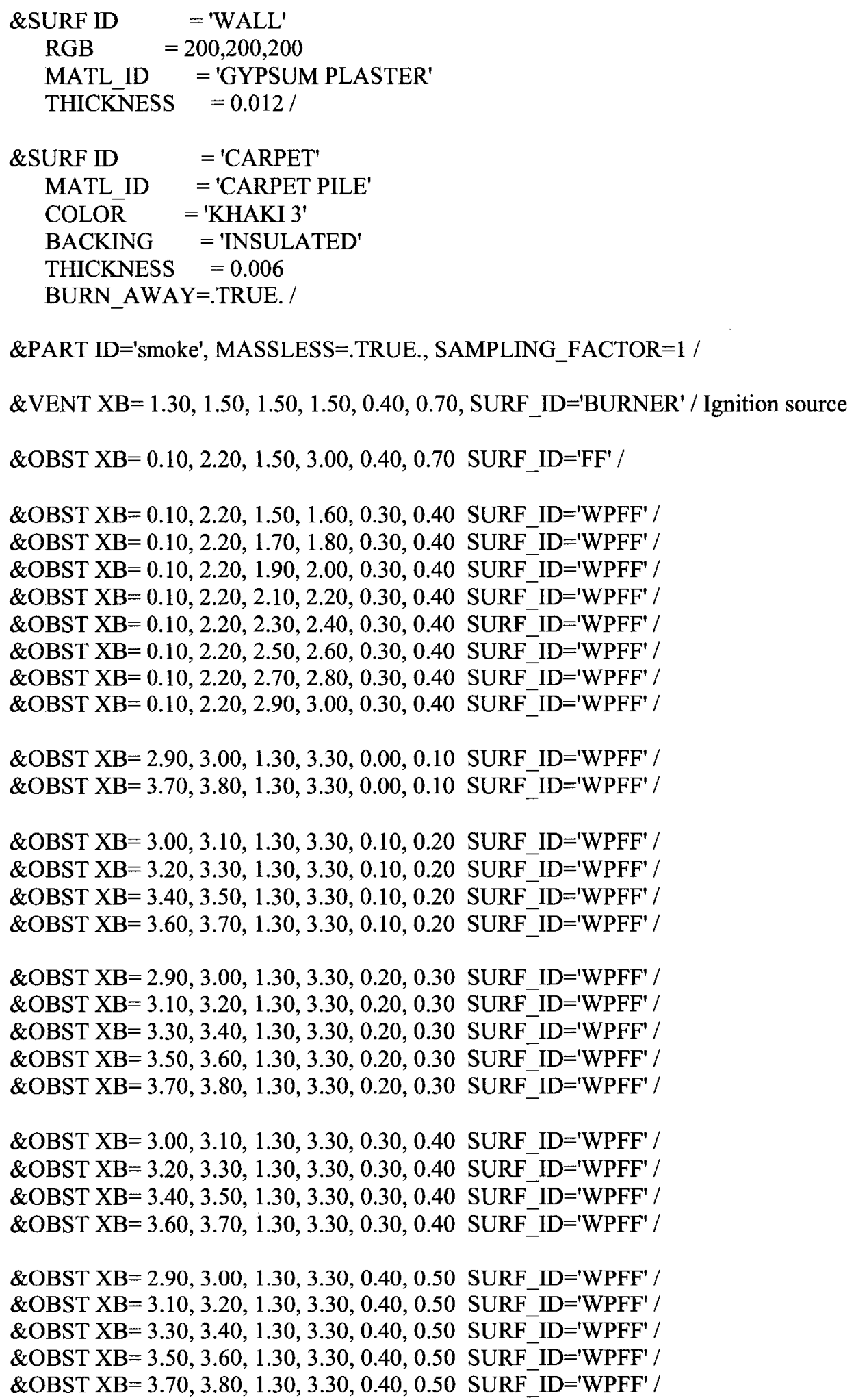

191 
\&OBST XB $=0.00,3.80,0.10,0.20,0.00,2.40 /$ Front wall

$\&$ HOLE XB $=1.15,2.65,0.11,0.21,0.50,2.00 /$ Window

\&VENT MB $=$ 'YMIN',SURF_ID $=$ 'OPEN' /

$\&$ VENT XB $=0.00,3.80,0.20,4.40,0.00,0.00$, SURF_ID $=' C A R P E T ' /$

\&DEVC XYZ=1.0,3.4,1.5, QUANTITY='carbon dioxide' ID='CO2-Top'/

$\& D E V C X Y Z=1.0,3.4,0.4$, QUANTITY $=$ 'carbon dioxide' $I D=' C O 2-$ Bottom'/

\&DEVC XYZ=1.0,3.4,1.5, QUANTITY='carbon monoxide' ID='CO-Top'/

\&DEVC XYZ=1.0,3.4,0.4, QUANTITY='carbon monoxide' ID='CO-Bottom'/

\&DEVC XYZ=1.0,3.4,1.5, QUANTITY='oxygen' ID='O2-Top'/

\&DEVC XYZ=1.0,3.4,0.4, QUANTITY='oxygen' ID='O2-Bottom'/

\&DEVC XYZ=0.3,3.9,2.3, QUANTITY='TEMPERATURE' ID='TC-NW Corner'/

\&DEVC XYZ $=0.3,3.9,1.9$, QUANTITY $=$ 'TEMPERATURE' ID $=$ 'TC-NW Corner'/

\&DEVC XYZ $=0.3,3.9,1.4$, QUANTITY='TEMPERATURE' ID='TC-NW Corner'/

\&DEVC XYZ $=0.3,3.9,0.9$, QUANTITY='TEMPERATURE' ID='TC-NW Corner'/

\&DEVC XYZ=0.3,3.9,0.4, QUANTITY='TEMPERATURE' ID='TC-NW Corner'/

\&DEVC XYZ=1.9,2.3,2.3, QUANTITY='TEMPERATURE' ID='TC-CC'/middle of room

\&TAIL / 